\title{
Innovation in finance to finance innovation : supporting pro-poor entrepreneur-based innovation
}

Citation for published version (APA):

Sonne, L. (2011). Innovation in finance to finance innovation : supporting pro-poor entrepreneur-based innovation. [Doctoral Thesis, Maastricht University]. Datawyse / Universitaire Pers Maastricht. https://doi.org/10.26481/dis.20110209ls

Document status and date:

Published: 01/01/2011

DOI:

10.26481/dis.20110209ls

Document Version:

Publisher's PDF, also known as Version of record

\section{Please check the document version of this publication:}

- A submitted manuscript is the version of the article upon submission and before peer-review. There can be important differences between the submitted version and the official published version of record.

People interested in the research are advised to contact the author for the final version of the publication, or visit the DOI to the publisher's website.

- The final author version and the galley proof are versions of the publication after peer review.

- The final published version features the final layout of the paper including the volume, issue and page numbers.

Link to publication

\footnotetext{
General rights rights.

- You may freely distribute the URL identifying the publication in the public portal. please follow below link for the End User Agreement:

www.umlib.nl/taverne-license

Take down policy

If you believe that this document breaches copyright please contact us at:

repository@maastrichtuniversity.nl

providing details and we will investigate your claim.
}

Copyright and moral rights for the publications made accessible in the public portal are retained by the authors and/or other copyright owners and it is a condition of accessing publications that users recognise and abide by the legal requirements associated with these

- Users may download and print one copy of any publication from the public portal for the purpose of private study or research.

- You may not further distribute the material or use it for any profit-making activity or commercial gain

If the publication is distributed under the terms of Article $25 \mathrm{fa}$ of the Dutch Copyright Act, indicated by the "Taverne" license above, 


\section{Innovation in Finance to Finance Innovation:}

Supporting pro-poor entrepreneur-based innovation

Lina Sönne 



\section{INNOVATION IN FINANCE TO FINANCE INNOVATION:}

Supporting pro-poor entrepreneur-based innovation

\section{PROEFSCHRIFT}

ter verkriiging van de graad van doctor

aan de Universiteit Maastricht,

op gezag van de Rector Magnificus, Prof. Mr. G.P.M.F. Mols, volgens het besluit van het College van Decanen

in het openbaar te verdedigen op woensdag 9 februari 2011 om 12.00 uur

door

\section{Lina Sönne}




\section{Promotor:}

Prof. dr. Robin Cowan

\section{Beoordelingscommissie:}

Prof. dr. Luc Soete, voorzitter

Prof. dr. Adam Szirmai,

Prof. dr. Sunil Mani, Centre for Development Studies, India 


\section{Acknowledgements}

I would like to start by thanking my promotor and supervisor, Robin Cowan for turning my writings into a PhD and me into an academic (sort of). I also thank the members of my reading committee, Luc Soete, Eddy Szirmai and Sunil Mani for insightful comments and suggestions. I am grateful to Andy Hall for introducing me to the wonders of agricultural innovation systems, and for the opportunity to spend a considerable amount of time at the UNU-MERIT hub LINK in India. I appreciate the funding LINK provided for fieldwork, and the scholarship provided by UNU-MERIT.

In India, I am grateful to Tara Nair, Rajeswari Raina, Rasheed Sulaiman and Mohna Joshi for contacts and advice. I would like to especially thank the many people at the organisations that are featured in my case studies, in particular D Raghunandan and Joginder Walia (CTD), NV Ramana and Sankar Datta (BASIX), Vineet Rai (Aavishkaar), Krishna Chaitanya Rao (S3IDF), and Paul Basil (Villgro).

I am thankful for fruitful discussions with, and advice from, academic staff at MERIT, including Micheline, Kaushalesh, Mulu, Lynn, Theophile, Claire, Banji, Hugo, Shyama, Padmashree and Anthony.

Many people at MERIT have been very helpful, in particular Eveline, Monique, Wilma, Ad, Silvana, Marc, Eric, Yvonne, Herman and Mourik Jan. At LINK I would not have survived long without Murali.

Then there are all those that provided fabulous work as well as extracurricular company over the years including Kirsten, Nora, Wangu, Noi, Evans, Eze, Zak, Daniel, Semih, Asel, Ngoc, Flavia, Maha, Lilia, Donatus, Sergey, Luciana, Tina, Jojo, Bilal, Mitie, Shuan, Anant, Radhika and Can.

Sist men inte minst vill jag säga ett stort TACK till mamma, pappa, Lotta och Johan för att ni har hejat på mig när det gått trögt. 


\section{Content}

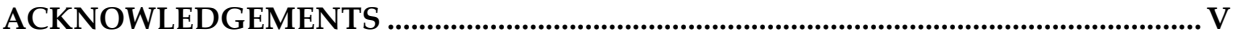

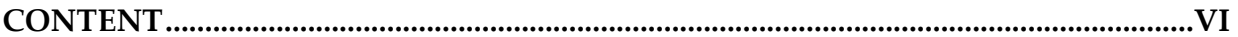

LIST OF TABLES, FIGURES AND BOXES........................................................................

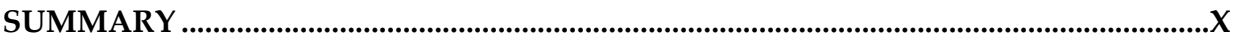

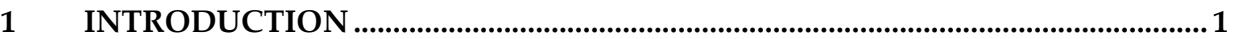

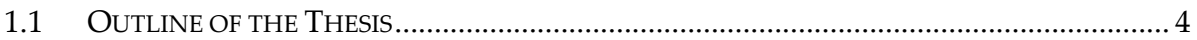

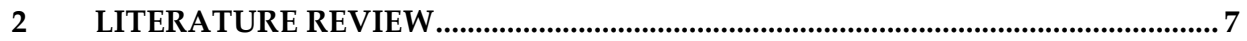

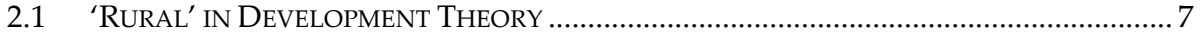

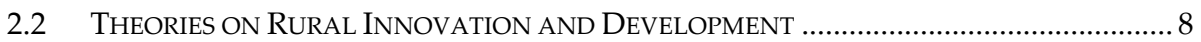

2.2.1 Small but Efficient and Technology Transfer ....................................................... 8

2.2.2 From Top-Down to Bottom-Up and Participatory Models ............................... 11

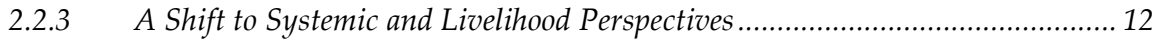

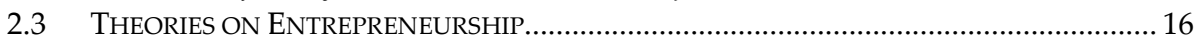

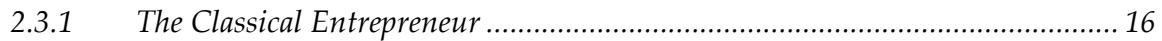

2.3.2 Entrepreneurship in Developing Countries .................................................. 17

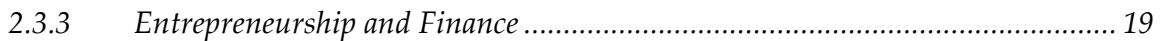

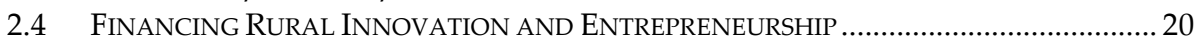

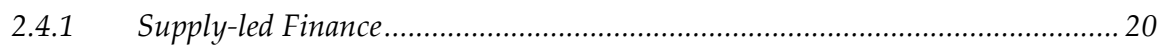

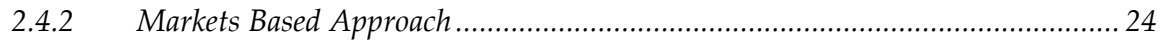

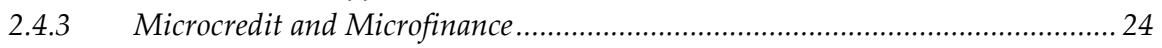

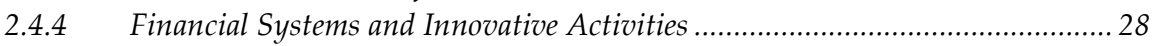

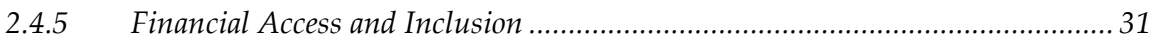

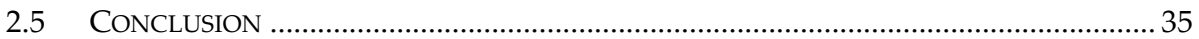

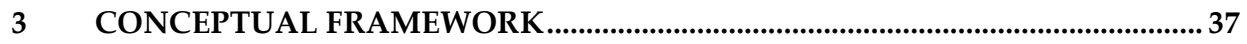

3.1 BARRIERS TO FINANCE FOR INNOVATIVE ENTREPRENEURS …..................................... 38

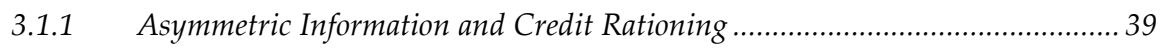

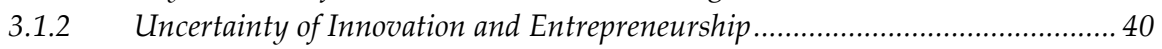

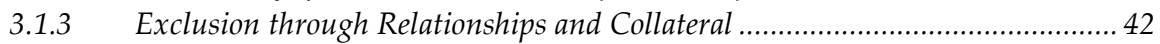

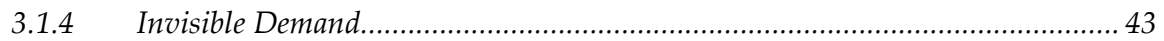

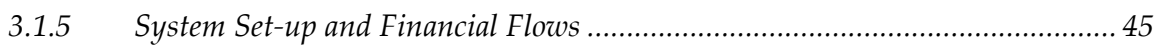

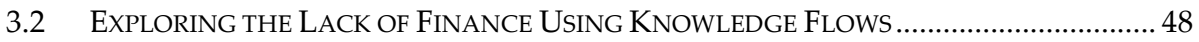

3.2.1 A System with a Core-Periphery Structure..................................................... 48

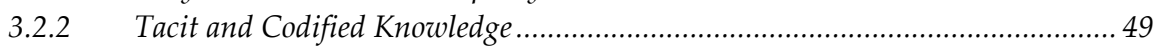

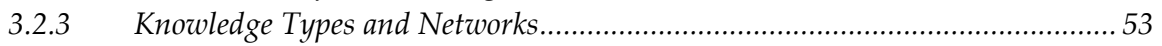

3.3 WHAT DO PERIPHERY ORGANISATIONS DO DIFFERENTLY? ............................................. 55

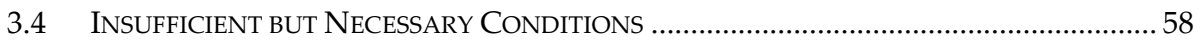

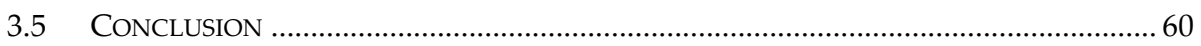

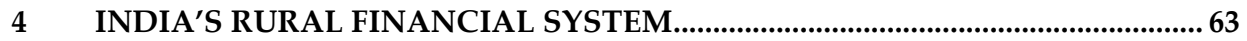

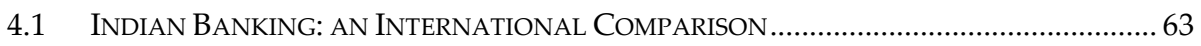




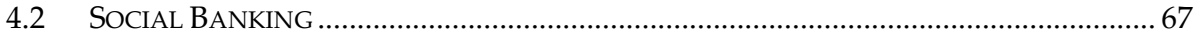

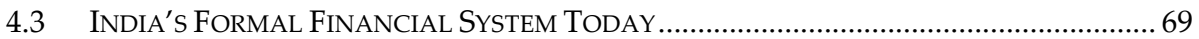

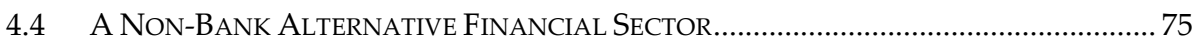

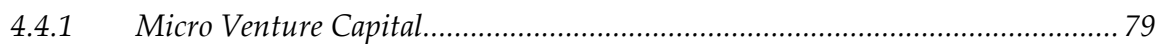

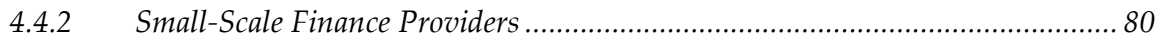

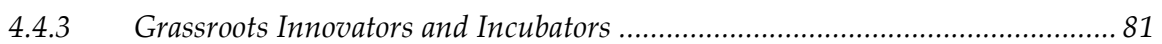

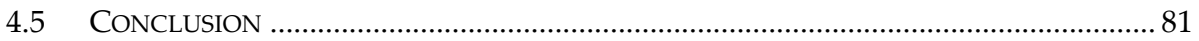

5 CASE STUDIES \# 1: MICRO VENTURE CAPITAL ..................................................... 83

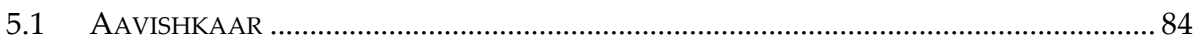

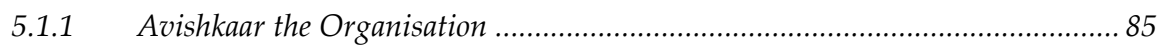

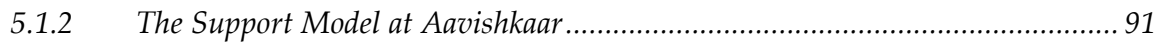

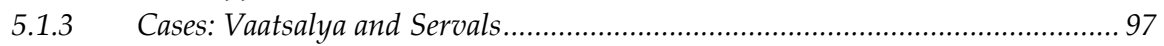

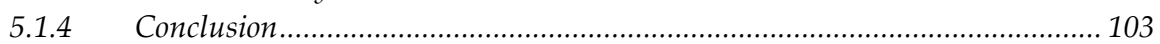

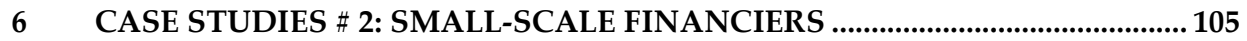

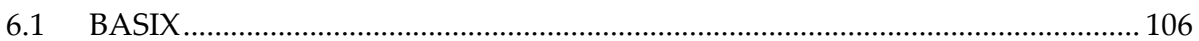

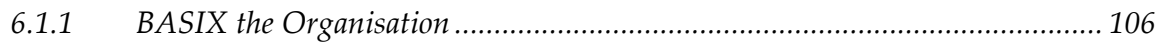

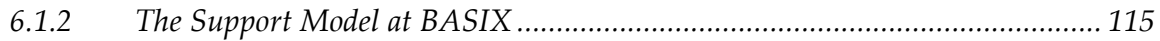

6.1.3 Cases: Quarry, Koutla-B MACS and PepsiCo Linkages ................................. 121

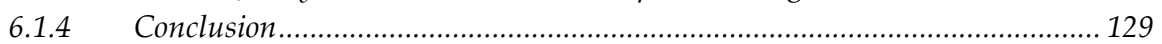

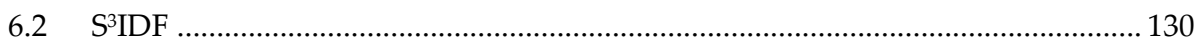

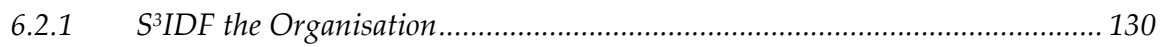

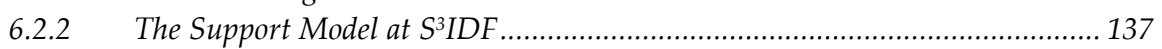

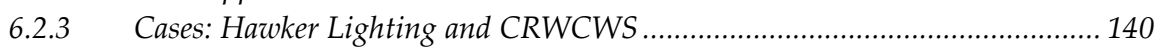

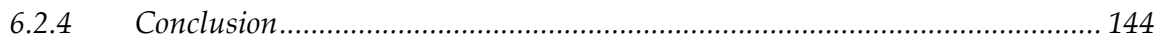

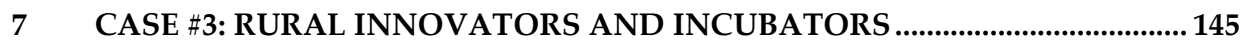

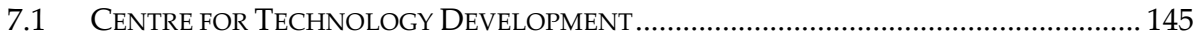

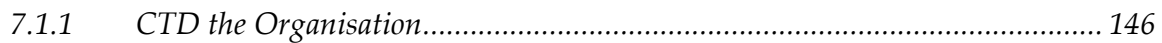

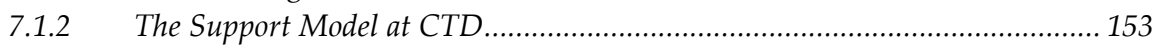

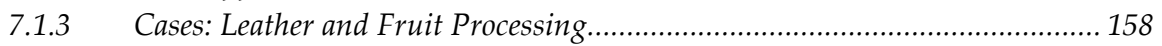

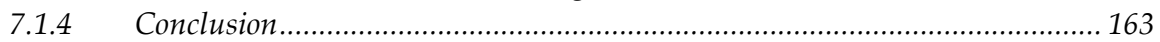

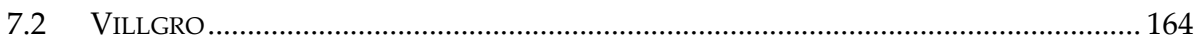

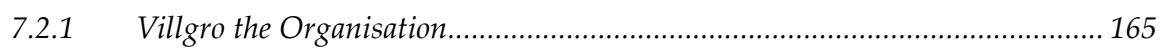

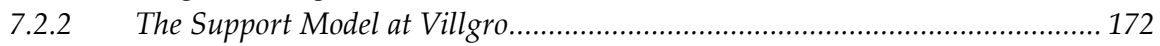

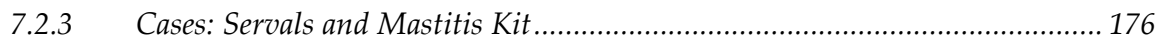

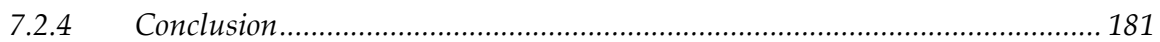

8 DISCUSSION OF CASE STUDIES IN LIGHT OF THE CONCEPTUAL

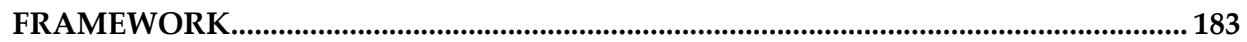

8.1 A FinANCIAL SYSTEM WITH A CORE-PERIPHERY StRUCTURE ....................................... 183

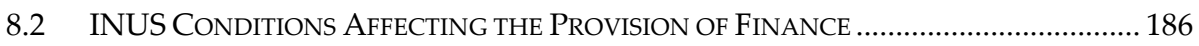

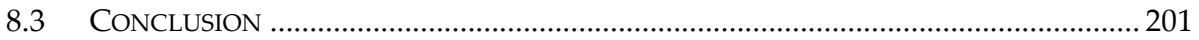

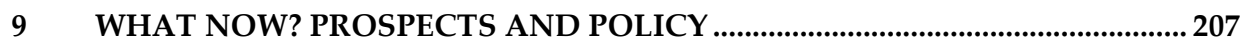




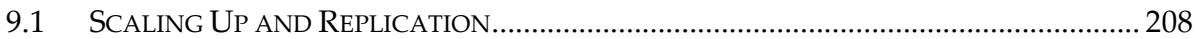

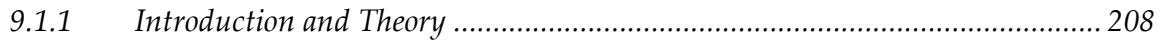

9.1.2 Scaling Up- Existing Evidence from the Case Studies ...................................... 209

9.1.3 Factors Affecting the Ability to Scale Up .........................................................2 210

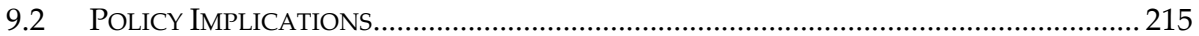

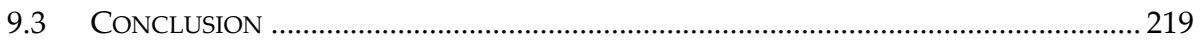

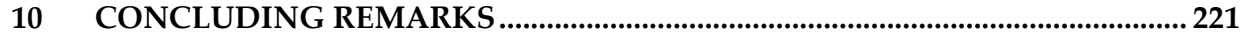

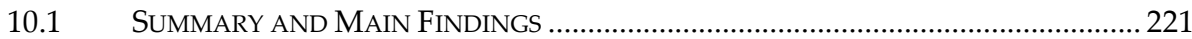

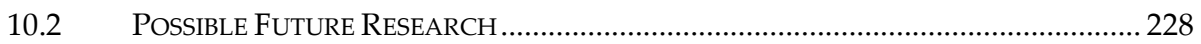

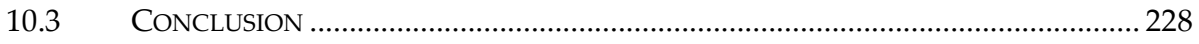

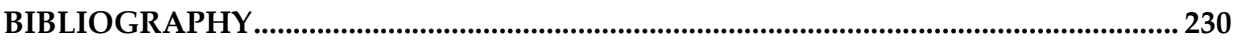

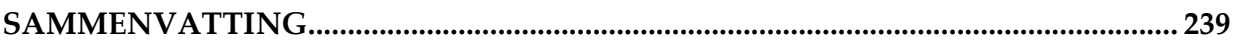

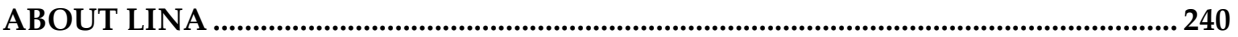




\section{List of Tables, Figures and Boxes}

TABLE 4.1 DEPTH OF FINANCIAL MARKETS: AN INTERNATIONAL COMPARISON IN 2000 ...............64 64

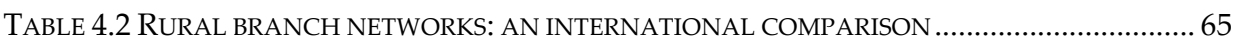

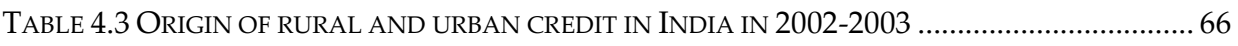

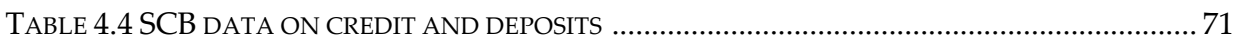

TABLE 4.5 GROSS NON-PERFORMING ASSETS OF TOTAL ASSETS (\%) OF SCBS AND RRBS ............ 73

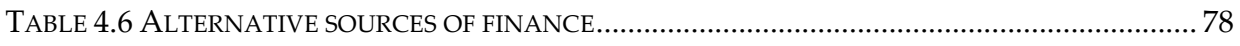

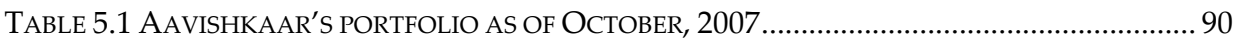

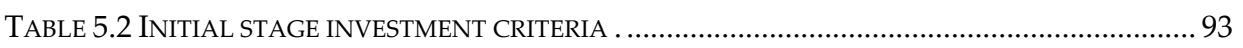

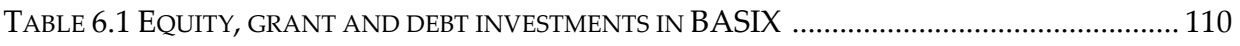

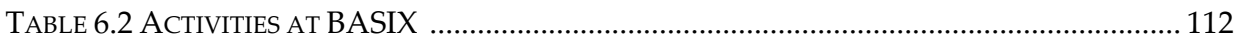

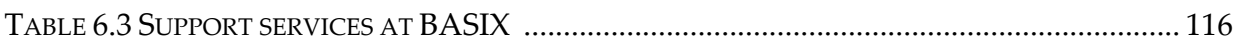

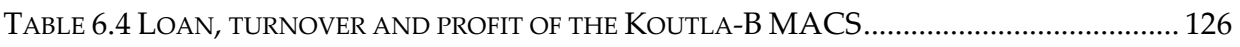

TABLE 6.5 THE OUTCOME OF BASIX-PEPSICO POTATO CONTRACT FARMING ........................... 128

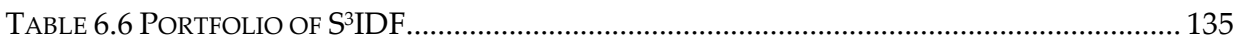

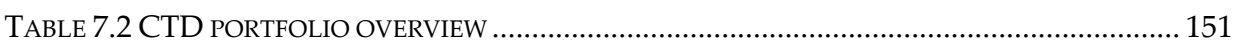

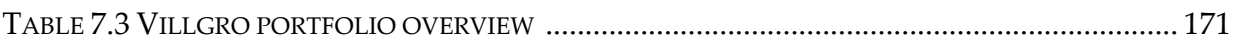

TABLE 8.1 OVERVIEW OF CASE STUDY ORGANISATIONS AND INUS CONDITIONS........................ 202

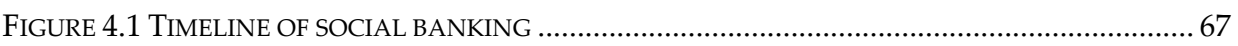

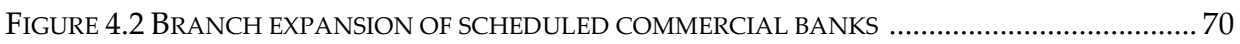

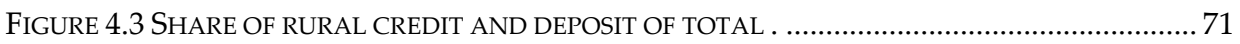

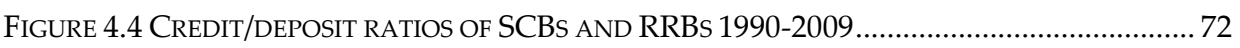

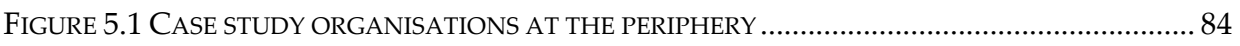

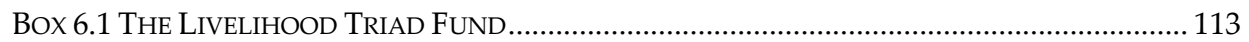




\section{Summary}

Pro-poor entrepreneur-based innovation (PEBI) is essential to the continuous development of, and poverty alleviation in, rural areas by creating employment, increasing income and providing improved goods and services. A vital factor influencing innovation and entrepreneurship is finance. However, PEBI suffers from a lack of finance, especially from the mainstream organisations that make up the core of the financial system. Instead the little support that exists comes from alternative sources at the periphery of the financial system. This substantial gap in finance for rural PEBI, which remains unexplored, is the focus of this thesis.

To start, a number of barriers to access to finance are considered, from which a conceptual framework is constructed. The framework considers the financial system as made up of a core (the banks) and a periphery, where the way knowledge flows within the system, the type of knowledge that can be accessed and accumulated, and the kind of relationships that exists matter. It is suggested that at the core, path dependence and institutional lock-in together with a closed network of similar knowledge types and a dependence on collateral rather than relationships, result in a rigid and closed system. The periphery organisations are better able to obtain and act on new knowledge (and provide finance) for a number of reasons which form the basis for a set of insufficient but necessary (INUS) condition. Accordingly, the organisations may posit the following characteristics: a dynamic and flexible approach to finance; a wide network of actors with varied knowledge; a focus on relationships; an emphasis on tacit knowledge, feedback loops and learning; an ability to innovate close to users; and a systemic and integrated approach to finance.

To test the conceptual framework, the thesis studies PEBI finance in India. Despite a relatively deep financial system, and impressive infrastructure including a huge bank branch network, rural India suffers from a lack of financial services. Decades of 'social banking' have failed to even out the distribution of financial services and today there is a noticeable bias towards urban areas. At the same time, small-scale credit for entrepreneurs and small businesses has reduced, suggesting that bank credit (from the core of the financial system) has failed to support socially relevant rural innovation and entrepreneurship.

However, in place of bank finance, a vibrant alternative sector has recently been emerging to support PEBI. There are three broad, categories: 1) micro venture capital funds that support ventures providing improved services, products or employment for the rural poor; 2) small-scale financial organisations that have gone beyond microfinance to support rural farmers and entrepreneurs; 3) organisations supporting grassroots innovation either by innovating themselves at the local level, or as incubators of rural entrepreneurs or inventors. An in-depth study of the sector is undertaken through case studies of five organisations to understand how they are able to support pro-poor entrepreneur-based innovation. These are Aavishkaar, a 
micro venture capital fund; BASIX, a livelihood finance promoter; S3IDF, a social merchant bank investing in inclusive infrastructure projects; CTD, which puts together community-run business models based on existing raw material and skills; and Villgro, an incubator.

Considering the conceptual framework in light of the case studies, it is clear that each of the periphery organisations fulfil several, though not all, of the INUS conditions, and in different ways. The organisations are complementary and form an eco-system of financial support for varying types of rural PEBI. In different ways they take an integrated approach to support, including both financial and nonfinancial assistance. They also emphasise partnerships and networks to provide better services, acquire expertise and to influence the sector itself; continuous involvement in the investees that goes beyond a simple credit disbursement contract; and a dynamic approach, providing them with flexibility to adapt as new challenges occur. Importantly the organisations tend to link to financial institutions at the core, which is important for scaling up existing initiatives, given the vast Indian bank system.

To conclude, this thesis argues that there is a need to partially shift the focus of financial support and livelihood creation in rural areas away from microfinance, to more productive entrepreneurship and innovation that hold potential for indirectly providing more livelihoods and poverty alleviation opportunities. Three broad Government policies to achieve an enabling environment in which the PEBI support organisations can flourish include: 1) supportive regulations and an overarching PEBI Agency to coordinate departmental, national and state efforts; 2) a PEBI Fund investing in PEBI support organisations; and 3) capacity building programmes in entrepreneurship especially for MFI's, NGO's and Banks. 



\section{Introduction}

This thesis investigates how innovation in rural areas, that is socially relevant in the sense of having a poverty alleviating and developmental effect, is, and should be, financed. It is well established that innovation spurs economic growth and is central to development. The Millennium Development Goals' (MDG) Science Technology and Innovation (STI) Task Force concluded that

"science, technology and innovation underpin every one of the goals. It is inconceivable that gains can be made in health and environmental concerns without a focused science, technology and innovation policy" (Juma and YeeCheong, 2005:16).

Earlier, the Human Development Report of 2001 (UNDP, 2001) had highlighted how new technologies affect developing countries whilst the 1999 World Development Report (WDR) emphasised the knowledge gap between rich and poor countries (WB, 1999). The WDR suggests that the 'resources versus knowledge' boundary has shifted so far in favour of knowledge that it is today perhaps the most important factor determining welfare and standards of living. This knowledge, however, does not suddenly and randomly appear, but is generated, utilised and transmitted through three currants of human activity (Sagasti, 2004): the evolution of speculative thought, the transformation of the technology base, and the modification of production and services. This environment is dynamic and continuously changing, shaped by the institutions and political, cultural and social settings in which it breeds (Sagasti, 2004). With knowledge, technology and innovation being of such central importance, Sagasti sees a clear and widening gap between the modern science societies and those societies lagging behind, relying on traditional methods. Modern societies are characterized by their own capabilities and effective ways of capturing and generating new knowledge. Societies lagging behind on the other hand have few of these capabilities to generate knowledge and understanding, or to apply existing knowledge productively. Such capability tends therefore to be externally sourced (in the guise of technology transfer) and often sits uncomfortably with the existing traditional production and processing systems. 
From this, Sagasti draws the conclusion that a minimum of own 'in-country' capabilities in terms of knowledge which can be transformed into technologies in products and services is needed for development.

The key therefore, it seems, is to close the gap between the knowledge 'have's' and 'have not's'. This, the WDR notes, entails: acquiring and adapting global knowledge in tandem with creating knowledge locally; invest in human capital (e.g. education and skills training) in order to improve the ability to absorb knowledge; invest in technologies facilitating the absorption and acquisition of knowledge, as well as the capacities, structures and institutions to make efficient use of it.

In other words, developing countries should build up and develop their own STI capabilities for sustained growth and economic development (Juma and YeeCheong, 2005; Sagasti, 2004).

However, the need for increased ability to innovate should not be confused with the fixation on new state-of-the-art technology (Juma and Yee-Cheong, 2005). Instead a paradigm shift is needed away from these, often labour saving, innovative activities on the international innovation frontier, to mature or platform technologies. These less complex technologies are more useful for smaller scale and local solutions needed in terms of technology upgrading in developing countries (Juma and Yee-Cheong, 2005). Whilst frontier technologies are considered 'exciting' or 'sexy' it is the smaller and simpler innovation process which provides solutions that are more easily adapted to fit with the needs of countries where labour is generally abundant and cheap. Take fruit processing for example. A juice making fruit processing unit in Europe may need a state of the art machine which, through a highly computerized and complex system, can process on a large scale for a large market, whilst saving on expensive labour. The developing country fruit processing unit however, may be run locally by a farmers' group, using seasonally available produce for ad hoc production and sale in the local market. Their need is of a smallscale and inexpensive machine which upgrades the production process into a semiindustrial process, making use of abundant labour whilst minimising the use of scarce resources like electricity.

Of particular interest, in a country like India, is rural innovation, ${ }^{1}$ since it is in rural areas that most of the poor live. ${ }^{2}$ Innovation especially relevant to the rural poor is innovation that provides improved goods, services and/or livelihood opportunities, here called pro-poor innovation. Such pro-poor innovation in rural areas is more likely to occur through small-scale ventures and entrepreneurs than industrial research and development. Furthermore, whilst previous rural

\footnotetext{
${ }^{1}$ Here innovation is defined as the continuous process of upgrading using new knowledge or the new combination of existing knowledge, that is new to the local area (Hall, 2003; Spielman, 2005). The innovation process thus emerges from a system of actors whose interactions, behaviour and patterns of learning are conditioned by institutions (Freeman, 1987; Lundvall, 1992; Edquist, 1997). 2 As noted in the WDR (2008) which is focussed on rural and agricultural development through innovation.
} 
development policies have focussed on small-holder agriculture, the fact is that most rural poor are landless poor (Sundaram and Tendulkar, 2003) and therefore unlikely to benefit greatly from agriculture-based policies. Instead most poor are entrepreneurs, running micro ventures, often at subsistence levels in both agriculture related and non-farm sectors. Though most rural poor are entrepreneurs out of necessity ${ }^{3}$ and therefore unlikely to possess the capacity or willingness to take on risks associated with scaling up to make a real impact on the rural economy or make a large profit, a few, especially those that are relatively less poor, are opportunity entrepreneurs pursuing a profitable business, innovating and looking to grow. These are the growth focussed entrepreneurs (Lazonick, 2005) that are likely to have a large indirect effect on the poor by providing employment opportunities as well as improved good and service. ${ }^{4}$ This thesis takes the view that pro-poor entrepreneur-based innovation (PEBI) is essential to the continuous development of, and poverty alleviation in, rural areas by creating livelihood opportunities, increasing income and providing improved goods and services. ${ }^{5}$

One of the pillars of entrepreneurship is access to finance ${ }^{6}$ (UNDP, 2004) and it is clear that finance has a poverty alleviating effect as access to finance for entrepreneurs results in employment and wages for the poor (Demirguc-Kunt, Beck and Honohan, 2008). In fact Beck \& Demirguc-Kunt (2008) note that

"pro-poor financial sector policy needs a broader focus than access for the poorest and that improving access by the excluded non-poor micro and small entrepreneurs can have a strongly favourable indirect effect on the poor" (2008:385).

However, despite a general agreement that finance affects growth by supporting innovative activities in the economy (Levine, 2005), little has been written specifically on how pro-poor entrepreneur-based innovation in rural areas should be supported and financed. ${ }^{7}$ This thesis sets out to form a conceptual

\footnotetext{
${ }^{3}$ Reynolds, 2004 in Lingelbach and de la Vina, 2005: whilst necessity entrepreneurs enter into entrepreneurship because of external shocks such as unemployment, opportunity entrepreneurs make their own choice to create a venture because of an identified unexplored market nice or business opportunity. See Banerjee and Duflo, 2006 on the poor as entrepreneurs.

${ }^{4}$ Innovation and entrepreneurship (or intrapreneurship) by large-scale firms and manufacturers can also be pro-poor, and play a large role in economic development (see for instance Szirmai et al., 2011). However, this thesis focuses explicitly on pro-poor innovation in relation to small-scale entrepreneurs and small entrepreneurial initiatives and firms.

${ }^{5}$ Pro-poor entrepreneurs are here defined broadly, therefore capturing both individuals and firms with an explicit 'dual bottom line' remit, as well as those entrepreneurs that are essentially operating without such a remit, but do provide employment opportunities for the rural poor in areas with high unemployment.

${ }^{6}$ The other pillars being a level playing field provided by fair laws and regulations and access to human capital according to UNDP (2004).

${ }^{7}$ Much has of course been written about rural finance in general (Adams, 2004; Von Pischke, 1991; Zeller, 2003) and recently about microfinance in particular (Robinson, 2001; Helms, 2006).
} 
framework to better understand why PEBI lacks finance and how it should be financed. Furthermore, using the case of India, this thesis focuses on the ability of different parts of India's financial system to support rural PEBI. India has a relatively deep financial system. However, despite an impressive infrastructure including a huge bank branch network, rural areas suffer from a lack of financial services and most poor do not have access to finance. Decades of 'social banking' have failed to even out the distribution of financial services and today there is a noticeable bias towards urban areas (Shah et al., 2007). Combined with reduced small-scale credit advances and accounts in rural areas, this would suggest that there is a financing gap and formal credit has failed to support socially relevant rural innovation and entrepreneurship. The thesis finds that in place of bank finance, an alternative finance sector has been emerging. There are three broad categories: first, there are micro venture capital funds that support ventures providing improved services, products or employment for the rural poor or inventors,; second, there are small-scale financial organisations that have moved beyond microfinance, or that are sector-specific financiers; third, those supporting grassroots innovation either as incubators for rural entrepreneurs or by themselves innovating at the local level.

Using a case study approach, this thesis details five organisations at the periphery to better understand how these organisations are able to support rural entrepreneur-based innovation benefiting the poor when the banks are not.

\subsection{Outline of the Thesis}

The thesis is divided into three parts. Part one, comprising two chapters, considers the theory relevant to financing prop-poor entrepreneur-based innovation in rural areas. Part two is using evidence on banks and other financial organisations ability to provide such financial and non-financial support in India. The theory built up in part one is used to analyse the empirical data of part two. Part three discusses the theory of part one in light of the empirical evidence of part two. It also formulates some policy implications. Below follows a summary of each chapter.

Chapter two builds a theoretical background by providing a review of the literature relevant to pro-poor rural innovation and how it may be financed. It does so by considering three separate but related strands of literature: that on rural innovation, on entrepreneurship and on financing innovation. The first section finds that historically, rural innovation has been equated with agricultural innovation and technology transfer programmes. However, in the 1990's there was a shift to participatory approaches and theory using systemic or holistic notions, including agricultural innovation systems, and sustainable rural livelihoods theory. The second part on entrepreneurship theory points to the importance of the entrepreneur in the innovation process. There is a difference between necessity and 
growth or opportunity entrepreneurs, with most poor belonging to the former whilst innovative activities are likely to come from the latter. The third part considers financing models of such pro-poor entrepreneur-based innovation. Supply-led financial models in support of the Green Revolution's technology transfer have given way to demand-led approaches which take a systemic view of finance and financial markets, including microfinance. More recently, a financial literature focussed on financial markets, access and inclusion in developing countries has emerged, mainly from research undertaken at the World Bank.

Chapter three constructs a conceptual framework model by highlighting concepts that are useful in understanding, analysing and explaining the situation that can be seen in India which will be explored in later empirical chapters. The chapter first maps the reasons for why there is a lack of finance, including asymmetric information and credit rationing, perceived uncertainty regarding innovation, Financial exclusion due to collateral and relationship-based financing, demand that is not clearly visible, and the set-up and financial flows of the system. Thereafter, a model is constructed which considers the financial system in India as a sectoral system with a core, populated by banks, and a periphery which is where alternative financial organisations such as NGOs are positioned. The type of knowledge, and how such knowledge flows impacts on the core and the periphery of the system, which in turn has an impact on the provision of finance. A number of issues are highlighted including the dynamism and stability of the sector, the knowledge types accessed and the source of knowledge, the importance of history, the impact of networks, and the ability of finance providers to innovate. These factors are likely to be the reason why the core appears unable to provide finance for PEBI when the organisations at the periphery are able to do so. Finally, a number of insufficient but necessary (INUS) conditions under which an organisation is able to provide PEBI finance are proposed.

The second part of the thesis uses the theoretical framework in the first part to consider how banks and other financial organisations are able to finance PEBI in India.

Chapter four provides an overview and discussion of the Indian banking system pertinent to rural innovation, and in particular its ability to finance PEBI. Despite the government policy of 'social banking' which pushed banks to increase their branch presence and lending in rural areas, rural entrepreneurs do not find finance to be easily available. In fact, since the end of social banking regulations, the credit flow and bank branch expansion has been reversed and instead there is evidently a flow of credit from rural to urban areas with rural deposits outweighing rural loans. Reasons for this are discussed including incentives to not lend to unorthodox projects as well as general inertia in the system. Furthermore, it is highlighted that outside of the financial core, comprising of the banks, alternative financing organisations are emerging at the periphery to fill some of the gap left by the banks in regards to PEBI financing. These can be divided into micro venture 
capital, small-scale financiers beyond microfinance, and financial innovators and incubators.

Chapter five is the first of three chapters introducing five in-depth case studies of organisations operating in the alternative financing sector in more detail. The aim of the case studies is to show a) that there are very different models of financing and supporting innovation, b) how these organisations are providing financial and nonfinancial support and c) to what extent they are able to operate sustainably. The three chapters are divided according to the grouping highlighted in chapter four: micro venture capital, small-scale financiers beyond microfinance, and financial innovators and incubators. The first group, micro venture capital, which is outlined in this chapter, is represented by Aavishkaar. Aavishkaar makes equity investments in ventures that provide products and services for the rural poor.

Chapter six continues the empirical focus by introducing the second group of small-scale financiers beyond microfinance include BASIX which is a Livelihood Finance Provider that provides microfinance as well as a wider range of services including larger loans for rural micro growth entrepreneurs, and S3IDF, a social merchant bank which invests in small-scale rural infrastructure projects.

Chapter seven discusses the third group -of financial innovators and incubators which includes Centre for Technology Development which is an NGO active in the rural innovation process through building complete and locally relevant business models based on existing skills and raw materials, and Villgro which incubates innovations and entrepreneurs with small firms from rural India.

The final part of the thesis discusses the first part in light of the evidence of the second part.

Chapter eight brings the five case studies of the second part of the thesis together with the conceptual framework of the theoretical part to consider the conditions under which finance can be made available for PEBI. The chapter finds that a number of conditions are fulfilled among the case studies though not necessarily all of them and not in the same way.

Chapter nine follows with a discussion on the replicability and scalability of the financing models at the periphery, noting that rapid expansion on a large scale could easily lead to institutional lock-in and rigidity as witnessed at the core of the financial system. It then provides some policy implications.

Chapter ten concludes the thesis by providing a summary, followed by some suggestions for future research. 


\section{Literature Review}

The introductory chapter introduced the concept of Pro-Poor Entrepreneur-based Innovation (PEBI) and highlighted the important role that financing plays. This chapter is divided into two parts. The first part will further discuss pro-poor entrepreneur-based innovation by reviewing existing rural development, innovation and entrepreneurship literature. The second part will review the literature on financing pro-poor innovation and entrepreneurship. It will begin with theories on linear supply-led subsidised credit before continuing with more recently developed areas including microfinance, financial systems theories, and financial access and inclusion.

\section{1 'Rural' in Development Theory}

Development theory began to take shape following WWII and the successful implementation of the Marshall Plan, when economists started to study economic development of underdeveloped regions. ${ }^{8}$ There was an early emphasis on technological blueprints and industrialization as the driving force behind development that would go through linear stages of growth ${ }^{9}$ (Hunt, 1989; Rostow, 1960) which was the dominant view for many decades. A number of scholars emphasised the need for a 'big push' in order to change the industrial structure of a developing country and invest in new technologies and production processes to kick-start the economy (Nurkse, 1953; Rosenstein-Rodan, 1964). Hirschman (1958) on the other hand believed a general mass-investment impractical, instead advocating larger investments in a select number of industries which would lead to imbalance within the economy. This imbalance in turn would result in reactions that provide new opportunities for profit-seeking entrepreneurs, and hence development. A 'dualist' model of development emerged which utilized the unlimited supply of labour in these countries (Lewis, 1955). By increasing the share

\footnotetext{
${ }^{8}$ The emphasis was historical rather than theoretical, using the economic history of the developed world and the successful implementation of the Marshall Plan as a "template" for economic growth and development (Hunt, 1989).

${ }^{9}$ Using the example of the UK, these stages were: traditional society, pre-take-off, take-off, drive to market and mass consumption.
} 
of net income for industrialists, resulting in higher profits, savings and investments in industry, labour would move from the less productive agricultural sector to the more efficient industrial sector. The priority of these theories was evidently the development of the industrial sector, which included large-scale mechanised agriculture, at the expense of subsistence agriculture. That is because this is where innovation and technical change was expected to occur.

\subsection{Theories on Rural Innovation and Development}

Rural development has, for most of the time since its inception in the post WWII era, focussed almost exclusively on agriculture and how improvements in agriculture can lead to economic growth, development and reduced levels of poverty. Agriculture, it is believed, contributes to structural development of a country through the supply of labour, capital, foreign exchange, food and market for domestically produced industrial goods (Johnston and Mellor, 1961). As economic growth and development of a country takes off, agriculture declines relative to the industrial sector. This is due to a net flow of resources, including labour, from agriculture to industry (Mellor, 1966). The dual sector model (Lewis, 1955) which favoured large-scale industrialised agriculture over subsistence agriculture, was based on the assumption that larger scale farming would reap economies of scale which would increase its productivity and efficiency. Small-scale subsistence farming would have no active role in economic development, rather providing resources for the industrialised sector (Ellis and Biggs, 2001).

However, by the mid 1960s it was clear that little improvement had been made to the living conditions of the poor and in fact South Asia was ravaged by severe food shortages. The old theories had not worked in practice.

\subsubsection{Small but Efficient and Technology Transfer}

A change in agricultural theory was provided by Schultz (1964) who argued that subsistence farmers were already efficiently allocating resources in his small but efficient hypothesis. Instead of considering subsistence farmers as passive providers of labour, and capital, Schultz put them at the centre of the agriculture-led process of economic development (Ellis and Biggs, 2001). Small-scale agriculture, he believed, improved production on-farm and spurred the growth of labour intensive, non-farm activities through rural growth linkages (Ellis and Biggs, 2001; Mellor, 1966). Mellor believed in a virtuous cycle where increases in agricultural activity and thus farmer income would be magnified by various linkages with the activities of the non-farm sector (Mellor, 1976; 1966). This shift to a small but efficient paradigm in the 1960's called for increased investment in research and development relevant to small-scale agriculture so that farmers could acquire more efficient new technologies together with the skills to use them. Furthermore, in accordance with 
the Induced Innovation Hypothesis (IIH) the abundant labour would be substituted for scarce land in small-scale farming through 'induced innovation'. The IIH is based on the American agricultural model of extension and diffusion, and asserts that changes in relative prices of factors of production will spur, or induce, the development and adaptation of new technology in order to economise on the relatively more expensive factors of production (Ahmad, 1966; Hayami and Ruttan, 1970). That the scarcity of factors can induce innovation, resulting in technical change, became a stylised fact. Thus, it became generally accepted that small-scale farmers in developing countries could increase productivity substantially by using existing resources more efficiently through the use of improved technologies and practices that had been transferred from national and international agricultural research organisations (Binswanger, 1978; Hayami and Ruttan, 1971).

Around the same time, new high-yielding varieties (HYV) varieties that increased food production were developed (Binswanger and Ruttan, 1978; Hayami and Ruttan, 1971). By using modified seeds, farmers would be able to drastically increase output quantity and quality (Lipton and Longhurst, 1989). This research originating in international research centres like IRRI, the Philippines and CIMMYT, Mexico $^{10}$, led to a huge increase in output in selected areas of South Asia (such as the Punjab and Haryana in India) in the 1960's. It was termed the Green Revolution, which came to dominate much of the rural development debate over the next couple of decades. Though heavily criticised later on, the Green Revolution and the HYV were credited with seeing off a severe humanitarian crisis of South Asia. This innovation was supplier, or science-led, and still today rural and agricultural policy in South Asian countries are often focussed on supply rather than demand led innovation.

A linear model of innovation and diffusion emerged during the Green Revolution whereby the international centres of the Consultative Group for International Agricultural Research (CGIAR) developed generic technologies such as high yielding varieties of seeds. These technologies would subsequently be adapted by the national research system before national extension agencies transferred them to farmers (Biggs, 1990). There is a debate about this linear model. Whilst in the literature this model criticises previous models for treating farmers as passive end-users (Szirmai, 2005), in practice, even when using this linear model, farmers often remained passive end-users, far removed from the innovation process (Biggs, 1990; Chambers, 1989). The linear model is a hierarchical model of innovation with a linear one-way flow of information and technology from top to bottom. Roles within the structure are clearly defined and networking and linkages outside of the hierarchical top-down path are limited or non-existent in formal plans (Biggs, 1990). Informal research and farmer participation and innovation by anyone

\footnotetext{
${ }^{10}$ The International Rice Research Institute (IRRI) in the Philippines and the Wheat and Maize Improvement Centre (CIMMYT) in Mexico.
} 
other than the central scientists were of inferior importance to central research (Biggs, 1990). Such transfer of technology (TOT) models rested on the assumption that by the time a new crop or technology reached the extension services it would not need to be further adapted by the farmers (Clark, 2002; Douthwaite, 2002). ${ }^{11}$

Separately, but in parallel with the mainstream small-farm efficiency focussed theories on rural development, an alternative movement called Appropriate Technology emerged, based on Schumacher's Small Is Beautiful book (Schumacher, 1973). Schumacher criticised the general neoclassical emphasis on blueprints, mass production and transfer of technology to developing countries, arguing that such an approach did not make economies sustainable. Instead Schumacher created a separate paradigm which stresses the need for technologies to be appropriate for local conditions, to be adapted to current economic and resource conditions and to avoid human displacement or environmental degradation. The paradigm further highlighted production using local resources, for established local needs, as the most effective for of human development. Within this model, technologies and the use thereof are dependent on the habits, attitudes and perceived needs of the users and producers. Schumacher is also known as a critic of economic growth and consumption as a measure for development and well-being (Schumacher, 1973; Society, 2008). The small is beautiful debate did not have a substantial impact on mainstream policy which continued to focus on the TOT model and its emphasis on generic technologies. Recently however, the appropriate technology debate has been re-emerging with, in particular, many actors in the third sector finding Schumacher's ideas appealing and especially microfinance, which emphasises selfemployment, finds that it resonates with the reality of today's need for smaller scale, context specific solutions that provide livelihoods for the rural poor. However, Schumacher's school came to emphasise engineering and (small-scale) technological solutions, ignoring the social and policy dimensions that are crucial since Schumacher's ideas are essentially implying a reorganisation of the economy.

Another alternative school of thought that also emerged in the shadow of the mainstream linear innovation model is indigenous technology knowledge (ITK) and indigenous innovation (Chambers et al., 1989; Richards, 1985). A major contribution with respect to pro-poor rural innovation that emerged from this field is that by Anil Gupta (1997) who developed the concept of grassroots innovation. Its focus is on grassroots, and inclusive innovation that emerges from developing countries' own entrepreneurs, small firms and NGOs, as an internal engine of growth in rural areas.

A final point to note is that 'grassroots innovation' is today often incorrectly paired with the fashionable notion of Bottom of the Pyramid (BOP) innovation, as introduced by Prahalad (2006). However, it should be noted that whilst Prahalad's Bottom of the Pyramid innovation is MNC based, and thus based on transfer of

\footnotetext{
${ }^{11}$ Farmers were at the time considered conservative and non-experimental
} 
external technologies, Gupta's grassroots innovators are close to the PEBI concept developed in this thesis. In a sense the notion of 'grassroots innovation' developed by Anil Gupta can be considered as the endogenous, intrinsic version of Prahalad's external, top down version of BOP innovation (Fu et al., 2010). This thesis does not focus, or build, on Prahalad's ideas.

\subsubsection{From Top-Down to Bottom-Up and Participatory Models}

Rural development scholars began to heavily criticise the TOT model for portraying farmers as passive technology adopters (Biggs and Clay, 1981) and for considering only exogenous technological change ${ }^{12}$ (and not endogenous). ${ }^{13}$ In fact, evidence suggested that farmers are natural experimenters and participate in the innovation process by reworking generic technologies to suit their specific needs (Biggs and Clay, 1981). It follows that farmers are actively involved in the innovation process and by implication, innovation emerges from diverse sources. Biggs constructs a multiple source model where innovation has many different sources including farmers, local researchers, extension agencies, NGOs, the private sector and R\&D centres (Biggs, 1990). In addition, Biggs (1990) highlights the importance of institutions. Other criticism of the TOT model focused on how the model lets scientists set research priorities and the fact that it operates in a manner that inherently resists change. The TOT model was arranged in a way which underrates farmer knowledge and the fact that farmers are heterogeneous, risk-prone, face a complex set of issues and continuously experiment, innovate and adapt according to historical and empirical evidence (Biggs, 1990; Chambers et al., 1989).

Without challenging the centrality of the small but efficient approach established by Shultz, the continuous criticism resulted in a paradigm shift taking place in rural development thinking from the top-down research and intervention approach that transferred generic technologies to farmers, to a bottom-up approach where farmers were not merely end-users but participating in the innovation process. The change in tack was most clearly noticeable in the various participatory approaches to agricultural development that appeared. ${ }^{14}$ What these methods had in common was an effort to improve the suitability of technologies by involving farmers more directly in the R\&D process (Mosse et al., 1998). At a practical level on

\footnotetext{
12 Exogenous technology in this case being the technology transferred from international and national researcher centres

${ }^{13}$ The developments in rural innovation and technical change from a linear, to a participatory and finally systemic approach mirrored the move from the linear model of innovation (Schumpeter, 1939) through the chain-link model (Kline and Rosenberg, 1986, to today's systemic perspectives (Freeman, 1987; Lundvall, 1992; Nelson, 1993)

${ }_{14}$ Including, among others, Participatory Technology Development (PTD), On-Farm Research (OFR), Participatory Action Research (PAR), Participatory Rural Appraisal (PRA) and various extension approaches.
} 
the ground, the actual participation varied widely between projects, managers and agencies resulting in equally varied results. These methods were often too context dependent as the success of a particular approach appeared more dependent on specific local history and institutions than the actual methods themselves, or the theoretical model behind it (Biggs and Smith, 1998). As a result, the transfer and diffusion of participatory research methods was not more successful than the linear technology transfer model of innovation. Participatory models were also criticised for being a mere label put on a wide range of activities with no clear conceptual foundation (Biggs and Smith, 1998).

Notable among research models emphasising increased grass-root participation is Farming System Research (FSR). This model introduced a systems perspective to agricultural research with the aim to improve its relevance to farmers (Chambers et al., 1989; Norman, 1989; Norman and Collinson, 1986). It uses a holistic, participatory and interdisciplinary approach (FAO, 2001). Influenced by Farming System Research, the important Farmer First model of Chambers (1989) emphasises the ability of farmers to learn, adapt, analyse and improve on their own with the help of outsiders rather than by outsiders. Farmer First is a set of principles that should be adapted to specific local needs, with a decentralised research model (Chambers et al., 1989:182-183). As the 1990s approached, these models emphasising both participation of end-users and the need to look at issues from a systems perspective, recognising that innovation stem from several sources, began to significantly influence rural development thinking. A further result of the shift to bottom-up development and participatory methods was the advent and rise of nongovernmental organisations (NGO) as agents for rural development (Ellis and Biggs, 2001). NGOs were steadily taking on more responsibility on the ground as well as gaining importance in the debate on rural development and appropriate interventions.

\subsubsection{A Shift to Systemic and Livelihood Perspectives}

Farming System Research evolved in two directions relevant for this thesis. Firstly, research continued taking on a sectoral systems dimension of farming systems research resulting in Agricultural Knowledge and Information Systems (AKIS) and later agricultural innovation systems (AIS). Secondly, farming systems research began moving towards an integrated on and off-farm view of rural activities, resulting in the (Rural) Sustainable Livelihoods (SL) field. The off-farm activities of rural livelihoods took on more significance, especially through Rural Non Farm Sector (RNFS) research. 


\section{Systems and Innovation}

In response to the shortcomings of earlier participatory models, authors like Röling $(1986 ; 1988)$ and Biggs $(1990)$ began to consider systemic approaches to agricultural development by analysing the importance and nature of institutions for innovation and the relationships between innovation and the institutional environment in which it takes place. This set of scholars argued that without supporting the institutional environment, participatory approaches will fail. One early systemic model is the Agricultural Knowledge and Information Systems (AKIS) which incorporates ideas from the study of knowledge economics, highlighting in particular the generation and diffusion of information and linkages (Röling, 1986; Röling and Engel, 1992). AKIS emphasises that knowledge processes are social, as actors seek to influence the process and each other through interaction. Therefore, knowledge and sharing thereof is intricately linked with communication and information (Engel and Salomon, 1997). Nevertheless, AKIS has been criticised for not taking into account the historical and cultural contexts in which the innovation process takes place as well as for lacking in understanding of the different kinds of actors involved (Engel and Salomon, 1997; Hall and et al., 2001). Engel (1997) went on to develop a methodology based on AKIS called Rapid Appraisal of Agricultural Knowledge Systems (RAAKS) as a tool for considering the social organisation of innovation and capacity building.

The most recent development in this area has been to conceptualise rural innovation within the framework of Innovation Systems theory. Drawing on the Schumpeterian perspective of innovation and technological change through creative destruction (Schumpeter, 1934) as well as evolutionary economics and systems theories, an innovation systems framework was constructed (Dosi et al., 1988; Freeman, 1987; Metcalfe, 1988; Nelson, 1993; Nelson and Winter, 1982). The Innovation Systems scholars would study National System of Innovation (NSI) (Freeman, 1987; Lundvall, 1992; Nelson, 1993) to understand how the difference in national set-up impacts on innovation. ${ }^{15}$ Within this NSI, innovation is a continuous process where institutions (habits and practices), learning and networks play a central role in generating innovation and technological change (Edquist, 1997; Freeman, 1987; Kline and Rosenberg, 1986; Lundvall, 1992). Subsequently these ideas of a systems perspective of innovation and technological change have been applied to developing countries (OECD, 1997). ${ }^{16}$

15 The unit of study was originally at the national level (Freeman, 1987; Lundvall, 1992; Nelson,
1993; OECD, 1997) but also includes regional (Cooke, 2001), sectoral (Malerba, 2002) and
technological (Carlsson et al. 2002) systems.
${ }^{16}$ In developing countries, scholars pursued mainly empirical work on innovation which has been
summed up by Derayangala, 2003 and include: Technologies are not easily transferable and
technological knowledge is often tacit, with institutions and internal capability playing a huge role
(Oyelaran-Oyeyinka, 2003; Mytelka,1999). A lot of technological change takes place below
international innovation frontier in developing countries and considerable adaption and 
The Agricultural Innovation System (AIS) concept (Clark, 2002; Hall et al., 2003; Hall and et al., 2001; Hall et al., 1998; Hall et al., 2004) builds on the NSI to focus specifically on the need for innovation induced development in agriculture from a systems perspective, emphasising political, social and economic dimensions of knowledge creation and innovation (Hall et al., 2003). It broadens the analysis of what creates innovation from a top down linear model to a complex system where agents and their interactions are influenced by institutions and this has an important influence on the innovation process. Studies on AIS in rural areas in India (Clark et al., 2003; Hall et al., 2004) suggest that the roles of actors and their relationships evolve over time. It follows that the system requires enough flexibility to evolve with the changing requirements and needs of these new networks and partnerships. Within partnerships and networks, individuals rather than organizations often play a vital role. Furthermore, partnerships grow out of shared values and trust which have built up during a long time, rather than from official agreements and negotiations. Personal and professional networks are therefore important. Such partnerships should be made up of actors with different knowledge and capabilities so that each can provide something new to others within the network. Critical reflection and learning are important so that actors can adjust to new challenges or improve the way they are dealing with existing ones as new knowledge and learning become available.

AIS as a framework for rural pro-poor innovation does, however, suffer two shortcomings from the point of view of the current study. Firstly, it is focused exclusively on the agriculture sector. However, it has long been recognised that the rural non farm sector (RNFS) is a vital part of the rural economy, and it is expected that most of the poverty alleviating developments are to come from this rather than the agriculture sector (Start, 2001). Secondly, AIS is not explicitly focussed on direct solutions, such as goods, services or income, for the rural poor. Nor does it focus on whether an innovation, or a set-up of an innovation system, is welfare enhancing for the rural poor as (Spielman, 2005) notes:

\footnotetext{
"few studies in the emerging literature on innovation systems in developingcountry agriculture ask the fundamental question: whether a given innovation is welfare increasing. This means asking whether an innovation increases efficiency in production or utilisation of knowledge directly relevant to those goods and services used by the poor..., or whether an innovation improves the distribution or social surplus in a manner beneficial to the poor". .."Ultimately, by putting innovation (rather than poverty) at the centre of its study of developing-country agriculture, the innovation systems framework is limiting its relevance and value to developing-country agriculture" (Spielman, 2005:41-42).
}

modification of technologies and innovation occurs (Bell and Pavitt, 1992; Katz, 1987; Lall, 1987). Such technological activity is the outcome of a variety of factors including the ability to learn and obtain relevant knowledge, skills and the capability to use these (Bell 1984; Bell and Pavitt 1992; Lall, 2000). 
Rather, Berdegue (2005) proposes a pro-poor innovation system to be

"a multi-stakeholder social learning process, that generates and puts to use new knowledge and which expands the capabilities and opportunities of the poor" (Berdegue, 2005:9).

This is a natural extension of the AIS, with a clearer focus on the rural poor. With these shortfalls in mind, the next section goes on to widen the understanding of pro-poor rural occupational activities by using a broader Sustainable Rural Livelihoods perspective.

\section{Rural Sustainable Livelihoods and the Rural Non-Farm Sector}

Whilst not focussing on innovation, the sustainable livelihood (SL) approach does have several principles in common with innovation systems models, including the emphasis on multi-level targeting, partnerships to roll out interventions and the dynamic nature of rural livelihoods. In addition, SL takes a people-centred approach that focuses on participation and responsiveness of end-users whilst emphasising economic, institutional, social and environmental sustainability (Carney, 1998). SL defines 'livelihood' as the capabilities, assets and activities required to make a living (Chambers and Conway, 1992) and puts the household at the centre of the analysis of how to empower the poor (Ellis and Biggs, 2001). SL consists of a range of farm and non-farm activities which together provide a variety of income strategies (Chambers et al., 1989). This approach thus brings together earlier theories on farming system research (Chambers, 1983; Chambers et al., 1989) with the food security and famine analysis school (Sen, 1981) as well as participatory approaches and poverty alleviation (Haug, 1999).

Furthermore, The SL approach does not exclusively focus on farming activities but crucially includes those of the rural non-farm sector (RNFS), that make up the total activities of rural household (Ellis and Biggs, 2001). The RNFS, which

"includes all economic activities in rural areas except agriculture, livestock, fishing and hunting" (Lanjouw and Lanjouw, 2000:3),

is important because it has the potential to absorb rural surplus labour and help diversify risks and employment opportunities within households (Davis and Bezemer, 2004). In fact, opportunities for growth and employment creation are most likely among the SME's of rural towns (Start, 2001:501). The RNFS is characterised by great heterogeneity and varying degrees of production which are greatly influenced by the access to capital, inequality, poverty education, caste, ethnicity, gender, infrastructure and access to markets (Lanjouw and Lanjouw, 2000; Davis, 2004).

Whilst the innovation system approaches focus on innovation, but tend to still be agriculture and in particular small-farm focussed, the rural sustainable 
livelihood approach emphasises a holistic view of the rural sector including the RNFS, but does not focus on innovation. The two approaches are important and ideas from both will be used in this thesis. The RNFS literature has noted that poverty alleviation and growth is likely to occur in the RNFS through entrepreneurs and small firms. However, neither innovation systems nor sustainable livelihood approaches focus on the entrepreneur or entrepreneurship as an avenue to empower the rural poor or as the focus of rural innovation. Whilst innovation system theories put a focus on innovation at the firm (or in the case of AIS, agriculture-related innovation), sustainable livelihoods emphasised the household. The work on the RNFS too failed to explicitly focus on the importance of entrepreneurs and entrepreneurship. The next section therefore, introduces literature on entrepreneurship to widen the understanding of entrepreneurshiprelated concepts pertaining to rural pro-poor innovation.

\subsection{Theories on Entrepreneurship}

Whilst previous rural development policies have focussed on small-holder agriculture, most rural poor are landless poor (Sundaram and Tendulkar, 2003) and therefore unlikely to benefit greatly from agriculture based policies. Instead many poor are entrepreneurs, running micro ventures, often at subsistence levels in both agriculture related and non-farm sectors. Since many of the rural poor operate as entrepreneurs, plenty of socially relevant innovation originates from entrepreneurs, whether in the commercial, financial or NGO sector. Businesses run by the poor normally operate at a very small scale with very few assets or machinery (Banerjee et al., 2006). Banerjee and Duflo in a study on the economic lives of the poor comment that

"all over the world a substantial fraction of the poor act as entrepreneurs in the sense of raising the capital, carrying out the investment, and being the full residual claimants for the earnings" (Banerjee et al., 2006:10).

\subsubsection{The Classical Entrepreneur}

Entrepreneurship shares with innovation systems theory both a common origin, in the work of Schumpeter ${ }^{17}$ (Schumpeter, 1944; Schumpeter, 1934; Schumpeter and Opie, 1961), and a lack of definitive clarity on underlying terms and characteristics.

\footnotetext{
${ }^{17}$ Non-Schumpeterian schools on entrepreneurship include the neo-classical school, represented by Marshall and Knight, which sees the role of the entrepreneur as that of leading the market to equilibrium through their activities. Meanwhile, the Austrian tradition under Kirzner, focussed on the entrepreneur's ability to perceive new and untapped opportunities and bring together resources to meet such needs or gaps (Kirzner, 1985; Marshall, 1961). Thus, entrepreneurship can mean both the creation of new opportunities and the response to exiting challenges, where the entrepreneur is prepared to face risks uncertainty" (Henrekson, 2007: 720).
} 
Schumpeter's early work saw the entrepreneur as an individual disrupting existing equilibrium by creating new combinations of existing resources through the process of innovation. Schumpeter later suggested that it was not the lone entrepreneur that was the innovator but the firm (Schumpeter 1943, 1950 in Lazonick, 2008) where the entrepreneur instead acts as the leader of an evolving business.

Recent definitions of entrepreneurship in the same vein include Wennekers and Thurik (1999), who explain that

"entrepreneurship is the manifest ability and willingness of individuals, on their own, in teams, within and outside existing organisations to: perceive and create new economic opportunities (new products, new production methods, new organisational schemes and new product-market combinations) and to introduce their ideas in the market, in the face of uncertainty and other obstacles, by making decisions on location, form and the use of resources and institutions" (Wennekers and Thurik, 1999:47).

The entrepreneur is then

"somebody who specialises in taking responsibility for making judgmental decisions that affect the locations, forms and the use of goods, resources, or institutions" (Herbert and Link, 1989:31).

Put differently, the entrepreneur is an agent in the economy catalyzing change and economic growth (Wennekers and Thurik, 1999). The main factor that links entrepreneurship to economic growth is 'newness' through new business start-up, innovation and competition. Using evolutionary theory, the authors emphasise the importance of innovation and the transformation of information into knowledge, where technical change is the driving force in the economy, supported by underlying institutions (Wennekers and Thurik, 1999:43-44).

\subsubsection{Entrepreneurship in Developing Countries}

There is a clear entrepreneurial divide between the west and developing countries. Most entrepreneurs in developed countries are opportunity entrepreneurs, reflecting many of the traits of the classic entrepreneur noted above, as exemplified by the success of Silicon Valley. In developing countries, however, whilst most entrepreneurs are so out of necessity ${ }^{18}$, those that hold the greatest promise for economic growth, development and increased employment are the far fewer entrepreneurs that act upon perceived opportunities. The difference between opportunity and necessity entrepreneurs suggests a different set of drivers and

\footnotetext{
${ }_{18}$ Reynolds, 2004 in Lingelbach and de la Vina, 2005: whilst necessity entrepreneurs enter into entrepreneurship because of external shocks such as unemployment, opportunity entrepreneurs make a choice to create a venture because of an identified unexplored market niche or business opportunity. See Banerjee and Duflo, 2007 on the poor as entrepreneurs.
} 
incentives. ${ }^{19}$ For instance, necessity entrepreneurs may be willing to take less risk compared to opportunity entrepreneurs. ${ }^{20}$ Naude (2008) translates this into an apparent lack of interest in seeking out entrepreneurial opportunities by the poor, although states that this would be because

"assuming the high risk of trying to exploit opportunities which are subject to uncertainty may be unacceptable as the potential losses may outweigh the potential gains. Thus manager-owners, family businesses and household enterprises often experience difficulty in innovation and adopting new technology" (Naude, 2008:6).

Furthermore, high entry costs due to corruption, regulations and bureaucracy makes it more burdensome to set up a business. The opportunity entrepreneurs however, are more likely to be better prepared for undertaking a business opportunity as well as better able to take risks. They look to grow, to be growthfocussed entrepreneurs in other words (Lazonick, 2005). Since entrepreneurship flourishes the most in small businesses with growth and innovation potential (UNDP, 2004), growth oriented entrepreneurs are of particular importance in developing countries. These growth oriented entrepreneurs differ from those in developed countries due to the differences in market inefficiencies (Lingelbach et al., 2005). For instance, the challenge for new firms in developing countries is rather than providing 'new to the world' innovation, to climb the value added ladder in order to further increase economic development (Lazonick, 2008:5).

What the preceding review of literature arrives at is an emphasis on innovation through entrepreneurship which in some way is beneficial to the poor, or pro-poor. It implies an adjusted view of rural development which moves away from smallholder agriculture and farms as the main targets of anti-poverty fighting measures and towards a recognition that many poor are not farmers and do not necessarily wish to be micro-entrepreneurs (as most are forced to be, operating at subsistence level). In this sense it actually brings back to the fore many of the ideas pioneered by Schumacher in the 1970 s of small being beautiful and highlighting context specific solutions.

Furthermore, the idea of entrepreneurs with most potential for poverty alleviation being those entrepreneurs who innovate, who look to grow and seek out new opportunities would question current mainstream ideas which focus either on

${ }^{19}$ It also suggests different financing and support needs. Whilst necessity entrepreneurs are recipients of microcredit or microfinance, which is often not sustainable or leads to growth in business and income opportunities in the long term, opportunity entrepreneurs require capital beyond what these organisations can offer.

${ }^{20}$ Furthermore, the productivity of entrepreneurs in a country varies more than the actual amount of entrepreneurs across countries, because there is an important distinction to be made between the allocation of productive activities which result in innovation and economic growth and unproductive activities such as rent seeking and crime that engage in tax evasion and slows down or eradicate competition (Baumol, 1990). 
supporting innovation in manufacturing or supporting entrepreneurs at the micro scale. Rather, this thesis argues that the slightly larger entrepreneurs and their innovative activities need increased support and attention from policy makers. In other words, this thesis argues for increased focus on the gap that lies between large-scale manufacturing on the one hand and microfinance and subsistence entrepreneurship on the other. ${ }^{21}$

Finally, this thesis moves beyond the focus on agriculture support to focus on the broader rural concept. By putting the entrepreneur at the centre, it avoids dividing opportunities and innovative activities into agriculture and nonagriculture based opportunities.

\subsubsection{Entrepreneurship and Finance}

One of the vital factors influencing and supporting entrepreneurship is finance. In fact, together with a level playing field provided by appropriate and fair regulations and laws, and access to human capital, access to finance constitutes the pillars of entrepreneurship (UNDP, 2004). However, whilst entrepreneurs in the west have business support programmes and venture capital, most developing country entrepreneurs lack such facilities (Lazonick, 2008). The SME programmes that do exist often underperform (Naudé, 2008). Furthermore, development focussed, 'propoor' business support programmes tend to work with cottage industries and be concerned with livelihood issues rather than growth oriented entrepreneurial activities (Naude, 2008; Schramm, 2004). In fact, Lingelbach and de la Vina (2005) note that

"while entrepreneurial opportunities are broader and resultant strategies are naturally self-hedging in developing countries, limited personal and family savings and an absence of financial innovation severely limits the growth prospects of promising start-ups in developing countries.... Reflecting the unpromising odds of entrepreneurial success, internal finance comprises the majority of financing for small and medium enterprises in most developing countries. Entrepreneurs in emerging markets rely very heavily on informal sources of finance to start their businesses: these sources provide between $87 \%$ and $100 \%$ of the outside capital raised by entrepreneurs" (Bygrave, 2003 in Lingelbach et al., 2005:4).

This lack of finance exists despite clear evidence that finance has a poverty alleviating effect as access to finance for entrepreneurs results in employment and wages for the poor and access to better products and services (Demirguc-Kunt et al., 2008). In a study on financial access, Beck and Demirguc-Kunt (2008) note that

"pro-poor financial sector policy needs a broader focus than access for the poorest and that improving access by the excluded non-poor micro and small

\footnotetext{
${ }^{21}$ However, it is not implied that a choice should be made between either supporting these entrepreneurs, or large-scale manufacturing.
} 
entrepreneurs can have a strongly favourable indirect effect on the poor" (2008:385).

However, despite a general agreement that finance affects growth by supporting innovative activities in the economy (Levine, 2004), little has been written specifically on how pro-poor entrepreneur-based innovation in rural areas should be financed. ${ }^{22}$

The next section will consider financing theories pertaining to innovation and entrepreneurship in more detail. As a starting point, it will look at the old supplyled financial theories before moving on to theories that have emerged more recently related to, in turn, microfinance, financial systems and financial access and inclusion.

\subsection{Financing Rural Innovation and Entrepreneurship}

Linked to the debate on innovation and technical change in agriculture, especially during the Green Revolution, were theories on the provision of finance in rural areas and how that could induce innovation.

Economists in the post war years such as Lewis, Higgins and Leibenstein drew direct parallels between availability of "entrepreneurial facilities, technological knowledge and credit facilities" and increased income per head (Penny, 1968). They suggested that farmers needed more capital than they could save from income, and that credit would be necessary in small agriculture and industry (Penny, 1968). So, just as the technology-led paradigm has been dominant in theory and practice, so has the supply-led financing model supporting it.

\subsubsection{Supply-led Finance}

In supply-led theory, finance was considered a means to induce innovation, as a form of input. Patrick (1966), for example, conveyed the idea that rural economic growth and development could be encouraged through interventions in the financial system by supplying finance in advance of demand. Such supply-leading financial theories came to dominate rural finance for several decades. Patrick (1966) suggested that

"supply-leading finance has two functions: to transfer resources from traditional or non-growth sectors to moderns sectors and to promote and stimulate entrepreneurial responses. Access to supply-leading funds opens new horizons, enabling the entrepreneur to 'think big'"' (Patrick, 1966:51).

\footnotetext{
${ }^{22}$ Much has of course been written about rural finance in general (Adams, 2004; Von Pischke, 1991; Zeller, 2003) and recently about microfinance in particular (Morduch, 1998; Robinson, 2001; Helms, 2006).
} 
It follows that if subsidised credit was provided to the agriculture sector, farmers would be induced, or spurred, to buy new and more efficient technology, such as tractors, which would have a positive impact on economic growth and development. Credit programmes ${ }^{23}$ were expected to help the rural poor increase agricultural production (and thus growth) not only by giving them the opportunity to purchase new technology but also by compensating farmers for the government prices and policies that were having a detrimental effect on their earnings (Adams et al., 1984:1). The result of this 'directed credit' approach was expected to be increased food production at a time when the world was facing a severe food crisis.

A further assumption underlying the need for government intervention and funding of subsidised credit programmes was that 'bad moneylenders' that were providing the majority of finance in rural areas, would charge usurious rates. Therefore, formal financial institutions needed to be created that could provide credit at a better rate for the rural poor (von Pischke et al., 1983). Providing credit was ultimately seen to be the responsibility of governments and international donors, either directly or through financial institutions. Internationally, USAID's predecessor was pioneering in providing rural credit for farmers in the 1950's followed by the Inter-American Development Bank and the World Bank. The UN's Food and Agriculture Organisation supported programmes with information dissemination and technical support (von Pischke et al., 1983:2-3). National governments of low income countries quickly adopted the credit programmes, which proliferated in the 1960's and 70's, with the arrival of new technologies and the Green Revolution, in particular in Asia.

Nevertheless, fierce criticism of the narrow supply-led finance theories and credit programmes surfaced almost before they had even developed. As early as 1952 Galbraith pointed out that credit programmes can be a means of stagnation and repression as well as progress, and in the same year Li wrote that farmers should have reached a certain level of development before taking part in credit programmes (Galbraith, 1952 and Li, 1952 cited in Penny, 1968:32-33). Furthermore, Mellor (1966) argued that credit programmes would serve their clients better by being provided alongside or after the implementation of technology improvement programmes, rather than being supplied in advance (Mellor, 1996 in Penny, 1968). In fact, according to Penny (1968),

"Galbraith, Li and Mellor are right, and the government rural credit programmes will remain ineffective until governments come to a better understanding of a) the role of credit in peasant economies and $b$ ) the attitudes of peasant farmers towards savings, investments and debt" (Penny, 1968:33).

\footnotetext{
${ }^{23}$ Empirically, credit programmes stem from discussions of surveys such as the All India Rural Credit Survey in 1951 followed by a conference on the agricultural credit in the US a year later (Von Pischke et al., 1983).
} 
Penny argued in his 1968 paper that much of the literature on the need for credit programmes is based on faulty or untested assumptions, and he showed through studies of credit programmes in Indonesia that credit will not be efficient unless a certain level of development among farmers has already taken place. Nevertheless, despite early criticisms, the major turning point only came with the USAID's Spring Review of Small Farmer Credit of 1972-73. The review surveyed a large number of credit programmes and severely criticised the model. Credit programmes continued to be heavily criticised as the approach failed according to empirical and theoretical evidence:

Programmes missed the real targets -the rural poor: The credit programmes were meant to make capital available to small-scale farmers and producers. However, instead larger producers gained increased access to credit whilst the smaller producers actually had even less access after the implementation of credit programmes (Gonzalez-Vega, 1984:131; Vogel, 1984:133). The nature of rural credit discriminates against the poor, since larger loans are, overall, cheaper and transaction costs as a proportion of the total cost is a much smaller burden for relatively better off borrowers (Blair, 1984:183). Furthermore, since

"cheap credit is rationed; the procedures usually are at least in part politically determined and provide opportunities for corruption, cronyism, and favouritism. A select group of relatively wealthy and powerful individuals or families tend to capture the benefits of concessional loans, making it more difficult for the weaker sections of society to obtain credit" (von Pischke et al., 1983:10).

Credit thus became concentrated among the rich and politically powerful elite and used for political patronage, including swinging votes, and as a profitable side income through corruption (Blair, 1984:183).

High default rates and debt forgiveness: The fungibility ${ }^{24}$ of credit means that it is difficult to control what exactly the credit is used for, whether it is used for the intended purpose, and what the impact of the credit is (Adams et al., 1984:75). The credit programmes were infeasible because of the very nature of credit (von Pischke et al., 1983). Credit worthiness estimates whether a borrower is likely to repay a loan, but because of the resulting selective nature of lending, a selective credit programme would not necessarily be expected to contribute to rural development. On the other hand when credit worthiness tests are not applied, defaults are likely to increase (von Pischke et al., 1983:9). High rates of default were exactly what followed in the wake of most of these credit programmes. Farmers were unable, and sometimes unwilling, to repay the loan. Many governments intervened with debt forgiveness programmes in order to lessen the hardship of poor and debt ridden farmers and credit became almost interchangeable with grants (Robinson, 2001).

\footnotetext{
${ }^{24}$ In the sense that a currency unit is fundamentally interchangeable with any other currency unit of the same value.
} 
Credit does not equal innovation: Supplying credit in advance would, according to theory, encourage farmers to adopt new technologies, but it was becoming evident that much of the supplied technology was not appropriate for small-scale farmers. Moreover, the impact of the credit programmes was not clear despite the huge investments made. Rather,

"in view of the large strides made by agriculture in developing countries, and the relatively small number of farmers who have received formal credit, it seems reasonable to conclude that most agricultural innovations in these countries have not depended directly on formal credit. The relation between innovation and credit has not been realistically viewed in part because credit tends to support large, lumpy investments in highly visible innovations such as tractors, as opposed to small, divisible investments in much more numerous and widely spread innovations such as improve seeds"(von Pischke et al., 1983:7).

It was unclear whether credit was significantly constraining development in agriculture (Bourne and Graham, 1984:37), since there are many other constraints that can slow productivity, including marketing and the availability of input supplies. In fact, Vogel and Larsson (1984) went as far as to say that credit programmes actually hinder innovation because of the rigidities and costs of the management and roll-out of very large programmes and the tendency to favour established crops and technologies over newer varieties. Generic technologies such as tractors were diffused widely without being necessary or useful for the local farmers. Such practices continued to be supported by heavy subsidies despite proof that mechanisations such as tractor subsidies did not increase employment opportunities much (Roumasset and Thapa, 1983).

Rural Finance is more than credit: Finally, rural households and firms are heterogeneous, and their needs vary over time, but the programmes' exclusive focus on credit over other forms of financial services did not take that into account (Meyer and Alicbusan, 1984). Savings, for instance, was the "forgotten half of rural finance" (Vogel, 1984) because it was assumed that the rural poor had neither the means nor the wish to use such services.

By the 1980's, the failings of the credit and subsidy-heavy supply-led financing approach became too obvious to ignore. Credit programmes were not geared towards the realities of rural markets or social and political issues facing the poor. Nevertheless, despite the criticism, countries such as India, China and Pakistan have continued with state run subsidized credit programmes to the present day, most plausibly because, as Blair (1984) noted 25 years ago:

"politics is the main reason for the persistence of subsidised credit. The large borrowers who gain most from cheap credit want to protect that benefit, and at the same time politicians and bureaucrats want the power and the fruits of corruption that these programmes put in their hands" (Blair, 1984:184). 


\subsubsection{Markets Based Approach}

New approaches emerged in the 1980s, resulting in a paradigm shift in rural finance away from the narrow focus on rural credit to emphasising a broader view of the financial system (Robinson, 2001). The change was led by the Rural Finance Programme at Ohio State University which created the Rural Financial Markets approach, summarised in two important collections of essays on rural finance edited by Von Pishcke et al. (1983) and Adams et al. (1984). The new paradigm was based on a changed and broader attitude towards informal financiers, mobilising savings and extending financial services beyond farm credit, to non farm activities and, in line with general development policy at the time, a more market driven approach where market forces would be expected to allocate financial services (Adams et al., 1984:229; Gonzalez-Vega, 1994). Additionally, there was a strong belief in competitive local informal financial markets and their ability to provide adequate access to finance. In fact, it was an almost complete turn-around on the 'evil moneylender' assumption, believing instead that informal financial institutions and markets could adequately support the rural poor (Robinson, 2001) and should be left to themselves. Furthermore, the World Bank discussed rural financial markets in several important articles and books in the 1990's including von Pischke, (1991), Hoff et al., (1993a), Benjamin and Yaron, (1997), all stressing an enabling environment and removing policies biased against rural markets in line with the prevailing Washington Consensus. These authors called for governments to correct market failures through policy and regulatory reforms rather through the subsidybased directed credit programmes.

Towards the mid 1990s, rural finance theory had moved towards demand-led models. Three separate but interrelated strands of financing theory particularly relevant to financing innovative entrepreneurs emerged which question the neoclassical view of economic development. One strand is the fashionable and currently much researched microcredit/microfinance approach. The second focuses on financial systems and innovation. Lastly since the start of the new millennium, work on financial access and inclusion has become increasingly popular.

\subsubsection{Microcredit and Microfinance}

Microcredit and later microfinance emerged in the 1980's to provide small amounts of credit for the rural poor, treating them as customers and expecting regular, and full, repayment, including interest. Microfinance institutions (MFI) thus came about as a response to the continual failure of financial services to reach the poor. For the past 20 years microfinance has grown rapidly and in 2001 Robinson wrote on the Microfinance Revolution and sustainable microfinance provision as the key to sustainable services for the poor.

Various forms of microfinance exist. Bangladesh predominantly uses Grameen's 'joint liability' model where small groups are formed where each 
member is required to act as a guarantor of the other members of the group in case of loan default. India on the other hand use a different group model based on larger Self-Help-Groups (SHG) where credit is lent to a self-formed village group of prevalently women who then administer the loan within the group. SHGs have been linked with rural banks, resulting in the 'SHG-bank-linkage model' 25 which has become enormously popular among Government and Apex institutions as the main mechanism for providing finance for the rural poor. Thirdly, apart from group lending, some microfinance organisations offer individual loans. Whilst the Grameen and SHG models often rely on government subsidised credit for onlending, models such as Latin American MFIs Banco Sol and Bank Compartimos, and Indian SKS, rely on for profit investments and savings.

However, microfinance, in particular microcredit, has also been criticised for not having a clear and sustainable impact among the poor (Morduch, 1998; Morduch, 1999) and several impact evaluation studies have substantiated this belief (Banerjee et al., 2009; Morduch, 1998; Pitt and Khandker, 1998). One problem with the credit provided to small-holders is that it is often too small to be used for the intended purpose such as buying healthy animals. Instead it is common for loans meant for productive purposes to be spent on household consumption (Birdar and Jayasheela, 2000) such as a new roof or family events including funerals and weddings. In fact, Banerjee, Duflo et al. (2009) find, through a randomized trial, that microcredit has little impact on the investment practices and business income of those micro entrepreneurs that did not already possess a functioning business at the time of loan disbursement, who chose instead to use the credit for consumption, whilst those entrepreneurs that already had a business were more likely to use the extra credit for business expansion purposes.

“While microcredit 'succeeds' in affecting household expenditure and creating and expanding businesses, it appears to have no discernible effect on education, health, or women's empowerment" (Banerjee et al., 2009:21).

This highlights another problem with microfinance, that it rests on the faulty assumption that all poor are willing, and able to be entrepreneurs. ${ }^{26}$

Nevertheless, a major point that microfinance has proved, is that the poor are reliable bank customers. Microfinance has thereby opened up financing for a new section of society, and using women, rather than men as clients in order to minimise the diversion of funds (Robinson, 2001). A number of other important issues

\footnotetext{
25 The SHG-bank linkage models create links between banks, NGOs and the local SHG groups and are widely supported by the state and apex institutions. It is much more common than any other model such as those inspired by the Bangladeshi Grameen model or commercial MFIs (Basu and Srivastava, 2005). A reason for the strong prevalence and popularity of the SHG model is that it relies on the already existing rural banking system which was already well built up in rural areas (Basu and Srivastava, 2005).

${ }^{26}$ As was noted above, most poor are entrepreneurs out of necessity, not will, and often operate at subsistence level, not being able (or have the means) to sustain a profitable business.
} 
regarding the provision of finance for the poor has been highlighted by the microfinance movement.

First, microfinance organisations are flexible in their approach to collateral. Whilst banks rely on assets as collateral to recover any potential loan default, effectively cutting off a large share of the population because of a lack of assets and/or a lack of adequate property right laws, microfinance takes a different approach, seeing collateral as a deterrent instead (Cull et al., 2006). Therefore they can take non-monetary or land assets that would not necessarily repay a defaulted loan, but would be important enough to the borrower to act as a deterrent to default on the loan (Cull et al., 2006).

Second, group lending has a number of risk mitigating qualities, which can importantly be used as a substitute for collateral. ${ }^{27}$ Peer selection acts as a screening method when forming groups, peer pressure enforces repayments whilst peer monitoring within the group reduces risk-taking behaviour (Morduch, 1999). Nevertheless, today microfinance is seeing a steady shift towards individual lending and bilateral contracts (Morduch and Armendariz, 2004). Individual loans tend to be much larger than group loans. These loans are provided for the relatively less poor, generally for investment in larger business opportunities where group lending mechanisms would quickly become unmanageable (Cull et al., 2006). Lending larger amounts to the relatively better off can potentially lead to better sustainability than lending smaller amounts to poorer clients (Cull et al., 2006). Though, organisations providing such loans have been accused of mission drift. This is an argument closely related to the debate between those believing that microfinance is first and foremost a social activity, as advocated by Mohammad Yunus of Grameen Bank (Yunus, 1999), and those who see it as a 'bottom/base of the pyramid' business opportunity (Prahalad, 2006) like the Mexican microfinance provider Banco Compartamos that went public in 2007, making substantial profits by charging very high interest rates (Morduch et al., 2009).28

Third, both individual and group models of microfinance use a progressive lending approach, building up a relationship and trust. By starting a borrowerlender relationship with small amounts of credit which grow larger on each successful repayment, there are dynamic incentives at work to encourage repayment. The repetitive nature of interaction overcomes information asymmetries as well as inefficiencies for both lenders and borrowers (Morduch, 1999). Furthermore, the regularity of repayments, which start soon after the loan is effective, often on a weekly basis, and in very small amounts, means that there are early warning sign on emerging problems and potential defaulters. In addition the

\footnotetext{
${ }^{27}$ Collateral is a major barrier to access to finance for the poor since the poor generally lack assets that can be used as collateral.

${ }^{28}$ The interest rates were as high as $94 \%$ once $15 \%$ value added tax had been included, according to Morduch (2009), though Banco Compartamos argued that this was still substantially lower than what informal moneylenders would offer.
} 
lending agency does not have to rely on the ability of the client to save up the amount over time. Nevertheless, demanding repayments soon after disbursement means that clients need to have a second income to cover the repayment (Morduch, 1999). Christen (1997) concludes from a manual on microfinance based on a survey of the MFI ACCION's operations in South America that

"repayment depends fundamentally on factors within the control of the lending institutions"

and highlight in particular the need for

"clear repayment expectations, administrative efficiency and the development of close, almost personal, relationships with clients"(Christen, 1997:16) .

Client-lender relationships are important in successful microfinance organisations, using these to mitigate risks by monitoring the lender and/or investment and by acquiring information that can flag potential problems early.

Fourth, some microfinance organisations not only form a closer relationship with their clients but also provide them with support in addition to credit. One important service is the ability to save. Whilst compulsory savings has often formed part of the initial pre-credit microfinance progressive lending strategy, there is now a move towards voluntary savings separate from credit provision (Morduch and Armendariz, 2004). Furthermore, whilst microcredit has focussed solely on the provision of debt finance, many microfinance organisations offer non-financial services such as business and accounting practices, education and health provision. This has resulted in a second debate between those that believe that credit alone is sufficient in order to provide the poor with the means to take themselves out of poverty, and those that believe that the poor do not necessarily maximise their profits by the simple provision of credit. Therefore, the latter camp argues, credit would be much more efficient, in maximising profits, if accompanied by business support. The former is highlighted by Yunus who states that since all humans have the basic skill to survive, and the poor in particular show proof of this skill,

"they do not need is us to teach them how to survive; they already know. So rather than waste our time teaching them new skills we (the Grameen Bank) try to maximise use of their existing skills. Giving the poor access to credit allows them to immediately put into practice the skills they already know" (Yunus, 1999:140).

The latter view, as supported by Morduch, Robinson and Karlan (Karlan et al., 2008; Morduch and Armendariz, 2004; Robinson, 2001) questions the ability of credit on its own to have an impact. Credit alone cannot increase incomes and standards of living in the rural sector for entrepreneurs without a supportive environment which facilitates market access and help build a sustainable business. Credit is, according this view, one of several interlinked parts of poverty, with healthcare and education playing a large role, and therefore an integrated approach of credit as well as other services may be more suitable to rural development (Cull 
et al., 2006; Helms, 2006). In fact, Karlan and Valdivia (Karlan et al., 2008) note that an increasing number of MFIs now invest in human capital as well as financial capital. They undertook an impact evaluation of a programme in Peru providing credit for female micro entrepreneurs through randomized control trials to assess the impact of business support in addition to credit. 144 banks with a total of 3265 clients were participating in the evaluation and divided into three groups: a treatment group (55 banks, with mandatory non-financial support), a voluntary treatment group (34 banks, where clients could choose whether to participate or not) and a control group (51 banks) that were supplied credit only. A baseline survey was carried out early 2003 with a follow up survey which reached approximately $80 \%$ of those in the base line survey, in the middle of 2005 . The authors found limited proof that general, non-customised business support training does have a positive impact on business knowledge as well as revenues and profits, and increases customer retention rates for MFIs. For instance, business profits during the low season increased by an average of 33\% for those that had attended more than eight training sessions and the effects of these training sessions on profits was significant. A shift in the direction of more integrated and holistic services is taking place with MFIs moving towards a wider livelihood-oriented view of finance and non-financial support, including business and livelihood support services as well as insurance In India, for instance, MFI-insurance linkage programmes are currently widely supported by the state (Basu et al., 2005).

This newer generation of microfinance organisations is, in fact, working in ways closely resembling those propagated by the research on financial systems, as well as financial access, topics that the next two sections will discuss.

\subsubsection{Financial Systems and Innovative Activities}

The way a financial system is set up has an impact on the financial institutions and flows within it. Creating financial institutions that are able to accumulate and diffuse knowledge is a way to bridge the information gap and deal with risks and uncertainties. The institutional set-up of the financial system in different countries may support or hinder the innovation process.

In one attempt to locate the importance of finance within innovation systems, Christensen (1992) analyses the role of finance within national systems of innovation, focussing mainly on external as opposed to internal financing of firms. He recognises availability of finance as one of the most important conditions in the innovation process. Such factors can vary across nations' financial systems and can affect firms and their ability to invest in new technology and innovation activities (Christensen, 1992:146). The financing of the innovative activities of domestic technology firms has been studied through three main angles: firstly, the financing issues of R\&D; secondly, the financing of new technology-based firms and why there is an apparent financing gap; and thirdly, a focus on specific financial 
instruments such as venture capital and its impact on innovation (Bartzokas and Mani, 2004; Hall, 2002). Christensen (1992) finds that institutional differences in national finance systems have serious implications for how innovation is financed.

The literature on financial systems has generally focussed on comparison between different countries' systems and their perceived effectiveness in encouraging economic growth. Such studies have shown that industries that are more dependent on external finance grow faster in more developed financial markets (Rajan and Zingales, 1998) and that the economic impact of the financial system may be visible at the national level through the rates of economic growth. Studies in number of countries that have compared different sectors performance in relation to access to finance found that that sectors with preferential treatment from a country's financial system are likely to do better (Beck et al., 2000; Carlin and Mayer, 2003; Demirguc-Kunt and Maksimovic, 2002; O'Sullivan, 2004).

Furthermore, bank and market based financial systems may affect the innovation process differently. Allen and Gale (2000) in a book length review comparing the capital market heavy economies of the UK and the US with the bank based economies of Germany and France note that where great new inventions and industries are launched, the stock market tend to be well developed and provide the required finance, whilst when the industry already exists and it is a matter of building up an industry or incremental innovation, financial intermediaries may be better suited to supply finance. ${ }^{29}$ Nevertheless, Beck et al. (2008) has since suggested that bank versus market discussion is no longer as relevant a discussion as most countries opt for a system that combines elements of the two.

A well-functioning financial system is essential for innovation since it promotes entrepreneurship in non-financial sectors, Bhatt (1995) argues in a comprehensive review on financial systems, innovation and economic development. Furthermore, the financial system's ability to innovate affects its ability to react to changing circumstances and new challenges for financial products, services and institutions from the non-financial sector. Financial innovation includes:

\footnotetext{
"new financial instruments, new decision processes and criteria, cultivation of new markets for financial instruments, new organisational and managerial practices and new institutions" (Bhatt, 1995:9).
}

\footnotetext{
${ }^{29}$ Their argument is that when a new technology or industry is launched where there is a great deal of risk but little prior information which results in a great diversity of opinion, the market is better placed to provide finance because at least some projects will be financed because there will be somebody in the market willing to do so. On the other hand, in a bank based system the process of acquiring information becomes cheaper but the diversity of believes on whether a project is good or bad means that investors may withhold funding because a bank may choose to support a project they do not believe in.
} 
Frame and White (2004) in a review of empirical studies on financial innovation ${ }^{30}$, have more formally defined financial innovation as

"representing something new that reduces costs, reduces risks, or provides an improved product/service/instrument that better satisfies participants' demands" (Frame and White, 2004:118).

Such financial innovation affects the access to the financial system as well as the efficiency and effectiveness with which the system supports PEBI.

Bhatt (1995) analyses three distinct types of financial systems and their propensity to innovate, the German, Japanese and Indian banking systems, to show how systemic innovation can reduce transaction costs and risks in the system. Rather than focussing on market versus bank based models (Allen and Gale, 2000), Bhatt looks to understand how different bank based systems, that are closer to what could reasonably be expected to exist in developing countries, emerged and what role innovation plays within them. In Germany, and most of continental Europe, a 'universal banking system' emerged, which combines commercial banking with investment banking in order to provide a wider range of services than would be available if the banks were specialised in either commercial or investment activities. ${ }^{31}$ Japan further built on this system after the Second World War, resulting in the 'main banking system' which was based on a very close relationship between borrower and lender in order to reduce risks and align goals, through for example establishing informal and formal information channels and emphasizing short-term loans to build up mutual trust and knowledge. The main bank system played a central role in the rapid recovery and industrialisation of Japan post WWII. India, meanwhile, evolved a 'lead bank system' influenced by the Japanese system in the 1970's, where the lead development banks take charge of appraising, approving and monitoring projects or clients, often, as is clearly visible in the Indian case, through excessively bureaucratic and rigid methods (Bhatt, 1995). Bhatt (1995) concludes his review on financial systems by suggesting that the Japanese main bank system that existed in the post WWII years most closely resembles the challenges facing developing countries today.

In a review of literature on financing the process of innovation, with respect to the fishing sector in Uganda, Kiggundu (2006) suggests that

"given the circumstances in which developing country firms operate, it might be the case that the usefulness of the main-bank arrangement is not so much in the

\footnotetext{
${ }^{30}$ The authors group financial innovation in similar manner to Bhatt (1995), as new products such as adjustable-rate mortgages, new services like online banking, new production processes as in credit scoring and new organisational forms such as new types of banks like internet only banks.

${ }^{31}$ Bhatt (1995) emphasizes that the most relevant German bank system was that which existed at the end of the 19th century when banks "performed more effectively all the main bank functions and , in addition, performed the entrepreneurial role that is so relevant for developing and transforming economies" (1995:100).
} 
multiplicity of services it provides, but rather in the pressures and incentives it places upon lenders to support the upgrading efforts of firms. That is, such mechanism not only inspires lenders to attend to upgrading and growth requirements of firms, but also dissolves costs and risks inherent in loan contracts that would ordinarily be too unsafe or too costly to make" (Kiggundu, 2006:28).

In fact, rather than simply screening and appraising project proposals, a bank in this type of system takes a proactive role in mentoring firms and providing management expertise and advise, as well as linking up with other institutions that can provide them with expertise appraisal, technology, suppliers and decisions related to strengthening the innovation process.

A financial system may have finance flowing inside it, but entrepreneurs can still have problems accessing funding. A recent literature, much of which has come from the World Bank, has been looking at issues of financial access and inclusion to conclude that the poor, especially the rural poor, have little access to finance. This is what the next section goes on to look at in greater detail.

\subsubsection{Financial Access and Inchusion}

The current interest in access to finance and financial institutions and markets can be partially traced back to a World Bank attempt to establish more rigorous data on financial systems, their structure and development (Beck et al., 2000). A number of papers and reports in recent years have further evolved the analysis and application of such work including Demriguc-Kunt et al. (2008); Beck and Demirguc-Kunt (2008); Beck and de la Torre (2007); Beck, Demirguc-Kunt and Maksimovic (2004). These authors have analysed financial access of the poor and of firms in developing countries, as well as the impact of financial access on economic development and growth, which will be explored in more detail below. Another set of authors has studied financial inclusion including Helms (2006) who focussed on microfinance and the inclusiveness of financial systems in developing countries; Basu (2006); Basu and Srinavasta (2005) on financial inclusion in India; ${ }^{32}$ Kumar and Beck (2005) on the inclusion of the bank system in Brazil; and Tejerina (2006) who looked more generally at financial inclusion in Latin America and the Caribbean. This set of literature notes a clear link between developed financial systems and economic development and growth. For instance, as noted previously, finance often has an indirect effect on poverty alleviation as access to better finance for non-poor entrepreneurs results in more work and better wages for the poor (Beck and Demirguc-Kunt, 2008; Demirguc-Kunt et al., 2008). Furthermore, access to finance promotes start-ups and small entrepreneurial firms that are thought to innovate more than other firms according to Beck and Demirguk-Kunt (2008) who summarised recent literature on measuring and analysing access to finance.

\footnotetext{
${ }^{32}$ Financial inclusion and access in India will be thoroughly discussed in chapter 4 .
} 
Access to finance is not the same as use of finance (Claessens et al., 2009). In terms of demand and supply, the use of finance is the intersection of demand and supply whilst the access to finance is shown along the supply curve. Three groups can thus be distinguished. The first group has access and does use financial services whilst the second group has access but chooses not to use financial services. The third group has no access and therefore cannot use financial services (Claessens, 2005). ${ }^{33}$ The voluntary non-users of financial services may start using services if the relative price of such services decreases. Those lacking financial services may be excluded because of high barriers.

Demirguc-Kunt et al (2008) review research on access and barriers to finance using household and firm level date from previous research whilst Beck, DemirgucKunt and Peria (2006a) empirically investigates barriers to access, using information from 193 banks in 58 countries to develop indicators of physical access, affordability and eligibility barriers to savings, debt and payment services. Both studies note that main barriers include geographical distance as well as lack of adequate documentation and high fees and minimum account balance (Beck et al., 2006a; Demirguc-Kunt et al., 2008). Furthermore, Peachey and Roe (2006) who analysed the results of two empirical studies on access to finance and savings across developing countries for the World savings Institute, found that constraints to access can in addition be caused by banks' weak coverage of rural areas, by an unwillingness on the part of commercial banks to focus on rural and SME business; and by a lack of sustainable financial practices by many MFIs. Beck and de la Torre (2007) also highlight geographical limitations whilst further stressing socio-economic limitations which excludes certain income, social or ethnic groups due to costs, financial illiteracy or discrimination (Beck and de la Torre, 2007:82). Finally there are limitations of opportunity where potential investments with good prospects are denied finance because of a lack of collateral or network (ibid, 2007:82).

The issues related to access to finance are due to transaction costs, agency costs and uncertainty according to Beck and de la Torre (2007) who provide a theoretical framework that uses 'access possibilities frontier' to study supply and demand constraints. The financial market and institutions exist to deal with these costs and uncertainties. Therefore, the nature of the system affects the way institutions are able to deal with a lack of access (Beck and de la Torre, 2007). The authors create a new conceptual framework to help identify 'bankable and banked' populations by defining an 'access possibilities frontier' of financial access. The authors find that the

\footnotetext{
${ }^{33}$ Claessens (2005) is a review of evidence of the importance of finance using literature as well as aggregate indicators across developing countries. The underlying data are from LSMS and Finscope surveys. The Living Standard Measurement Survey (LSMS) is a World Bank survey that includes finance data in Ghana for instance, whilst Finnish Finmark has undertaken Finscope surveys on financing arrangements of households in Africa. Another major survey that is not used in this paper is, those by IADB that has included financial data in their Measurement of Living Conditions in Latin Maerica \& the Caribbean (MECOVI) (Kneiding, 2009).
} 
problem of access occurs where 1) an economy settles below the frontier and therefore excludes potential customers; 2) the possibilities frontier is too low in comparison to other countries in a similar situation; and 3) where imprudent lending leads to excess credit beyond the constrained optimum. Because of scale economies and network externalities, access problems as outlined above, are particularly relevant to small transactions, small financial institutions and markets of a small size (Beck and de la Torre, 2007). In fact, a major reason there is little finance available for firms is the small absolute size of banking markets in many developing countries, which constrains the access to finance for firms, according to Peachey and Roe (2006).

Access to finance, especially among smaller and start-up firms promotes innovation since small firms often do not have adequate internal financial resources (Demirguc-Kunt et al., 2008). It follows that,

"the availability of actual finance is positively associated with the number of startups - an important indicator of entrepreneurship- as well as with firm dynamism and innovation" (Demirguc-Kunt, Beck et al. 2008:60; italic in original).

In fact, financing constraints reduce firm growth by $10 \%$ for small firms but only $6 \%$ for large firms, confirming that small firms are more adversely affected by a lack of financial access (Beck et al., 2006c). A survey on worldwide financial patterns that used data on 48 countries on formal and informal banking, leasing and supplier (trade) finance notes that small firms located in countries with weaker financial systems use less external finance and especially bank credit compared to other countries (Beck et al., 2004). The authors further make three relevant points. First, property rights are particularly important for small firms as regards access to finance. Second, small firms use a lower proportion of formal external sources for their finance requirements, instead relying to a larger extent on informal finance. Third, small firms actually rely significantly less on government and development sources of finance compared to larger firms, which is surprising considering such programmes usually highlight their small firm and developmental credibilities. Small firms thus face considerable financial constraints (Beck et al., 2004).

Reasons for these access constraints, according to a review on recent research on access to finance and household and firm level data by Demirguc-Kunt, Beck and Honohan (2008) include a lack of appropriate products and services for micro enterprises, the affordability of those product and services as well as the lack of documentation that customers hold.

The impact of making finance available for non-poor rural firms and entrepreneurs is therefore likely to be significant on the rural poor:

"existing evidence suggests that indirect, second round effects through more efficient product and labour markets might have a greater impact on the poor than direct access to finance" (Demirguc-Kunt et al., 2008:11). 
On the supply side, a number of different types of surveys and analysis have been undertaken on financial institutions ${ }^{34}$ (such as Helms (2006) on inclusive financial services for the poor), and in particular those focussing on banks, like Beck, Demirguc-Kunt and Peria (2006a), on banking services for everyone, and Peachey and Roe (Peachey and Roe, 2006) which focussed on saving bank characteristics, as well as Djankov (2007) that compared credit access in 127 countries. An early survey by Christen (2004) looked at bank access for the poor, in particular focussing on microfinance as financial institutions with a double bottom line approach. Composite studies of demand and supply factors have been undertaken by Honohan (2008) who looked at financial assets of households and its link to development; Kumar, (2005) who looked at Brazil's financial system and how inclusive the system is; and Basu (2006) who focussed on demand and supply factors within India's financial system.

Finally, reviewing a number of surveys and research, Beck, Demirguc-Kunt and Peria (2006a) note four reasons in the literature for the importance of access to financial services for small firms. First, financial market imperfections are likely to hit smaller firms harder (Beck et al., 2006b; Levine, 2004). Second, new firm entry, as mentioned above, has a clear impact on economic growth and access to finance provides more opportunities for new firm formation (Klapper et al., 2006). Third, access to finance can act as an incentive to spur knowledge creation (King and Levine, 1994). Fourth, access to finance, according to Peachey and Roe (2006) should be considered as a basic need alongside the provision of health, education and water.

It can be concluded from the last section that despite much of mainstream finance still being caught between the old supply-led theories of subsidised credit and the newer microcredit programmes which also to a large extent function on subsidised credit, there is a decisive recent shift towards new thinking on how and what kind of finance needs to be provided.

These new approaches recognise that supply-led agriculture focussed credit is out of date. Not least because many rural poor are landless poor and the sector that is likely to have a large poverty alleviating impact is the non-farm sector and its entrepreneurs and small enterprises. Furthermore, despite the huge popularity of microcredit and microfinance, questions are being asked as to the impact such financing arrangements are actually having. Furthermore, it is becoming clear that microcredit certainly does not support small-scale firms and growth focussed entrepreneurs beyond the micro-entrepreneurs that are best classified as necessity entrepreneurs operating at subsistence level. Therefore there is an evident gap in financing and financing theory regarding innovative entrepreneurs and small firms.

\footnotetext{
34 See Kneiding (2009) for an overview of financial access related surveys and empirical research and Honohan (2008) for household access analysis.
} 
The financial access and inclusion literature has begun to highlight this gap through empirical investigations. They highlight the need for increased flexibility in financial arrangements as well as a shift in focus towards these innovative entrepreneurs and enterprises in rural areas.

\subsection{Conclusion}

This literature review began by discussing the concept of pro-poor entrepreneurbased innovation and argued that such entrepreneur-based innovative activities are essential for the continuous development of, and poverty alleviation in, rural areas, by creating employment opportunities, and improved goods and services.

The first section found that historically, rural innovation has been equated with agricultural innovation. This was particularly the case during the Green Revolution and its associated technology transfer programmes. Such supply-led theories were later criticised for focusing only on exogenous technical change in a linear manner, leaving farmers as passive end-users. Instead there was a shift to participatory approaches and theory using systemic and holistic views. Two strands are relevant here: systems theory which viewed agricultural innovation as part of a complex system, and sustainable rural livelihoods theory which went beyond agriculture to recognise activities both on and off the farm. Explicitly putting innovation at the centre and seeing development and innovation as a systemic phenomena is a relatively recent development.

Whilst innovation theories centre around the farmer and the livelihood approach on the household, this thesis posits that rural entrepreneurs and small firms are vital to innovation and development so entrepreneurship theories have been incorporated. The entrepreneurship literature makes a distinction between necessity and opportunity entrepreneurs, noting that opportunity entrepreneurs are more likely to be active in the innovation process.

The second part of the review focussed on financing pro-poor innovation and entrepreneurship. It highlighted that financial theories have moved from the linear supply-led subsidised credit theories towards a systems perspective where a number of factors impacts on the financial system as a whole and the provision of finance.

Recently, a financial literature focussed on financial markets, access and inclusion in developing countries has emerged, mainly from research undertaken at the World Bank. It has noted that small firms, entrepreneurs and poor households have significant problems in accessing finance. Restricted access to finance for entrepreneurs can be traced to transaction costs, agency costs and uncertainty.

However, there is no explicit analysis of what obstructs the access to finance especially for pro-poor entrepreneur-based innovation in rural areas. The next chapter will go on to probe why there is no finance available for this type of entrepreneur-based innovation. 


\section{Conceptual Framework}

The financial system which is made up of markets, intermediaries and contracts, originally emerged because of the significant cost of acquiring information, enforcing contracts and making transactions (Levine, 2004). The market frictions arising from information, transaction and contract costs motivates the emergence of distinct types of financial arrangements (Levine, 2004:5) which act as incentives or barriers to accessing finance. There are five main functions of the financial system in its role to reduce such transaction, information and contracting costs (Levine, 2004). First, the financial system reduces the cost of acquiring and processing information (Boyd and Prescott, 1986 in Levine, 2004) which improves the resource allocation. Second, intermediaries monitor and influence the way in which firms use capital which affects their savings and capital allocation. Third, the financial system facilitates the trading, diversification and management of risk. It mitigates risk of individual projects or organisations as intermediaries provide a vehicle for trading, pooling and diversifying risk (Levine, 2004:15). Fourth, the financial system mobilises a large amount of small individual savings, or capital, from different savers that can be used for investment purposes at a much larger scale than what each individual saver could provide. Finally, the financial system and its markets, intermediaries and contracts ease the exchange of goods and services, moving from a barter economy where the evaluation process can be very costly, to using a common medium of exchange (such as money).

The literature review concluded that there is not much finance available for rural pro-poor entrepreneur-based innovation, yet there exists finance in the system, as witnessed by many programmes involved in rural finance as well as policy directives steering banks towards rural lending, so there must be barriers at work within the financial system which prevents the adequate finance of PEBI. Nevertheless, organisations outside of mainstream finance, notably microfinance, have been able to provide finance for clients that were previously without financial access.

The goal of this chapter is therefore twofold. To understand the gap in mainstream finance in relation to PEBI, as well as what makes it possible for some 
organisations to still provide such finance. Due to the separate but related nature of these different ideas, the conceptual framework will have a two-part structure. The first part will consider why, according to the literature, there is no finance, i.e. clarify the reasons for the 'gap'. The second part of the framework will describe how it is possible that some organisations exist that appear to be filling this gap.

There is a huge literature on finance and this chapter will draw on number of concepts that together are useful to understand, analyse and explain the situation that can be seen in countries like India as regards PEBI. This conceptual framework will begin by mapping the reasons for the lack of finance, before considering how knowledge flows impact on the provision of finance. The final section of the chapter will discuss how some organisations are able to provide finance when the mainstream financial institutions are not.

\subsection{Barriers to Finance for Innovative Entrepreneurs}

There is little finance available for pro-poor entrepreneur-based innovation. One major argument is, of course, that it is not profitable. There is some truth in this as banks often find it difficult to cover costs in rural areas because of the high cost of lending relative to the size of the loan. Credit is generally borrowed in small amounts but with high frequency, which drives up administrative and due diligence costs for banks. This situation is further aggravated by a heterogeneous client base spread over a sizeable geographic area, which together with high illiteracy increase the monitoring costs for banks post loan (Basu, 2006; Helms, 2006). However, as the microfinance movement among others have shown, it is possible for financial institutions to provide small-scale firms and entrepreneurs with finance in a sustainable manner. Furthermore, the emerging funds investing in pro-poor innovation and entrepreneurship such as Acumen and Ashoka suggest there is potential for profit making.

Several other arguments exist, however, to explain the lack of available finance. First, credit may be rationed due to information problems. Second, there is uncertainty related to innovation focussed investments. Third, to combat such risk the financial intermediaries may rely on collateral and relationship based finance that can lead to financial exclusion. Fourth, the demand for finance may not be clearly visible, and fifth, the financial system itself may affect the flow of credit in a number of ways due to regulatory issues and government policy, legal barriers and contract enforcement, information flow and the physical infrastructure underlying the system. The result could be flows of finance moving from rural to urban areas, directed credit that is diverted and inertia and institutional lock-in. Finally, politically motivated rent-seeking has an effect on where finance flows, though this is outside the scope of this thesis. 
The remainder of this section will outline and discuss each of the five arguments identified as barriers to understand what impact they have on the availability of finance for rural PEBI.

\subsubsection{Asymmetric Information and Credit Rationing}

The perceived risk of lending by providers of finance is a major reason for the shortage of available credit. One argument posits that such perceived risk is due to problems related to a lack of information about borrowers. Hoff, Braverman et al. (1993b) find that

"features of rural credit markets in developing countries can be understood as responses to the problems of screening, incentives and enforcement" (Hoff et al., 1993b:45).

In perfect markets there should be no shortage of credit, since interest rates will adjust until supply of finance meets demand. However, considering the difficulty of obtaining credit for both rural entrepreneurs and especially, poor entrepreneurs, this may not be the case.

According to asymmetric information theory, the lender may not have the same information or knowledge about creditworthiness, the actual intended use of the loan and the likelihood of repayment as the loan applicant has himself. Due to such disparity in information, it can be difficult to distinguish bad loan applicants, or lemons according to Akerlof (1970), from good borrowers. Therefore, a market failure occurs since credit may not be available to potential borrowers because credit is restricted to certain categories of borrowers (Stiglitz and Weiss, 1981). Stiglitz and Weiss (1981) posit that the interest rate banks charge in part to screen good from bad borrowers, affect the risk of the pool of applicants in two ways. It may sort potential applicants- adverse selection- and it may affect the actions of the actual borrowers- incentives, or moral hazard. The inability of banks to distinguish between good borrowers and lemons leads to higher interest rates which in turn results in good borrowers looking elsewhere as loans become increasingly expensive. The bank is therefore left with a pool of applicants with a lower probability of repaying the more expensive loan so that the average risk profile of the applicants increases. The inability of bankers to distinguish the lemons from good applicants result in overall higher costs for all applicants because the higher rates will in part take into account that some will default in the future. A willingness to accept high interest rates may therefore signal a low probability of repaying. The result is a process of adverse selection. A second effect of the increasingly expensive loan is that since the loan is costly and the borrower may not be able to repay, the loan once taken may be spent on an investment that is riskier than the borrower had initially intended. It follows, according to the concept of moral hazard, that economic agents maximise their own utility to the detriment of others when they do not have to bear the full consequences for their actions because 
of uncertainty and incomplete contracting (Arrow, 1963). In other words, moral hazard suggests that higher interest rates work as an incentive for borrowers to choose, on average, riskier projects because the potential pay-off is higher. ${ }^{35}$ Stiglitz and Weiss (1981) conclude that as interest rates increase, the average risk of the pool of borrowers rises, whilst at the same time the bank's profits decrease. It follows that banks' expected return may increase less rapidly than the interest rates they charge so that at a point the return to the bank from increased interest rates would decrease. Banks would therefore prefer not to take on new borrowers willing to pay a higher interest rate and instead stay with the present portfolio of borrowers. Those denied credit will be unable to obtain credit even if they are ready to pay increased rates of interest. Credit is therefore rationed for risky as well non risky potential borrowers.

\subsubsection{Uncertainty of Innovation and Entrepreneurship}

There are two types of market failure according to theory on innovation financing that can explain why there is a lack of investment in innovation and entrepreneurship-related activities. Firstly, the appropriability argument suggests it is more difficult to recover investments in innovation as others may be able to copy the technology at a much cheaper rate. This public goods quality means that the return on investment may decrease when information becomes public. Firms may prefer to invest themselves (i.e. internal finance) rather than relying on external investments in order to avoid having to make information publicly available (Leland and Pyle, 1977). Firms are therefore face with a trade-off as making information available to financiers to attract finance could result in diminishing value of the previously private knowledge. Firms may therefore prefer to keep information private despite then being unable to attract external finance (Myers and Majluf, 1984).

The second market failure building on Arrow (1962) occurs when innovation activities rely on external sources of finance. When the private rate of return expected by the entrepreneur differs from the cost of capital (or private rate of return) of the external financier, there is a wedge between the two rates of return (Hall, 2002:2). Therefore,

"unless an inventor is already wealthy, or firms already profitable, some innovations will fail to be provided purely because the cost of external capital is too high, even when they would pass the private returns hurdle if funds were available at a 'normal' interest rate" (Hall, 2002:3-4).

The reasons for the higher expected private rates of return for the external investor are related to information problems associated with the characteristics of

\footnotetext{
35 The moral hazard problem was first studied in the insurance market by Arrow (1963).
} 
innovative activities. Drawing on Hall's (2002) characteristics of high tech, R\&D intensive industries and adapting these to the kind of entrepreneur-based innovative activities that this thesis is concerned with provide three important characteristics. First, the workforce of the innovative firm creates an intangible asset which is the firm's knowledge base that will be the future basis of a firm's profits. As the knowledge is mainly tacit, it will be held by the workforce and would likely leave if they were to leave. Furthermore, it is difficult to assess or measure such knowledge. Second, innovative activity is uncertain by nature and the greatest amount of uncertainty occurs at the early stages. Third, investments in innovation are not one-off inputs of funding, but are made over time and during this time new information becomes available. This information can change and reduce the uncertainty of the output. The investment decision is therefore reassessed over time, as is for example noticeable in venture capital financing which is provided according to milestones, and in separate rounds of financing.

Adding to these characteristics of innovation investment are additional attributes that entrepreneurs and small-scale firms possess that result in them being perceived as particularly risky. First, the competitive environment is more uncertain than for larger established firms and their rate of return is more variable. Second, new and smaller firms are comparatively less well equipped with human and capital resources to deal with economic shocks and business challenges. Third, inadequate business practises and accounting systems results in unreliable information which undermines their accountability and trustworthiness as regards profitability and repayment probability. Finally, their operating environment is more volatile than more established firms which results in a greater risk that lenders will be repaid

It follows from the lack of information that investors such as banks cannot fully differentiate between good and bad R\&D projects, i.e. which ones are, or are not, the lemons, it becomes difficult to attract funding (Leland and Pyle, 1977; Myers and Majluf, 1984). Banks therefore do not fully understand the risks of innovation and entrepreneur based activities or how to evaluate them. This informational problem results in a funding gap as banks either perceive risks to be higher than they are, or do not understand how to monitor and evaluate such activities appropriately.

Although the intangible nature and risks inherent in innovation investments mean that it is difficult to attract external finance, Bougheas (2004) finds in a survey on European and American firms that despite most small firms having to rely on internal finance to fund R\&D activities, many German, French and Japanese firms are able to attract bank finance. Bougheas (2004) therefore argues that bank funding is feasible provided banks are able to renegotiate terms of contracting, and if the banks are willing to monitor the investment. In fact because of the intangible nature of the assets, banks have a high incentive to monitor (Bougheas, 2004). 


\subsubsection{Exchsion through Relationships and Collateral}

When screening risk through arm's length financial intermediation does not work, as evidenced by credit rationing of potentially good customers through the use of increased interest rates, other strategies have been employed such as relying on collateral as well as relationship based lending. Though both can have positive effects on lending, both measures at the same time effectively exclude good potential customers such as entrepreneurs and small firms.

\section{Relationships}

By relying on established ties, through networks and personal relationships, banks minimise risk. Networks can overcome information problems by sharing information within a group and more easily enforce contracts (Biggs and Shah, 2006). Biggs and Shah (2006) show that a positive externality of network membership for SME's in Africa is better access to finance in the form of supplier credit. However, by the same token, being excluded from a network can erect severe barriers to financial and other business development sources.

An alternative to wider networks are closer relationships between financiers and clients. Banks use consecutive contracts as a way to build up a relationship of trust, and to gather information. Petersen and Rajan (1994) study the benefits of such a lending relationship and find, using small business data, that the main advantage of building relationships with institutional creditors is the increased availability of finance. They note that borrowing by small firms is very concentrated and explain this in two ways. First, the availability of finance increases as a firm buys more financial services from a certain bank which results in small firms increasingly concentrating their borrowing with that one lender to receive better financial services and access to more finance. Second, relationship-based financing has benefits for the lender as it reduces their expected information costs. However, the greater concentration simultaneously increases the lender's informational monopoly over clients which means the lender is unlikely to share benefits of decreased costs with the borrower, other than making finance more readily available (Petersen and Rajan, 1994).

The concept of concentrating finance with one lender, building up a relationship can be seen in informal finance too. Aleem (1993) surveyed moneylenders in Pakistan and found that they spend much time and effort on screening applicants and will reject one in two potential borrowers. 'Relationship specific capital' is then built up between lender and borrower so that the borrower knows it would take a lot more effort to borrow money somewhere else where that capital would have to be established all over again, whilst the lender prefers to lend to somebody he has built up a relationship with and therefore excludes new borrowers. 


\section{Collateral}

The use of collateral is a common risk-mitigating tool which banks generally rely heavily on, in order to deal with information problems and repayment incentives. The use of collateral can partially off-set potential losses in case of default and reduce the likelihood of asymmetric information as well as moral hazard occurring.

Bester (1985), for example, shows that credit rationing will not occur if banks use collateral requirements as well as interest rates to screen the risk-level of potential investments. This is because investors who run a lower risk of bankruptcy are more willing to accept increased collateral for a reduction in the rate of interest compared with higher risk applicants. Therefore, self selection mechanisms will occur which sort risky investments from less risky investments as those more likely to not repay would prefer the higher interest rate and lower collateral whilst safer investments would prefer higher collateral and lower interest rates. Furthermore, the, moral hazard problem is reduced as the borrower with a collateral is less likely to make risk-seeking investments. The problem is of course that few pro-poor entrepreneurs and small-scale firms have access to adequate collateral. A lack of collateral thus makes these potential customers more difficult to screen, whilst from the point of view of the bank, there will be fewer incentives to make such investments. The collateral therefore constitutes a barrier to access. According to surveys on entrepreneurs and SMEs, collateral is in fact the biggest barrier to accessing enterprise finance (Zavatta, 2008). The problem of collateral for innovation focussed firms and entrepreneurs, is further aggravated by the nature of the innovation process that provides few tangible assets that can be offered as a collateral (Zavatta, 2008). Furthermore, the lack of clearly defined, and enforced, property rights, in many developing countries further reduces the possibility of providing sufficient collateral (Helms, 2006; Robinson, 2001). Nevertheless, in microfinance, recent approaches have seen more flexibility as regards collateral, shifting from demanding collateral to cover a potential loan default, to demanding a collateral that provides a high enough deterrent to default on a loan (Cull et al., 2006).

\subsubsection{Invisible Demand}

The demand for financial products and services may not be immediately visible. At least two reasons may be distinguished from the supply-side: an old-fashioned view that the poor are not interested in, or able to handle credit; and an equally backward assumption that informal financial markets are nearly perfectly competitive and thus cover the demand for rural finance. On the demand side the cost to borrowers of taking a loan may decrease the demand.

That poor people do not have the pre-requisite knowledge to handle credit is an old, and faulty, view. Zeller (2003) explains that: 
"at first glance many might be tempted to say that the poor, earning incomes of less than a dollar per day, are neither credit worthy nor are they able to save; nor can they pay for insurance against any of the risks they face. That these common assumptions are wholly unfounded has been demonstrated time and again by empirical research on informal financial markets ad the risk-coping behaviour of households" (Zeller, 2003:6).

That the poor are bank and credit worthy has further been shown extensively by the very low default rates of many MFIs (Morduch, 1998; Yunus, 1999). The related viewpoint that informal markets such as moneylenders are near to perfectly competitive and adequately cover rural financial demand (von Pischke, 1991; von Pischke et al., 1983) has also been disproved by microfinance, but still exists today. Such views are based on the idea that directed credit from the Government does not work but instead rural moneylenders provide finance at acceptable rates of interest considering the risks and small loan amounts that these are dealing with. The view that the moneylenders cover rural finance appears to idealise the informal markets as informal lenders often charge interest rates far above commercial lenders' (Robinson, 2001; Robinson, 1994). Apart from exorbitant interest rates, informal finance providers offer limited services and low amount often at short term.

On the demand side, an actual lack of demand could be caused by the high transaction costs of accessing finance for borrowers, a lack of suitable services and products as well as a general urban bias in banking and banking policies. Transaction costs for poor people in rural areas to access loans are often high. The procedure of acquiring a loan can be lengthy and time consuming with plenty of bureaucratic hurdles that often involves several return trips to the financial institutions. A cross-country survey finds that physical infrastructure such as communication and electricity has a significant impact on credit access and can explain cross country variation regarding banking barriers (Beck et al., 2006a). In addition, many banks have (sometimes high) fees for opening and maintaining accounts as well as for transfer and other services. There may be minimum deposit and borrowing requirements. Importantly for many poor, the documentation requirements are often rigorous, sometimes asking for up to four pieces of proof of identity, which many people do not possess. Geographic centralisation of decision making further reduces physical presence and ease of access in rural areas (Beck, Demirguc-Kunt and Peria 2006a). This results in both direct transportation costs but also opportunity costs in the form of loss of income.

The problem is further aggravated by the tendency by bank officials to demand bribes for loan processing. Basu (2005) found for instance that a third of borrowers of finance in rural India had to pay a bribe. Furthermore, loan products are often limited in scope whilst the terms of the loans are inflexible The result is a limited range of products that do not take into account the borrowers needs and therefore makes formal finance less attractive to the rural poor (Basu, 2006; Goodland et al., 1999). 


\subsubsection{System Set-up and Financial Flows}

There is a lack of finance available for pro-poor entrepreneur-based innovation in rural areas, yet there appears to be plenty of finance flowing into the system.

\section{Financial Flow from Rural to Urban}

A reason for the lack of finance in rural areas is the net flow of finance from rural to urban areas. According to urban bias theory (Lipton, 1977), ${ }^{36}$ domestic and urbanbased industry has been favoured over rural-based agriculture by national governments and policies as part of development strategies. The World Development Report noted in 1986 that:

"Paradoxically, many countries which have been stressing the importance of agricultural development, have established a complex set of policies that is strongly biased against agriculture...... many have set up complex systems of producer taxation that and then have set up equally complex and frequently insufficient systems of subsidies for input to offset the taxation" (WB, 1986:16).

Farmers received low prices for their output. However, the high taxation of farming exports together with excessive margins charged by state run marketing agencies for agricultural produce were not offset by the subsidies, causing farming to become increasingly unprofitable. This discrimination against agriculture through high trade barriers and other policies were expected to make agriculture unattractive so as to shift resources out of agriculture and rural areas to domestic manufacturing and urban areas (WB, 1986). The result of this strategy turning the terms of trade against agriculture and superficially changing the agriculture output prices were that agricultural exports suffered, agricultural products competed with imported goods and industrial inputs used by the agricultural sector grew more expensive (WB, 1986). Furthermore, when the public funding decreased following the end of the Green Revolution towards the early 1980's, it was expected to be substituted by private investment. However, there turned out to be strong linkage effects between public and private investments that saw private investments plummet once public funding withdrew, causing a decrease on agricultural investment of $20 \%$ in real terms from 1978 to 1986 (WB, 1986). Thus the decline in

\footnotetext{
${ }^{36}$ Lipton (1997) argued that there was a clear urban bias that placed rural areas at a distinct disadvantage. The two gaps that already existed in income and output, as well as efficiency of capital were widening. This was due to a cycle that started with low capital availability which caused low productivity in rural areas as farmers were unable to invest in improved production tools and techniques. This in turn resulted in low rural income which in turn lowered the capacity to save in rural areas. Of course low savings resulted in low capital availability. This gap was further widened by urban biased policies that suppressed rural prices in order to keep prices low in urban areas. According to Lipton (1997), this resulted in resources being transferred from rural to urban areas, and from the poor to the relatively less poor. More recently this rural/urban price differences have reduced, however the urban bias remains in the significantly larger public investments in goods, services and infrastructure in urban areas (Lipton and Eastwood, 2000).
} 
public investment had both a direct and indirect effect on agriculture investment and the financial flows in rural areas. As farming became less and less profitable, finance flowed out of rural areas to fund domestic industries in urban areas.

\section{Legal and Regulatory Framework}

The efficiency with which financial institutions can overcome asymmetric information issues depend on the contractual (legal and enforcement) and informational ${ }^{37}$ (transparency and information access) framework within which they operate as more efficient systems allow financial institutions to better assess loan applicants (Beck et al., 2006a). Where the regulatory framework is in place, weak contract enforcement or a complicated and cumbersome legal framework can still obstruct the efficient allocation of financial flows since there are fewer incentives to follow Government policy and directives (Berger and Udell, 2006). Furthermore, without the assigning and enforcement of property rights, contracting and enforcement of contracts are more problematic, as noted by Berger and Udell (2006):

"The legal environment that affects business lending consists of the commercial laws that specify the property rights associated with a commercial transaction. The judicial and bankruptcy environments determine how well these laws are enforced in commercial disputes and in bankruptcy resolutions. This enforceability, in turn, determines the confidence of contracting parties in financial contracts" (Berger and Udell, 2006:2957).

Furthermore, Beck, Demirguc-Kunt and Maksimovic, (2006c) show that firms in countries with strong property rights alongside a developed financial system are able to attract substantially more external finance, whilst firms in less developed countries are more likely to rely on informal sources or government sponsored credit programmes.

However, rather than providing the rural poor with more finance, policies such as interest rate ceilings and credit allocation quotas can raise the de facto cost of capital (Bhatt, 1995).

"The transaction costs and risks for dealing with small enterprises are higher for the banks than those for medium or large enterprises in the trade and industry sectors. The banks therefore would either not lend to the small sector or forestall the government directives by passing on a greater part of their costs and risks to the small sector through non-interest charges of various types. If the banks did actually implement government directives, their financial viability would be adversely affected, and this would endanger the health of the financial system" (Bhatt, 1995:23).

\footnotetext{
37 Udell and Berger (2006) emphasise the importance of the information environment such as accounting information and credit ranking tools as components of loan contracting and risk assessment.
} 


\section{Inertia and Institutional Lock-in}

There is considerable inertia in bank lending which results in a lack of finance for clients that have unusual projects to finance, such as innovation which may require increased due diligence. Banerjee, Cole and Duflo (2005), use quantitative analysis to show that this inertia is likely due to incentive issues having its roots in the perception that lending to entrepreneurs and small firms, and other unconventional or risky customers would increase the likelihood of being investigated for bad loans, if the client defaults, as well as laziness and risk aversion. The inertia is noticeable in the lack of compliance with pro-poor lending requirements, as noted by Nair (2006) in a study about India. This is likely due to the low level of threat that non-compliance fines pose. The end result is that finance flows in the system but even when it is earmarked for certain types of borrowers or clients, it 'disappears' off through investment or lending to areas other than what was initially intended.

At the same time, whilst increasingly specialised tools and techniques for cash flow analysis and evaluation of potential borrowers reduces the lender's risk by more accurately predicting risk and ability to repay (Bhatt, 1995), it can result in institutional lock-in. Kiggundu (2006) points to the issue of institutional lock-in occurring because the specialisation is likely to result in difficulties when bankers, and their mind-sets are confronted with a potential borrower different from the neatly sorted categories of borrowers they usually deal with.

This section has noted that mainstream finance organisations are unable to provide finance for entrepreneur-based innovation for a number of reasons. However, this is not because of lack of finance within the financial system. Bhatt (1995) and Biggs $(1991)^{38}$, for example, show that there are organisations operating outside of the mainstream financial system that are able to provide such finance. The next section will therefore go on to discuss why the mainstream institutions are not providing finance by focussing on knowledge flows within the financial system.

\footnotetext{
${ }^{38}$ Bhatt (1995) notes that innovation in finance is more likely to come from informal sources of finance than formal finance, which are then in a better position to support alternative investments. In a study by Biggs (1991) on small enterprise finance in Taiwan, the author observes an interlinking between informal and formal financial intermediaries and puts forward the idea of a dualistic financial system. Whilst government controlled banks foster industrial policy, and deal with inflation and measures to control private economic power, the informal financial market is able to link informal lenders that become de facto intermediaries with information-intensive borrowers at a lower transaction cost than if they had used formal financial intermediaries (1991:169).
} 


\subsection{Exploring the Lack of Finance Using Knowledge Flows}

This chapter has so far noted that whilst the mainstream, or the 'core', of the financial system, that is, the banks, are unable to provide finance for entrepreneurbased innovation, organisations outside of the mainstream, or at the 'periphery' of the financial system are able to do so. It could therefore be suggested that these organisations operating at the periphery must be innovating, and thus access different knowledge or use knowledge differently, to circumvent or reduce the problems faced by the banks at the core.

\subsubsection{A System with a Core-Periphery Structure}

One way to conceptualise the financial system is through a sectoral innovation system (Malerba, 2004). The concept has evolved from the national innovation system idea which stipulates that the innovation process emerges from a system of actors whose behaviour, interactions and patterns of learning are shaped by institutions, by which is meant habits, practices, norms and routines. The institutions make up the "organisational architecture" (Coriat and Weinstein, 2002) of the innovation system and it is the interaction between these institutions that result in change. It defines the functions and interactions of all participants in the system. Institutions provide governance of, and mechanisms for, learning and knowledge creation and transfer between different actors within the system. Institutions determine "the speed, quality and magnitude" of the innovation process (Berdegue, 2005). Combining forms of knowledge, continuous learning and institutions therefore take centre stage (Edquist, 1997; Freeman, 1987; Lundvall, 1992; Nelson, 1993; Nelson and Winter, 1982). The systems concept is central as the:

"main process of innovation must be viewed as a series of changes in a complete system" (Kline and Rosenberg, 1986:275).

Consider then, the financial system as a sectoral system of innovation (Malerba, 2004) with a core and a periphery. The core-periphery structure is generally comprised of a dense and cohesive core and a periphery that is sparse, even disconnected (Borgatti and Everett, 2000). In a technical core-periphery structure, the core distinction can be made in two ways. Firstly, the vertical, backwards linkages from the periphery generally lead to the core as the periphery is dependent on inputs, both goods and knowledge. However, the core is not dependent on the periphery despite the existence of a few linkages from periphery to core. Instead the core is

"a largely self sustaining combination that may generate growth and stability for the system as a whole" (Arora, 2009:31). 
Secondly, the knowledge which the periphery uses stems from the core, whilst the core is not dependent on the knowledge on which the periphery is based (Arora, 2009). It follows therefore that the periphery, in most cases, depends on the core for innovation and growth as:

"elements in the core are connected to each other in a positive feedback loop: changes in one core element send reinforcing signals to other core elements. This positive reinforcement makes the core self-sustaining and gives it the dynamism to support innovation in peripheral elements" (Arora, 2009:3).

Though when the system has stabilised and matured, it may become difficult to sustain the rate of knowledge accumulation which in turn will affect the willingness to seek out new and better solutions in the system, resulting in stagnation of both innovation and knowledge flows (Arora, 2009).

Turning to the financial system, it is evident that the core no longer appears to be driving innovation and knowledge accumulation in the system. It has matured into a stable system with little dynamism or willingness to change or acquire new knowledge. Instead, new knowledge accumulation and innovation appears to take place at the periphery of the financial system. Among these organisations, there is a greater need and drive to find new solutions to problems not solved by the core and innovative activities take place to a greater extent than at the core. What is more, the periphery organisations not only appear to innovate more, but are able to find solutions that a more suitable than the core organisations do. Nevertheless, the periphery organisations are still dependent on the core for certain inputs such as credit, whilst the core is not yet, to a great extent, dependent on periphery organisations. Two questions then arise. Firstly, why is the core of the financial system unable to accumulate useful knowledge and innovate and thus provide finance when organisations at the periphery are able to do so? Secondly, how can the periphery organisations continue this innovation and knowledge accumulation process and resulting provision of finance? To answer this, the next section will consider knowledge.

\subsubsection{Tacit and Codified Knowledge}

When considering the sources of knowledge that flow in the system, it may be natural to emphasise knowledge that is written down, or codified. However, plenty of knowledge that assists in understanding the codified variety, is not articulated, or written down: it is tacit. For instance, a farmer may have codified knowledge of the technicalities of harvesting potatoes in the form of manuals, agricultural experts and schooling. However, having worked on the same land for many years, his tacit knowledge may tell him which field, or on which part of a field to start because of, for example, the quality or composition of the soil in perhaps relation to the drainage of that field. Such knowledge has not been written down, and may indeed be very costly and time consuming to articulate, but it is nevertheless knowledge 
that has a great impact on the efficiency with which the farmer can use his codified knowledge of the harvesting process.

The knowledge that flows between parts of the system can change in nature from tacit, i.e. unarticulated to codified, that is, articulated and written down, using language and codes (Cowan et al., 2000). If the farmer would like somebody else to do the harvesting for him, the knowledge of how to do so would have to be transferred. The codified knowledge would be relatively cheap to transfer. However, transferring the tacit knowledge would pose certain problems. It may not be a problem if the transfer of the knowledge is not too distant, perhaps to his son, who has spent many years helping out on the farm. His son would have picked up plenty of the tacit knowledge over time and would have a similar background which would make it more probable that he would use his knowledge in a similar way to his father and thus reach similar conclusions. However, knowledge of a tacit form is expensive to transfer, especially over longer distances to, for example, a new arrival with little prior experience of harvesting. The farmer may therefore attempt articulating his knowledge of where to begin the harvesting. In other words, codify his tacit knowledge and create a 'codebook' (Cowan and Foray, 1997).

Such a process of codification would entail building a model, creating a language for that model and articulating the messages that form part of the codification (Cowan and Foray, 1997). It can be a costly endeavour, especially when the knowledge is difficult to articulate, for instance requiring a new code or language. Nevertheless, once knowledge is codified, it is much easier to transfer. Just as with the example of the son of the farmer interpreting knowledge in much the same way as his father, the opposite is true of people with different backgrounds within an organisation. An organisation, such as a bank could therefore be expected to rely increasingly on codified knowledge as it grows (increasing number of heterogeneous staff) and matures (using a more stable codification process) to make sure information is read in the intended way.

"Since internal communication channels can be designed, their structure can be chosen with a view to cost minimisation. In particular, the efficiency of a channel can be increased by suitable choice of a code. This term is used both literally and metaphorically. It refers to all the known ways, whether or not inscribed in formal rules, for conveying information. As is well known from information theory, the optimal code will depend upon a priori distribution of possible signals, as well as upon the costs of communicating differingly coded signals." (Arrow, 1974:55).

Coding could therefore be expected to have two economic implications: firstly, it would decrease (but not completely eliminate) the increasing cost to scale of operation resulting from communication costs. Increasing scale means increased specialisation, which in turn means that the organisation's staff:

"will be accumulating differing types of skills in information-processing, learning (acquiring capital) in the areas in which they are specialising and unlearning 
elsewhere. As a result, communicating among them become more difficult and the codes used in their intercommunication have to become more complex" (Arrow, 1974:55).

It follows that codifying knowledge allows for a greater number of knowledge sources to be pooled together. Furthermore, codification creates intrinsic irreversible capital commitment of the organisation since an individual learning the code of the organisation is an irreversible investment (Arrow, 1974). It could therefore be expected that banks at the core of the financial system have codified much of their knowledge in order to communicate more easily. For the same reason, periphery financial organisations may be relatively new and still in a state of change which would mean they still relay to a great extent on tacit knowledge.

Between organisations too, codes ease communication, and as Arrow (1974) suggests, organisations roles become increasingly specialised resulting in more complex codes. Such codes built up over times would encourage a sector or group of organisations to learn in a certain way. In a state of change, various models and codes may exist among organisations. Codification can thus be seen

"as an investment good: a contribution to the resolution of the competition among variant languages and models. It is in this context that we can expect to find situations of 'excess codification'. That is to say, the accumulation of successive generation of codes can prevent the development of radically new knowledge simply because explicating and understanding it would require entirely new codes" (Cowan et al., 2000:247-248).

If the cost of building a code occurs in one generation

"during a period of change [when] infrastructure is developed, languages and models are built, learned and standardised, and a community of agents with shared tacit knowledge grows" (Cowan et al., 2000:248),

then it can be expected that a subsequent generation reaps the benefits and there will be:

"an intergenerational externality problem which can result in a lack of adequate private (or social) incentives for allocating resources to the development of more powerful codes and systemising those that already exist" (Cowan et al., 2000:249).

Furthermore, the increasing number of organisations and actors using the codification will decrease learning costs.

However, the codification of knowledge to ease communication in and between an organisation has side effects since codification to a great extent relies on what has previously been codified, i.e. history. An implication of this is that the actual pursuit of efficiency in communication through codification may in actual fact lead to rigidity in the system, a lack of response to creativity and future changes (Arrow, 1974:49; Cowan et al., 2000). In other words, 
"codified knowledge can be a potent 'carrier of history' -encapsulating influenced of essentially transient and possibly extraneous natures that were present in the circumstances prevailing when particular codes took shape. Having that power, it can become a source of 'lock in' to obsolete conceptual schemes, and to technological and organisational systems that are built around those" (Cowan et al., 2000:248).

What follows is excess inertia in the stable system as there is less flexibility. This rigidity is an effect of the system having been built up in the previous period when the knowledge environment was unstable. Thus, the core of the financial system will, once it has reached a steady state, gravitate towards rigidity in its modus operandi. Codification has at this point stopped improving communication efficiency and instead made the financial intermediary wary of new approaches to finance or new types of clients or projects.

Even tacit knowledge can lead to rigidity in a mature organisation or system. For instance, a financial institution may act in a certain way through conventions and collective memory. Using the 'Washington consensus' as an example, Cowan et al. (2000) note that:

"The IMF for example, has nowhere written that there is only one prescription for all the monetary and financial ills of the world's developing and transition economies; but, its advisers, in dispensing 'identikit' loan conditions, evidently behaved as if such a 'code' has been promulgated. Such uncodified but stable bodies of knowledge and practice, in which the particular epistemic community's members silently concur, will often find us as a test for admission to the group or a signal of group membership to the outside agents"(Cowan et al., 2000:233).

Hence what has happened at IMF, as with many other maturing organisations, is that the need for a certain codes has imposed a uniform requirement on the staff of the organisations. Even when not explicitly written down, intermediaries at the core of the financial system, appear to believe in much the same way of providing finance. For instance, despite no rules stopping banks lending to certain projects, and even encouragement from Government, banks can be extremely hesitant in changing their approaches, client base or lending methods. Arrow (1974) concludes that the staff are thus:

"specialised in the information capable of being transmitted by the codes, so that, in a process already described, they learn more in the direction of their activity and become less efficient in acquiring and transmitting information not easily fitted into the code. Hence, the organisation itself serves to mould the behaviour of its members" (Arrow, 1974:56-57).

Such institutional 'lock-in' is often caused by path dependence, which means that it can be expected that an institution, organisation or system will be constrained by its historical context (David, 1994). History therefore matters because of the role of the historical experience, including particular events, in shaping mutually 
consistent expectations. Furthermore, complex organisations looking to fit with bigger structures (such as the financial system) need to make choices that are consistent with these and therefore constraints are imposed (David, 1994). Path dependency can then result in particular avenues being taken or solutions chosen due to what is considered 'correct' at the time. What follows is that:

"the organisational structure can become 'locked in' to a comparatively narrow subset of routines, goals and future growth trajectories" (David, 1994:214).

Again, it is noticeable that such path dependence leads to inertia in the system. Cowan and Gunby (1996) for instance, found that choices made at an early stage regarding pest management technology greatly influenced and reinforced later choices. The technology is then locked in and it becomes very difficult to make the switch to a different technology even if that technology has been proven to be superior.

It can be concluded that even if the new knowledge is considered better, there are still many constraints on its adoption and use. In fact,

"The resistance to new propositioned knowledge is to be expected in any society, but its degree of success depends on the standards by which society judges it and the tightness of the knowledge- that is, how strongly it is confirmed by these standards and becomes part of the 'consensus' (Mokyr, 2002:227).

The impact of this on the financial system, then, is that formal financial institutions that make up its core are rigid, institutionally locked in and unwilling to innovate. Formal financial dealers or intermediaries are often reluctant to change to new technologies or methods because of preconceived risks or costs. Therefore informal dealers operating much more on personal information, contacts and knowledge are in a better position to identify new opportunities. In fact, markets with new products tend to be created and nurtured by informal dealers rather than formal (Bhatt, 1995).

\subsubsection{Knowledge Types and Networks}

The knowledge flowing in the financial system stems from actors. Actors are those individuals or groups of individuals who are able to influence outcomes and cause change. The importance and role of each actor can change over time and often individuals can play a more decisive role than a team or an organisation. Actors include for example suppliers, traders, wholesalers, end users, core financiers, cooperatives, competitors, entrepreneurs, NGOs, Government and rural clients.

These actors have embodied knowledge and skills. Therefore, knowledge types are spread across actors (Arora, 2009). Because knowledge is spread across actors, interaction is required for the knowledge types to mix. It follows that knowledge types, or actors, interacting in a way governed by institutions create innovation. It is this collaborative knowledge accumulation and learning process that forms the 
basis of the innovative activity (Arora, 2009). The performance of an innovation process is a function of the structure of its knowledge sharing network. The consequence of this would be that innovation is a social process and that networks hold a central position as it is through networks that new relations of knowledge types form that result in knowledge sharing and this innovation.

There are intuitively three reasons why networks are of importance to the innovation process (Arora, 2009): first, innovation is the result of new combinations of diverse knowledge types that somehow must interact in order to provide a coherent whole (Rosenberg, 1976 in Arora, 2009); second, there is no single actor that can have all the necessary expertise for an innovation process or system, which means that networks are necessary in order to both share information and make sure the system functions; third, such networks are vital in order for non-codified, i.e. tacit knowledge, to travel throughout the system. Such knowledge may flow between experts, between experts and end users, or between end users, and as has been noted previously, flow more easily through close interaction. A point to emphasise here is the importance of user-user interaction for innovation (von Hippel, 1988). Manufacturers or producers have conventionally been the focal point as the functional source of innovation. However, as von Hippel (1988) notes, users and suppliers can also act as innovators or provide central input to the process of innovation. The functional role of an actor is determined by the functional relationship (as a manufacturer, supplier or end user) in the innovation process through which they derive benefits (von Hippel, 1988). Therefore, the role can change over time and innovation. Whilst a user will innovate to gain personal benefits from an improved product, process or service, the producer is more likely to look to a market of several users with similar requirements. Furthermore, lead users often have the best understanding of new challenges and needs (von Hippel and Riggs, 1996), and they are characterised by an expectation to benefit significantly from the innovation they are involved with and are generally ahead of the rest of the market (von Hippel and Riggs, 1996). By acting as a lead user in the financial system therefore, an organisation at the periphery is able to circumvent discrepancies between what intermediaries supply and what their clients demand. An innovating organisation as a lead user is additionally in a better position to acquire and use tacit knowledge to create, monitor and evaluate financial models supporting innovation.

Just as codification leads not only to better communication but also rigidity, embeddedness and social networks can also lead to an actual seal from information flowing outside of the network. This in turn can reduce the adaptive capacity an individual or an organisation possesses (Uzzi, 1997). Therefore, organisations such as banks may in fact be closed off from information flowing freely outside of their close network.

Furthermore, when networks are made up of similar actors, such a close banking network or academic network, they are likely to bring very similar 
knowledge types. Therefore they are unlikely to yield the same level of knowledge accumulation that could occur from a wider network made up of actors from different backgrounds. It follows that it could be assumed that organisations at the core of the financial system, who all use similar codification to share knowledge, would gain less in terms of innovation and knowledge accumulation from their networks, than would an organisation operating at the periphery which may be part of a wider and more varied network. New useful knowledge would be more likely to occur at the periphery of a network than the core of it which again would suggest that wider networks of actors, as used by the periphery organisations would be more useful.

A final point about networks is that certain organisations or individuals can act as 'go-between's', which is a role that the periphery organisations could be expected to take on since these organisations are able to match new clients with finance. Uzzi (1996) notes that:

"embedded ties develop through stages which begin when existing embedded ties match up new exchange partners. In such cases, go-betweens write to one another prime the relationship between those newly introduced actors for embeddedness by setting expectations for trust and reciprocity and by equipping it with resources that are 'rolled over' form the go-between's existing embedded ties to one of the new network partners" (Uzzi, 1996:39).

Therefore, the clout held by an organisation working with financing of propoor innovation could assist in creating ties between previously unconnected actors. Furthermore, by setting expectations for trust and reciprocity, the organisation can move around the problems that are often solved with collateral and high interest rates in arm's length finance.

\subsection{What do Periphery Organisations do differently?}

From the above discussion it is clear that the core and the periphery of the financial system operate in different ways, which has an impact on their level of innovation in the provision of finance. This section will recapitulate what these differences are in six points.

\section{Mature and stable vs. Unstable and Dynamic}

The core has over time matured into a stable system that has become rigid. Instead of positive feedback loops reinforcing the dynamic and knowledge accumulating system, the core is reinforcing its rigidity and lack of flexibility. The result is a stagnation of innovation and knowledge accumulation. The periphery on the other hand, is still evolving and dynamic. Although, it does rely on some backward linkages from the core, notably credit and other types of finance, it does not suffer 
from the rigidity of the core. It therefore supports knowledge accumulation and the innovation process.

\section{Reliance on Different Kinds of Knowledge}

The organisations at the core and the periphery are relying on different sorts of information. Whilst the matured and stable core is to a great extent using codified knowledge to share information widely in a cost efficient manner, the periphery is relying more on tacit knowledge. Though tacit knowledge is more expensive to transfer and require close, face to face interaction, it is more likely to highlight new issues or news needs that organisations would need to deal with. The periphery organisations are therefore in a better position to act on project or area specific knowledge that either is too new or too difficult to articulate to have been codified. This tacit knowledge thus allows the periphery organisations to adapt their models to suit local needs, as well as changing needs over time.

\section{History Matters}

The codification of knowledge at the core has further implications as a carrier of history resulting in both path dependence and institutional and behavioural lock-in.

\section{Path Dependence}

Path dependence further strengthens the lock-in effect caused by the codification of knowledge. The financial intermediaries at the core are locked in to the same way of doing business, such as lending using the arm's length finance approach, as they have always done. To change to a new type of lending behaviour would cause disruptions throughout the core system as the interconnected parts of the organisations that provide finance are all geared towards the traditional arm's length approach. The periphery organisations however, do not suffer from history to the same extent as they were set up only very recently and have never used the historical approach to providing finance. Therefore, history and path dependence do not act as a severe barrier to further innovation and change, as is the case at the core.

\section{Institutional Lock-in}

A side effect of the codification of knowledge, as witnessed at the core, is that the process of codification relies heavily on what has already been codified. By acting as a 'carrier of history' the codified knowledge leads to rigidity in the system, as noted in section 0 . Thus the effect of such rigidity is institutional lock-in, which acts as deterrence to innovation. A further effect of the lock-in itself is a reinforcement of codes, even those that have not been written down.

The periphery organisations that do not suffer such institutional lock-in are much more flexible in nature. Such flexibility allows them to keep a more 'open mind' and 
able to react on and incorporate new knowledge and information as there are no previous codes that lock them in to a certain way of doing business or thinking.

\section{Network \#1: Similarities vs. Dissimilarities of Knowledge Types}

As a result of the codification of knowledge as well as path dependency and institutional lock-in, the core is likely to operate in an environment with a network of very similar knowledge types. Since the network is made up of similar knowledge, it is unlikely to lead to much new knowledge accumulation and innovation. The structure of the network is likely to be closed at the core, due to the modus operandi which further reinforced the limited typed of knowledge available. At the periphery the story is quite the opposite with a network structure that is wide and open, therefore including a far wider range of knowledge types. These knowledge types may be established at the core or the periphery, and from different (sectoral, geographical and professional) sources, providing a much more stimulating mixture of knowledge than the core, which results in improved knowledge accumulation and innovation, as well as a better understanding of the operating environment which has effects on expected risks. At the same time an open network, as witnessed at the periphery, ensures that organisations and individuals are accessing knowledge that flows outside of their immediate knowledge network. The core, however, which operates a more closed network, is likely to be sealed off from information that flows outside of their network.

\section{Network \# 2: Network Extension through Go-between's}

A final point related to the network of knowledge types and improved understanding of the risks involved, is that the periphery organisations are able to use their extensive and varied networks to provide new services outside of their own direct capabilities. They are able to do so by acting as 'go-betweens', building and transferring trust between two parties, such as an entrepreneur and a financial intermediary or a supplier of inputs, that were not previously directly connected. By acting as a go-between as well as building up a reputation for such a role, the organisations at the periphery are able to break down barriers and connect knowledge types and actors that would previously not have interacted. The core does not possess this ability and since their institutional lock-in stops them from interacting with new clients, they can neither provide services directly, nor act as a go-between linking these un-serviced clients to another intermediary that would provide such services.

\section{Periphery Organisations as Lead User Innovators}

The periphery organisations are closer to the users than are the intermediaries at the core of the financial system. This closeness coupled with their reliance on tacit 
knowledge makes them more likely to see financial innovation from the point of view of the users, even interact more with users in the innovation process. In certain respects they are the actual users, in the user-producer relationships that exist between them and the intermediaries at the core. In this sense these organisations can be thought of as lead user innovators of financial solutions. By being lead users, these organisations have a direct experience of the financial products and models that the core lack and are therefore in a better position to improve existing models by innovating at the user end. This additionally puts them in a unique position to understand what actual works on the ground and what suits their clients.

Having noted that there is a distinct difference in the way organisations at the core and periphery are operating in terms of the stability and dynamism of the system, the reliance on different kinds of knowledge, the importance of history in contributing to path dependence and institutional lock-in, the variety of knowledge types in their networks, the reliance on relationships and the tendency to be innovating, the next section will elaborate on conditions under which finance can be provided for rural pro-poor entrepreneur-based innovation.

\subsection{Insufficient but Necessary Conditions}

In a system, such as the financial system, many conditions are interrelated. Some conditions or factors are known whilst others are not. Therefore it is difficult to know exactly which factor or factors affect access to finance for pro-poor entrepreneur-based innovation. There may be many variables in which case the exact combination of factors is likely to be unknown. It follows that singling out one variable as the reason for a lack of finance for entrepreneur-based innovation is not useful since that one factor would be heavily constrained by all the other, unknown, but interrelated, variables in the system that have not been accounted for. Given that there are no mathematical or statistical tools that can aid in singling out such necessary and sufficient conditions for the provision of finance, this model turns instead to probabilistic conditions that can form the basis causal attributions in real world settings, such as in the financial system. Such conditions are an

"insufficient but necessary part of a condition which is itself unnecessary but sufficient for the result" (Mackie, 1974:245).

These INUS conditions can then be used to undertake causal attribution in a model. For instance, Mackie writes that the causality of light in a room is normally attributed to the light switch, when in actual fact electricity infrastructure; a power generator and a light bulb for example, are also necessary conditions, although none, on its own is sufficient.

In section 3.2 it was noted that knowledge accumulation and innovation are important for the provision of finance to customers outside of the mainstream 
group of borrowers. Linking the reasons for the apparent gap in finance from section 3.1 with the reasons for the core and periphery acting differently, as discussed in section 3.3, a list can be formed of insufficient but necessary conditions related to the ability to provide pro-poor entrepreneur-based innovation finance. It is likely that these conditions will be more evident among the organisations at the periphery, whilst (mostly) lacking at the core. Furthermore, it is likely that these conditions are evident to different extents and in different shapes in the various organisations at the periphery. Therefore, the thesis does not set out to make a black and white list of conditions that are or are not fulfilled, but instead focuses on how the conditions may be fulfilled in different ways at the periphery and the core.

\section{Flexible and Dynamic}

By using a flexible approach to finance, the organisation avoids being 'stuck in history' or institutionally locked in. Instead they can look at new problems and challenges without such barriers. This dynamism additionally means that organisations are quicker to adapt to new situations and more open to new ideas.

\section{A Wide Network of Actors with Varied Knowledge}

By having access to a wide network of different knowledge types (from end users to banks at the core and academia for example), financial intermediaries can access expertise to deal with, and better evaluate the risk of potential endeavours or clients. A wide network provides new knowledge that can be used to improve existing models of finance. In addition, it is likely that the core of the financial system plays a role as supplier of finance to the periphery since the periphery organisations probably cannot access enough finance among themselves.

\section{Relationship Improve Risk Profile and Replaces Collateral}

By relying heavily on relationships an organisation can provide a wider range of services than intermediaries that operate in isolation. This can improve the risk profile of clients as well as the intermediary's portfolio and reduce the need for collateral. Furthermore, by acting as a go-between, organisations can use their relationships to transfer trust to its clients and therefore do away with some of the risk the normally require collateral in arm's length finance.

\section{Tacit Knowledge, Feedback Loops and Learning}

By emphasising tacit knowledge rather than simply codified knowledge, organisations can access 'newer' knowledge. By doing so, they are more likely to understand a local or new situation and financial needs, for which their financial models can then be adjusted. Mechanisms for feedback need to be in place so that the organisation can acquire, use and learn from new knowledge and information. 


\section{Lead User Innovation}

By acting as a lead user in the financial system, the organisations are able to circumvent discrepancies between what intermediaries supply and what clients demand. An innovator as a lead user is additionally in a better position to evaluate the usefulness of a certain model.

\section{A Systemic, Integrated Approach to Finance}

An organisation operating as part of a system is in a better position to deal with risk because it can focus its support model on a particular niche of that system, knowing that other intermediaries will complement that service. Such an organisation is more likely to support entrepreneur-based innovation efficiently since operating in a systemic manner requires it to be dynamic, and changing in nature.

Furthermore, an integrated approach provides different kind or different combinations of financial and non-financial support. It recognises that such nonfinancial support not only provides for the most efficient use of the financial support, but also reduces client risk. In doing so, it reduces the portfolio risk of the intermediary too. Moreover, at the sector level, an integrated approach means that these organisations are involved in financing innovation beyond directly dealing with clients. The organisations therefore have an impact on the environment in which it operates and by improving the external environment, the organisations are likely to improve their internal operations too.

\subsection{Conclusion}

This chapter began by outlining a number of reasons why there may not be finance available for innovative activities among small firms and entrepreneurs, assuming that it is not simply because it is impossible to make a profit. First, credit may be rationed due to information problems. Second, there is uncertainty related to innovation focussed investments. Third, to combat such risk the financial intermediaries may rely on collateral and relationship based finance that can lead to financial exclusion. Fourthly, the demand for finance may not be clearly visible and finally the financial system itself may affect the flow of credit in a number of ways due to regulatory issues and government policy, legal barriers and contract enforcement, information flow and the physical infrastructure underlying the system. The result could be flows of finance moving from rural to urban areas, directed credit that is diverted and inertia and institutional lock-in.

Given that there appears to be finance flowing in the system, the second part of the chapter went on to explore the lack of finance using knowledge flows. Considering the financial system as made up of a core and a periphery, the chapter went on to suggest that the way tacit and codified knowledge flows within the system and the knowledge types that can be accessed through networks matter. As do the trust and relationship that exists, and the ability of organisations to 
accumulate new knowledge. This analysis was taken a step further in the third part where the knowledge flows at the core were contrasted with those at the periphery of the financial system. At the core, path dependency and institutional lock-in together with a closed network of similar knowledge types and a dependence on arm's length collateral rather than relationships, resulted in rigidity and a closed system. The periphery organisations, however, were able to avoid these issues for a number of reasons which form the basis for the INUS conditions in the final part of this chapter.

The INUS conditions posit that finance is available when organisations within the system (or part of the system as is the case of the periphery) have some though not necessarily all of the following characteristics: dynamic and flexible approach to finance; a wide network of actors with varied knowledge (including core financial institutions); relationship focused (because it reduces the risk profile as well as the need for collateral); an emphasis on tacit knowledge, feedback loops and learning; ability to innovate close to or with the end user thus action as a lead user innovator; and finally by adopting a systemic and holistic approach to finance.

The INUS conditions of the model marks the end of the theoretical part of this thesis. In part two, the model will be used to better understand the financial system in India and the lack of finance for pro-poor entrepreneur-based innovation in rural areas by first exploring the financial system as a whole in chapter 4 , followed by case studies of five organisations at the periphery in chapters 5-7. 


\section{India's Rural Financial System}

Having built a theoretical framework to explain the lack of financial access for rural pro-poor entrepreneur-based innovation, this second part of the thesis will empirically explore the issue using the case of India. As the first chapter of this empirical part, this chapter will map the financial system and explore how well the core financial institutions are supporting rural PEBI.

India has a relatively deep financial system. However, despite an impressive infrastructure including a huge bank branch network, rural areas suffer from a lack of financial services and most poor do not have access to finance. Decades of 'social banking' have failed to even out the distribution of financial services and today there is a noticeable bias towards urban areas. Combined with reduced small-scale credit advances and accounts in rural areas, this would suggest that there is a financing gap and formal credit has failed to support socially relevant rural innovation and entrepreneurship. The chapter finds that in place of bank finance, an alternative sector has been emerging. There are three broad categories: first, there are micro venture capital funds that support ventures providing improved services, products or employment for the rural poor; second, there are small-scale financial organisations similar to microfinance but with expanded services that support rural projects and entrepreneurs; and third, those supporting grassroots innovation either as incubators for rural entrepreneurs or inventors, or by themselves innovating at the local level.

The next section will explore how India compares with other emerging economies, before considering how the financial system has evolved. Thereafter, the chapter will discuss disparities between rural and urban banking services and how that is relevant to finance for PEBI. The chapter concludes by highlighting the alternative financing sector that is emerging, discussing some of its attributes.

\subsection{Indian Banking: an International Comparison}

The soundness and depth of a country's financial system has a clear impact on economic growth and poverty alleviation. In fact, 
"deep and efficient financial markets promote investment and total factor productivity through growth through their role in selecting and monitoring projects; diversifying risks; reducing asymmetries of information; improving resource allocation; and encouraging the optimization of scale, time frame and technology" (Kumar et al., 2005:2).

Although the size of India's financial system in absolute terms does not impress next to other large countries such as China or Brazil (see table below), it compares well with other emerging economies. For instance, India's financial assets in nominal terms amount to USD 430 billion which is more than Malaysia at USD331 billion and Mexico at USD 386 billion. Nevertheless, as figures are from 2000 , the total assets of India's financial system are likely to have improved relative to other countries since then. Taking into account the low GDP per capita, India's financial system appears deep compared to other emerging economies. Whilst in Mexico the total financial assets amount to $68 \%$ of GDP, in India the equivalent figure is $93 \%$. The Indian equity market stands up well in comparison with other emerging economies both in terms of market capitalization and value traded relative to GDP.

Table 4.1 Depth of financial markets: an international comparison in 2000 (source: Kumar, 2005)

\begin{tabular}{|l|l|l|l|l|l|l|}
\hline & $\begin{array}{l}\text { GDP per } \\
\text { capita 1999 } \\
\text { (USD) }\end{array}$ & $\begin{array}{l}\text { Total } \\
\text { Financial } \\
\text { Assets } \\
\text { (USD m) }\end{array}$ & $\begin{array}{l}\text { Equity Mkt } \\
\text { Cap /GDP } \\
(\%)\end{array}$ & $\begin{array}{l}\text { Equities } \\
\text { Value Traded/ } \\
\text { GDP (\%) }\end{array}$ & $\begin{array}{l}\text { Total } \\
\text { Financial } \\
\text { Assets / } \\
\text { GDP (\%) }\end{array}$ & $\begin{array}{l}\text { Private } \\
\text { Credit/ } \\
\text { GDP } \\
(\%)\end{array}$ \\
\hline Brazil & 4350 & 780739 & $39 \%$ & $17.0 \%$ & $139.7 \%$ & $50.9 \%$ \\
\hline Mexico & 4440 & 386366 & $24.7 \%$ & $7.9 \%$ & $68.3 \%$ & $32.3 \%$ \\
\hline India & 440 & 437293 & $34.2 \%$ & $104.7 \%$ & $92.8 \%$ & $36.4 \%$ \\
\hline China & 780 & 2153717 & $42.5 \%$ & $66.8 \%$ & $199.4 \%$ & $128.9 \%$ \\
\hline Malaysia & 3390 & 331302 & $146.5 \%$ & $65.5 \%$ & $370.9 \%$ & $144.8 \%$ \\
\hline Korea & 8490 & 1091499 & $64.7 \%$ & $233.1 \%$ & $267.0 \%$ & $140.3 \%$ \\
\hline
\end{tabular}

Equally, India can count an impressive number of formal financial institutionsboth in urban and rural areas. The financial system in India is bank heavy and as such banks play a particularly important role in providing finance in the economy. Apart from private and state owned banks there are cooperative banks which are particularly important in rural areas, a huge post office network providing savings facilities, as well non bank financial institutions such as savings societies and credit societies like primary agricultural credit societies (PACS) that have a vast network in rural areas (Basu et al., 2005). ${ }^{39}$ Here too, India compares well with other

\footnotetext{
${ }^{39}$ Banks in India include private and public banks (Scheduled Commercial Banks- SCB) as well as rural regional banks (RRB). Cooperative banks operate at the state or district level whilst PACS are
} 
countries as shown in the table below. For instance, whilst the average bank branch in India covers $44 \mathrm{~km}^{2}$, in the US a branch would cover an area of $177 \mathrm{~km}^{2}$, in Mexico $236 \mathrm{~km}^{2}$ and in Brazil a vast $470 \mathrm{~km}^{2}$. Even in terms of population per branch, India does of course, with its huge number of citizens, cover larger number of people per branch than other countries.

However, if cooperative bank branches are taken into account, the population per branch stands at 12800 (according to Basu and Srivastava, 2005) which puts India on a par with Indonesia and Mexico. This would suggest that India's deep financial system is complemented by a far reaching and well developed financial infrastructure. It is worth noting that the Indian financial system is influenced by a very high level of Government ownership of banks. Government owned bank assets amount to a staggering $80 \%$ of total as compared with $55 \%$ in Brazil, $43 \%$ in Indonesia, 25\% in Mexico and only 15\% in the Philippines (Basu, 2006).

Table 4.2 Rural branch networks: an international comparison (source: Kumar, 2005)

\begin{tabular}{|l|l|l|}
\hline & Area / Branch $\mathbf{( k m}^{2} \mathbf{)}$ & Population/ Branch \\
\hline Japan & 6 & 1959 \\
\hline France & 22 & 2331 \\
\hline India & 44 & 14888 \\
\hline Indonesia & 110 & 12547 \\
\hline US & 117 & 3568 \\
\hline Mexico & 236 & 11924 \\
\hline Brazil & 470 & 9331 \\
\hline Chile & 535 & 10727 \\
\hline
\end{tabular}

Despite such promising figures, closer inspection reveals that a large share of the population still has no access to formal finance.

That formal credit is more difficult to obtain in rural areas is confirmed by the National Sample Survey (NSS) round in 2003 which indicates that whilst $75 \%$ of households access formal credit in urban areas, only $57 \%$ of rural households do likewise. Instead, moneylenders still play a significant role, providing about $30 \%$ of credit in rural areas. Furthermore, the bundle of services provided by rural bank branches tends to be much inferior to urban bank branches (Basu, 2006).

local. According to Basu and Srivastava (2005): 32000 RRB and SCBs, 14000 Cooperative Banks, 98000 PACS and 154000 post office branches 
Table 4.3 Origin of rural and urban credit in India in 2002-2003 (source: NSSO, 2005)

\begin{tabular}{|l|l|l|}
\hline Credit Agency & Rural & Urban \\
\hline Government & $2.3 \%$ & $7.6 \%$ \\
\hline Co-operatives & $27.3 \%$ & $20.5 \%$ \\
\hline Commercial Banks & $24.5 \%$ & $29.7 \%$ \\
\hline Insurance & $0.3 \%$ & $3.5 \%$ \\
\hline Other Financial Institution & $2.0 \%$ & $11.0 \%$ \\
\hline Other & $0.7 \%$ & $2.9 \%$ \\
\hline All institutional agencies: & $57.1 \%$ & $75.2 \%$ \\
\hline Landlord & $1.0 \%$ & $0.2 \%$ \\
\hline Agricultural Moneylender & $10.0 \%$ & $0.9 \%$ \\
\hline Professional Moneylender & $19.6 \%$ & $13.2 \%$ \\
\hline Traders & $2.6 \%$ & $1.0 \%$ \\
\hline Friends and Relatives & $7.1 \%$ & $7.6 \%$ \\
\hline Others & $2.6 \%$ & $1.9 \%$ \\
\hline All informal agencies: & $42.9 \%$ & $24.8 \%$ \\
\hline
\end{tabular}

That more than $40 \%$ of the rural population should not have access to formal finance in a country that has as deep and wide a system as India does is related to how the financial system has evolved in India.

Together with the Reserve Bank of India (RBI) the Government policy set the strategy for India's banking system and the financial system has evolved through various phases since independence. Immediately after independence the vast majority of India's rural population had no access to formal finance, instead moneylenders including landowners and traders would provide credit at usurious interest rates, trapping the poor in a never ending debt cycle (Shah et al., 2007). ${ }^{40}$ The 1954 report on the 1951 All India Rural Credit Survey (AIRCS) concluded that the poor still had very little access to formal credit. In fact less than $9 \%$ of rural credit was provided by the formal financial system, less than $1 \%$ of rural credit was provided by commercial banks, $70 \%$ of credit came from moneylenders whose average annual rate of interest was above $20 \%$, and there was a strong positive correlation between land ownership and access to credit (Burgess and Pande, 2003; Burgess et al., 2004; Shah et al., 2007). The 1954 AIRCS report therefore recommended that the Government and the RBI policy should make banks provide

\footnotetext{
${ }^{40}$ There had been attempts at addressing the issue through legislative intervention against usurious rates and for the provision of low interest loans which had little impact. The colonial administration had set out to copy the, in Europe successful, cooperative credit movement in India with the Cooperative Credit Societies Act in 1904 and the Cooperative Societies Act in 1912. However, due to the pervasive caste system, and the strong socio-economic divisions in society that followed, the cooperatives never fully worked. Further Government Acts dealing with usurious rates and indebtedness made little headway (Shah et al, 2007; Burgess and Pande, 2003).
} 
credit for the rural population in order to allow them to adopt new technologies and to reduce importance of moneylenders.

\subsection{Social Banking}

In response to the lack of formal finance available to the poor, the Government and RBI pursued a 'social banking' strategy of aggressively pushing banks to provide financial infrastructure and services to rural areas, in particular to the most disadvantaged groups. This was done: 1) by expanding the number of financial intermediaries in rural areas; 2) through directed lending; and 3) through subsidised credit. To oversee the expansion of rural finance, the Government set up the National Bank for Agriculture and Rural Development (NABARD), whilst it created the State Bank of India (SBI) in 1955 from the nationalised Imperial Bank of India to expand the branch network and increase agricultural lending.

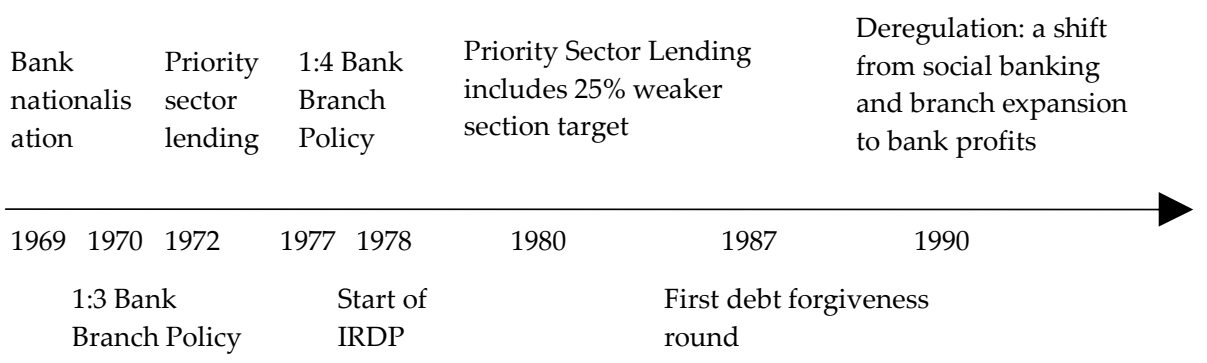

Figure 4.1 Timeline of social banking (adapted from Burgess and Pande, 2003)

Despite such measures, commercial lending in rural areas remained very limited during the 1950's and 1960's. Commercial bank lending amounted to $2.4 \%$ of total and most of that small lending still went to the relatively better off such as plantation owners or agro-processing units (Shah et al., 2007). By 1961, only 50\% of towns and none of the villages had a commercial bank. With such abysmal results, the Government went ahead with a nationalisation drive of 14 commercial banks in 1969.

The RBI restructured the banking system considerably closing down a larger number of banks and subsequently expanding the branch network with a bias towards rural and un-served areas. By 1970, the RBI demanded that for each branch opened in an area already served by banks, the bank needed to open three branches in un-served areas and six years later that ratio had increased to four branches in un-served areas for one new in an existing area. To further increase rural finance, the RBI created the Rural Regional Banks (RRB) in 1976. These were expected to provide credit and other financial services to small-scale entrepreneurs, artisans and 
farmers. As a result the number of branches expanded rapidly from 1443 RRBs to 35000 by 1990, towns or villages with a bank rose from 1000 to 25000 (Shah et al., 2007) and rural credit was surging.

Two further reasons for the sharp increase in rural credit were NABARD's refinance scheme for commercial, state and rural banks to encourage rural lending and saving, as well as priority sector lending. In the early 1970's the RBI introduced the policy of prioritising lending to certain parts of society and by 1975 the target was set at $33 \%$ (to be achieved by 1980) which was extended to $40 \%$ of total lending in 1979. In 1980 the policy was further enforced by demands that 16\% (up to $19 \%$ by 1985) had to be lent to the agriculture sector whilst another $10 \%$ were earmarked for the 'weaker sections', i.e. the scheduled castes and tribals ${ }^{41}$ (Burgess and Pande, 2003). The RBI introduced fixed interest rate ceilings on credit for prioritised borrowers and the weaker section had a maximum interest rate ceiling of $4 \%$, whilst the RRBs and Scheduled Commercial Banks (SCB) charged a flat rate of $9 \%$ on other priority sector loans.

Alongside the policy interventions in bank lending as stipulated by the RBI, the Government ran state funded large-scale development programmes such as the Integrated Rural Development Programme (IRDP). The IRDP was introduced in 1978 to offer cheap credit for the rural poor to alleviate poverty by making available new sorts of income generation through credit provision. It was rolled out fully in India two years later. By 1987, four million households had take part in the programme (Shah et al., 2007) but millions of poor defaulted which resulted in the first of several official debt forgiveness rounds by the Government, in 1989. Not only had it made defaulters out of millions of poor who therefore would no longer have access to the formal credit system, but the IRDP was responsible for $40 \%$ of total losses of rural banks by 1988 (RBI, 1995 in Shah et al., 2007). By the end of the 1980 's there was little credit discipline left (with only half of loans outstanding being recovered) and corruption and political interference had become the norm.

The IRDP had put further pressure on the banking system which was already straining under interest rate ceilings and priority sector lending requirements and banks were crumbling under the huge debts that they were incurring.

In 1991 the Government of India set up a review of the credit system under the Committee on the Financial System (called the Narasimkam committee after its chairman). The committee recommended liberalisation of the economy and that directed credit should be phased out (Shah et al., 2007). It was clear that the banks were simply not profitable, mainly because of the terms they were lending at. This was a shift in economic policy from centralised economic decision-making to market orientation and higher private involvement and initiative as rural financial institutions now needed to become commercially sound, cost-effective and more

\footnotetext{
${ }^{41}$ Scheduled castes are made up of lower castes and those that did not belong to a caste, formerly known as untouchables, whilst tribals, or adivasis do not belong to the caste system.
} 
professional (Satish, 2004). The financial liberalisation of the 1990's thus saw the end of social banking and bank expansion ceased in, as yet, un-banked areas.

\subsection{India's Formal Financial System Today}

Today, rural India suffers from a more serious lack of finance than urban India (Bose, 2004; Shah et al., 2007; Misra, 2008; Ramesha, 2003). ${ }^{42}$ Using data on SCBs and RRBs this section will examine the disparity between rural and urban banking. Since SCBs do not publish separate data on the performance of their rural branches, this analysis rests on the assumption, made in Basu (2006), that RRBs can be used as a proxy for rural branches of SCBs. ${ }^{43}$ Furthermore, cooperative banks, although forming a large part of the rural branch network, are not included in the analysis due to lack of data. Again, cooperative banks are assumed to be less profitable and provide fewer services than SCBs (Basu, 2006) so for the purpose of depicting the difference in bank performance and credit availability between rural and urban areas, the omission does not have a major impact on the analysis.

That India's bank branches grew exponentially due to the earlier bank expansion programme is clear from the graph below. It highlights the focus on rural bank branches as part of the Government's effort to expand banking into rural unbanked areas. However, since the 1990's that rural bank expansion ceased, even reducing the number of branches in rural areas as some banks were allowed to close loss-making branches. There is now a clear difference in bank expansion in rural and urban areas with banks much more likely to open new branches in towns and cities. It is particularly evident that since the end of social banking policies, rural branches, as a percentage of total, has decreased quite rapidly.

\footnotetext{
42 For a review of rural finance in India see Shah et al. (2007) and Basu (2006); for RRB's see Bose (2004) and Misra (2008); and for cooperative banks Ramesha (2003).

${ }^{43}$ SCBs are the public as well as private commercial banks operation in urban and rural areas, whilst RRBs by their very nature are specifically designed to operate in rural areas.
} 


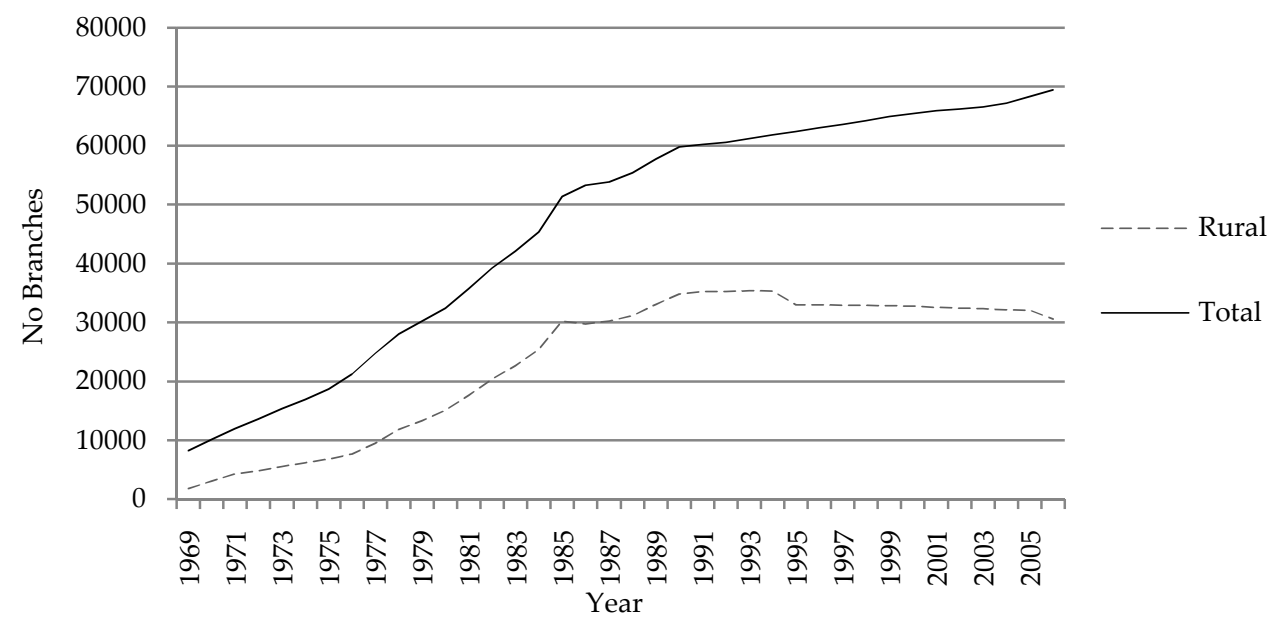

Figure 4.2 Branch expansion of scheduled commercial banks (source: RBI)

Furthermore, the growth of rural credit and deposit out of total credit and deposit has decreased since 1990, as depicted below. What is most striking is the sharp decrease in rural credit as a percentage of total credit. In addition it is noteworthy that rural areas used to have a higher rate of credit out of total than deposits but since 1990 a shift has taken place and deposits as a percentage of the total have been the higher of the two. 


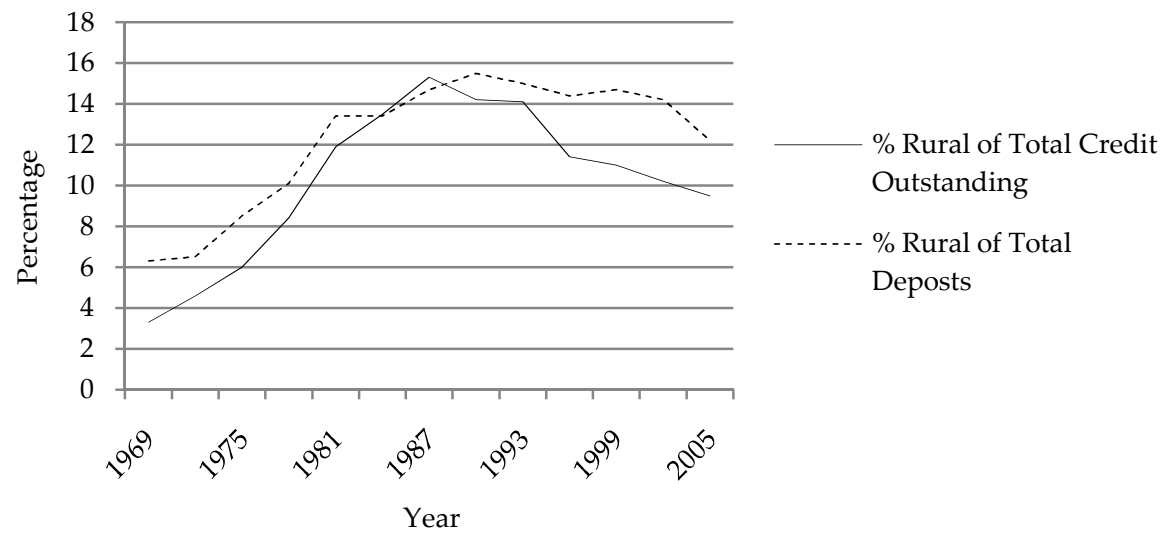

Figure 4.3 Share of rural credit and deposit of total (sources: Shah et al. 2007: 1354; RBI).

In other words, the credit ratio has decreased more rapidly than the deposit ratio.

Table 4.4 SCB data on credit and deposits (sources: RBI, 2008; Shah et al., 2007)

\begin{tabular}{|l|l|l|l|}
\hline & $\begin{array}{l}\text { Rural of all SCB } \\
\text { branches (\%) }\end{array}$ & $\begin{array}{l}\text { Rural of Total Credit } \\
\text { Outstanding (\%) }\end{array}$ & $\begin{array}{l}\text { Rural of Total } \\
\text { Deposits (\%) }\end{array}$ \\
\hline 1990 & $58.20 \%$ & $14.20 \%$ & $15.50 \%$ \\
\hline 1993 & $56.30 \%$ & $14.10 \%$ & $15.00 \%$ \\
\hline 1996 & $51.20 \%$ & $11.40 \%$ & $14.40 \%$ \\
\hline 1999 & $49.30 \%$ & $11.00 \%$ & $14.70 \%$ \\
\hline 2002 & $47.80 \%$ & $10.20 \%$ & $14.20 \%$ \\
\hline 2005 & $46.90 \%$ & $9.50 \%$ & $12.20 \%$ \\
\hline
\end{tabular}

Furthermore, it is clear from the table above that in 1990 deposits as a percentage of total, roughly equalled credit in rural areas with rural of total credit outstanding at $14.2 \%$ and rural deposits of total deposits at $15.5 \%$. Whilst by 2005 there were considerably more deposits made of total at $12.2 \%$ than credit, at $9.5 \%$, as a percentage of total in rural areas. In other words, there is not only a lack of expansion of rural branches and rural credit but there has in addition been a change in the flow of rural deposit and credit from a point where deposits were flowing to rural credit to a point where much of the deposits appear to be flowing out of rural areas. 
This bleak picture is further enforced by the credit-deposit (CD) ratio which is an indication of the amount of deposit used for credit purposes. A high CD ratio can indicate a certain level of stability of the source of funding for banks. In addition it could indicate that much of the bank's funds stemming from deposits have been used for the purpose of credit advancement as opposed to other banking business.

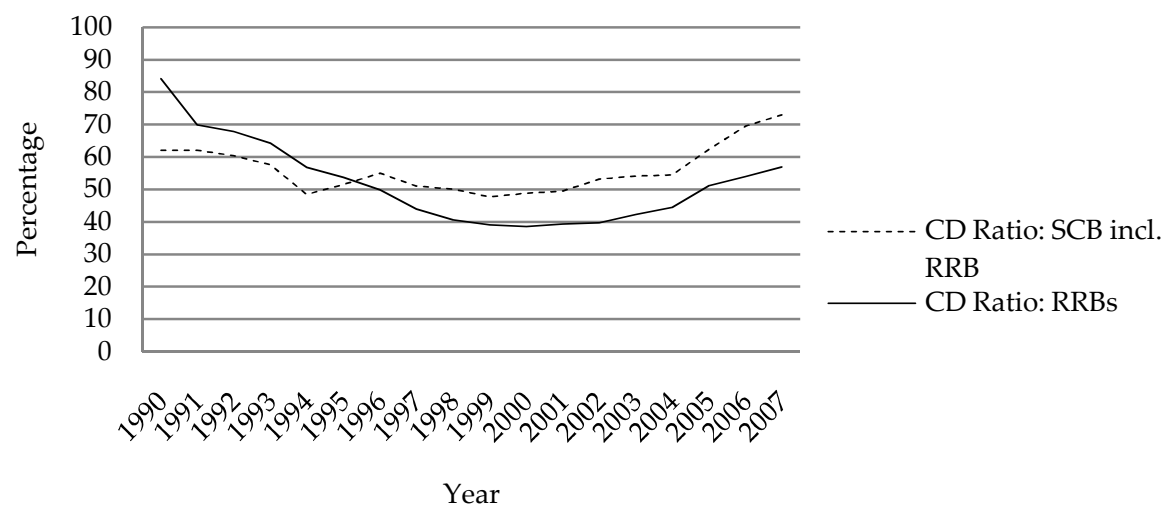

Figure 4.4 Credit/deposit ratios of SCBs and RRBs 1990-2009 (sources: RBI and NABARD, 2008)

India has in general seen relatively high CD ratios, although it did decrease in the 1990's. Furthermore, despite an improved CD ratio, it is far lower in rural areas, considering the RRB's CD ratio of below 60\% compared to SCB's corresponding ratio which is above $70 \%$. In fact the gap appears to be widening between the two ratios despite recent measures.

Thus, to recapitulate, there has been a sharp decrease in rural credits as a percentage of total. This credit out of total has fallen more rapidly than rural deposits out of total since after 1990 the percentage of rural deposits of total is larger than credit of total. Furthermore, this change in flow of rural credits and deposits has moved from a situation in 1990 where rural deposit and credit percentages out of total were roughly equal to today where the fall in rural credit of total to $9.5 \%$ is much sharper than deposits of total which today stand at $12.2 \%$. This is further confirmed by CD ratios that are $10 \%$ lower in rural areas than in urban areas, suggesting that rural deposits are flowing out of rural areas into non-rural credit. There are three explanations for this changing flow of funds. First, after the green revolution there was a general shift in development focus from rural areas and small-holder agriculture to urban-based manufacturing by the government in India as well as elsewhere. Trade and tax policies effectively discriminated against 
agriculture due to an urban bias (Lipton, 1977; Lipton and Eastwood, 2000) ${ }^{44}$ whilst the expectation that the withdrawal of state-originated credit would be offset by an influx of private funds did not materialise (WB, 1986). Fan et al (2005) found that the disparity in income between rural and urban areas is between 1.5-1.6, even after adjusting for cost of living differences. Meanwhile, Dhatta (2004) notes that in 2000, rural areas contributed to $27 \%$ of the GDP (mainly through agriculture) whilst it received in return about 5\% of GDP whilst rural expenditure per capita amounted to Rs 500 compared to urban per capita expenditure of Rs 915. Second, the end of social banking and the new emphasis on business profits made banks look to alternative revenue sources. Banks found a substitute to advancing funds for credit as a profitable business: investment. With few incentives to take on lending, banks, including the RRBs, began investing large amounts in Government bonds in order to meet profit targets. This was also how the relatively high and stable levels of credit flow to priority sector lending were achieved. However, since a recent injection of funds in the rural credit system and a curb on such investments, the CD ratios have increased again in the last few years. Third, the low CD ratio until recently is in part due to the lacklustre performance by banks' lending business, as evidenced by non-performing assets (NPAs) of rural regional banks in comparison with SCBs. Again, SCB's do not provide separate NPA data on their rural branches, but assuming that RRB's are a proxy for rural branches of SCBs it can be seen that despite a major reduction of NPA's over time, the percentage of NPA's in rural banks is substantially higher than in urban banks.

Table 4.5 Gross non-performing assets of total assets (\%) of SCBs and RRBs (sources: NABARD, 2008; RBI, 2008).

\begin{tabular}{|l|l|l|}
\hline & SCBs & RRBs \\
\hline 1996 & $7.0 \%$ & $34.0 \%$ \\
\hline 2001 & $4.9 \%$ & $18.3 \%$ \\
\hline 2004 & $3.3 \%$ & $12.6 \%$ \\
\hline 2007 & $1.5 \%$ & $6.5 \%$ \\
\hline
\end{tabular}

\footnotetext{
${ }^{44}$ Lipton (1997) argued that there was a clear urban bias that placed rural areas at a distinct disadvantage. The two gaps that already existed in income and output as well as efficiency of capital were widening. This was due to a cycle that started with low capital availability which caused low productivity in rural areas as farmers were unable to invest in improved production tools and techniques. This in turn resulted in low rural income which in turn lowered the capacity to save in rural areas. Of course low savings resulted in low capital availability. This gap was further widened by urban biased policies that suppressed rural prices in order to keep prices low in urban areas. The end effect, according to Lipton (1997), was that resources were transferred from rural to urban areas, and from the poor to the relatively less poor. More recently this rural/urban price differences have reduced, however the urban bias remains in the significantly larger public investments in goods, services and infrastructure in urban areas (Lipton and Eastwood, 2000).
} 
What this discussion suggests is that rural branches and banks appear to be doing significantly worse than their urban counterparts. They are in a worse shape in terms of profitability and undercapitalization, whilst NPA's constitute a much larger share of total rural bank assets than urban which suggests that many loans are unprofitable and should perhaps not have been sanctioned. Basu (2006) shows that in rural areas, up to $30 \%$ of rural regional banks are unprofitable, whilst a staggering $65 \%$ are undercapitalised. Scheduled commercial banks do not provide separate statistics for their rural branches, but if, as Basu (2006) suggests, it is true that RRBs is a close proxy for the state of rural bank branches or SCBs, these are high numbers.

Whilst rural branch expansion is much slower with many branches having closed or merged, those that operate tend to offer inferior services and technology compared to urban branches. Furthermore, the credit flow to small-scale borrowers from RRBs has been decreasing since the mid 1990's with credit falling 6.7\% between 1996 and 2003. ${ }^{45}$ This is particularly noteworthy for two reasons: firstly, the RRBs have, historically, had as their special remit to serve the rural poor, a majority of who borrowed up to Rs25000, and secondly, the decline in small-scale credit has occurred despite a re-classification of 'small loans' from below Rs25000, up to Rs200,000. This change can be traced to policy changes in the 1990's when RRBs, were able to participate in other bank business outside of the priority sector lending which had constituted its main target group. The RRBs were allowed to spend up to $60 \%$ of their credit on non target groups and increased the number of profitable banks from 24 out of 196 in 1990 to 164 of 196 in 2004 (Bose, 2004). The profitability was mainly due to non-credit activities and by 2003 interest from loan advances amounted to only $37 \%$ of total income despite a wider range of clients than previously, compared to interest on investment which amounted to $52 \%$ of total income. It was not only the RRB's policy of investing in their target groups under priority sector lending that got diluted to include richer and more profitable clients as well as investment activities. The priority sector lending policy itself was radically widened. Rather than a narrow focus on agriculture, small non farm sector business, artisans and weaker sections, it was broadened to include investments in venture capital and larger investments in small-scale industries classified as those whose investment in plant and machinery does not exceed Rs10,000,000. ${ }^{46}$ The result was not simply a flow of credit away from rural to semi-urban or urban areas, but also a flow of credit away from the poor and the micro and small-scale entrepreneurs.

That finance poses a real problem for entrepreneurs is confirmed by the 2006 World Bank Enterprise survey which found that finance was most likely to be a constraint among Indian enterprises employing 10 staff or less and /or operating in

\footnotetext{
${ }^{45}$ Bose, 2004, quoting RBI data.

${ }^{46}$ RBI: Priority Sector Lending guidelines
} 
traditional sectors (WB, 2006). Again this would be particularly likely to be the case in rural areas. If the average small-scale firm faces such constraints, it is reasonable to assume after the assessment of rural banking, that rural entrepreneurs, and crucially rural innovation, face much tougher financial constraints.

To suggest that banks (and bank managers) are simply unwilling to provide finance to innovative entrepreneurs in rural areas is too simple an answer. Firstly, some of this inability of banks to support new ventures can be explained as inertia and risk aversion. Banerjee, Cole and Duflo (2005), believe that there is considerable inertia in bank lending and use quantitative analysis to show that this is likely due to incentive issues having its roots in the perception that lending to growth enterprises and other unconventional or risky customers would increase the likelihood of being investigated for bad loans if the client defaults, as well as laziness and risk aversion. In fact, Nair (2006) finds that there is a serious lack of compliance with priority sector lending requirements and that this is likely due to the low threat that non-compliance fines pose. ${ }^{47}$ Secondly, the banking system is constructed in such a way that new and innovative initiatives at the local level are de facto discouraged because of the bureaucratic, hierarchical and inflexible nature of the system. This results in a risk averse and self protecting system where financing for unconventional or atypical investments or clients like the rural poor is difficult to obtain. Thirdly, the focus in recent years on profit maximisation by banks together with a widening of priority sector lending definitions have resulted in banks moving away from the prioritised sections to those that are 'safer' and more profitable. Finally, the poor as clients are considered risky by the banks because of the risk of default of rural households who live on the margin. However, microfinance has made substantial progress is proving that the poor are indeed bank worthy clients (Yunus, 1999).

Investments in small innovative firms and entrepreneurs are considered risky because there is an information gap. This lack of expertise and knowledge on the part of the bank results in the banks being unable to adequately assess such potential clients. In addition, the amounts required are often small which, according to the banks, increases the transaction costs in relation to the loan and potential bank profit. There is thus a need to narrow this information gap by obtaining information that such arm's length finance as banking cannot do as well as decrease the transaction costs. The next section will go on to look at alternatives to rural bank finance.

\subsection{A Non-Bank Alternative Financial Sector}

Outside of the bank system, the Government could be expected to provide rural finance schemes, where gaps exist and this is also the case in India. There are

\footnotetext{
${ }^{47}$ In fact some banks prefer paying the fine for non-compliance to risking taking higher losses from providing loans under the priority sector lending schemes.
} 
several schemes especially focussed on agriculture-related innovation such as the Ministry of Rural Development's Council for Advancement of People's Actions and Rural Technology (CAPART) which runs an 'Advancement of Rural Technologies (ARTS) scheme. There are also schemes for rural poor women such as the "Women in Science and Technology" scheme by the Department for Science and Technology that provide subsidised credit (without additional input or assistance) for e.g. machinery, fertilizers or seeds.

However, schemes rarely support entrepreneurs outside of the microfinance remit which, as has already been noted, is generally not conducive to enterprise growth or innovation. In fact, in recent years, microfinance and in particular microcredit based SHG-bank-linkage models have become immensely popular with government as well as financial apex institutions such as NABARD and SIDBI. The result has been that most discussions surrounding rural and pro-poor entrepreneurship and innovation rarely move beyond microfinance. At the other end of the spectrum, there are Government schemes that provide finance and support for innovation and entrepreneurship. However, generally the focus is on high-technology innovation and larger scale projects than the entrepreneur-based innovative activities that take place in rural areas. Examples of these schemes are the Department of Scientific and Industrial Research's Technopreneur Promotion Programme (TePP). However, within TePP there is a Micro Technopreneurship Support programme (TS) which invests up to Rs75000. Additionally, the related Council of Scientific and Industrial Research (CSIR) also focuses mainly on R\&D but offers a Technologies for Rural Sector Fund. Nevertheless, the programme most relevant to rural innovation is the Department for Science and Technology's Science and Society programme focussed on technologies for rural livelihoods. In addition DST set up the National Innovation Fund (NIF) in 2000. NIF has on the one hand been involved in setting up the Honeybee Network and the grassroots incubator GIAN together with SRISTI and IIM Ahmedabad. On the other it has worked with the apex institution SIDBI to set up a Micro Venture Innovation Fund (MVIF) in 2004, though its outreach has been limited so far. However, the problem with these programmes apart from the extensive bureaucracy involved, is that they are one-off project funds that are available for a set period and do not stretch beyond the implementation of an intervention. Since some government schemes are involved in assisting innovation and entrepreneurship and these are included in the discussion below.

In recent years an alternative financial sector has been emerging outside of the mainstream financial system which appears to, to some extent be making up for the lack of bank finance for innovative entrepreneurs in rural areas. Although microfinance is the best known type of non-bank finance and is flowing to rural areas, it does not necessarily support innovative entrepreneurship. A reason for this is the small amounts of the loans, often not amounting to more than Rs 10,000 . Additionally, microfinance institutions do not provide many other add-on services 
that make them different to banks, and often prefer proven business models to new kinds of investments that innovation finance would support.

On the other hand, the seed fund sector, which is to a large extent urban based, invests especially in innovative young ventures. However, much of such funding is spent on high-tech firms. Nevertheless to get an idea of the size of the sector, using measurements of the above sources of finance, it is estimated that microfinance was worth around Rs219,610,000,000 according to Sa-Dhan figures (including NABARD sponsored initiatives), whilst the seed funding sector was estimated to be worth around Rs1220-1,700,000,000 in 2006 (Dutz and Dahlman, 2007). Of course out of the seed funding sector only a very small amount reaches rural projects and entrepreneurs.

Despite its current size, this alternative financial sector is of interest because of the way in which it appears to overcome information asymmetries and perceived risks in order to invest in innovative entrepreneurs, and by extension innovation, that banks appear unwilling or unable to support. 
Table 4.6 Alternative sources of finance for pro-poor entrepreneur-based innovation in rural areas

\begin{tabular}{|l|l|l|l|}
\hline Innovation Initiatives & Gov & NGO & Private \\
\hline $\begin{array}{l}\text { DST's Technology Information, Forecasting and Assessment } \\
\text { Council (TIFAC)'s Home Grown Technology Programme (HGTP) }\end{array}$ & v & & \\
\hline DST's Science and Society Programme & v & & \\
\hline Council of Scientific and Industrial Research (CSIR) & v & & \\
\hline $\begin{array}{l}\text { Department of Scientific and Industrial Research's Techno- } \\
\text { entrepreneurs Promotion Programme (TePP) and Technology } \\
\text { Development and Demonstration Programme (TDDP) }\end{array}$ & v & & \\
\hline National Innovation Fund & v & & \\
\hline Grassroots Innovation Augmentation Network (GIAN) & (v) & v & \\
\hline $\begin{array}{l}\text { Society for Research and Initiatives for Sustainable Technologies } \\
\text { and Institutions (SRISTI) }\end{array}$ & & & \\
\hline Villgro (formerly RIN) & & $\mathrm{v}$ & \\
\hline Honey Bee Network & & $\mathrm{v}$ & \\
\hline Aavishkaar & & & $\mathrm{v}$ \\
\hline Acumen & & & $\mathrm{v}$ \\
\hline Micro Innovation Venture Fund (MIVF) & $\mathrm{v}$ & & \\
\hline Small-Scale Sustainable Infrastructure Development Fund (S3IDF) & & $\mathrm{v}$ & \\
\hline Ashoka & & $\mathrm{v}$ & \\
\hline ICICI Ventures & & & $\mathrm{v}$ \\
\hline SIDBI Schemes including Micro Venture Innovation Fund (MVIF) & $\mathrm{v}$ & & \\
\hline BASIX & & (v) & $\mathrm{v}$ \\
\hline SKS & & $\mathrm{v}$ & \\
\hline (Adapted from Singh Dhingra, 2007 in Dutz and Dahlman,2007) & & & \\
\hline
\end{tabular}

It is noteworthy that the organisations in this alternative finance sector provide different kinds of financial and non-financial services to different kinds of rural entrepreneur-based innovation. They are in other words recognising the heterogeneity of rural innovation and therefore provide complementary services that form an eco-system of financial support. This is quite a change from both MFIs and banks that instead have a tendency to provide similar models of support for the same range of customers. There are essentially three types of organisations: Government sponsored programmes and council schemes, private for profit investors and NGOs generally aiming towards sustainable operations but often with some way to go. These three organisational forms can be broadly categorised as firstly micro venture capital, secondly small-scale finance providers and finally grassroots innovators and incubators. 


\subsubsection{Micro Venture Capital}

Entrepreneurs are often technical experts and arms' length investors such as banks have problem in understanding the risks and possibilities in such investments which is where intermediaries such as venture capital have a role to play. These financial organisations either have in-house expertise or access to experts able to assess risks involved, and an ability to take firm-specific risk that banks avoid.

Venture capital is an important source of finance for new companies in developed countries and in India the sector has grown exponentially in the last few years. ${ }^{48}$ There have been plenty of domestic and international funds investing in urban high-tech growth enterprises in India. This bias towards larger investment amounts and already proven business models is partly due to the high transaction costs inherent in such investments. These costs are a major hindrance for early stage VC finance as the costs as a percentage of profit is much larger. Early stage finance, comprising seed funding of up to USD1,000,000 and start-up capital of USD2$3,000,000$, make up a small part of the industry. In 2005, early stage finance accounted for $4-6 \%$ of the total volume of venture capital, or $13 \%$ of the total number of deals (Dutz and Dahlman, 2007).

The Government is involved in early stage finance through the government sponsored early stage VC funds created in the 1990's that invest in the range of USD 0.5million-USD3million. Nevertheless, these funds still invest mainly in ventures that are already developed compared to those of the rural innovative entrepreneurs this chapter is considering. However, as noted above there is a fund that was set up in 2004 by the DST's National Innovation Fund together with SIDBI called the Micro Venture Capital Fund to bridge the financing gap for micro enterprises. However, the impact appears to be negligible, both on the financing gap and the policy towards the sector. SIDBI is in addition involved with another venture fund for SME's called SIDBI Ventures though it funds firms much larger than what this thesis is concerned with. So despite several venture funds, it seems government and apex institutions are not able to breach the financing gap.

An alternative to the early stage VC financing is the smaller seed funding stage comprising business angels such as Band of Angels and Seed Fund (Dutz and Dahlman, 2007). However, such investments are done on a small scale and generally out of reach for the rural innovative entrepreneurs. Generally, 'angels' are private investors that are not officially organised in associations. However, seed funding is closer to the funding requirements of entrepreneur-based innovation as regards the amount financed, the risk investors are willing to bear and the flexibility in terms that they may agree to.

Micro venture capital finance makes up a very small part of seed funding with only two or three funds currently in operation. The funds that do operate a dual

\footnotetext{
48 See Mani (2009) for a recent overview of venture capital and angel financing in India for knowledge-intensive entrepreneurship.
} 
bottom line approach to venture capital such as Seedfund and Aavishkaar combine funding models of classical VC but adapted to maximise social as well as financial sides. The funds provide hands-on non financial support alongside the financial investment. Such funds manage to operate in the alternative financing areas and take larger risks than classical VC, expect lower returns and expect these returns to take longer to materialise. To mitigate risk, this type of fund is often heavily involved in managing the investee companies, tend to take a large shareholding and sit on the board. The funds use different instruments or a different combination of instruments than $\mathrm{VC}$, for example royalty rather than equity, equity debt hybrids or offer loans on top of the non-debt investment.

\subsubsection{Small-Scale Finance Providers}

There are two types of financial organisations that provide small-scale entrepreneur support. Firstly there are microfinance institutions. ${ }^{49}$ As noted previously, microfinance amounts are often too small to be used for the intended (productive) purposes, such as upgrading an existing venture, as well as for their lack of non financial support. This is where rural small-scale growth entrepreneurs face a severe financial constraint. However, some MFIs, notably BASIX, a livelihood finance provider, and SKS, are using financing models that go beyond the traditional microfinance funds to support small-scale entrepreneurs as an alternative investment opportunity in rural areas. These MFIs provide larger grants coupled with non-financial support for rural ventures that promise increased employment opportunities for the poor. Already established in rural areas, MFIs have an advantage in local networks and understanding the risks of a potential investment.

Outside of the microfinance movement, there are other organisations involved in financing rural entrepreneurs or infrastructure in villages, often with a specific remit such as environmental sustainability. Financial organisation such as S3IDF work together with local NGOs to provide basic infrastructure services in rural areas and train local entrepreneurs to take charge of the projects or services. Although finance is the primary service, the organisations provide additional services to link the technology with finance, suppliers and markets in order to root the technologies or projects in the local community. S3IDF is also a good example of an organisation that uses different kinds of financial instruments, such as credit risk guarantees in order to encourage banks to lend to local entrepreneurs. ${ }^{50}$ Another example is Ashoka, a worldwide organisation with an office in India that supports

\footnotetext{
${ }^{49}$ The most common microfinance model in India is the Self-Help-Group (SHG) model in which credit is lent to a small self-formed village group. A reason for the strong prevalence and popularity of the SHG model is that it relies on the already existing rural banking system which was already well built up in rural areas (Basu and Srivastava 2005).

${ }^{50}$ S IIDF provides a bank with a credit risk guarantee of $25 \%$ of the value of the loan in order to lower the perceived risk of the entrepreneur so that the bank is willing to lend.
} 
entrepreneurs with socially relevant ideas, and builds general capacity through its research on pro-poor entrepreneurship.

\subsubsection{Grassroots Innovators and Incubators}

At the grassroots level, there are two types of rural innovation support models that support innovation and existing knowledge, practices and resources. Firstly, there are organisations that themselves identify issues in rural areas that can be solved with the help of new and appropriate technology or new innovative ways of organising production, reaching markets or using natural resources. Such organisations essentially innovate for the poor. Basing their work on needs and problems of the poor and the resources at hand, these organisations create new technologies or adapt existing technologies. In addition they provide extensive nonfinancial support in implementing small-scale business models in, for example, fruit processing. This kind of model needs grants for the early stages of preliminary studies and setting up projects, forming groups and building up the local institutions. However, as the intervention matures it is managed by the poor themselves and sustained through profits from sales revenue, whilst bank loans are accessed (with the help of the organisation) for additional scaling up and investment. The Government's Department of Science and Technology is involved in grassroots innovation support through its Science and Society Programme, whilst non-governmental organisations include, for example, those connected through the All India People's Science Network, and Delhi based Centre for Technology Development.

A second type of grassroots organisations acts as incubators for rural entrepreneurs with exciting ideas. Here too limited financial support is provided as well as the facilities to test an idea, to build a prototype, to research markets and to establish a network of contacts. The focus is on creating a viable venture around the new product or service. There are essentially two forms of organisations involved in rural incubation: governmental and non-governmental. The Department for Science and Technology has been involved in rural innovation through its incubator Grassroots Innovation Augmentation Network (GIAN) together with IIM Ahmedabad. DST was also involved in the Honey Bee Network which collects and documents new rural inventions and the Society for Research and Initiatives for Sustainable Technologies and Institutions (SRISTI). SRISTI is in addition involved in GIAN. On an international level, the World Bank has recently started incubator programmes in India through its InfoDev initiative though it focussed specifically on (pro-poor) incubation in the ICT related area.

\subsection{Conclusion}

This chapter found that the Indian bank system does not efficiently support rural pro-poor innovation. Though there is finance in the system and even credit 
specifically allotted to the rural poor and entrepreneurs, banks are unwilling to lend. Instead, there is a decrease of credit in rural areas and a decrease in credit towards small and micro enterprises. In fact, the chapter suggests that there is a flow of credit from rural to urban areas. Even where schemes are in place to specifically provide credit for the rural poor or entrepreneurs banks often prefer non-compliance. Alternatively, their funds flow towards what they perceive to be the least risky alternative such as investments in government funds or the largest enterprises allowed under priority sector lending rules.

There are several funds set up by the government to deal with the financing gap but so far they have had little impact. Instead an alternative financing sector has been emerging recently. There are three broad categories of organisations in this sector: micro venture capital funds, small-scale finance providers, and grassroots innovators and incubators. The discussion of the alternative financing sector suggests that there is a move away from microfinance and self-help groups as the solution to rural pro-poor finance among these organisations. Instead the focus is on how to support rural ventures, entrepreneurs and innovation. An eco-system of different innovation support has sprung up- including finance, rather than exclusively relying on finance. There is a recognition that there are different kinds of needs within rural areas. For example, those involved in grassroots innovation support work differently to those supporting innovation through micro scale venture capital. These organisations are supporting rural innovation but at different extremes, for different kinds of entrepreneurship with different mechanisms or instruments of support. Together they complement each other and form a system of finance for different types of rural innovation. Furthermore, what these organisations have in common is an integrated or holistic approach to support which includes both financial and non-financial assistance.

To further explore this alternative finance sector at the periphery of the financial system, the next three chapters will look at five case studies in-depth. The organisations on which the case studies are based are all active in the alternative financial sector but in different ways and supporting different kinds of rural PEBI. Together they represent the three categories mentioned above. 


\section{Case Studies \# 1: Micro Venture Capital}

In chapter four the nature of the Indian banking system was outlined. It was found that credit has been flowing out of rural areas and into urban areas, whilst credit in addition has been shifting from smaller to larger investments. The result is a banking system that appears to have access to finance but where finance does not reach pro-poor entrepreneur-based innovation, at least from the core banking institutions. However, the chapter concluded by noting three groups of an alternative financial sector outside of the core system, that were able to finance PEBI in alternative ways. The next three chapters will shift the focus to these organisations located at the periphery of the financial system, and how they are financing PEBI.

Using the groups of alternative financing sources identified in chapter four as a departure point, the next three chapters detail five case studies of organisations. The case studies demonstrate how financial and non-financial services can be provided in a range of different ways. The first group, detailed in chapter 5, which closely mimics venture capital tools and strategies, is represented by Aavishkaar, a micro venture capital fund based in Mumbai and focussing on entrepreneurs and small firms providing new innovative products and services for rural areas. The second group, detailed in chapter 6, are closer to banks in their features and main focus on credit as their financial instrument of choice. The group, named small-scale finance beyond microfinance, is exemplified by two organisations: BASIX, a livelihood finance provider which provides a range of financial and non-financial services for rural poor as well as rural non-poor entrepreneurs; S3IDF which operates as a social merchant bank, builds and supports small-scale entrepreneur-driven infrastructure projects in rural and semi-urban areas. The final group, which makes up chapter 7 , called rural incubators and innovators, is especially concentrating on a range of non-financial support by either being an originator of the innovation process in rural areas, or incubating rural inventions coming out of rural areas. The Centre for Development Studies creates new or adapted technologies within complete business 
models, using existing resources and skills, for disadvantaged communities in rural areas. The Villgro, on the other hand, scouts existing inventions in rural areas and incubates and commercialises these, by for instance focussing on the entrepreneurial skills needed, building prototypes and assisting in creating business plans.

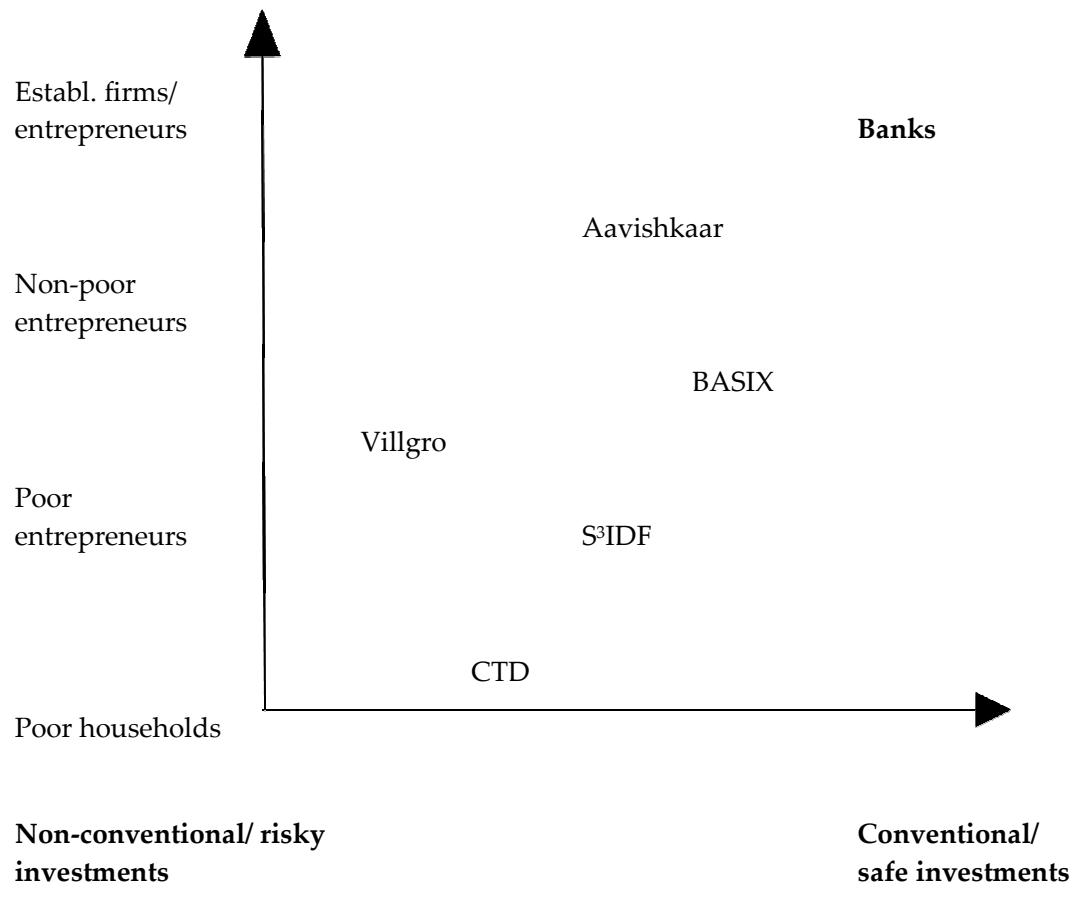

Figure 5.1 Case study organisations at the periphery

Each case study is structured in the same way. First there will be a general introduction to the organisation, its mission, organisational structure and business, how it is funded and finally an overview of its portfolio. Secondly, the focus turns to the particular support package, or model, that the organisation provides, including investment (pipeline) sourcing, financial support, non-financial support and monitoring. The third section details two particular investments or projects that highlight how the organisation works. Finally, the concluding section discusses performance, successes and challenges.

\subsection{Aavishkaar}

As noted in chapter 4, venture capital is an important source of equity financing for start-ups in high-tech industries. A smaller scale version of such risk capital, primarily investing through equity, has recently been emerging within pro-poor 
financing. ${ }^{51}$ Such social, or micro, venture capital ${ }^{52}$ funds use classic venture capital funding models, adapted to maximise social benefits alongside profit, to invest in small-scale ventures or entrepreneurs that provide products and services for the base of the pyramid. As with standard VC, these organisations provide nonfinancial support alongside the financial investment. Furthermore, the investment is conditioned on a number of milestones that must be achieved for the release of funds.

These micro venture capital firms target entrepreneurs and small firms with growth potential, that have, generally, already generated a prototype that can be further developed and commercialised. Micro venture capital funds are generally the first firms to invest in the business and will therefore take a relatively large stake. In India Aavishkaar India Micro Venture Capital Fund has been pioneering the social venture capital model, investing in small businesses providing products and services in rural India.

\subsubsection{Avishkaar53 the Organisation}

\section{Background, Mission and Objectives54}

Aavishkaar is a Mumbai based micro venture capital fund that explores rural social opportunities and looks to strengthen the innovation-financing-commercialisation chain. More concretely, Aavishkaar, established in 2001, invests in entrepreneurs that combine sound business and financial aims with social objectives and a rural focus. By providing entrepreneurial capital and expertise it seeks to empower local entrepreneurs and enterprises (Nageswaran, 2003:11). Specifically, Aavishkaar looks to provide venture capital to sustainable, socially relevant commercial ventures that are unable to find financing within the mainstream system.

\footnotetext{
${ }^{51} \mathrm{VC}$ funds use a number of different instruments such as royalty, equity, equity debt hybrids and debt.

52 Social venture capital refers to venture capital that is socially responsible. One type of social venture capital is micro venture capital which invests amounts that are much smaller than standard venture capital into businesses that are deemed too risky to access debt financing through banks.

53 The data are based on interviews on the $19^{\text {th }}$ October, 2007 with Vineet Rai, Founder and Director, and two Investment Managers; the Aavishkaar website, www.aavishkaar.in, accessed on 11 September, 2007, 10 August, 2008 and 21 November, 2009; Internal memos including a portfolio overview and overview of the social impact of investment, both from 2007 and a funding communication memo; Press Release on Financing, 29 August, 2007; a Venture Fund brochure from 2007: Conference Paper on Aavishkaar by then board member Dr. Anantha Nageswaran (2003), Investing for Sustainable Growth: The Aavishkaar Experiment for Sustainable Financing, presented at the Congress with Innovation Fair on Sustainable Management in action at the University of Geneva, September 2003; A study by the Ford Foundation's CFED SME small Grants Programme called Aavishkaar India Micro Venture Capital Fund published by Ford on 31 May, 2007.

${ }^{54}$ The information in this paragraph stems from the Aavishkaar website accessed 11 September, 10 August, 2008 and 21 November, 2009; Interviews on 10 October, 2007 and Nageswaran (2003).
} 
At the time of fieldwork, the company had no direct competition, having positioned itself uniquely in the large gap between traditional venture capital and microfinance. ${ }^{55}$ Since Aavsishkaar takes an equity stake in a company, it seeks to achieve a commercial return for its investors. At a policy level, Aaviskaar aims to be a successful financier of pro-poor innovation in order to demonstrate that micro venture financing is commercially viable whilst fulfilling social goals. ${ }^{56}$ To do so, Aavishkaar set out to be a "catalyst for positive change" by "nurturing ventures into enterprises". ${ }^{57}$ This idea stems from personal experiences the Aavishkaar founder, Vineet Rai, had from working at the Gujarat Grassroots Innovations Augmentation Network (GIAN), which supports small rural enterprises. He noted that because financial institutions found early stage or seed funding finance too risky, the ensuing lack of risk capital was a real bottleneck in the 10 000-100 000 dollar range.

Aavishkaar works with external actors from two sectors- the NGO sector including BASIX ${ }^{58}$, with whom it runs a fund, and Villgro ${ }^{59}$, which provides potential investment deals, as well as the corporate sector. Aavishkaar does not, however, work with academics to any great extent. The investment committee and advisory board play an important role in providing links to potential experts or partners. It is also through these boards that some of the potential deals, the pipeline, reach Aavishkaar. In general the committee and board members act as mentors and experts to Aavishkaar and lend credibility to the business, especially at the earlier stage, before it had achieved additional rounds of funding. Though Aavishkaar does not work in partnership with banks, it has other indirect links with the core financial system through its boards on which sits members of the core financial system organisations. Further links are created through co-financing rounds with external funds, such as Seedfund (see the case on Vaatsalya) which is closer to conventional venture capital and the core than is Aavishkaar.

\section{Organisational Structure $e^{6 o}$}

The Aavishkaar board includes its founder and CEO Vineet Rai, Pradeep P and Dutch social financier Wim van De Beek who runs the Dutch microfinance fund Goodwell that Aavishkar has partnered with. Aavishkaar's Investment Team is headed by a CEO (and founder Vineet Rai) and was in 2007 assisted by two investment managers and three investment associates. ${ }^{61}$ The team sources potential deals, undertakes due diligence, evaluates projects, prepares investment reports for

\footnotetext{
${ }_{55}$ Aavishkaar website: www.aavishkaar.in accessed 10 August, 2008

56 As noted in Aavishkaar Brochure, 2007 and Nageswaran, 2003:11

57 Slogans from Aavishkaar's website, accesses 10 August, 2008 and 21 November, 2009.

58 One of the case studies in this thesis, detailed in chapter 6.

${ }^{59}$ One of the case studies in this thesis, detailed in chapter 7.

${ }^{60}$ Data from interviews, 19 October, 2007; Aavishkaar website accessed 21 November, 2009.

${ }^{61}$ Aavishkaar had by November 2009 grown to include an investment team of nine people headed by Vineet Rai. The team manages three funds.
} 
the investment committee, monitors and mentors investee companies and evaluates and reports on progress towards commercialisation and / or exit. An Investment Committee, comprised of experienced practitioners in the fields of venture capital, development, business and finance, takes decisions on investment on behalf of Aavishkaar. In addition it has a strong advisory role in all things relating to investments both leading up to, and following deals. The Committee holds an important role in managing the amount of risk Aavishkaar takes on. ${ }^{62}$

The Advisory board, which includes experts in Venture Capital, Finance and Development, acts as an additional check on the activities of the fund. Both the investment and advisory boards contribute with important networks both in terms of deals, expertise and opportunities.

Finally, the fund management company of Aavishkaar, Aavishkaar Venture Management Services, is headed by Vineet Rai and the managing partner of the microfinance fund Aavishkar Goodwill, Win Van Der Beek among others. There are thus three tiers, as is the standard for a Venture Capital firm: Investment Committee, Advisory Committee and a Fund Management company.

Due to low staff numbers and financial limitations, Aavishkaar chose a simplified one tier structure to begin with, having only a fund management company. Once the concept of equity investments had been proven to work successfully, more investors and sectoral and business experts were willing to come on board and the company was able to expand to the standard VC three tier structure. The main incentive for putting a more complicated structure in place was to attract further investment. ${ }^{63}$ When Aavishkaar began operations there were no other existing micro venture capital firms like it. Therefore, Aavishkaar chose to start small and to evolve and grow as it was learning from its experience- learning by doing.

\section{Activities64}

By 2009, Aavishkaar was running three funds: Aavishkaar India Micro Venture Capital Fund (AIMVCF) created in 2001; Aavishkaar-Goodwell India Microfinance Development Company which invests in microfinance organisations, created in 2008; and BYST Growth Fund which invests in socially disadvantaged entrepreneurs, also created in 2008. Since the fieldwork took place in 2007, and the focus is on the entrepreneurs that the venture capital fund supports, this case study will focus solely on Aaviskaar India Micro Venture Capital Fund and will be generally referred to as Aavishkaar.

The Aavishkaar India Micro Venture Capital Fund (Aavishkaar India) is based in Mumbai under a Foreign Investment Promotion Board of the Government of

\footnotetext{
62 FORD, 2007:14

${ }^{63}$ Interview on 19 October, 2007.

${ }^{64}$ Aavishkaar website downloaded on 10/08/08 and 21/11/09.
} 
India approval. It is a 'for profit' Trust registered and regulated by the Securities and Exchange Board of India. Furthermore, given the stringent regulations in India in relation to setting up investment companies with foreign investors, a holding company based in Singapore called Aavishkaar International Private Limited (AIPL) ${ }^{65}$ was created to attract international investments. The Singaporean entity initially attracted investment from international venture capital investors, which was subsequently invested in Aavishkaar India. However, in the last rounds, investments have been made directly in the India-based Aavishkaar fund. ${ }^{66}$ The Aavishkaar India fund initially made investments between USD 20000 - 100000 , but by 2007 the investment target had shifted to a range between USD 50 000- USD $500000 .{ }^{67}$

\section{Funding ${ }^{68}$}

Initially Aavishkaar's funding originated from investments made in its Singaporean Holding company. These initial USD 1.4 million included substantial funds from family and friends. However many institutional investors have come on board since, and in 2007 Aavishkaar closed a round of funding which took the total fund up to a value of US\$6 million with investments from NABARD, CORDAID (a Dutch NGO), CEP Investment Trust Fund (Canadian social entrepreneurship fund), ENAM Capital (an Indian financial services company) and Lasing Nominees. By 2007 international banks and the VC community had shown interest and by January 2009 a second round closed at USD 14 million. Here Aavishkaar links with the core financial system, as it relies on the core as a source of capital for its fund. These investments are made both in the Singaporean Holding company and directly into Aavishkaar India. Indian based funding sources include individuals and institutions, with or without an emphasis on social aspects, investing in Indian companies. Non-Indian investors are mainly institutional investors.

Since Aavishkaar seeks to be financially sustainable, it mimics venture capital funds in taking a management fee to pay for operational and management costs of the deal sourcing and evaluation process. The management fee is a set percentage of the total investment in a portfolio company. ${ }^{69}$

\footnotetext{
${ }^{65}$ AIPL is purely a holding company and entity to attract international investment which flows to the Indian based entity and does not invest directly in entrepreneurs and will not be further mentioned

${ }^{66}$ Aavishkaar Brochure, 2007.

${ }^{67}$ Interview on 19 October, 2007.

${ }_{68}$ This paragraph refers to the AIMVCF fund only. The data stems from memos about funding, website accessed 21 Novermber, 2009, unless stated otherwise.

${ }^{69}$ Ford, 2007
} 
Finally, Aavishkaar aims, according to internal funding memos, for investment returns for its investors of around $12-15 \%$ IRR over a 10 year investment horizon, ${ }^{70}$ something that it had successfully achieved in two exits by 2010.

\section{Portfolio $^{71}$}

Aavishkaar, which is based out of offices in Mumbai and Bangalore, had undertaken nine investments at the time of the fieldwork in 2007, with an additional seven investments having been undertaken in 2007-2009. It invests in

"product and service providers in rural and semi-urban India that have positioned a social return within an overriding commercial business model" (Brochure, 2007).

Aavishkaar's investments are geographically centred in South and West India. This is because hands-on support is most easily provided to those close to the office or close to already existing portfolio companies. There are also economies of scale to be had by restricting the geographic reach as support on a firm-by-firm basis is expensive. Equally, the sectors in which Aavishkaar invests tend to be concentrated due to the potential synergies and existing experience, network and expertise. Currently, it is investing in rural innovation and development technologies, renewable energy, handicrafts, health and education. Furthermore, there is a wide diversity in the types of ventures Aavishkaar is investing in, especially compared to classical venture capital firms which tend to be more narrowly focussed sector-wise and more organisationally homogenous. Within Aavishkaar's portfolio, organisations range from high-tech firms (Vortex) and wholesaler (Naveen Gram) to more support or NGO influenced organisations (Rangsutra) and larger scale health service provider (Vaatsalya).

\footnotetext{
70 Aavishkaar Fund memo

${ }^{71}$ Information in this section comes from internal memos from 2007, Aavishkaar website accessed 10 August, 2007 and 21 November, 2009; memo of Portfolio, 2007, and this has been substantiated by FORD, 2007.
} 
Table 5.1 Aavishkaar's portfolio as of October, 2007

\begin{tabular}{|c|c|c|c|c|c|}
\hline $\begin{array}{l}\text { Portfolio } \\
\text { Company }\end{array}$ & Sector & Description & Year & \begin{tabular}{|l} 
Investm. \\
(\$)
\end{tabular} & Social Impact \\
\hline $\begin{array}{l}\text { Servals } \\
\text { Automat- } \\
\text { ion Private } \\
\text { Ltd }\end{array}$ & \begin{tabular}{|l} 
Energy/ \\
Sustainable \\
Technology
\end{tabular} & $\begin{array}{l}\text { Produces rain guns } \\
\text { and kerosene burners, } \\
\text { and out to other rural } \\
\text { energy solutions }\end{array}$ & 2002 & Rs 18000 & $\begin{array}{l}\text { Decreases the use of } \\
\text { kerosene and makes } \\
\text { water use more } \\
\text { efficient }\end{array}$ \\
\hline SKEPL & $\begin{array}{l}\text { Agri/Rural } \\
\text { Innovation }\end{array}$ & $\begin{array}{l}\text { Computer equipment } \\
\text { for milk analysis and } \\
\text { collection }\end{array}$ & 2003 & Rs 40000 & $\begin{array}{l}\text { Improves the analysis } \\
\text { of milk before sale, } \\
\text { providing accurate } \\
\text { data on what farmers } \\
\text { should be paid }\end{array}$ \\
\hline $\begin{array}{l}\text { TIDE } \\
\text { Technocrat } \\
\text { s } \\
\end{array}$ & $\begin{array}{l}\text { Energy/ } \\
\text { Sustainable } \\
\text { Technology } \\
\end{array}$ & $\begin{array}{l}\text { Renewable energy } \\
\text { services provider }\end{array}$ & 2003 & & $\begin{array}{l}\text { Provides electricity in } \\
\text { rural India and trades } \\
\text { in carbon }\end{array}$ \\
\hline $\begin{array}{l}\text { Craftsbri- } \\
\text { dge }\end{array}$ & $\begin{array}{l}\text { Arts and } \\
\text { Handicraft }\end{array}$ & $\begin{array}{l}\text { Orders local handicraft } \\
\text { and resells to } \\
\text { companies }\end{array}$ & 2004 & Rs 70000 & $\begin{array}{l}\text { Improves the market } \\
\text { for rural artisans }\end{array}$ \\
\hline N-Syst & $\begin{array}{l}\text { Technol. } \\
\text { Innovation }\end{array}$ & $\begin{array}{l}\text { Builds computer } \\
\text { software assessing the } \\
\text { user friendliness of IT } \\
\text { for disabled people }\end{array}$ & 2005 & \begin{tabular}{|l|} 
Rs 3 000 \\
000
\end{tabular} & $\begin{array}{l}\text { Enables disabled } \\
\text { people to access the } \\
\text { internet and computers } \\
\text { in general }\end{array}$ \\
\hline $\begin{array}{l}\text { Naveen } \\
\text { Gram }\end{array}$ & $\begin{array}{l}\text { Agri/Rural } \\
\text { Innovation }\end{array}$ & $\begin{array}{l}\text { Re-sells products in } \\
\text { rural India }\end{array}$ & 2005 & $\begin{array}{l}\text { Rs } 1500 \\
000\end{array}$ & $\begin{array}{l}\text { Provides products to } \\
\text { small rural businesses } \\
\text { and populations }\end{array}$ \\
\hline $\begin{array}{l}\text { CK } \\
\text { Technologi } \\
\text { es }\end{array}$ & $\begin{array}{l}\text { Technol. } \\
\text { Innovation }\end{array}$ & $\begin{array}{l}\text { Creates software in } \\
\text { local non-English } \\
\text { languages }\end{array}$ & 2006 & Rs 100000 & $\begin{array}{l}\text { Provides IT access to } \\
\text { those that don't speak } \\
\text { English -such as the } \\
\text { rural poor }\end{array}$ \\
\hline Vortex & $\begin{array}{l}\text { Technol. } \\
\text { Innovation }\end{array}$ & $\begin{array}{l}\text { Creates cheap rural } \\
\text { ATMs }\end{array}$ & 2006 & & $\begin{array}{l}\text { Increases access to } \\
\text { finance by providing } \\
\text { ATM's in rural areas. }\end{array}$ \\
\hline Vaatsalya & Healthcare & \begin{tabular}{|l} 
Provides affordable \\
healthcare by \\
establishing rural \\
healthcare system. \\
\end{tabular} & 2006 & $\begin{array}{l}\text { Rs7 500 } \\
000\end{array}$ & $\begin{array}{l}\text { Provides medical } \\
\text { services in rural areas. }\end{array}$ \\
\hline $\begin{array}{l}\text { Rangsutra } \\
\text { Crafts } \\
\text { India }\end{array}$ & $\begin{array}{l}\text { Arts and } \\
\text { Handicraft }\end{array}$ & $\begin{array}{l}\text { Supports textile } \\
\text { artisans from remote } \\
\text { areas with design, } \\
\text { product development, } \\
\text { planning and finance } \\
\end{array}$ & 2007 & & $\begin{array}{l}\text { Improves the } \\
\text { businesses or remote } \\
\text { rural artisans and } \\
\text { develops rural Indian } \\
\text { craftmaship. }\end{array}$ \\
\hline $\begin{array}{l}\text { Desert } \\
\text { Artisans } \\
\text { Handicraft } \\
\text { s }\end{array}$ & $\begin{array}{l}\text { Arts and } \\
\text { Handicraft }\end{array}$ & $\begin{array}{l}\text { Outsourcing firm } \\
\text { creating an innovative } \\
\text { intermediary model } \\
\text { that aggregates rural } \\
\text { artisans }\end{array}$ & 2007 & & $\begin{array}{l}\text { Ensures fair price and } \\
\text { market access }\end{array}$ \\
\hline
\end{tabular}

Aavishkaar invests on average USD 70000 and normally its investment is the first that the portfolio companies receive. In 2007, over half the investments had been made since 2006, with the average investment size increasing over time. Aavishkaar had by 2007 evolved from making investments between USD 20 000-100 
000 in the early years to USD 50 000-500 000. This, Aavishkaar says, is due to various factors such as inflation, rural integration in the world economy and the fact that the idea of what 'micro' investment has changed. It is also because the team found that the impact was higher when they were able to offer substantial financial backing. Furthermore, the risk and investment profile was shifting from smaller investments for larger stakes to larger investments for smaller stakes (Ford, 2007:20), suggesting that the overall risk on the portfolio was reducing. For instance, Aavishkaar invested USD 40000 for a $49 \%$ stake in Servals, its first investment in 2002, whilst in 2007 it invested USD 70000 in Craftsbridge for $15.69 \%$ stake. The shift in funding pattern has occurred at a time when pro-poor entrepreneur-based innovation has been gaining increased attention as more and more new firms look to mix social aspects with a commercial focus. So it can be expected that the quality of ventures engaged in PEBI may be increasing as more business-minded entrepreneurs cross over to social enterprises. This is important because as the perceived overall risk is falling, more external investors, including those from the core, come on board. Furthermore, Whilst there had been no exits at the time of fieldwork, by 2010, there had been one partial exit from Servals and one from SKEPL.

Finally, it should be noted that there are clear social effects from the investments Aavishkaar is making, from non-English speaking people accessing information online (CK Technologies) and hospitals in previously underserved areas (Vaatsalya) to improved electricity access (TIDE) and networks and support for rural artisans to improve their livelihoods (Rangsutra and Desert Artisans). In this way, Aavishkaar is able to have a poverty alleviating impact without investing micro amounts directly in poor people. Instead it chooses to make fewer but substantially larger investments in ventures that are expected to have a significant impact on the poor. Nevertheless, despite the centrality of the social objectives of its mission, Aavishkaar is keen to shake off the tag of 'social' investor or 'social' enterprise. It is a micro investor investing in small commercially minded ventures that, like the fund itself, believes that social objectives should be integral to any commercial venture. In this idealised world, there should be no need for 'social' specific ventures since all business would have social elements to some extent.

\subsubsection{The Support Model at Aavishkaar}

Aavishkaar provides financial input in the form of equity as well as some additional debt financing and non-financial input in terms of strategic advice, business development, capacity building, networking and management support. ${ }^{72}$ The aim of this support package is threefold. By acquiring equity finance, the portfolio companies are able to grow their business and attract additional growth financing. Secondly, the business development and networking increases potential sales and

\footnotetext{
72 This part is based on Ford, 2007: 8.
} 
profitability. Finally, management training including cost/benefit analysis, organisational structure, business strategy and management increases efficiency, whilst the adoption of formal accounting rules increases accountability, transparency and efficiency, making them more attractive for external financiers and improving their ability to plan effectively for the future. As part of a sustainable model, Aavishkaar looks to provide an 'exit' strategy ${ }^{73}$ for their portfolio companies. Traditionally, venture capital exits rely to a large extent on public listing of the portfolio companies or alternatively large buy-out schemes. Aavishkaar however, as a very early stage micro VC emphasises the possibility for company promoters to buy back shares, for mergers, take-overs and further financial investments from larger venture capital funds. ${ }^{74}$

Aavishkaar manages the risk of its portfolio in three ways. By specializing in certain geographical locations or specific sectors in which they have expertise; by clearly focusing on entrepreneurs rather than inventors in order to maximize business potential; and by asking promoters of the portfolio companies to put in some money as co-financiers to show clear commitment, and as a security.

\section{Deal Source, Decision Making and Due Diligence 75}

Aavishkaar previously received a majority of its investment opportunities through its website where entrepreneurs approached the organisation through an on-line form. Despite not actively advertising for the website, Aavsihkaar has been receiving on average three to four prospective plans every week since 2006. However, Aavishkaar found that the average quality of proposals was poor; often lacking a coherent and thought out business plan for example, so, as a consequence, by 2007, it decided to prioritise proposals that were referred to them from within its existing network, which is comprised of four types of sources. First, Aavishkaar relies on referrals from the senior team including the CEO and the senior project managers who all have extensive networks from years of experience of working with grassroots innovation in India. Second, Aavishkaar has signed Memoranda of Understanding with various organizations such as the Indian System of AgriBusiness professionals, Ashoka, the Infrastructure Development Finance Corporation, and Villgro (the incubator which is detailed in 7.2.). These organizations send on to Aavishkaar proposals or leads they have received that are not suitable for their own investments. Third, Aavishkaar receives proposals through referrals from its Board and Investment Committee as well as its network

\footnotetext{
${ }^{73} \mathrm{An}$ 'exit' is a way for Aavishkaar to recover its investment (preferably with a profit) in a portfolio company once it has received all the financial and non-financial support and no longer forms part of its ongoing portfolio.

${ }^{74}$ Information on exit from the Aavishkaar Brochure

75 The data in this paragraph stems from Interviews on 10 October, 2007: Avishkaar, 2007 Brochure and Ford, 2007.
} 
of external contacts. Fourth, entrepreneurs that work in existing portfolio companies or who are in other ways already involved with Aavishkaar refer proposals.

In the past, when proposals were unsolicited, the business plan aspect was often seriously deficient. Aavishkaar therefore spent considerable resources developing business plans. Now however, applicants are better prepared and they are all expected to provide a ready business plan as part of the application package. Though Aavishkaar does not outright reject a proposal which does not have a good business plan, a poor plan is considered a major deficiency and venture may be asked to re-apply with an improved plan. This differs from the earlier days when Aavishkaar would help develop the plans themselves, and is in part due to the increased competition for funding, which has driven the average quality up, as well as the shift by Aavishkaar towards larger investments which, as a consequence, has seen it attract more mature ventures and better thought out proposals.

Aavishkaar evaluates the social and commercial/financial prospects of a potential investment thoroughly. Whilst the social side of the evaluation lacks formal methods and is focused on 'getting a feel' for the social potential, the commercial side is taken through formal venture-capital-style due diligence.

The investment screening is a four step process. At the first step, the programme team decides whether a potential investment is worth looking into more thoroughly. A decision to go ahead or not is taken by the Fund Manager.

Table 5.2 Initial stage investment criteria (adapted from FORD, 2007).

\begin{tabular}{|l|l|l|l|l|l|}
\hline Commercial/Financial & $\begin{array}{l}\text { Cost } \\
\text { efficient }\end{array}$ & Growth potential & $\begin{array}{l}\text { Commercial } \\
\text { viability }\end{array}$ & \multicolumn{2}{|l|}{} \\
\hline Social & $\begin{array}{l}\text { Socially } \\
\text { relevant }\end{array}$ & $\begin{array}{l}\text { Environmen1tally } \\
\text { friendly }\end{array}$ & Entrepreneurial & $\begin{array}{l}\text { Mission } \\
\text { driven }\end{array}$ & $\begin{array}{l}\text { Creation } \\
\text { of } \\
\text { returns }\end{array}$ \\
\hline
\end{tabular}

At a second stage, a more in-depth evaluation is prepared and presented by the team to an Investment Committee which considers the business opportunity and risk of the investment. Emphasis is put on the ability of the entrepreneurs in terms of leadership and business skills as well as on the financial prospects of the business. The third stage involves a more thorough due diligence procedure of technology, financial and market aspects of the proposition as well as operational and exit strategies. Decision on whether to invest as well as details of such a potential deal is taken by majority voting of the Investment Committee. ${ }^{76}$ If the goahead is given the final stage of external due diligence by auditors and legal firm takes place. The time it takes for getting through this process varies from 45 days up

${ }^{76}$ FORD, 2007 
to a year (for Naveengram and CK Technologies respectively). ${ }^{77}$ The investment process provides opportunities for Aavishkaar to acquire a good understanding of how the potential investee company operates, its opportunities within the sector, its management and risk profile. Aavishkaar is therefore in a position to offer very tailored support whilst also assuring itself that the investee company's interests and aims are aligned with those of Aavishkaar.

\section{Financial Support ${ }^{78}$}

By 2007, Aavishkaar had invested between USD 50000 and USD 700 000, but on average, USD 70000 per project. The main tool that Aavishkaar uses for investment is common equity, thus taking a stake in the new company. In addition, for some projects the organisation has provided debt for working capital expenses. The structure of the fund does, in principle, permit Aavishkaar to use other equity-based tools such as preferred redeemable, quasi-equity, preferred convertibles, mezzanine loans and royalties, though up to 2007, these had not been used.

Sometimes all the funding is put in at once, though generally the investment is put in at separate stages as the company fulfils certain milestones, or partial goals, as set out in the investment agreement. This is done in order to minimize risk and to align the portfolio company with the aims of Aavishkaar.

If a portfolio company needs additional funding it is possible to obtain this either from Aavishkaar as an additional round of investment, or from external investors, including debt and equity, with the help of Aavishkaar. Such external investors are for example other venture capital firms such as Seedfund that has invested in Vaatsaalya. A second alternative is debt financing from banks. Although banks were not keen on providing debt for entrepreneurs when Aavishkaar started out, the team has since found that due to good relations that have been established over time, the Aavsihkaar portfolio companies do not have a problem accessing such finance, once associated with Aavishkaar. ${ }^{79}$ In other words, Aavishkaar has here been able to lower the risk profile of its portfolio companies and build up trust with banks that has enabled entrepreneurs that were previously unable to finance innovative activities through mainstream bank loans, to access such loans. Aavishkaar has thus been able to connect isolated firms with the formal banking system, something that could be very valuable for both the firms and the system, since one problem, as highlighted in the conceptual framework of chapter three, is the lack of access for these firms to the bank system as well as the disconnect between the mainstream, or formal system, and the periphery.

\footnotetext{
77 According to FORD's 2007 survey

78 Data from interviews, 10 October,2007.

${ }^{79}$ Aavishkaar interview, 10 October, 2007.
} 


\section{Non-Financial Support 80}

Aavishkaar recognizes that a financial investment is much more efficient when accompanied by non financial support. Therefore it provides a range of services that goes beyond the provision of finance. Non financial support includes services such as arranging for MBA students from the top schools in India to work on market strategy as part of their course projects, developing internal structures and processes for the portfolio company, providing experts in design or technology, mentoring to improve the management and business strategy, and networking opportunities with potential buyers, funders and partners. Aavishkaar also assists in negotiations with potential suppliers, market dealers, partners and financiers. By doing so, it establishes links between the periphery and the formal financial system, as well as between different parts of the periphery. Aavishkaar is able to link its investee companies to new networks by acting as a 'go-between' which transfers the trust that Aavishkaar has built up within the industry, to its investee companies, as described in section 3.2.3 of chapter 3 .

Much of the support is geared towards making the management of the company more efficient and putting in place business structures. It also entails practical business needs such as accounting and legal practices, as well as improved business plans. This, in other words, codifies knowledge, which makes it easier for these ventures to acquire finance from the formal financial sector since the formal sector is to a much larger extent reliant on codified knowledge, as noted in chapter 3.

Since many of the companies Aavishkaar invests in are at a very early stage, they often do not have a clear operational structure: there may simply be one or two people in the company. Aavishkaar puts in place financing and accounting systems, and legal structures. ${ }^{81}$ For all portfolio companies Aavishkaar's is their first major investment. This means that they have had to learn about financial reporting, managing investments, answering official questions and explaining the business logic, holding board meetings, writing and holding quarterly reviews. Aavishkaar additionally works on the business reporting side, putting into practice regular reporting, and help upgrade and reformulate business plans. The aim for Aavishkaar here is to make the portfolio companies more competitive by improving the business management aspects of the ventures. Improved business management practices in turn makes them more likely to succeed in terms of improved sales or attracting finance from external organisations and the core institutions of the financial system. In other words, the non-financial support that Aavishkaar offers creates a trajectory for the portfolio firms out of the periphery and towards the core.

\footnotetext{
${ }^{80}$ Information source: Aavishkaar interviews, 10 October, 2007.

${ }^{81}$ Often putting new structures in place can be met with resistance of those who are used to doing things "the way they have always been done".
} 
The non-financial support differs depending on the degree to which the company needs help and advice in reaching the milestones set out in the investment deal. Some companies are left with few changes if the management is already working well, whilst others may need a whole new set of institutions, management principles as well as a team. The amount of time spent coaching a portfolio company appears to depend on how the company is performing as those doing well require less attention than those struggling, however in general Aavishkaar speaks to its portfolio companies on a weekly basis.

That Aavishkaar works with its portfolio companies in such a commercial and strategic way puts it apart significantly from other organisations or periphery subsectors that also claim to support entrepreneurs, such as microcredit. Whilst microcredit and microfinance provide, as noted in chapter 2, mainly financial support (rather than a package of finance and non-financial services) and such support is geared towards opening or operating a very small (micro) business, Aavishkaar is clearly set on commercialising and swiftly growing a business. It follows that Aavishkaar may not be directly poverty alleviating, as microfinance often claims to be, but its potential for reaching a larger amount of poor through larger ventures that employ the poor and provide them with better goods and services is much higher. Furthermore, whilst organisations focussed on social entrepreneurship such as Ashoka, emphasises the social or 'do-good' aspects of the entrepreneurs it supports, Aavishkaar takes the social aspect as a prerequisite and works with its investments in the same business focussed way that commercial organisations without the social emphasis do. Aavishkaar supports its social entrepreneurs to become sharp commercial entrepreneurs -this is a significant shift in attitude from the pervasive view that socially focussed undertakings are to a smaller or larger extent charity based and that these cannot be profitable, commercially competitive or financially sound.

\section{Monitoring, Feedback and Learning ${ }^{82}$}

Monitoring of investment companies at Aavishkar is done for three purposes. Firstly, Aavishkaar's fund managers monitor whether investee companies meet the agreed milestone so that further disbursements of investements that are linked to milestones can be made. Secondly, Aasvishkaar believes that through monitoring it is able to fine-tune the support that it provides to each of the investments in its portfolio. For instance, Aavishkaar may advise a change of business strategy for a company, or demand that its fund managers are more active on the board to steer the company in the direction that Aavishkaar wants. A third reason to monitor its investments, is to gain feedback and learn from past successes and failures. Aavishkaar started out with relatively few investments early on- this is something that the founder noted as a deliberate tactic to learn-by-doing at a small scale to

\footnotetext{
${ }^{82}$ Information from interviews, 10 October, 2007 and FORD, 2007.
} 
fine-tune the instruments and support mechanisms it uses before scaling up investments. One such learning is the shift from very young companies to slightly later stage investments, which allowed Aavishkaar's portfolio to stabilise. Another learning is the choice to keep to certain geographic technical areas of expertise which allows Aavishkaar to profit from previous experiences, and emphasises the importance of monitoring the portfolio companies to tailor and provide the most suitable support package as well as to minimise risk. Furthemrore, Aavishkaar appears to not be locked in to certain behaviours or modes of operating, instead evolving with new learnings. It should also be noted that the close monitoring of investee companies, including placing Aavishkaar representatives on their boards, is distinctly different from banks which use an arm's length approach. Aavishkaar's close involvement decreases informational asymmetries including moral hazard, which as noted in 3.1.1., can lead to credit rationing.

The main information flows through which monitoring takes place, are the regular reviews and meetings taking place between Aavishkaar and the investee companies. These include informal reviews between the investee and members of the investment team at Aavishkaar as well as formal reviews including the Aavishkaar board. Aavishkaar in turn is obliged to report to the Advisory Board and Investment Committee on a regular basis on its portfolio as well as pipeline.

Finally, as noted above, Aavishkaar puts in place formal reporting mechanisms which detail how the company is performing and flag potential issues. Furthermore, the demand for business reporting is a way for Aavishkaar to put in place structures and transparency that did not exist previously. However, such continuous reporting and monitoring has been difficult to implement, with companies resisting both increased transparency as well as the perceived higher workload. However, such codified knowledge of the proftolio companies make them more attractive to the financial organisations at the core which rely on codified knowledge to a greater extent. It is therefore necessary in order to attract finance for core financial organisations.

\subsubsection{Cases: Vaatsalya and Servals}

\section{\#1: Vaatsalya ${ }^{83}$}

\section{Business Overview}

Vaatsalya is a healthcare service provider founded in 2004 by medical doctors Dr. Ashwin Naki and Veerendra Hiremath i Hubli, Karnataka in South India. The company is building a chain of hospitals which provide basic and affordable

\footnotetext{
${ }^{83}$ Data stems from Portfolio overview of Vaatsalya on www.aavishkaar.in; FORD, 2007 and Article from Business Outlook India on July, 11, 2009; Artcile from The Week November 15, 2009; Article from www.livemint.com posted 11 May, 2009; Vaatsalya website www.vaatsalya.com
} 
healthcare to the semi-urban and rural population and had by 2007 three hospitals in operation, growing to seven in 2009, and 13 in 2010. By offering expertise in paediatrics, medicine, surgery, gynaecology, medicine and physiotherapy, Vaatsalya estimates that it covers about $70 \%$ of the health needs of the communities in which it operates. Its model is based on locating themselves close to the rural and semi-urban customers and minimising operating costs in order to reduce the overall cost of seeking medical help for customers, who are usually not insured. By being located in rural and semi-urban areas which often lack adequate medical facilities, Vaatsalya reduces transaction costs for hospital customers and their families. This is important because for every Rs10 that a rural patient spends on medical care, a further Rs30 is spent by him or her to access that service- including travels, food, loss of income and cost of improper diagnosis or treatment. ${ }^{84}$ Vaatsalya additionally provides training for healthcare workers and consulting services for the healthcare sector. Vaatsalya provides beds at a below average rate of between Rs100-200 (USD2.20-6.60) per night. The organisation is able to do so by having a high patient turnover and saving on operational costs. For example Vaatsalya operates large wards of over 20 beds, even in hospitals with a total of 50 beds, and avoiding the use of air-condition. Furthermore, the rent is lower than in urban areas, as are the wages for non-medical support staff.

One thing it does not save on is medical staff. The organisation targets young doctors between 28-32 years who have finished medical college as specialists, but are due to start working as junior doctors for between Rs20-25000 (USD450-550) per month. Instead Vaatsalya offers a salary of Rs30 000 (USD660) and the opportunity to join a hospital as specialists rather than junior doctors. A major problem of rural hospitals is understaffing as well as quality of staff. By offering newly qualified specialists to work at a specialist level Vaatsaalya attracts more doctors to rural hospitals whilst in all likelihood improving the quality of that service too since newly qualified doctors are likely to have received better training than rural practitioners without access to regular professional development courses.

The average operating cost per hospital per month is USD33000 whilst it costs between USD220-440 000 to set up a new hospital. Vaatsalya breaks even within six to twelve months of opening a new hospital. Furthermore, in 2009, Vaatasalya's customers totalled 175000 and it was operating in seven districts in the state of Karnataka, managing a total of 300 hospital beds. The average yearly revenue was USD4.6 million (Rs 210 000000) in 2009.85 Vaatsalya's rapid expansion and ability to break even within one year is down to an expansion strategy that is based on using an existing building. or partnering with an existing medical facility that is adapted

\footnotetext{
${ }^{84}$ Aavishkaar Portfolio Overview on Vaatsalya

${ }^{85}$ By 2010 the monthly revenue was USD 1000000 according to an email exchange with the CEO on 12 October, 2010.
} 
to suit Vaatsalya's service requirements. Therefore, when expanding, Vaatsalya looks for medical practices or medical individuals with a similar healthcare vision.

\section{Aavishkaar's Role 86}

Aavishkaar first got involved with Vaatsalya in 2005, when it invested Rs2500 000 (USD 55 000) as part of an angel round which totalled USD 200 000. That funding provided capital to start a 10-bed pilot project in Hubli, Karnataka as well as two further hospitals where Vaatsalya was able to try out slightly different models such as 20 or 30 bed wards. The company is comparatively advanced in its business models and practices, so Aavsihkaar's main role has been in building on Vaatsalya's network. In other words, Aavishkaar is here using its own reputation to build up the reputation of Vaatsalya and include it in new networks, thus acting as a 'gobetween' or network broker. One reason was to reposition Vaatsalya from a local or state based medical group towards a national level. The other, is of course to look for additional funds for Vaatsalaya so that it can expand further. Aavishkaar has been courting potential investors and working on strategic partnerships and assisting in negotiations. Aavishkaar has also introduced the company to NGOs that Vaatsalya works with to provide some local basic medical care, such as Deshpande Foundation and Grameenkoota, an MFI. Aavishkaar is using its wide network of different knowledge types to widen Vaatsalya's network to attract more external finance, to access better market linkages and reposition the firm from a regional to a national venture. Aavishkaar's network appears more open and varied than bank networks, since it comprises many different types of actors and sectors. This is likely to explain why the Aavihskaar team, which is relatively small, can support such a varied portfolio of ventures.

Furthermore, early on, Aavishkaar worked on building confidence in the Directors in representing the company and approaching potential investors and funds. Aavishkaar also helped improve the business vision and expansion strategy, deciding to expand further in Karnataka before going to neighbouring states such as Andhra Pradesh and Tamil Nadu. Furthermore, this has been backed up with PR and marketing, streamlining Vaatsalya's mission and vision, improved management and strategy, as well as putting in place a reporting system to increase credibility and better monitor performance. Aavishkaar put in on average 10-20 hours per month working directly with Vaatsalya. Better reporting systems and monitoring signals credibility to potential investors as it is likely to reduce asymmetric information problems.

Having fine-tuned its model with the help of Aavishkaar, Vaatsalya successfully went for a further round of funding to expand the existing operations both within and beyond the state of Karnataka. In the second round Aavishkaar participated with USD 1 million in 2007 whilst venture capital fund Seedfund

\footnotetext{
${ }^{86}$ Source: FORD, 2007 and Article from Business Outlook India, July, 11, 2009.
} 
provided USD 500 000. The USD 1.5 million investment allowed Vaatsalya to expand operations to seven hospitals in total, all located in the state of Karnataka. Furthermore, in April 2009 Europe based VC Oasis Fund ${ }^{87}$ (also called Bamboo Finance) invested an additional USD5 million which allows Vaatsalya to expand operations with 13 more hospitals around South India, as well as upgrade its operating system, including HR and finance. Aavishkaar's strategy of going in as a very early investor and working with the company to build it up, through financial investment and non-financial support, to a level where it attracts external finance has clearly been a success in the case of Vaatsalya. The investment by Bamboo Finance, which is still considered an early stage venture capital firm but crucially within conventional venture capital, means that Aavsishkaar is well on the way to bridge the gap between micro-scale or social finance at the periphery, and the mainstream risk capital firms at the core of the financial system. It is doing so not by working in isolation, providing a large amount of finance that covers that gap, but through investing comparatively small amount but bringing in partners that are at a later stage of the venture capital chain. Seedfund, for instance, invests as a minimum the amounts that Aavishkaar invests as a maximum, whilst Bamboo Finance is an early stage venture capital firm of the conventional sort and part of the core risk capital.

\section{Social impact and commercial sustainability}

According to Vaatsalya, about $60 \%$ of the cost of healthcare to the poor is due to the lack of adequate services and facilities in rural areas so that the rural poor need to travel to urban areas at great expense. Vaatsalya clearly fills a gap here by providing new healthcare facilities in rural towns. So far it has established 7 medical facilities with a total of 300 beds across Karnataka, and a total of 175000 patients a year.

Vaatsalya is able to offer its services at prices that are $30-50 \%$ lower than the average cost of private hospitals in India. It does so by operating a model that minimises operational costs without affecting the medical care, for instance not using air-conditioning, and putting 20 beds in each room. By being located in rural areas it also saves on rent as well as salary for non-medical support staff. Furthermore, the high turnover of patients compensates for the small profit margins per patient.

Vaatsalya is profitable with revenue of USD 4.6 million in 2007 and are able to recover costs within six to twelve months of opening a new facility.

Vaatsalya has won three major awards for its business model: the BID Challenge first prize in 2007, an LRAMP award in 2008 and the Sankalp Award for Social Enterprise in 2009.

\footnotetext{
${ }^{87}$ Oasis Fund is invests in emerging enterprises worldwide, whilst Seedfund which had invested in an earlier round of Vaatsalya, is an Indian venture capital fund providing seed investments.
} 


\section{\#2: Servals Automation Pvt Ltd (Servals)88 89}

\section{Business Overview}

Servals is a social enterprise that manufactures products focused primarily on providing clean, green, affordable and sustainable energy for cooking and lighting purposes. Its flagship products include energy efficient kerosene stoves and burners that save up to $27 \%$ kerosene, a straight vegetable oil stove and a hybrid vegetable oil/kerosene stove. Servals has also produced a rain gun, which is a micro irrigation device that saves on water, and plant oil lamps.

Servals has a central office in Chennai as well as three production units, one of which is based in a Dalit rural village. Servals had initially had problems selling adequate amount of its stoves and burners but by 2007, the brass of which traditional burners are made was becoming expensive, resulting in increased interest in Servals' burners and stoves. Thus, wholesalers were starting to put in larger orders than previously. Approximately 250000 kerosene stoves had been sold at the time of fieldwork, whilst about 200 rain guns had been sold. In 2007, they were estimating (through the pipeline of future sales) average sales of about 20000 burners per month, whilst planning to increase the scale of production to 50000 burners per month. The company has received several awards including the LRamp Award for Excellence in 2007 and the "most energy efficient burner" by the Paraffin Safety Association of South Africa (PASASA).

\section{Aavishkaar's Role9o}

Servals was introduced to Aavishkaar by Villgro (an incubator that will be further detailed in chapter 7), in 2001 and became its first investment in 2002. Aavishkaar initially provided funds for improving its assembling, marketing and distribution channels in order to increase sales. Aavishkaar made a further investment in 2006 and took a $49 \%$ stake in the company, leaving $51 \%$ for Servals' CEO, Mr Mukundan. Aavishkaar has complemented its financial support with non-financial, or management, support including developing the business units and products through being actively involved in reviews of performance and strategies for the future. Aavishkaar has assisted in implementing improved financial planning and reporting, including putting in place a reporting system. Aavishkaar also worked on Serval's business strategy and used its network to expand the links Servals has with suppliers, NGOs, banks and sales agents. Again, as highlighted in the Vaatsalya case, it is notable that Aavishkaar's networks go far beyond 'financial'

\footnotetext{
${ }^{88}$ Information based on website http://servalsgroup.blogspot.com; interview with the owner, Mr P. Mukundan, Managing Director on 7 November, 2007; and portfolio information from Aavishkaar.

${ }^{89}$ This case features in the study on Villgro too, as Villgro provided early incubator services and introduced Aavishkaar to Servals.

${ }^{90}$ From FORD, 2007
} 
knowledge types, unlike the core financial institutions. Instead its network includes technical experts, suppliers, business and industry experts, the NGO sector and sales agents or wholesalers with direct market linkages. Under Aavishkaar's supervision, Servals opened a rural production unit which employs 20 people that previously did not have secure full-time employment. The unit was opened in partnership with a local NGO that works with Dalits. Servals has also diversified its product range to different kinds of stoves and burners since Aavsihkaar got involved. Aavsihkaar has also used its network to link Servals with NGOs that act as distribution and marketing channels. Aavishkaar monitors the investment through regular reviews of production, cost efficiency, performance and management including monthly or quarterly visits to Servals' office and production sites. As with Vaatsalya, the improved reporting system not only improves the overview of the business that the CEO now has, but improves transparency, which has made monitoring for Aavishkaar easier too. In turn, informational problems are reduced.

The risk of Servals has decreased because of Aavishkaars substantial (49\%) stake in the company, as well as the work it has done on strategy and operations, for instance introducing an improved business plan and connecting Servals with improved suppliers and sellers of its stoves and burners. This has also increased credibility. One outcome of this is the ability of Servals to seek debt financing now. Servals' increased visibility has attracted MFIs such as Madurai Microfinacne Ltd which is keen to work with the company in promoting their products through rural self help groups. Servals has increased its visibility online too, with the owner, $\mathrm{Mr}$ Mukundan running his own website and blog detailing what Servals does and the products it offers, as well as advocating for green, sustainable and pro-poor products and market segments. Mr Mukundan has, with the help of Aavishkaar, become a spokesperson for environmentally friendly social enterprises and now acts as a mentor for other young entrepreneurs. It is through individual entrepreneurs such as Mr Mukundan that Aavishkaar is able to find new potential investments, since Mr Mukundan is himself now establishing a reputation as a 'lead' social entrepreneur, if not a lead-user innovator. So, Aavishkaar has acted as a 'go-between', facilitating and building up Servals' network and Mr Mukundan's credibility. Mr Mukundan can now, in turn, act as a 'go-between' himself to connect new ventures and entrepreneurs with Aavishkaar.

\section{Social impact and commercial sustainability}

The kerosene stove and burner reduce the use of kerosene by about $30 \%$ resulting in a substantial cost saving. Furthermore, since kerosene is hazardous, this reduction improves the health of users (mainly women whilst cooking). These burners are particularly safe since they do not explode if toppled over, which is otherwise a common problem. Furthermore, the rain gun saves substantially on water by providing even irrigation with the minimum amount of water 
Servals is working with a local rural NGO to employ landless rural poor peoples in manufacturing, thus providing livelihoods for 20 people that previously did not have a full-time or stable job. Furthermore, setting up a production unit in that village has resulted in improved infrastructure, including roads and sewage systems. Furthermore, Servals works with approximately 30 NGOs to use SHGs as a grassroots level marketing and sales channel thus providing livelihood opportunities for more women.

Finally, Mr Mukundan now acts as a 'lead' social entrepreneur, advocating sustainable, energy efficient innovation and firm formation among fellow entrepreneurs in India.

\subsubsection{Conchusion}

In the context of rural India, Aavishkaar is innovative in its use of the venture capital model, by using equity instead of debt in its portfolio investments. It provides comparatively large investments in relatively established ventures and entrepreneurs, compared to other case study organisations in this thesis.

The model is mainly supporting the poor indirectly by financing ventures that provide improved products and services to the poor- from healthcare to internet access and better stoves. In addition, these ventures create livelihood opportunities.

Aavishkaar is the most 'commercial' of the case studies as it is positioned the closest to commercial financing options including banks at the core but also regular seed or venture capital. As such, its portfolio companies do not have problems in obtaining external (debt) financing from banks once Aavishkaar has invested, as this signals that the venture is commercially sound. Portfolio companies have even attracted attention from risk financiers, including early stage venture capital company Seedfund, though this is still an area where micro venture capital needs to grow as the gap between conventional venture capital and micro venture capital is still considerable. Aavishkaar also has links with periphery organisations including Villgro (chapter 7) which, as an incubator, supplies potential deals, and BASIX (chapter 6) with which it runs a new and separate MFI focussed funding programme.

This chapter looked at Aavishkaar, a micro venture capital organisation. The next chapter will go on to study organisations that provide finance at a smaller scale, the small-scale financiers. 


\section{Case Studies \# 2: Small-Scale Financiers}

The first case study looked at finance for the most advanced innovative entrepreneurs in rural India, in terms of the scale of investment and expected growth path of the venture. However, as already noted theoretically in the theoretical chapters, and empirically in chapter 4, PEBI finance is multi-faceted and innovation and entrepreneurship takes different shapes and occurs on many levels. This chapter looks at a separate, but related gap in finance for innovative entrepreneurs that are much too new or too small for micro venture capital financing. Rather, these entrepreneurs are closer to microfinance in scale, but having outgrown such finance, and being unable to access bank credit, they find themselves facing a severe lack of finance.

This gap is being filled by organisations relying mainly on credit (as opposed to equity, or grants), that have moved beyond microfinance. These organisations, importantly, provide a range of non-financial support to improve the impact the credit intervention will have, as well as minimise risk. That microfinance institutions provide amounts that are too small for innovative growth entrepreneurs and that they generally use a 'credit only' approach are two important critiques highlighted in chapter 2. The organisations studied in this chapter however, deal with both these issues by providing larger amounts, and doing so whilst also offering complementary non-financial services.

The first case study organisation, BASIX, is a large and multi-faceted livelihood finance service provider that works with rural clients ranging from small-holder farmers to non-farm growth entrepreneurs, providing debt as well as a range of non-financial support on a fee-paying basis. Whilst BASIX targets a wide range of rural entrepreneurs in a number of sectors, the second case study organisation, SiIDF, focuses specifically on entrepreneurs involved in environmentally sustainable infrastructure investments. S3IDF works together with local NGOs to provide basic infrastructure services in rural areas and to train local entrepreneurs to manage and run the implemented infrastructure services. Although finance is the 
primary service, the organisation provides additional services to root the technologies or projects in the local community.

\section{1 BASIX}

\subsubsection{BASIX ${ }^{91}$ the Organisation}

\section{Background, Mission and Objectives ${ }^{92}$}

Bhartiya Samruddhi Investments and Consulting Services (BASIX) is a group of companies, set up in 1996, that supports rural livelihoods through a mixed strategy of financial and non-financial support. Since its inception BASIX has called itself a livelihood promotion organisation. Whilst microfinance has been one of its core services, BASIX has evolved over time to support rural entrepreneurs in a number of ways that goes beyond classical microfinance. ${ }^{93}$

More specifically, BASIX provides integrated financial and non-financial support through a number of different models which it develops and tests in its inhouse R\&D department.

BASIX is based on an underlying belief that credit must be provided in a sustainable manner and that credit alone can be useful, but not as effective as credit bundled together with other financial and non-financial services. This originates from two sets of experiences: firstly, a World Bank study ${ }^{94}$ from the mid 1990's conducted by the promoters of BASIX, Vijay Mahajan and Bharti Gupta Ramola,

\footnotetext{
91 The fieldwork was carried out February- April, 2007 and data are based on: Initial interview with the CEO and the VP Operations at BASIX HQ, Hyderabad on 21 February, 2007, followed up on 5 March 2007; interviews with staff, including the unit head and Area Manager at Nalgonda Unit Office, 28 February, 2007; Interview with managers of the Ag/BDS Programme at BASIX HQ, 6 March, 2007; Interviews and fieldtrips to speak to staff and clients at Nirmal Unit Office, 7 March, 2007, Bhainsa Unit Office, 8 March, 2007 and Ramaynpet Unit Office, 9 March, 2007, Wardha and Bandhara Unit Offices on 25-27 April, Kurnool Unit Office on 30 April, 2007; BASIX Annual Report 2005/2006- 2008/2009; OLE: The organisational Learning and Evolution Process, BASIX, 2005; BASIX: A Decade in Institutional Development, 2007; IGS Annual Report 2001/2002- 2005/2006; Website www.basixindia.co.in accessed 25 January, 2007, 28 March, 2007, 21 November, 2009; BASIX Arm to Raise up to \$25m PE Money, www.vcircle.com, November 16, 2009; Armanath, S, Financing the Agricultural Value Chain- BASIX Experiences, 2008; Confederation of Indian Industries, 2008. Indian Companies with Solutions that the World Needs, 2008.; Sharma, A. Farming Reaps Harvest, The Telegraph, Calcutta, 28 June, 2008; informal conversations with BASIX staff at multiple levels during February- April, 2007.

${ }_{92}$ Based on the BASIX Annual Reports 2005/2006-2007/2008; OLE BASIX: A decade in Institutional Development, 2005; Initial interview with the CEO and the VP Operations at BASIX HQ, Hyderabad on 21 February, 2007, followed up on 5 March 2007

${ }^{93}$ Livelihood promotion to BASIX means promoting sustainable livelihoods, which may go beyond simply generating income or generating full-time formal sector employment, to include for example building capacity, creating market linkages, providing mentoring and agriculture sector expertise. ${ }^{94}$ Study on Financial Services for the Rural Poor and Women: Access and Sustainability
} 
concluded that access to finance cannot come at the cost of sustainability; secondly, during previous experiences in setting up MFIs ${ }^{95}$, the founders found that whilst credit is important, once it is in place, other non-financial support has a significant impact on the effectiveness of credit use.

Whilst BASIX started out small, with only microfinance operations, it has added services such as technical support, insurance and savings over time whilst simultaneously refining its strategy and mission. By the time of fieldwork, in 2007, a multifaceted and complex strategy to financing rural livelihoods which included an increased emphasis on non-financial support services was in use.

This strategy is, operationally, based on a 'Livelihood Triad' where financial services are combined with business development and institutional development services (such as group formation and training for other NGOs) to offer all-round support promoting livelihoods in rural areas. Apart from the activities that have a direct impact on the grassroots, the rural clients, BASIX engages in policy formulation and capacity building related to rural poverty, financing and support at sectoral as well as federal levels. Sectorally, BASIX was active in starting Sa-Dhan, a microfinance network, which encourages cooperation and best practices within the industry. Furthermore, BASIX is a capacity builder of NGOs.

As regards nation-wide policy, BASIX has built up a strong reputation for expertise in livelihoods promotion at state, national and international levels. In this regard, BASIX is able to turn its practical experience from the field into implementable policy and to influence regional and national policies.

In order to be active on the number of levels and in different sectors that BASIX is, partnerships and cooperation are at the core of the organisation's modus operandi. BASIX partners with banks to provide further financial assistance above and beyond what BASIX offers to rural clients, and with insurance companies to make insurance available to its clients. Furthermore, state-run organizations such as dairy boards and private production companies provide non-financial support in the form of business and agricultural advice and better market access. It is clear that BASIX has a network that is very varied geographically, as well as sectorally. Geographically, it reaches actors in most of India, as well as abroad, whilst sectorally its network includes actors in the political, financial, and business sectors, the NGO sector, as well as its clients - the rural poor.

BASIX is very active in influencing the sector in which it operates, both directly and indirectly. Direct influence such as setting up an umbrella organisation (SaDhan), as well as training other organisations, ensures that capacity is built up in the micro and livelihood finance sector, and that the sector is able to lobby collectively for better policy. Such activities also improve the overall standard of the sector whilst putting in place some quality assurance mechanisms (membership of the powerful Sa-Dhan requires a certain level of transparency and adherence to best

\footnotetext{
${ }^{95}$ An example is Pradhan, an early and well-known Indian MFI.
} 
practices) in a sector that had until recently been relatively under-regulated. Indirectly, BASIX has an impact on the sector by influencing policy through an active dialogue with policy-makers, sitting on Government Committees and working with apex bodies like NABARD. Its role in connecting the periphery with the core therefore extends far beyond being a prominent livelihood services organisation. Furthermore, it should be noted that since most of the member organisations of Sa-Dhan are microfinance organisations, BASIX importantly has the ability to influence microfinance organisations to move towards a wider remit of entrepreneurship-support and an emphasis on innovation as opposed to microcredit, which should benefit PEBI.

\section{Organisational Structure 96}

BASIX is a group of companies which functions under the holding company Bhartiya Samruddhi Investments and Consulting Services Ltd (BASICS).

In 2007 there were four companies within the group, apart from the holding company, BASICS. These were: Bhartiya Samruddhi Finance Ltd (BSFL), a nonbank financial company (NBFC) started in 1997, which runs micro and livelihood financial services; Krishna Bhima Samruddhi Local Area Bank Ltd (KBSLAB), a local area bank started in 2001; a non-profit Livelihood School, which provides livelihood services training to individuals, inside and outside of BASIX, as well as to external MFIs and NGOs; and the non-profit Indian Grameen Services (IGS), which undertakes action research and pilots and evaluates new services models. ${ }^{97}$

The BASIX Group is run by a Board of Directors that includes founder and Chairman Vijay Mahajan. It holds overall responsibility for strategy and directions. In addition there are several Committees set up by the BASIX Board to deal with specific issues such as HR, investments and audit. Furthermore, each of the companies has its own Board of Directors.

Whilst the senior management is based at the Hyderabad head office, most of the staff is based in local unit offices across the country..$^{98}$ In 2007 , there were unit offices in 45 locations across India. Each unit office is managed by a unit head who has got four to five field executives (FX) under him. Four to five unit offices are grouped under one area manager. The area manager and unit head together have a considerable amount of freedom in determining investment size, clientele and local initiatives within the parameters of what BASIX sets out do to. BASIX is in other

\footnotetext{
${ }^{96}$ Information based on BASIX Annual Report 06/07; initial interview with the CEO and the VP Operations at BASIX HQ, Hyderabad on 21 February, 2007, followed up on 5 March 2007; OLE BASIX: A decade in Institutional Development, 2005; and www.basixindia.co.in downloaded 21 November, 2009.

${ }^{97}$ By November 2009, there were in addition two consultancy service firms and two additional Livelihood and MFI Schools (www.basixindia.co.in, accessed 27 November, 2009).

${ }^{98}$ BASIX covers 15 states across India, from Sikkim in the North, West Bengal in the East, Rajhastan in the West and Tamil Nadu in the South.
} 
words a relatively decentralised organisation. Whilst Aavishkaar, for example, is centralised, BASIX has provided its unit offices with a lot of independence. This decentralisation may be an explanation for the organisation's ability to adapt its services to what clients need at the grassroots level. This in turn reduces risks by making the services more suitable to the clients. This decentralisation also stands in stark contrast to the banks at the core of the financial system, which, as noted in chapter 3, are highly hierarchical and where all decision-making is done centrally.

\section{Activities99}

Within the BASIX Group there are two companies providing finance: KBSLAB and BSFL. KBSLAB, as noted above, is a bank providing micro loans and savings accounts, whilst BSFL is a non-bank financial entity which provides a range of financial and non-financial services. BSFL is the main focus of this case study, because it provides most of the innovative financial and non-financial services to entrepreneurs and farmer groups within BASIX. BSFL works in close cooperation with IGS, which is the not-for-profit entity of BASIX in charge of non-financial support. IGS researches and tests new financing models, methods of production, market linkages, technology and techniques. ${ }^{100}$ In this sense BASIX has its own R\&D centre that assures, as it calls it, 'continuous pioneering'. BASIX puts a great emphasis on innovation within its organisation and through IGS it is constantly updating and evolving its support models. IGS has the overarching responsibility for both the Agricultural and Business Development Support services (Ag/BDS), as well as the Institutional Development Services (IDS), that form the bulk of the nonfinancial support that BASIX offers as part of its livelihood support services package. The Ag/BDS services are evolving on a yearly basis and much of that change is driven by the IGS, as further detailed in section 6.1.2.

\section{Funding 101}

BASIX started its lending activities based on grants and loans from Sir Ratan Tata Trust, Ford Foundation and the Swiss Development Cooperation. However, in 1999, BASIX reached a milestone when it was able to raise a loan of Rs 20 million from the Global Trust Bank. This was the first time a MFI raised a loan from a commercial bank, the first loan to an MFI registered as a for-profit non-financial institution and the first time NABARD refinanced such a loan without imposing an on-lending rate

\footnotetext{
${ }^{99}$ Information based on BASIX Annual Report 06/07; initial interview with the CEO and the VP Operations at BASIX HQ, Hyderabad on 21 February, 2007, followed up on 5 March 2007, IGS Annual Report, 2005/2006, www.basixindia.co.in accessed on 21 November, 2009.

${ }^{100}$ In fact, early action research by IGS was instrumental in the establishment of the BASIX group of companies.

101 Data from BASIX Annual Report 2005/2006-2006/2007 and 2008/2009; initial interview with the CEO and the VP Operations at BASIX HQ, Hyderabad on 21 February, 2007, followed up on 5 March 2007, IGS Annual Report, 2005/2006, www.basixindia.co.in accessed on 21 November, 2009.
} 
from the MFI to its clients. Since then, a number of large equity investors have invested for stakes in BASIX and these investments now make up the core of the organisation's capital base. Historically the organisation has received loans, grants and equity investments from a number of sources as depicted in the table below. Now however, BASIX operates its financial services almost exclusively on loans and equity investments (whilst the non-profit IGS sustains itself on grants).

Table 6.1 Equity, grant and debt investments in BASIX (source: Annual Report 2006/2007)

\begin{tabular}{|l|l|}
\hline $\begin{array}{l}\text { Equity } \\
\text { Investors }\end{array}$ & $\begin{array}{l}\text { Ford Foundation, Swiss Agency for Development and Cooperation (SDC), } \\
\text { International Finance Corporation (IFC), ShoreCap International, Triodos Bank, } \\
\text { ICICI Bank, HDFC }\end{array}$ \\
\hline IGS Grants & $\begin{array}{l}\text { Government of India Min of Rural Dev., Sir Ratan Tata Trust, Oxfam, } \\
\text { Interchurch organisations for development cooperation, ABN Amro } \\
\text { Foundation, Water Partner International }\end{array}$ \\
\hline $\begin{array}{l}\text { Lending } \\
\text { Agencies }\end{array}$ & $\begin{array}{l}\text { ICICI Bank, HDFC, SIDBI, Cordaid, Standard Chartered Bank, Citi Bank, } \\
\text { Corporation Bank, Axis Bank, IDBI Bank, Development Credit Bank, ABN- } \\
\text { Amro, ING Vysya, HDFC, Development International Desjardins }\end{array}$ \\
\hline
\end{tabular}

It should be noted that two of the equity investors, and all but three lending agencies, are part of the core financial system in India. For instance, large loans for on-lending to the organisation's clients have been acquired from major national banks, whilst the equity investors include HDFC and ICICI Banks. BASIX has, in other words, created strong finance linkages from the core feeding to the periphery.

As regards BSFL, the main focus of this case study, it was first fully owned by BASICS, the holding company, with an equity base of Rs 45000000 (USD 1,020,000). However, an additional round of equity in 2001 increased BSFL's equity base to Rs 206,000,000 (USD 4,700,000). ${ }^{102}$ At the same time the holding company invested an additional Rs 97,000,000 (USD 2,300,000) to keep its shares at 49.5\%. ${ }^{103}$ By 2009, a further round of equity resulted in BSFL raising USD 10 million from Lok Capital, Aavishkaar Goodwell, and Small Industries Development Bank (SIDBI), with plans for another USD 20-25 million in early 2010. ${ }^{104}$ Furthermore, it should be noted that by 2007, the turnover from the for-profit businesses (such as lending and insurance) was high enough to cover the costs of the organisation's funding operations and make an additional $1 \%$ profit. 105

102 This equity originated from IFC, Washington; Shorebank, Chicago; Hivos- Triodos Fund, Netherlands; the ICICI Bank and HDFC Limited from India.

${ }_{103}$ BASIX Annual Report 2006/2007

${ }^{104}$ BASIX Arm to Raise up to \$25m PE Money, www.vcircle.com, November 16, 2009.

${ }^{105}$ In order to operate sustainably, BASIX relies on interest rates on its loans as well as fees from its services. Whilst a debate is raging on the 'right' level of interest, BASIX has tried a number of different strategies. Early on high operational costs of $18 \%$ of loans together with operational inefficiencies resulted in interest rates on loans of $24 \%$. There was additionally a processing fee of 1 - 


\section{Portfoliono6}

BASIX has a large portfolio of clients, which has grown rapidly since 2005. In 2007, BSFL had cumulatively disbursed over 193282 loans worth Rs 1702 million (USD38.5 million), across India. By 2009, a cumulative total of 1,267,607 loans had been disbursed, totalling Rs 13,966 million (USD 316 million). These loans had been disbursed in 13,436 villages in 77 districts, spread across the 13 states of Andhra Pradesh, Karnataka, Orissa, Maharashtra, Madhya Pradesh, Jharkhand, Rajasthan, Chattisgarh, Uttarakhand, West Bengal, Sikkim, Meghalaya and Delhi. In fact, BASIX is the case study with the most geographically wide-reaching services by a substantial margin. In 2009, there were over 574,421 active loans, and the on-time repayment rate stood at $99.1 \%$. Such a high on-time repayment rate suggests that the risk in lending to the rural poor is actually very low when the kind of support and monitoring structure that BASIX uses is in place. This, in other words, questions one of the major reasons for banks to ration credit - the perceived risk of default. A further point to note is that the rapid increase in loan disbursement and geographical outreach has not had a negative impact on the on-time repayment rates, suggesting that substantial scaling up can be achieved without compromising the portfolio. One result of its successful portfolio and risk management is that many equity investors and lending agencies have come on board, i.e. BASIX is, by proving the low risk of its rural clients, attracting core institutions willing to provide finance to the rural poor (in cooperation with BASIX).

However, a large part of the overall portfolio is made up of very small group loans to joint liability and self-help groups in rural India, which is not what this thesis is concerned with. Instead, the areas of BSFL's vast portfolio that are particularly relevant for this case study are the investments in: micro growth entrepreneurs, farmer groups called MACS, and market linkage programmes. These areas will be considered in further detail below. As one example of each of these three areas will be illustrated in the final section of this case study, the introductions below are kept brief.

$2 \%$ for its rural clients. As BASIX' operations streamlined, the interest rates on loans have come down and by 2007 , it was $12 \%$ for group loans.

106 BASIX Annual Report 2005/2006- 2006/2007; www.basixindia.co.in, downloaded on 21 November, 2009; interview with the VP Operations at BASIX HQ, Hyderabad on 21 February, 2007. 
Table 6.2 Activities at BASIX relevant to pro-poor entrepreneur-based innovation (author's own)

\begin{tabular}{|c|c|c|c|c|c|c|}
\hline Type & Description & Sector & Support & Innovation & Scale & $\begin{array}{l}\text { Social } \\
\text { Impact }\end{array}$ \\
\hline MGE & $\begin{array}{l}\text { Firms with } \\
\text { potential to } \\
\text { provide } \\
\text { employment } \\
\text { and } \\
\text { opportunities } \\
\text { in the local } \\
\text { economy. }\end{array}$ & $\begin{array}{l}\text { Rural } \\
\text { non-farm: } \\
\text { quarry, } \\
\text { waste } \\
\text { mgmnt, } \\
\text { fodder } \\
\text { processi- } \\
\text { ng, }\end{array}$ & $\begin{array}{l}\text { Individual } \\
\text { loans of up } \\
\text { to Rs 200 } \\
000 \text { (USD } \\
4500) .\end{array}$ & $\begin{array}{l}\text { Larger } \\
\text { individual } \\
\text { loans to } \\
\text { established } \\
\text { entrepreneurs } \\
\text { with track } \\
\text { record } \\
\text { resulting in } \\
\text { indirect } \\
\text { poverty } \\
\text { alleviation } \\
\text { impact }\end{array}$ & 38 in 2007 & $\begin{array}{l}\text { Provide } \\
\text { employment, } \\
\text { e.g.. a quarry } \\
\text { business } \\
\text { provides } 60 \\
\text { livelihoods. }\end{array}$ \\
\hline MACS & $\begin{array}{l}\text { Farmer } \\
\text { cooperatives } \\
\text { called MACS } \\
\text { for which } \\
\text { BASIX } \\
\text { provides } \\
\text { integrated } \\
\text { pesticide } \\
\text { management } \\
\text { assistance. }\end{array}$ & Cotton & $\begin{array}{l}\text { Group } \\
\text { formation, } \\
\text { loan, } \\
\text { insurance, } \\
\mathrm{Ag} / \mathrm{BDS}, \\
\text { negotiation, } \\
\text { access to } \\
\text { market }\end{array}$ & $\begin{array}{l}\text { Form } \\
\text { cooperatives } \\
\text { that } \\
\text { independentl } \\
\text { y can take on } \\
\text { wholesalers } \\
\text { and input } \\
\text { suppliers to } \\
\text { buy and } \\
\text { supply in } \\
\text { bulk for better } \\
\text { prices }\end{array}$ & $\begin{array}{l}20 \text { groups } \\
\text { in Adilabad } \\
\text { in } 2007\end{array}$ & $\begin{array}{l}\text { In Adilabad } \\
\text { district, AP, } \\
\text { the farmers } \\
\text { together } \\
\text { provided for } \\
600000 \\
\text { working days } \\
\text { per year for } \\
\text { casual labour. }\end{array}$ \\
\hline $\begin{array}{l}\text { Value } \\
\text { Chain/ } \\
\text { Market } \\
\text { Linkage }\end{array}$ & $\begin{array}{l}\text { Create value } \\
\text { chain from } \\
\text { farmer to } \\
\text { retailer. } \\
\text { Contract } \\
\text { farming. }\end{array}$ & $\begin{array}{l}\text { Potato- } \\
\text { Pepsico } \\
\text { and } \\
\text { Dairy- } \\
\text { Reliance } \\
\text { Fresh and } \\
\text { APDCM }\end{array}$ & $\begin{array}{l}\text { Group } \\
\text { formation, } \\
\text { small JLG } \\
\text { loans, } \\
\text { insurance, } \\
\text { Ag/BDS. } \\
\text { Additional } \\
\text { support } \\
\text { from } \\
\text { retailer. }\end{array}$ & $\begin{array}{l}\text { Connecting } \\
\text { BASIX with } \\
\text { retailer, } \\
\text { building up } \\
\text { complete } \\
\text { value chain in } \\
\text { between and } \\
\text { offering } \\
\text { portfolio of } \\
\text { financial and } \\
\text { non-financial } \\
\text { services. }\end{array}$ & $\begin{array}{l}1 \text { potato } \\
\text { project } \\
\text { reaching } \\
3000 \\
\text { farmers in } \\
\text { Jharkand; } 2 \\
\text { dairy } \\
\text { projects. }\end{array}$ & $\begin{array}{l}\text { New } \\
\text { livelihoods } \\
\text { during the } \\
\text { lean season } \\
\text { for } 3000 \\
\text { farmers in } \\
\text { one of the } \\
\text { poorest states } \\
\text { of India. For } \\
\text { dairy the } \\
\text { prices went } \\
\text { up and the } \\
\text { animals are } \\
\text { healthier so } \\
\text { that output } \\
\text { increased. }\end{array}$ \\
\hline
\end{tabular}

\section{Micro Growth Entrepreneurs (MGE)}

BASIX provides up to Rs 200,000 (USD 4500) to rural growth entrepreneurs to expand an existing business. These entrepreneurs are relatively better off than the majority of the organisation's clients, and own assets that can be used as collateral required for the larger loans. BASIX expects that supporting these relatively better 
off rural entrepreneurs will have important indirect effects on the rural poor through the creation of additional livelihoods. This is in line with the arguments of the access to finance literature highlighted in chapter 2, which holds that finance that indirectly targets the poor is likely to have a larger impact than directly targeting finance. There were 38 micro growth entrepreneurs in 2007. However, according to the management of BASIX, the number of MGEs had been expected to be higher. The explanation for the gap between expected and actual number of investments was said to be due to resistance to these large loans at the unit offices because the unit managers were not used to sanctioning and managing such large investments and did not fully understand the level of risk. This is, in other words, an example of credit rationing due to a lack of understanding of the risk profile, as discussed under the barriers to finance chapter 3. Here, the lack of understanding or awareness of entrepreneurship and innovation, and the associated risks, results in a refusal to lend. Nevertheless, the management of BASIX, including the CEO at the time, were keen on the MGE model and it was envisaged that the micro growth entrepreneur investments would increase in the coming years because of the creation of a new fund called Livelihood Triad Fund (see box below).

Box 6.1 The Livelihood Triad Fund

Though this case study does not detail specific cases that stem from the Livelihood Triad fund, it should be highlighted because it is unprecedented. In 2005 BASIX applied to the Swiss Agency for Development and Cooperation for a Rs 100 million (USD 2.2 million) grant to set up a fund that would invest in innovation related to livelihood promotion. By 2007, at the time of the field study, a grant for a three year fund had been sanctioned and a call went out throughout the organisation to ask staff, both at HQ and in the field, to submit proposals related to agriculture, livestock, dairy, non-farm sector, cooperatives, financial services, environment, gender and technology on innovative models of support that the organisation could trial.175 full project proposals were received and out of these, 75 proposals passed the initial stages whilst 52 projects completed the implementation and trial phase. In 2009, 10 projects were considered for scaled up implementation: a livestock development centre, livelihood resource centre, system of rice intensification, integrated crop management, new savings promotion, rural employment exchange, rural business outsourcing, credit cooperatives reform programme, technology assisted financial inclusion, and a sustainable ragpickers institution. In all projects an important overarching goal was to spur creativity within the organisation and to innovate as in service delivery models.

The specific focus of this fund is to provide financial incentives for staff to test come up with and test new kinds of support models. By strongly encouraging innovative thinking, BASIX reduces the problem of institutional lock-in. A review in 
the Annual Report 2008/2009 noted that the fund had helped staff at all levels of the organisation to think and act more creatively.

\section{Mutually Aided Cooperative Societies (MACS)}

The MACS were first created by the passing of the MACTS Act in 1995. BASIX began lending to farmers that were members of MACTS in Andhra Pradesh in $1998 / 1999$. The aim is to provide farmers with improved bargaining power in regard to seed and pesticide suppliers in the cotton industry. For instance, by buying seeds and fertilizers in bulk, as a cooperative, the farmers got better deals. The MACS have become very popular among farmers in AP and the neighbouring state of Maharasthra and have diversified from cotton to other kinds of vegetables and spices. The MACS' collective action's was by 2007 also seeing farmers seeking out manufacturers of output, such as cotton mills, directly and therefore avoiding the middlemen that were previously taking a large share of the rents. BASIX provides agricultural and business development support services to the MACS for a yearly fee. In 2007, there were, for instance, 20 MACS in Adilabad District, Andhra Pradesh, where the MACS originally started out. ${ }^{107}$

\section{Market Linkages}

Whilst working with dairy farmers in Andhra Pradesh, BASIX began experimenting with setting up value chain links between small-holder farmers and large retailers. BASIX had, by 2007, implemented complete value chain models in dairy together with the AP Dairy Cooperative Federation (APDDCF) and retail giant Reliance Fresh in Andhra Pradesh, and in potatoes with the Frito Lay division of PepsiCo in the state of Jharkhand. In the dairy sector this entailed setting up local chilling stations, forming farmer groups, providing loans for cattle, offering veterinary specialists and animal health checks, and capacity building in dairy management. In the potato sector, which will be detailed below, it involved forming farmer groups that could sign a legal agreement with PepsiCo to provide a certain quantity of potatoes each season. BASIX is thus putting in place linkages between farmers and major industry actors and enabling these linkages by supporting the farmers financially and non-financially. In 2007, one potato linkage project, which created livelihoods for 3000 farmers, and two dairy linkage projects had been started.

Whilst much of the innovative activities within the BASIX portfolio appear to take place in the organisation's home state of Andhra Pradesh, it is noteworthy that its potato linkage programme is based in Jharkhand, one of the poorest states of India. BASIX supports a number of different livelihood options but is, sectorally, focussed mainly on agriculture and dairy. However, an exception is in the MGE

\footnotetext{
107 This district is cited throughout since several MACS in this district were visited during fieldwork. Furthermore, since the district hosts the original MACS it has the biggest network of MACS, as well as the most advanced MACS.
} 
investment model which also supports non-farming activities such as waste management and quarry businesses.

The financial and non-financial services that BASIX offers reaches a larger number of different kinds of rural poor and rural entrepreneurs than do the other case studies in this thesis. For example, non-poor entrepreneurs benefitting from the MGE programme have very different needs to poor farmers involved in market linkage programmes. Whilst MFIs and government programmes often use a onesize-fits-all solution, BASIX realises that the heterogeneous rural poor need a whole range of financial and non-financial services. BASIX is in other words dynamic in terms of the range of services it offers and how these services change over time.

\subsubsection{The Support Model at BASIX}

BASIX's livelihood triad strategy includes three lines of business. Firstly, it provides credit as individual or group loans so that entrepreneurs and firms can expand their businesses. Secondly, the credit is complemented by a range of non-financial support such as business management, market linkages, local value addition, farm and dairy related expertise and institution building services to maximise the use of the loan. Thirdly, add-on products, such as insurance for farmers, combat the uncertainties inherent in rural livelihoods such as a lack of income resulting from bad crops, sick animals or weather conditions.

BASIX manages its own risk in a number of ways. At the level of the overall portfolio, it uses a decentralised organisational structure which collects reliable local information quickly. The local unit offices also build up relationships with customers over time. Beyond these informal ways of managing risk, BASIX requires collateral for large individual loans, whilst smaller loans are provided through groups, which is a conventional alternative to collateral in microfinance. Furthermore, BASIX keeps a mixture of many safe investments with a few riskier ones in the portfolio so that, overall, the portfolio risk is low. BASIX also works with risk at the grassroots level, since lowering risk for its clients in turn lowers the risk of the overall portfolio of BASIX. It does so by providing insurance, by providing new information about latest technologies, and by assisting with access to markets and good suppliers and sales agents. 
Table 6.3 Support services at BASIX (source: Annual Report 2006/2007)

\begin{tabular}{|l|l|l|}
\hline Livelihood Finance (LFS) & $\begin{array}{l}\text { Agri/Business Development } \\
\text { (AG/BDS) }\end{array}$ & $\begin{array}{l}\text { Institutional Development } \\
\text { (IDS) }\end{array}$ \\
\hline Savings (in three areas) & Productivity enhancement & $\begin{array}{l}\text { Formation of groups, } \\
\text { federations, cooperatives }\end{array}$ \\
\hline $\begin{array}{l}\text { Credit- agricultural, allied } \\
\text { and non-farm }\end{array}$ & $\begin{array}{l}\text { Risk mitigation (non } \\
\text { insurance) }\end{array}$ & $\begin{array}{l}\text { Accounting and management } \\
\text { information system }\end{array}$ \\
\hline $\begin{array}{l}\text { Insurance- lives and } \\
\text { livelihoods }\end{array}$ & Local value addition & $\begin{array}{l}\text { Building collaborations to } \\
\text { deliver services }\end{array}$ \\
\hline Financial orchestration & $\begin{array}{l}\text { Market linkages- input supply, } \\
\text { output sales }\end{array}$ & $\begin{array}{l}\text { Sector and policy work, } \\
\text { analysis and advocacy }\end{array}$ \\
\hline
\end{tabular}

\section{Deal Source, Decision Making and Due Diligence ${ }^{108}$}

Deal sourcing at BASIX is decentralised to each Unit Office which operates independently, under an Area Manager. ${ }^{109}$ The unit office has a unit head and four field executives. The field executives at the unit can sanction loans of up to Rs 10,000 (USD 225), which is a 'standard' microcredit loan size, whilst the head of the unit office can sanction loans up to Rs 50,000 (USD 2,250). For larger loans, of up to Rs 200,000 (USD 4,500), the area manager must be consulted.110 The decentralised model of investment reduces the risk of asymmetric information, since local staff is likely to have better knowledge of local conditions than a central investment committee would. The risk of asymmetric information is further reduced by the Local Service Area providers (LSAs) that are attached to each unit. The LSAs are the "backbone of BASIX" and act as the initial contact between BASIX and its clients. They visit the villages and have the day-to-day contact with the organisation's clients. Each LSA covers approximately 12 villages, with a maximum of 400-500 customers in total. The LSAs are the first port of call for new clients. In this role the LSAs help potential clients form joint liability or self help groups that can apply to BASIX for loans. The LSAs thus carry the responsibility for information flowing between the clients and BASIX. To verify the information on the application, the LSAs also interview village elders, neighbours and other senior people in the local area. BASIX relies on tacit knowledge as villagers provide very few documents. The

\footnotetext{
108 Based on www.basixindia.co.in downloaded on 25 January, 2007 and 21 November, 2009; Annual Report 2006/2007, OLE BASIX: A decade in institutional development; interviews with field staff 28 February, 2007- 27 April, 2007.

109 The decentralised unit office operations are based on a business plan worked out at the beginning of the year for each unit, detailing the number of new clients that are expected and disbursement targets.

${ }^{110}$ Based on interviews with unit head and area manager at Nalgonda Unit Office, February, 2007.
} 
role of LSAs in obtaining this tacit knowledge, and subsequently codifying it by filling in forms that are entered into BASIX' computer system, is therefore crucial. ${ }^{11}$

For the micro growth entrepreneurs, the due diligence process is more extensive given that they are asking for individual, and larger, loans. MGEs are also expected to already have existing businesses and assets. Such existing ventures provide information to BASIX about the ability of the entrepreneur to successfully run an innovative business. This process involves, for example, interviewing locally powerful men such as large farmers or politicians to verify that the entrepreneur is reliable and has not in the past defaulted on debt. The MGEs generally work with field executives rather than the LSAs, given the substantial investments and more personalised services provided for them.

BASIX in other words adjusts due diligence practices to the kind of applicant that the proposed loan is for. Where the risks are considered greater because loans are larger and individual, the measures taken by BASIX to seek out information about the applicant and his business are more extensive. Furthermore, a range of risk-reducing measures are uses, such as collateral, documented pervious business experience and testimonies from local powerful and wealthy persons. Meanwhile, for the group loans that are much smaller a limited amount of information is available so BASIX reduces the information problem by providing group loans, speaking to village elders and providing add-on services such as insurance.

\section{Financial Support112}

BASIX recognises the diversity of rural clients and therefore offers various forms of loans- some on an individual basis requiring collateral and some on group basis without deposits. The individual loans are disbursed to established entrepreneurs and larger commercial farmers. The two group-lending models in use include joint liability groups (JLG) which are individual in nature but with joint risk-taking and self-help groups (SHG) that access smaller loans to marginal farmers, women and entrepreneurs. JLGs and SHGs provide amounts of between Rs 10 000-20 000, which is arguably too small to make a sustainable difference in terms of innovation and entrepreneurial activities. ${ }^{113}$ Cattle, for example, cost Rs 12000-16-000. A similar argument can be used for the joint liability groups of women each borrowing say Rs 10000 for household expenses such improving their house or a wedding or other immediate expenses. However, part of the reason for these loans is that through this

\footnotetext{
111 The villages where the LSAs operate have been chosen by the unit office staff together with the area manager after an initial survey of villages in the catchment area, detailing the scope for livelihood financing, opportunities and clients in each village

112 Information from www.basixindia.co.in downloaded on 21 November, 2009; Annual Report 2005/2006-2006/2007; interviews with field staff 28 February, 2007- 27 April, 2007; interview with the CEO, 21 February, 2007.

${ }_{113}$ Although BASIX has since the time of fieldwork increased the JLG loans up to Rs 50000 in certain cases.
} 
type of lending, BASIX expect clients to build up trust with the organization by start to save before taking small loans of increasing size over time which means that an entrepreneurs with an innovative idea may have to wait for several years before being allowed a large enough loan. Here BASIX is teaching or building basic skills of living in a financial economy such as trading with money, saving and making investments beyond day-to-day survival.

However, where these small loans are used successfully is in the market linkage programme referred to above, where BASIX provides crop loans for farmers through JLG groups.

An emerging but as yet small minority of loans which are interesting from the innovation funding perspective goes to the growth micro enterprises. As noted above, these entrepreneurs can receive up to Rs 200,000 (USD 4500). BASIX prefers to invest in working capital and the scaling up or diversification of existing business in order to, as it sees it, minimize risk. Because of aversion to risk and a lack of understanding of what the risks involved are, the micro growth enterprises in which BASIX invests do not necessarily appear very innovative in their businesses, but they do create livelihood opportunities (for instance, 20 -30 extra jobs in the example of the quarry, that is detailed below) by expanding the business or diversifying.

MACS, on the other hand, receive a mixture of the small JLG loans but once they are sustainable and well managed can apply for the larger micro growth entrepreneur loans, as in the case of Koutla-B, detailed below. Hence, there seems to be a system in place in BASIX which is flexible enough to allow clients to graduate from one kind of financial model to another. There seems to be a continuation of finance in the way the financial options allow customers to graduate from one financial option to another. Having acquired loans from BASIX also makes it easier for SHGs and JLGs to access bank finance as a BASIX loan signals reliability and low risk. The clients may graduate to an internal financial option or an external financial option, with the help of BASIX.

In 2003, insurance was added as a risk mitigating tool as part of the financial packages. BASIX itself is not allowed to act as an insurance company but is instead the sales agent for insurance companies such as Aviva and Royal Sundaram. By using a product like insurance, BASIX is able to reduce the risk at client level as well as in their investment portfolio. Insurance is increasingly used at MFIs as a risk mitigating tool for both farmers and institutions. It can be considered an alternative to collateral in some instances because it does away with part of the risk of default.

Finally, it should be noted that BASIX facilitates linkages between its clients and external financial sources such as local banks. ${ }^{114}$ Although not a major part of its strategy, it does mean that BASIX helps entrepreneurs and farmer groups access

\footnotetext{
${ }^{114}$ In addition, BASIX provide limited savings only services, but these are of little relevance to micro growth enterprises, MACS or the market linkage programmes.
} 
finance from the core. BASIX also assists farmers and entrepreneurs in becoming more attractive to core financial institutions by forming groups, providing insurance to minimise risk, and by proving that the these entrepreneur and farmers are reliable clients.

\section{Non-Financial Support115}

BASIX puts great emphasis on the non-financial support it provides in addition to its financial services. The non-financial support services, the Ag/BDS, have developed into a comprehensive support service for farm and non-farm activities including advice on crops, fertilizers, market linkages and business development. Whilst the head office coordinates trials of Ag/BDS services, and oversees the overall strategy, the day-to-day Ag/BDS activities are managed by the unit offices. At these offices, managers responsible for Ag/BDS provide information on best practices and technologies. They look for technologies used elsewhere which would be suitable locally. ${ }^{116} \mathrm{Ag} / \mathrm{BDS}$ has also been active in linking producers in dairy with chilling stations and factories along the dairy value chain. A significant feature of $\mathrm{Ag} / \mathrm{BDS}$ is that clients pay for these services in order to meet their costs. This should make the services more likely to be attractive to clients (as they would otherwise not pay for them), as well as increasing the potential for scaling up the services profitably.

So, through Ag/BDS, BASIX staff actively looks for new techniques, market linkages, and local value addition for its clients. However, there does not seem to be a systematic way of seeking out local market gaps, value addition possibilities and linkages, and the interest and effort that go into these activities vary between areas and units.

BASIX focuses its Ag/BDS efforts on a few specific crops such as cotton, chilli and sugarcane, in addition to dairy management. This is because of two reasons: the majority of farmers grow these types of crops and/or have cattle, and BASIX has, over time, built up expertise in these areas. BASIX has, however, found it considerably more complicated to offer support in a coherent manner at a low cost in the non-farm sector since these entrepreneurs are more heterogeneous and rarely operate in clusters, unlike farmers. For example, BASIX tried out an Inter Borrower Expertise Exchange Programme (IBEX) in 2000-2001, to assist its entrepreneurs in the non-farm sector with a kind of mentoring support, where experts among BASIX'

\footnotetext{
115 Annual Report 2005/2006-2006/2007; interviews with field staff 28 February, 2007- 27 April, 2007; interview with the CEO, 21 February, 2007; interview with managers of Ag/BDS programme 6 March, 2007; IGS Annual Report 2005/2006.

116 An example of a technology that was found elsewhere and implemented locally is the implementation of the procedure of turning sugarcane residue into fertilizer. This technology had not been used in Andhra Pradesh until BASIX staff at a unit office imported the technology from the neighbouring state of Maharasthra.
} 
clients were identified and trained to support other entrepreneurs. However, this service did not have a sustainable revenue basis and discontinued.

To complement Ag/BDS, BASIX offers Institutional Development Services (IDS). These activities include forming groups, such as farmer's cooperatives, SHGs and joint liability groups. These groups are taught how to work together, to share decision making and risks, such as the risk of repayment default, and to learn how to save and repay loans. After this, they can collectively borrow from BASIX. ${ }^{117}$ IDS, in other words, build up the institutions, or habits and practices, of borrowing and repaying, prior to a loan being issued. This makes the loan more effective and the repayment more certain. Again, habits and practices that are in line with what BASIX wants, reduce the risks associated with moral hazard and asymmetric information. Furthermore, by shaping such habits and practices, BASIX makes the clients 'bankable', and it is feasible to believe that once borrowers have been through such training at BASIX, they should be good customers even for core financial institutions, such as local banks. BASIX thus breaks down barriers associated with the assumed unreliability of rural clients. ${ }^{118}$

At BASIX, this system has worked remarkably well with on-time repayment rates of above $99 \%$, which is substantially above most MFIs in the sector. In this sense BASIX recognizes the importance of building new habits and practices among its clients so that they are in a better position to use the loans effectively.

To conclude, the Ag/BDS services ensure that farmers and entrepreneurs maximise the output of their activities through having the latest information or knowledge on technology as well as market conditions and access. Meanwhile, IDS builds up the institutions, or habits and practices that are able to better benefit from the financial services Ag/BDS support. There is thus a model in place that is holistic as it includes separate but interlinked services for finance, non-financial support and appropriate institutions.

\section{Monitoring, Learning and Feedback119}

Two main aims of monitoring at BASIX, beyond making information available to the senior management team, are to gain feedback on the service models in use, so that it can BASIX improve them, and to keep risk in check. The key to the monitoring and information of its clients are the LSAs. The LSAs visit their clients

\footnotetext{
117 Such group-lending is a classic alternative to collateral in micro-level lending.

${ }^{118}$ It should be recalled that in the literature review of chapter 2, it was highlighted that one of the outcomes of the excessive debt forgiveness schemes of governments, was the break-down of habits and repaying loans. Instead, loans from formal institutions, whether government, or banks, were in practice often considered grants.

119 Information from www.basixindia.co.in downloaded on 21 November, 2009; Annual Report 2005/2006-2006/2007; interviews with field staff 28 February, 2007- 27 April, 2007; interview with the CEO, 21 February, 2007; participation in quarterly review 25-27 April, 2007 in Wardha and Bandhara Unit Offices and BASIX HQ.
} 
on a weekly or monthly basis to collect repayment, and to discuss progress and issues that the clients may have with repayment or their business. The LSAs bring back the information to the unit offices and from there the information is put on a large information management system. This computer system holds information gathered on all its clients. In this way information from unit offices, even in remote areas, is codified and flows to the head office within 48 hours. There are thus clear feedback loops in place that send information and new knowledge about clients and services to the head office. BASIX acts on this information and uses the feedback loops to implement changes at grassroots level.

Furthermore, there are yearly reviews through the so-called PLR Process, when each unit and every staff member reports on successes and failures, where gaps in services are, what works and what clients need. The best known reviews, however, are the quarterly reviews, where external people (fellow professionals and academics with an interest in BASIX) are invited to take a look at one or two field units over two days, and to assess how BASIX is operating and what impact it is having. The review groups always include representatives from other NGOs or people who plan to start NGOs. The interesting part of this review, therefore, is not only the feedback BASIX receives from these visitors, but also the way in which BASIX disseminates its model and best practices, which then influences other existing and prospective organizations in the sector. Furthermore, such openness gives clear signals about transparency and accountability to any potential future partners.

The most extensive internal review of BASIX, however, is the Organisational Learning and Evolution Process, or OLÉ for short, which took place in 2000, with a second major review, VISTAR, five years later. BASIX reviewed all of its activities, its mission and its direction. An external part of the review led by experts in the field focussed on the operational efficiency, financial robustness and customer satisfaction, whilst the internal part of the review by employees looked at the organisation's strategy, vision and mission. During year long reviews BASIX thus studied itself critically and the result was an almost new organization with a clearer purpose of what it was there to do and a more flexible and wider range of services focussed on rural livelihoods. Here BASIX appears to avoid the effects of path dependence such as institutional lock-in by critically reviewing itself, using both internal and external reviewers.

\subsubsection{Cases: Quarry, Koutla-B MACS and PepsiCo Linkages}

To illustrate the varied ways in which BASIX supports pro-poor entrepreneur-based innovation, this section will provide one example of each of the three areas, micro growth entrepreneurs, farmer cooperative (MACS), and market linkages, which this case study has identified. 


\section{\#1: Micro Growth Entrepreneur: Mr. Nagaswany's Quarry ${ }^{120}$}

\section{Business Overview}

Mr. Nagaswany is a micro growth entrepreneur near Kurnool, Andhra Pradesh who runs a quarry business. He has agricultural land which he turns into a quarry when it is no longer feasible to grow crops on it, due to the depletion of nutrients. He started the quarry in 2001 and prior to that he already had experience in the business through his family. The business involves a two step procedure: 1) at the quarry the stone is broken by machine and manual labour; and 2) at the factory the stone is cut more precisely and polished.

Nagaswany started the manufacturing unit in 2004. He now stores some of the stone of the quarry so that the polishing and manufacturing unit is still in operation throughout the rainy season when the quarry is filled with water.

In 2007, he took a Rs 100,000 (USD 2,260) loan from BASIX to expand his quarry business, in addition to earlier loans which total Rs 110,000 (USD 2,490). He also has working capital loans from rich farmers, a common and traditional source of informal finance in rural areas, of Rs 200,000 (USD 4,500), and a Rs 200,000 loan from the local State Bank of India branch.

He has no problem obtaining loans because he is a well established person with connections to locally powerful people such as rich farmers, and does not think there is a lack of financial sources for asset-rich entrepreneurs like himself. It is worth noting that he has a relatively safe business, collateral and connections which most of the poor do not. Furthermore, he finds that labour is abundant and therefore cheap. At the time of fieldwork, Mr. Nagaswany was looking to expand with further units.

\section{BASIX Role}

Mr. Nagaswany knew of BASIX from other customers and has so far received four loans: initially Rs 10000 for a buffalo, then Rs 50000 (USD 1,130) for granite in 2004 when he started the quarry, followed by Rs 50000 for a polishing unit and finally Rs 100000 for raw materials and polishing.

Although he has several loan options available, he has chosen BASIX as the main lender over the two core financial institutions, the Bank of Hyderabad and State Bank of India because of the monthly and regular repayment schedule that BASIX offers, together with its willingness to visit him to obtain repayments. So the entrepreneur had already established links with core financial institutions and was therefore considered low risk by BASIX.

\footnotetext{
${ }^{120}$ Based on fieldtrip to Kurnool Unit Office on 30 April, 2007, backed up by general Micro Growth Entrepreneur information from visit to Wardha and Bandhara Unit Offices on 25-27 April, 2007.
} 
Mr. Nagaswany benefits from regular visits from BASIX field staff who provide advice on business management and help with market linkages outside the local area such as new wholesalers across AP. BASIX is helping Mr. Nagaswani with marketing as this is a key weakness according to the entrepreneur. BASIX does so by using its established reputation and network to make connections with sales agents and sales outlets. It also helps establishing contracts with finishing units that buy the un-polished stone from the quarry. The market linkages provided by BASIX help strengthening the company sales and reduce the overall risk of the financial investment. However, overall it appears that BASIX' involvement has been mainly financial. This is because Mr Nagaswany's firm is relatively well established and he already has the skills to manage the quarry efficiently. Furthermore, the fact that Mr. Nagaswany had access to other sources of formal funding, may question the usefulness of BASIX' investment from a social or pro-poor perspective. Though, BASIX may have suffered from asymmetric information here. Nevertheless, this kind of investment does provide livelihood opportunities and therefore qualifies for a BASIX loan.

\section{Social impact and commercial sustainability}

The investments in his business mean that he is able to employ 40 people in the quarry and 20 people in the polishing and manufacturing unit. Providing livelihood for 60 people is a significant amount in a small rural village. Furthermore, because Mr. Nagaswany now has the ability to store stone, he is able to keep his manufacturing staff on throughout the year. Finally, he has doubled the output of the quarry since the latest investment and now keeps his whole family employed.

\section{\#2: MACS: Koutla-B121}

\section{Business Overview}

Koutla-B is a village in Adilabad district, one of the poorest and least developed districts in Andhra Pradesh. Here the average landholding is 5-6 acres and the main crop is cotton. ${ }^{122}$ Cotton is generally grown under rain-fed conditions and the average yields are $4-5$ quintals/acre. ${ }^{123}$ Cotton farmers tend to use a large amount of

\footnotetext{
${ }^{121}$ Based on a fieldtrip to Nirmal Unit Office on 6 March, 2007; Annual Report, 2006/2007; A Decade in Institutional Development, 2007; Armanath, S., Financing the Agricultural Value Chain- BASIX Experiences, 2008.

${ }^{122}$ BASIX' intervention in cotton was a direct response to a wave of farmer suicides due to indebtedness, which made BASIX study the situation of the cotton farmers. The field executive in charge of the study found that farmers were using chemical pesticides indiscriminately, borrowing in kind from pesticide dealers and becoming heavily indebted in the process. Furthermore, farmers had comparatively higher input costs whilst received lower and fluctuating prices.

${ }^{123}$ BASIX Annual Report 2006/2007.
} 
pesticides on the crop, accounting for up to $55 \%$ of total pesticides used in India. ${ }^{124}$ Across Andhra Pradesh (and other states of India) NGOs have long been working with cotton farmers to introduce integrated pest management (IPM) and non pesticide management (NPM) practices to cut down both on the high cost of expensive fertilizers and pesticides which tend to be used excessively, and to improve the health of farmers who otherwise use these chemicals with little awareness of the risks involved. In Koutla-B, 82 farmers are now organised into a mutually aided cooperative society (MACS) through which they collectively bargain for input and output prices. They also use the MACS to improve the linkages to sales agents and markets. Each farmer contributed Rs 1,000 at the outset, as start-up capital of the society.

\section{BASIX Role}

BASIX' first intervention in 2001 was to group 50 farmers into JLGs of five to seven persons per group, through which it provided crop loans. The JLGs in Koutla-B began organising meetings together to discuss problems and possible solutions. Finding that information exchanges in groups of five to seven farmers were not as useful as larger group discussions, the farmers formed the larger MACS out of the JLGs. BASIX' field executives meanwhile looked for improved pesticide management solutions fro the 50 farmers that were part of the MACS in the first year. In this way BASIX facilitated improved technologies by searching for new knowledge, using the wider network of knowledge types that BASIX staff had access to. ${ }^{125}$ BASIX worked with AP Agricultural University to find improved and cheaper practices, resulting in integrated pest management (IPM), and with Pest Control India (PCI) to improve the quality and timeliness of required inputs. BASIX persuaded farmers to implement IPM and in one year farmers decreased pesticide sprays from 20 to 7 and the following year to 3 sprays in total, whilst the pesticide management cost had decreased to $25 \%$ of the original, without decreasing yield. It required trust from the farmers to give up previous practices and experiment with new when they were already operating at subsistence level. Whilst 50 farmers agreed to do so at first (the lead users) with small plots of land, the positive results meant that the number of adopters and the number of acres used grew rapidly.

In 2003 the farmers asked BASIX to help them procure inputs for IPM as well as improve their marketing. Also, with the help of BASIX the farmers established a mutually aided cooperative society (MACS). Using its strengthened bargaining power, the Koutla-B MACS was able to buy in bulk and improve prices on inputs like seeds, fertiliser and pesticides.

\footnotetext{
124 BASIX- A decade in institutional development, 2007.

125 This non-financial support was subsidised by IGS (the BASIX R\&D arm) when it first started. By 2007, parts of these services were covered by fees of Rs 100 per year paid by participating farmers. Nevertheless, IGS still finances part of the non-financial support.
} 
In the following couple of years, additional services were added, including insurance and agricultural development services. By 2007, the MACS had taken a Rs 2300000 loan from BASIX to build storage facilities and upgrade existing machines. Most of this had been paid back at time of field visit. The MACS was planning to take an additional loan for their input business and had already approached commercial banks in addition to BASIX, at the time of fieldwork in 2007. So the farmers in the MACS had moved from being members of a JLG to support each other and share knowledge, which developed into a MACS, which they finally developed into a business in its own right.

Once input supplies had been established with the MACS, BASIX turned to the output and marketing side, looking for new buyers that would buy directly from the MACS, thus avoiding the costly middlemen. BASIX evolved it services with the new demands and /or capabilities of the farmers. It did so through its local unit offices which acted as mentors, and through the IGS which provided the overall support structure and field tested initial services and products. Demand that had previously been invisible or not there, became visible as output and income improved and farmer's capacity increased. For instance, farmers expected better prices for inputs and outputs as they got access to better information. They also sought to increase value addition by for instance sign contracts with spinning mills. 'Super Spinning Mills' from Coimbatore agreed to buy cotton from Adilabad district, leading to stabilised prices that were improved by about $5 \%$. However, since the MACS bargaining power would be further improved if the MACS farmers had their cotton ginned in order to sell lint instead of raw cotton, BASIX linked the farmers with a local ginning factory.

By 2007 there were 20 cotton farmers' MACS in Adilabad district which were planning to establish a federation which was in the process of leasing a ginning factory. So, along with improved capacity of farmers and increased income, empowerment of local farmers through the MACS increased.

Finally, BASIX worked with the National Commodity Derivatives Exchange (NCDEX) to install a price display terminal in the village so that the farmers would have up-to-date information on cotton prices in both spot and futures markets. There were also plans to enable farmers to trade directly on the NCDEX in order to get the best prices.

\section{Social impact and commercial sustainability}

The MACS started with 51 members but quickly grew to 81 members the following year. ${ }^{126}$ By 2007, it had 82 members with another 80 wanting to join. The MACS has

\footnotetext{
${ }^{126}$ It should be noted that BASIX has a policy of mixed groups but admits that it is very difficult to form groups of different casts, religions and sex because of the strong traditions and a culture going very much against this which means sometimes it is better forming non mixed groups than none at all. The Koutla-B MACS are all from the same landholding caste of Reddy.
} 
become a business not only buying good quality inputs for its members directly from the factory but also lending to members whilst selling seeds, fertilizers and pesticides to non-members of what is left over. Their turnover was Rs 8100000 in 2007 with a net profit of Rs 880000 .

Table 6.4 Loan, turnover and profit of the Koutla-B MACS (source: Amanth, 2008 Financing the Agricultural Value Chain)

\begin{tabular}{|c|c|c|c|c|}
\hline Financial Year & $\begin{array}{c}\text { No of Farmer } \\
\text { Members }\end{array}$ & $\begin{array}{c}\text { Loan from } \\
\text { BASIX (Rs) }\end{array}$ & Turnover (Rs) & Net profit (Rs) \\
\hline $2003-04$ & 51 & 750000 & 5500000 & 180000 \\
\hline $2004-05$ & 81 & 3000000 & 8100000 & 730000 \\
\hline $2005-06$ & 82 & 3000000 & 6800000 & 610000 \\
\hline $2006-07$ & 82 & 5000000 & 8100000 & 880000 \\
\hline Note: Rs 100= USD 2.25 & \multicolumn{4}{|l}{} \\
\hline
\end{tabular}

The Koutla-B MACS is famous throughout the area and other farmers interested in starting a MACS visit. Furthermore, companies with new seeds and products now come to Koutla-B as well to try new ideas on one to two acres. In 2007, BASIX estimated that farmers had on average improved their income by Rs $4000-6000$ or the equivalent of $10 \%$ of their annual income through the new pesticide management alone. ${ }^{127}$ In addition lower input prices, higher output prices and better quality inputs further increased their income. Furthermore, in the years up to 2007 that the MACS and IPM had been implemented in the area, BASIX estimated that the overall gain for participating farmers was Rs 75000000 . In addition to such wealth creation, BASIX had also provided substantial crop loans to the cotton farmers which supported wage labour of an average of 600,000 person days per year or the equivalent of 30,00,000 person days over the whole period. ${ }^{128}$ The total income of those labourers was about Rs120,000,000 over the period. In addition, BASIX provides insurance and Ag/BDS services for which they charge fees and in 2007 BASIX estimated that the organisation had earned a net profit of about Rs9,000,000 over the period in Adilabad district. Finally, it is noticeable that pesticide usage was cut dramatically by the equivalent of 150,000 litres of harmful pesticides over the period.

By assisting farmers in forming MACS, BASIX not only provides financial support, but crucially builds up the ability of farmers to run work together to share information and to bargain collectively. In the case of the Koutla-B MACS this resulted in the MACS essentially running their MACS as a business which signs

\footnotetext{
127 Since BASIX works with over 3000 farmers in the area, and the 82 farmers that are members of the Koutla-B MACS are particularly successful, it is likely that the farmers that are members of the Koutla-B MACS has a substantially higher income than the average reported here.

128 Figurtes from BASIX Annual Report 2006/2007, p. 14.
} 
agreements with suppliers of input, manufacturers and wholesalers of output and with financial institutions.

\section{\#3: Market Linkages: PepsiCo Potato Contract Farming ${ }^{129}$}

\section{Business Overview}

BASIX has been forming market linkages with major retail brands on a trial basis since 2006, and two very interesting cases are the linkages between potato growers and PepsiCo chips makers. BASIX initiated a project in the poor state of Jharkand to supply Atlanta potatoes to the Frito Lay factory of PepsiCo in Calcutta, West Bengal. Jharkand has suitable conditions for potatoes during the December to April rabi season. ${ }^{130}$ The factory normally prefers larger farms as suppliers, but during the lean season they are able to process yield from smallholders. The market linkage along the value chain is a joint effort between PepsiCo, which supplies seed potato, and has put in place a buyback scheme with fixed prices depending on quality and quantity, and BASIX which organises the farmers and acts as a facilitator in the process.

\section{BASIX Role}

BASIX provides three types of assistance to the farmers. Firstly, through IDS, the organisation puts farmers in production groups, along the JLG model.131 The JLGs are necessary because PepsiCo does not go into contract with individual smallholder farmers (and these farmers have on average provided 1 acre for cultivation) a group of 15-20 farmers was needed for reasons of scale. Grouplending also ensures on-time repayment, and reduce risk without demanding collateral which is important since farmers had previously not borrowed from sources other than informal moneylenders. This support, focusing on forming and strengthening farmers' groups, further ensures increased sustainability since farmers are able to sign contracts directly with the factory as a group and

\footnotetext{
129 Based on interviews at BASIX HQ with the Ag/BDS Managers on 6 March, 2007; www.basixindia.co.in accessed 21 November, 2009; and interviews with Unit Office staff implementing market linkage programmes 28 February- 27 April, 2007; Armanath, S., Financing the Agricultural Value Chain- BASIX Experiences, 2008; Confederation of Indian Industries, 2008. Indian Companies with Solutions that the World Needs, 2008.; Sharma, A. Farming Reaps Harvest, The Telegraph, Calcutta, 28 June, 2008.

130 There are two growing seasons in India: Rabi during December-April and Kharif during JuneNovember. The monsoons falls under the Kharif season which is also the season when most crops are growing and with the highest output. The Rabi season suffers from lack of rain which makes irrigation much more important then.

131 Where each member has joint liability for the whole group so that there is significant group pressure on each member to cooperate.
} 
this can be done even in the event that they no longer need the assistance of BASIX .

Secondly, BASIX as well as Pepsico provides a significant amount of nonfinancial support which would be too costly to provide at an individual level. BASIX provides Ag/BDS Services such as assisting the groups in becoming legal structures so that the groups to have legal agreements with Pepsico and later continue without facilitation help, advice on fertilizers and on NPM. Additionally, farmers receive services from Pepsico such as advice on row planting and spacing as well as on the quality and price. The non-financial support maximises the utility of the financial investment by improving farmer's capacity in potato cultivation.

Thirdly, BASIX provides loans as start-up and working capital for the farmers of about Rs10,000. This goes towards inputs like fertilizers as well as labour costs.

Table 6.5 The outcome of BASIX-PepsiCo potato contract farming in Jharkhand, 2006/2007 (soure: BASIX Annual Report 2006/2007)

\begin{tabular}{|l|l|}
\hline BASIX-PepsiCo Potato Contract Farming, Jharkhand, 2006/2007 \\
\hline Total Acreage & 518 Acres \\
\hline No of Farmers & 1108 \\
\hline Of whom, fee paying Registered Farmers & 907 \\
\hline No of farmers who took loan & 873 \\
\hline Total Loan & Rs 42,700,000 (USD 96,500) \\
\hline Net interest earned (3 months) & Rs 53,700 (USD 1,200) \\
\hline Ag/BDS Revenue & Rs 272,100 (USD 6,150) \\
\hline Net Ag/BDS net income & Rs 64,200 (USD1,450) \\
\hline Total Payment made to farmers & Rs 13,900,000 (USD 314,000) \\
\hline Avg. Payment made to farmers & Rs 12974 (USD 293) \\
\hline Avg. Price paid to farmers & Rs 7.60/ Kg \\
\hline
\end{tabular}

\section{Social impact and commercial sustainability}

Initially 216 farmers participated in 2005-2006. A year later, about 1100 farmers participated, collectively cultivating over 500 acres of land. This occurred after farmers had noticed the significant increase in crop yield, delivery of quality planting material at field and advantages of pre-determined price and harvest from field with yield, ease of credit and crop insurance.

In 2008 BASIX was reaching over 3000 farmers cultivating over 800 acres. ${ }^{132}$ So, the impact has been significant on farmers' livelihoods. Forming groups has provided them with better access to market linkages. Their farming practices have also improves with the access to expertise and mentoring, best practices, and improved technology.

${ }_{132}$ S. Armanath, Financing the Agricultural Value Chain- BASIX Experiences, 2008. 


\subsubsection{Conclusion}

BASIX is a livelihood financial services provider that finances and supports a wide range of rural clients, primarily using debt. The financing is complemented by payfor non-financial services such as agriculture and dairy expertise and new technology training as well as business development. BASIX is a complex organisation which runs a number of different models, the three most interesting for this thesis being the Micro Growth Entrepreneurs, the MACS- farmer cooperatives, and the establishment of market linkages between farmers and big firms such as potato farmers with PEPSICO.

Whilst the MGEs are already established, non-poor entrepreneurs, the MACS and the market linkages models are formed mainly for and by poor farmers. Supporting the MGEs indirectly affects rural poverty through the creation of livelihoods- 60 in the case of Mr. Nagaswany's quarry for example, whilst supporting and establishing MACS and market linkages has a direct effect through better access to markets, improved prices for supplies and farm produce, better access to technologies including improved seeds and access to animal healthcare.

BASIX is unique in the way it caters to such a wide range of rural clients. Whilst the MGEs generally need financial support and some business development services and improved linkages to new markets, MACS and the market linkage projects need a greater amount of services. As such, BASIX works with banks, large enterprises, dairy boards and dairy firms and NGOs.

BASIX is positioned rather close to MFIs, where it has its roots, and has set up a number of initiatives to further the sector, in terms of regulation, best practices and policy. However, it also works with banks to established further loans for its clients. In this sense, the model can been seen as more 'conventional' and closer to the core banking system than S3IDF or Aavishkaar for instance. Nevertheless, BASIX does work with Aavishkaar on a microfinance fund, and there could potentially be financing complementarities emerging if MGEs outgrowing BASIX's support tools could look for risk capital in order to expand.

As regards the framework of chapter 3, BASIX highlights that flexibility does not need to mean that each client needs to receive a unique mixture of services especially tailored to their needs. Instead BASIX is able to minimise risk whilst increasing access to finance for the rural poor by providing a menu of financial options. These financial options are based on the same idea of financing entrepreneurship and innovation through loans, but tailored to the needs of different kinds of farming or to non-farm sector activities. 


\section{$6.2 S^{3} I D F^{133}$}

\subsubsection{S3IDF the Organisation}

\section{Background, Mission and Objectives 134}

The Small-Scale Sustainable Infrastructure Development Fund (S3IDF) finances and implements environmentally, and financially, sustainable infrastructure solutions in rural and semi-urban India. S3IDF was set up in 2001 in the US and began operations in Bangalore, India two years later. ${ }^{135}$ The organisation uses a Social Merchant Bank model which is based on the belief that if poor people are given access to knowledge, business management, financial support, and linkages to markets, then the lack of infrastructure can be solved in a financially sustainable manner. Locally SIDF involves the poor both as clients and as entrepreneurial owners and managers of the infrastructure services. More concretely, S3IDF uses locally available financial and non-financial support to put together, adapt and implement technical solutions such as solar lights, LED lanterns, grid lights, coin phones, pressure cookers, hawker lighting, and village computer kiosks. To this end, the organisation's mission is

"to foster pro-poor, pro-environment small-scale infrastructure services with financing and technical assistance for electricity, water, sanitation and other infrastructure (e.g. transport and telecommunications) necessary for poverty alleviation" ${ }^{\prime 36}$

SIIDF is the brainchild of a group of people with a background at the World Bank. Believing that there are real gaps in the approach to infrastructure implementation programmes among the major providers such as Governments, the private sector and international organisations, they saw the potential in using the techniques of large-scale infrastructure projects in a scaled down version to reach rural and semi-urban poor. However, the group behind S3IDF also noted that to operate sustainable infrastructure services, some minimum criteria must be met. Therefore, SIIDF sees itself as operating in the overlapping area of the 'connected'

\footnotetext{
133 The information in this case study is based on: interviews in Bangalore and Nayakanahatti, Karnataka, India, 16-17 November, 2007; S3IDF's Intraspark Newsletter No. 1, June, 2006; No, 2, January, 2007; No. 3 July, 2007; Business Plan: long internal version, August, 2006; Business Approach Document, 2007; 12 investment projects sheets from 2007 and 2008; website www.s3idf.org accessed on 7 December, 2006; 28 October, 2007; 28 November, 2009.

134 Data stems from interviews in Bangalore and Nayakanahatti, Karnataka, India, 16-17 November, 2007; Business Plan: long internal version, August, 2006.

${ }^{135}$ The choice to focus on India came from the founders' extensive experience in the country. India also had the prerequisite conditions including a (relatively) supportive regulatory environment, local institutions interested in co-financing projects and know-how and technology providers willing to form partnerships.

${ }^{136}$ www.s3idf.org, downloaded on 28 November, 2009
} 
and the 'unconnected' worlds where there is some access to infrastructure and potential customers have enough income to pay for such services, if rightly priced.

Finance such as debt is available in the connected world where the core of the financial system operates, but not in the unconnected world. Positioning itself in the overlapping area of the connected and unconnected worlds, S3IDF is able to provide incentives for formal technology and finance suppliers to offer their services to those that were previously not connected to such infrastructure services. A large part of S3IDF's work in India is convincing such local mainstream finance and technology providers to provide their services to the local infrastructure entrepreneurs that S3IDF supports. In this way, S3IDF has been able to influence the core financial sector to finance rural innovative entrepreneurs. Furthermore, part of its remit is to disseminate information and lessons from its infrastructure projects in order to influence large international organisations such as the World Bank.

Given that SIDF looks to act as a facilitator bringing together local technology suppliers and banks with local entrepreneurs and NGOs, external actors play a significant role within the Social Merchant Bank model. All the investment related activities that SIDF undertakes is done through local partnerships. In fact, if there is no local partner available to run a project, S3IDF does not go through with the investment. These partners can be either entrepreneurs or local NGOs (the cases in 6.2.3. provide illustrations of both types of partnerships). Furthermore, as in the case of BASIX, S3IDF works with academics, in this case the Administrative Staff College of India (ASCI). In addition, S3IDF partners with local financial institutions such as banks to improve access to financing for their projects. Finally, S3IDF has a network of technology suppliers including SELCO and Sowparnika Bio Energy to a) provide technology and expertise and $b$ ) as a source for highlighting potential new projects. ${ }^{137}$ S IDF clearly has access to a wide network of actors that provide very different services- technical suppliers, academic experts and financial provision for instance.

\section{Organisational Structure $\mathbf{e}^{138}$}

S3IDF was set up in 2001 in Cambridge, Massachusets, USA by Dr. Lucia da Silva, a former World Bank employee with expertise in infrastructure projects. The following year, S3IDF created a non-profit affiliate in India with the same name and mission, and operations in India finally began in 2003. ${ }^{139}$

The team at the headquarters in the USA oversees the strategy of S3IDF, the international fundraising and international diffusion of the Social Merchant Bank model. Dr. da Silva is instrumental in formulating the strategy and fundraising

\footnotetext{
${ }^{137}$ S'IDF Summary October, 2007

138 Information stems from the Business Plan: long internal version, August, 2006, this was substantiated by interviews in Bangalore, Karnataka, India on 16 November, 2007.

139 The status of its US entity is a non-profit, 501(c)(3) public charity status, whilst in India the company is registered as a non-profit entity under Section 25 of the India Companies act.
} 
internationally. The India office, meanwhile, is based in Bangalore, Karnataka, with a satellite office in Hyderabad, Andhra Pradesh. The India office is directly investing in, lending to, and providing support for infrastructure related projects. In 2007, the India team consisted of one director and two investment managers as well as investment assistants. ${ }^{140}$ Despite its small size, it is through the work of the India office that the main learnings occur. However, being constrained by both staff numbers and finance, the organisation started with few investments and sought to learn-by-doing before scaling up operations. ${ }^{141}$

Dr. da Silva appears to be particularly influential within S3IDF, as he drives the mission, strategy and direction of S3IDF whilst also having the important international network. That the organisation is relying on one individual to such as extent may have consequences for its ability to scale up and replicate its model.

\section{Activities ${ }^{142}$}

S3IDF has divided its operations into three main areas of business including social merchant banking, support and special approach business, and monitoring, evaluation and dissemination (ME\&D).

The merchant banking business provides finance (grant and loan) to investee projects for business development, to suppliers as an incentive to provide more appropriate technologies, and to banks as a credit guarantee to lower the risk profile of its portfolio projects looking for a loan. Furthermore, the merchant banking business also raises funds for operations that are not sustainably financing themselves, such as evaluation of the pipeline projects.

The second line of business provides support across multiple projects, for instance by investing in improved technologies that can be used by several portfolio investees. The support business also takes on projects that are considered 'worthy' but too risky for the social merchant bank business.

Finally, the monitoring, evaluation and dissemination area evaluates investments to reduce the risk of failure of projects and to improve the overall profile. It also seeks out lessons for the future for internal use and for wider dissemination.

\section{Funding 143}

S3IDF is currently funded mainly by two sets of money: generated fees like interest on credit guarantee fees for loans from banks and technology fees from diffusing

\footnotetext{
${ }^{140}$ The India entity has its own Board of Directors, including four members. The founder, Dr. da Silva, sits on both Boards.

${ }^{141}$ However, scaling up occurred more rapidly than anticipated when S3IDF won a substantial award from the Shell Foundation for its activities.

142 Information from the Business Plan of August, 2006

${ }^{143}$ Data from S3IDF summary, downloaded from www.s3idf.org November 15, 2007; Business Plan, August, 2006, pp. 312-134;
} 
technology for supplier firms; and grant funding from, for example, the Shell Foundation. It had in October, 2007 raised around \$4 million in external sources. ${ }^{144}$

In addition, the founder of SIDF and an anonymous social philanthropist have put in a substantial amount of personal funding into the project since the beginning. It should be noted that a majority of the fundraising takes place in the US. Furthermore, most of the operating money of the Indian entity has been raised by the American entity. That the entity in India that has direct contact with its clients is financed mainly by money raised by the entity in the US may have implications for how the business manages to become sustainable in the long term.

Furthermore, S3IDF works with local banks to provide further funding for local projects. By August, 2006, S3IDF had obtained financing for projects from a number of banks in South India: for nine projects with Canara Bank; six projects with Syndicate Bank; three projects with State Bank of Mysore, two projects with Karnataka Vikas Grameen Bank, ten transactions with Pagathi Grameen Bank and one project with State Bank of India. S3IDF was also in talks with other banks at the time of fieldwork in the autumn of 2007. Banks such as Syndicate Bank have agreed that all its bank branches in the state of Karnataka will agree to financing projects under the 'Lighting for Street Vendors' sub sector of S3IDF. This active involvement with banks creates important links to the core financial system. This active role in changing the behaviour of local banks is setting S3IDF apart form the other case studies in this thesis. None of the others are actively seeking to influence the banking sector to be an integral part of PEBI finance as S3IDF does by signing formal agreements at regional and state level with banks. So, whilst Aavishkaar for example is to some extent grooming its portfolio companies so that they become attractive propositions to the core financial system, S3IDF is instead using incentives (credit guarantees) and persuasion to get the banks to approach the financing opportunities that exist in pro-poor entrepreneur-based innovation.

\section{Portfolio ${ }^{145}$}

S3IDF began in 2003/2004 with three investments. By 2006, S3IDF had made a total of 53 investments in 19 projects within seven sub-sectors (Business Plan, August, 2006). ${ }^{146}$ A total of $\$ 31000$ had been invested in the projects, which had generated $\$ 5000$ in revenue. Furthermore, the portfolio had at the time had over 2000 direct

\footnotetext{
${ }^{144}$ These include: the Shell Foundation, British Foreign and Commonwealth Office in conjunction with the Renewable Energy and Energy Efficiency Partnership, Blue Moon Fund, the Yahoo! Employee Foundation, EDF Energy, The Energy Collaborative, Marcled Foundation and USAID (S3IDF summary, downloaded from www.s3idf.org November 15, 2007)

145 Information from Portfolio document, downloaded 28 November 2009; Business Plan, August 2006; Project Summaries from 2007 and 2008; www.s3idf.org, downloaded 28 November, 2009.

${ }^{146}$ By 2009, S3IDF had made over 120 investments, with another 90 projects in various stages of predevelopment (www.s3idf.org, downloaded 28 November, 2009).
} 
beneficiaries and 10000 indirect beneficiaries, including managers, owners, employees and customers. ${ }^{147}$ A further 100 projects were in the pipeline in 2007.

By 2007, all projects investments were made in South India, either in Andhra Pradesh or Karnataka states. The reason for this concentration is that the frequent visits that are integral to the organisation's support model are easier to make when investments are close to the head or satellite office.

The table on the next page shows the wide range of sectors in which S3IDF was investing by 2007, from lighting services for micro entrepreneurs and households, to micro and larger scale electricity and LGP projects and livelihood and transportation as well as ICT.

All investments by S3IDF go towards services that target poor households or micro entrepreneurs, such as street vendors. However, unlike microcredit which directly targets the poor, S3IDF targets NGOs or entrepreneurs that in turn provide services for the poor. This is similar to the strategy that Aavishkaar uses, but contrasts with some of the activities of BASIX, for example.

It is noteworthy that there are generally three models of investment that S3IDF uses. Firstly, it invests directly in local entrepreneurs that provide services (such as lighting). Here it also provides a large amount of capacity training and looks for better, more suitable technologies. Secondly, S3IDF partners with a local NGO, such as CRWCWS, providing mainly finance. The local partner takes care of the direct interaction with clients. Thirdly, S3IDF invests in larger scale entrepreneurs or projects such as the electricity feeder for villagers. Here the support includes gapfilling finance, some working capital and partial guarantees to link the entrepreneurs or local partner with banks. S3IDF is thus dynamic in the way it targets different forms of infrastructure investments.

147 Source: www.s3idf.org, downloaded 28 November, 2009. 


\begin{tabular}{|c|c|c|c|c|}
\hline Sector & Examples & S3IDF's role $^{3}$ & Social impact & Commercial viability \\
\hline $\begin{array}{l}\text { Lighting } \\
\text { services }\end{array}$ & $\begin{array}{l}\text { Lighting for street } \\
\text { vendors (see case } \\
\# 1 \text { ), and lighting for } \\
\text { silk cocoon rearing } \\
\text { farmers }\end{array}$ & $\begin{array}{l}\text { Silk farmers: } \\
\text { make solar } \\
\text { lights available } \\
\text { together with } \\
\text { financing } \\
\text { scheme. }\end{array}$ & $\begin{array}{l}\text { Farmers can } \\
\text { work longer } \\
\text { hours, in a } \\
\text { cleaner } \\
\text { environment, } \\
\text { which has } \\
\text { improved the } \\
\text { quality of } \\
\text { work and } \\
\text { income. }\end{array}$ & $\begin{array}{l}\text { S3IDF arranged for } \\
\text { local bank to provide } \\
\text { loan by providing } \\
\text { loan guarantee. The } \\
\text { farmers pay } 15 \% \\
\text { upfront and pay the } \\
\text { loan over } 36 \text { months } \\
\text { with } 14 \% \text { interest. } \\
\text { After the initial } 16 \\
\text { farmers, } 18 \text { more } \\
\text { farmers are } \\
\text { interested. }\end{array}$ \\
\hline $\begin{array}{l}\text { Biomass } \\
\text { energy }\end{array}$ & $\begin{array}{l}\text { Local business } \\
\text { installing biogas } \\
\text { plants and biogas } \\
\text { based generators. }\end{array}$ & $\begin{array}{l}\text { Providing } \\
\text { working } \\
\text { capital and } \\
\text { assistance in } \\
\text { developing the } \\
\text { business plan. }\end{array}$ & $\begin{array}{l}\text { Improve } \\
\text { access to } \\
\text { energy for } \\
\text { households; } \\
\text { improve } \\
\text { sanitation. }\end{array}$ & $\begin{array}{l}\text { In } 2007 \text { projects were } \\
\text { still being rolled out. }\end{array}$ \\
\hline $\begin{array}{l}\text { Micro-Scale } \\
\text { Energy and } \\
\text { infrastructure }\end{array}$ & $\begin{array}{l}\text { Partnership with } \\
\text { CRWCWS (see case } \\
\text { \#2) that provides } \\
\text { pressure cookers, } \\
\text { stoves, phone } \\
\text { booths and other } \\
\text { infrastructure in } \\
\text { villages. }\end{array}$ & $\begin{array}{l}\text { Providing local } \\
\text { partner with } \\
\text { capital to } \\
\text { provide } \\
\text { services, buy in } \\
\text { bulk, and for } \\
\text { start-up } \\
\text { capital. }\end{array}$ & $\begin{array}{l}\text { Safer cookers } \\
\text { and stoves } \\
\text { burn less } \\
\text { energy whilst } \\
\text { improving the } \\
\text { health of } \\
\text { women } \\
\text { (cooking in } \\
\text { the kitchens) }\end{array}$ & $\begin{array}{l}\text { S3IDF provides the } \\
\text { initial capital for on- } \\
\text { lending or investment } \\
\text { for bulk purchases } \\
\text { that CRWCWS sells } \\
\text { on local households. } \\
\text { Repayments are made } \\
\text { in small weekly } \\
\text { instalments to enable } \\
\text { poor households to } \\
\text { invest. }\end{array}$ \\
\hline ICT projects & $\begin{array}{l}\text { Rural kiosks that } \\
\text { provides internet } \\
\text { access where there, } \\
\text { and/or phone } \\
\text { access where there } \\
\text { previously was } \\
\text { none. }\end{array}$ & $\begin{array}{l}\text { Provides start- } \\
\text { up capital for } \\
\text { purchasing } \\
\text { computers and } \\
\text { phones, help } \\
\text { bulk buy } \\
\text { phone cards. }\end{array}$ & $\begin{array}{l}\text { Internet access } \\
\text { where there } \\
\text { previously } \\
\text { was none, and } \\
\text { courses in } \\
\text { how to access } \\
\text { the internet } \\
\text { and use email; } \\
\text { convenient } \\
\text { phone access } \\
\text { to villagers. }\end{array}$ & $\begin{array}{l}\text { S3IDF allowed for the } \\
\text { loans to be repaid in } \\
\text { instalments thus } \\
\text { allowing the } \\
\text { entrepreneurs to } \\
\text { collect revenues and } \\
\text { re-invest. }\end{array}$ \\
\hline
\end{tabular}




\begin{tabular}{|c|c|c|c|c|}
\hline $\begin{array}{l}\text { Livelihood } \\
\text { and } \\
\text { Transportation }\end{array}$ & $\begin{array}{l}\text { Providing a vehicle } \\
\text { and setting up a } \\
\text { milk route (see case } \\
\# 2 \text { ); installing local } \\
\text { flour grinding } \\
\text { machines }^{148}\end{array}$ & $\begin{array}{l}\text { Grinder: } \\
\text { supporting } \\
\text { entrepreneurial } \\
\text { women by } \\
\text { providing } \\
\text { capital for } \\
\text { investment in } \\
\text { grinding } \\
\text { machine }\end{array}$ & $\begin{array}{l}\text { The } 3 \text { women } \\
\text { cater to 100- } \\
200 \\
\text { households } \\
\text { each that do } \\
\text { not have to } \\
\text { use the larger } \\
\text { mills which } \\
\text { are often } \\
\text { inefficient }\end{array}$ & $\begin{array}{l}\text { S3IDF providing } \\
\text { partial risk guarantee } \\
\text { to a local bank to } \\
\text { provided loans for the } \\
\text { women. The women } \\
\text { have complemented } \\
\text { their existing } \\
\text { businesses (such as } \\
\text { shops) and each } \\
\text { woman has increased } \\
\text { their income. They } \\
\text { also plan to grind } \\
\text { grains to sell flour } \\
\text { commercially. }\end{array}$ \\
\hline $\begin{array}{l}\text { Enterprise } \\
\text { Support } \\
\text { Transactions }\end{array}$ & $\begin{array}{l}\text { Existing businesses } \\
\text { with pro-poor } \\
\text { impact such as one } \\
\text { installing energy } \\
\text { efficient ovens in a } \\
\text { silk reeling } \\
\text { business and } \\
\text { another } \\
\text { entrepreneur } \\
\text { installing energy } \\
\text { efficient stoves for } \\
\text { an arecanut } \\
\text { business }\end{array}$ & $\begin{array}{l}\text { S3IDF provides } \\
\text { larger gap- } \\
\text { filling finance- } \\
\text { providing gap } \\
\text { financing and } \\
\text { working } \\
\text { capital as well } \\
\text { as partial } \\
\text { guarantee for } \\
\text { local banks }\end{array}$ & $\begin{array}{l}\text { Energy } \\
\text { efficient ovens } \\
\text { were installed } \\
\text { in } 400 \text { silk } \\
\text { reeling units } \\
\text { and stoves in } \\
100 \text { arecanut } \\
\text { units. There } \\
\text { was about } \\
40 \% \text { reduction } \\
\text { in fuel usage } \\
\text { for both the } \\
\text { stove and } \\
\text { oven }\end{array}$ & $\begin{array}{l}\text { The Arecanut } \\
\text { entrepreneur had } \\
\text { some problems with } \\
\text { growers meeting } \\
\text { repayments due to } \\
\text { lack of tracking } \\
\text { system, but it was } \\
\text { profitable and he } \\
\text { looked to expand. }\end{array}$ \\
\hline $\begin{array}{l}\text { Larger scale } \\
\text { electricity and } \\
\text { fuel }^{149}\end{array}$ & $\begin{array}{l}\text { Taking over a local } \\
\text { electricity feeder to } \\
\text { improve electricity } \\
\text { services for } 3 \\
\text { villages }\end{array}$ & $\begin{array}{l}\text { S3IDF and a } \\
\text { partner } \\
\text { support } \\
\text { franchisee of } \\
\text { the local feeder }\end{array}$ & $\begin{array}{l}640 \\
\text { households } \\
\text { and } 370 \\
\text { agricultural } \\
\text { pump-sets } \\
\text { had improved } \\
\text { electricity } \\
\text { access. }\end{array}$ & $\begin{array}{l}\text { Improved metering } \\
\text { and collection of fees } \\
\text { in the villages saw an } \\
\text { increase of } 70 \% \text { of } \\
\text { income for the } \\
\text { franchisee }\end{array}$ \\
\hline
\end{tabular}

Finally, it should be noted that the investments that S3IDF makes, such as improved cookers and stoves, as well as access to internet, have a clear social impact. Several lighting projects have improved the working conditions and health of street vendors. These projects have also increased street vendors' income by reducing the cost of lighting whilst improving the quality of their produce (since it is no longer spoilt by kerosene fumes).

${ }^{148}$ In rural India, flour is not usually available, instead grain is bought or grown and then grinded locally.

${ }^{149}$ Source: www.s3idf.org, downloaded 28 November, 2009. 


\subsubsection{The Support Model at S3IDFi5o}

S3IDF implements its business model in a three stage project cycle: the preinvestment phase, implementation and construction phase, and an operations phase. These phases will be further discussed within the financial and non-financial support sections below.

A potential investment must be environmentally sustainable, financially sound and have a clear social impact. In addition it should have the potential for replicability and be viable in terms of the technology to be used and the financing arrangements proposed.

During the implementation phase, S3IDF is initially very involved, but its role decreases as local NGOs and entrepreneurs take ownership. Whilst the initial phase is funded through grants, the implementation phase uses loans and loan guarantee fees, as will be discussed below.

S3IDF manages the risk of its portfolio in two ways. The most obvious is through monitoring its investments whilst at the same time building up a relationship over time with the local entrepreneurs and NGOs that run the projects. At a separate level, S3IDF deals with the investment risk, as perceived by banks, by providing credit to guarantee the investee's loans.

\section{Deal Sourcing, Decision Making and Due Diligence}

During the pre-investment phase, S3IDF identifies potential investment areas and projects by speaking to technology supplier, NGOs, banks as well as contacts in local communities. When SIDF started out, its staff used to go to rural areas on what appears to be an ad hoc basis to survey needs and possibilities. However, by 2007, the organisation was relying mostly on its existing network of local partners including NGOs, entrepreneurs, technology suppliers and banks. S3IDF found that having built a critical mass of knowledge types within its network, it was more efficient to use its network to discover new investment opportunities.

To assess initial feasibility of a project, S3IDF surveys the infrastructure needs of local communities and their ability to pay. In addition, S3IDF speaks to technology suppliers and studies the available technologies to evaluate the appropriateness of existing technological solutions, as well as the technical feasibility of a project.

This stage involves S3IDF staff as well as external experts who assess the risk and feasibility of a project. Furthermore, the end-users - the rural poor, are also participating and consulted during the pre-implementation stage. In this way, S3IDF

\footnotetext{
${ }^{150}$ The information in this section stems from the following sources: interview at S3IDF in Bangalore, Karnataka, India, 16 November, 2007; S3IDF's Intraspark Newsletter No. 1, June, 2006; No, 2, January, 2007; No. 3 July, 2007; Business Plan: long internal version, August, 2006; Business Approach Document, 2007; website www.s3idf.org accessed on 7 December, 2006; 28 October, 2007; 28 November, 2009.
} 
minimizes the problem of inappropriate technological and service solutions. Furthermore, it addresses the issue of invisible demand by evaluating required services and the ability to pay for these services by the end users. By involving the community from the start, it also seeks to ground the services locally to build supportive institutions to increase the likelihood of the investment becoming a sustainable change.

This process requires grants because of the high cost of evaluation of potential investments. Whilst Aavishkaar, for example, is able to charge a management fee to cover those costs, S3IDF relies on grants since its entrepreneurs operate at a different economic level at the periphery and do not have the same ability to pay such fees.

\section{Financial Support}

S3IDF invests between USD1000 and USD10,000 per project, with some exceptions of projects that were funded up to USD50 000, such as the local electricity feeder for villages as detailed in the portfolio table. S3IDF provides grants to evaluate projects, loans to start such projects, it invests in suppliers in order for these to provide more appropriate technology, and finally, S3IDF provides guarantees to banks so that they provide debt financing for S3IDF's entrepreneurs. To date investments have been made through debt or partial guarantees. S3IDF had at the time of fieldwork additionally used lease financing in one project, something it planned to expand on. The partial risk guarantee loan is a particularly useful financing tool for S3IDF. By guaranteeing a loan by depositing a certain amount, normally $25 \%$ of the total amount of the loan, it reduces the perceived risk by the bank by sharing that risk. Once the loan is successfully repaid, the deposited amount is returned to S3IDF for use in other projects. This link with banks is particularly important as it links the financial system's periphery with the core and makes use of the existing and very large bank network in rural India. In the early days, S3IDF provided a $60 \%$ partial guarantee fund to be able to persuade local banks to take part in funding the projects. This has now dropped significantly to $25 \%$ suggesting that S3IDF is being successful in its mission to persuade financiers and other service providers to support infrastructure projects. In a further boost in the same direction, the Syndicate Bank (of Karnataka State) has approved the hawker lighting model and agreed to finance such projects across the State of Karnataka.

Moving forward, S3IDF plans to use other instruments such as equity in larger projects, as well as secondary debt or quasi equity. With a wider range of financial instruments at its disposal, S3IDF can tailor financial solutions to each project and subsequently reduce the risk that project investments will default because of unsuitable financial arrangements.

Furthermore, S3IDF found, soon after starting operations, that it was necessary to support technical services suppliers in order to access the kinds of technology and know-how needed. Therefore, S3IDF pursues the upstream integration of 
technology suppliers by investing in these suppliers in order to acquire more appropriate technology and access their expertise. In this way it is able to stimulate appropriate innovation.

This kind of financing is part of a larger business support area within S3IDF that arranges assistance for designing, negotiating and establishing viable investments. The organisation works with local financial and technical institutions. Such assistance is expensive and contributes significantly to the transaction costs of all small-scale enterprises. The business support area focuses on assistance that is not tied to one particular project, but rather an area where there are already multiple projects, such as lighting for silk farmers or hawkers.

Another instance where SIIDF provides special business support finance is for larger projects, such as that providing electricity in villages in Andhra Pradesh. Here the scale of the project and/or the risk is considered too risky for a more standard portfolio investment. This is, in other words, S3IDF's innovation, or risk, capital fund. ${ }^{151}$

Hence, within S3IDF there are a number of financing sub-models for different use. Financing is dynamic and used beyond direct lending to those implementing infrastructure projects, by, for instance, investing in technology suppliers to innovate to provide more appropriate technology, which in turn improves the chances of success of the infrastructure projects. S3IDF also uses finance to curb risk and credit rationing by providing guarantees for banks, and is in this way successfully linking with banks.

\section{Non-Financial Support}

S3IDF provides support either directly or indirectly through local partners. For instance, whilst the hawker lighting project (further detailed in 6.2.3) is more directly managed by S3IDF and the entrepreneur the organisation has trained, CRWCWS (also detailed in 6.2.3) runs its projects more independently and consults S3IDF mainly for financing opportunities.

The most important aspect of S'IDF's non-financial support is its emphasis on linking local projects with local entrepreneurs that are trained by SIDF to run them, with local banks that provide debt finance, with local technology suppliers, such as SELCO and Sowparnika Bio Energy, that provide technical assistance and knowhow, and in some cases with local NGOs that oversee local day to day operations. This increases the likelihood that a project will be sustainable, according to S IDF. It also puts SIIDF in a position to reduce frequent hands-on support once the local entrepreneurs or NGOs in charge are sufficiently comfortable in running, and expanding, their businesses. S3IDF then takes on more of a supervisory role in relation to further financing, scaling up or diversification of the business. S3IDF therefore evolves in its role as the capacity of the local NGO or entrepreneur grows.

151 Business Plan: long internal version, August, 2006 
Furthermore, S3IDF acts as a facilitator, bringing together suppliers, entrepreneurs and financiers, that are local, to implement the projects. It uses its vast network of varied knowledge types to act as a 'go-between', bringing together different knowledge types and transferring trust to entrepreneurs that S3IDF posits, as an established organisation.

The ongoing capacity building that takes place includes training some of the entrepreneurial rural poor to take ownership and manage the projects at a local level. Entrepreneurs are now, as a result, running successful businesses and even expanding, as in the hawker lighting case. The non-financial support that S'IDF provides includes assistance with writing business plans, thus codifying information to make it more attractive to the formal sector which relies on codified knowledge to a larger extent, assistance with negotiations with banks as well as technical and managerial development of businesses.

\section{Monitoring, Feedback and Learning}

According to S IDF, there are three aims of the monitoring of its project investments. First, to make sure that services provide value for money to the poor; second, to make sure that its entrepreneurs receive the most suitable support; and third, to learn from its projects and diffuse such new knowledge on best practices and policy expertise to governments and international organizations like the IFC. This suggests that SIDF is not only working actively to influence the banks at the core of the financial system, but also the large international organizations that implement large-scale infrastructure projects. However, S3IDF does not, unlike BASIX, undertake work that aims to strengthen the sector or change policy relevant to the sector at a national level in India. This may be due to the fact that the founder of S'IDF has strong links with the World Bank since he used to work there, but not with the Indian Government or NGO sector. This indicates that S3IDF focuses on finance organizations at the core, but not those that regulate and provide an enabling environment for the core and periphery organizations.

\subsubsection{Cases: Hawker Lighting and CRWCWS}

These cases illustrate two slightly different ways in which S3IDF investment and support models operate. The first case is a model where S3IDF works directly with entrepreneurs in providing finance, support, linkages and know-how. In the second example, S3IDF works with a local partner, an NGO. The NGO oversees the services provided. 


\section{\#1: Hawker Lighting ${ }^{152}$}

\section{Business Overview}

Hawkers, or street vendors, sell fruit, vegetable and foods from push-carts throughout Indian towns and villages. Although they are mobile, they tend to frequent the same customer base or area in a semi-permanent fashion. They use kerosene-based petromax lanterns or LPG-based gas lighting to light their stalls or carts in the evening, which is their busiest trading time. However, these are expensive in terms of fuel and maintenance and bad for both the health of the hawker and the goods sold. Since the hawkers earn a daily wage at subsistence level, with no possibility to access financial services from core financial institutions, they lack the possibility to make a longer term investment in lighting or any other infrastructure services. A local entrepreneur, Mr. Murugesh, in the rural town of Hassan, Karnatka, in South India, has solved the problem together with S3IDF by providing rechargeable compact fluorescent lights (CFL). The hawkers are charged Rs12 per day for the use of the lights compared to the expense of Rs 26 per day for kerosene. The lights are charged at Mr. Murugesh's battery charging station during the day and delivered to them early evening.

The rental fee pays for the batteries as well as the salary of the S3IDF trained entrepreneur who charges the batteries during the day powered by solar photovoltaic (PV) panels, full grid electricity systems or hybrid grid-PV systems.

\section{S3IDF's Role}

S3IDF initially intervened by creating a completely new rental service model of battery driven lighting for the hawkers, paid for on a daily basis. There were no appropriate technologies available, so S3IDF partnered with a technology supplier (SELCO Solar Light Pvt. Ltd.) to provide new and more suitable technology which they developed together. S3IDF found a local entrepreneur, Mr Murugesh, willing to take on the micro enterprise. Furthermore, S3IDF as a guarantor for the technology company which was persuaded to agree to a buy-back guarantee of the infrastructure. In other words, this process of innovation was driven by S3IDF as a facilitator that brought in technical experts. To start up the enterprise, S3IDF secured a loan for Mr Murugesh from a local bank by providing a credit guarantee. Here, S3IDF is taking on the role as a 'go-between', using its influence within the sector to link banks within its network with the entrepreneur.

SIIDF, in addition, provided business development support which includes feasibility and profitability studies of the micro-enterprise.

\footnotetext{
152 The information is based on: interviews in Bangalore, 16 November, 2007; S'IDF's Intraspark Newsletter, No. 1, June, 2006; No. 2, January, 2007; No. 3 July, 2007; Business Plan: long internal version, August, 2006; project investment sheets from 2007 and 2008; website www.s3idf.org accessed on 7 December, 2006; 28 October, 2007; 28 November, 2009.
} 
The local bank was impressed with the results of Mr Murugesh's battery rental business and was willing to sanction a further loan for expansion of his venture. S3IDF provided the entrepreneur with a direct loan to access a larger loan at a local bank and facilitated the loan application process and searched for applicable schemes such as interest rate reduction schemes.

For the business development services together with the partial risk guarantee, S3IDF charges a small fee once the entrepreneur make enough money to be able to pay. These fees are flexible and depend on the micro-enterprise's ability to pay.

\section{Social impact and commercial sustainability}

The entrepreneur, Mr Murugesh, is doing well commercially, and has expanded the business from the 50 lights S3IDF invested in, in 2005 to 120 lights in 2007. He was able to acquire bank finance for the additional lights. Mr. Murugesh has also employed a couple of people to assist in his business, thus providing livelihoods for the local community.

For the hawkers, the light is not only improving their health and their products (since there are no longer kerosene fumes affecting the fruit and vegetables they sell), but is also proving cheaper than kerosene. Kerosene had to be bought in bulk got a price of Rs 35 per litre and the hawkers used approximately 750cl per night at a per day cost of Rs 26. The new lights are costing them Rs12 per day- a nonnegligible saving of Rs14 per day. So, what S3IDF has done in this case is to build a venture that supports poor vendors. It has done so by facilitating technology development, access to finance and training a local entrepreneur to run the batter rental business. Furthermore, S3IDF has been involved in monitoring the business since it was implemented and helped access additional financing. What is particularly interesting is how S3IDF can persuade the banks at the core to finance these ventures by providing a credit risk guarantee of $25 \%$ of the loan.

\section{\#2: Partnership with CRWCWS153}

\section{Business Overview}

S3IDF has partnered with a local NGO called Chaitanya Rural Woman and Children Welfare Society (CRWCWS) in rural Karnataka, to provide a range of basic infrastructure services to the poor. The NGO was started by Mr. Ramesh, a former teacher and entrepreneur in the printing business, in 2003. One of the interventions that SIDF and CRWCWS have worked on together is a milk route run by local farmers. An existing milk route was about to shut down because the previous

\footnotetext{
153 The information is based on: interviews in Bangalore and Nayakanahatti, Karnataka, India, 16-17 November, 2007; SIDF's Intraspark Newsletter No. 1, June, 2006; No, 2, January, 2007; No. 3 July, 2007; Business Plan: long internal version, August, 2006; project investment sheets from 2007 and 2008; website www.s3idf.org accessed on 7 December, 2006; 28 October, 2007; 28 November, 2009.
} 
entrepreneur running the route did not find it profitable. However, without the milk route, 225 farmers in 15 villages would be without access to the dairy market. Therefore S3IDF and CRWCWS worked together to take over the milk route and allow the farmers themselves to run it as a cooperative.

\section{S3IDF's Role}

CRWCWS, got to know about the problem the farmers were facing through its local network. It therefore approached S3IDF to finance a truck worth Rs 750000 or USD 14,250 . With this truck the farmers were able to transport the milk from the village to the nearest chilling unit.

A second initiative by S3IDF was to help CRWCW send a bid for the milk route together with the farmers to the state dairy board- the Karnataka Cooperative Milk producers Federation (KMF). The farmers would on their own not have been in a position to approach the state dairy board. However, they won the bid and were allowed to operate their milk route officially paid by the dairy board. The payment for the milk and the mileage is enough to cover the interest on the loan for the truck as well as paying the salary of the driver.

In this way, SIDF and CRWCWS collectively assisted dairy farmers in taking ownership of the milk collection.

\section{Social impact and commercial sustainability}

The social impact of the milk route has been significant as 225 farmers in 15 villages risked losing their access to the dairy market before S3IDF and CRWCWS stepped in. This intervention has provided livelihoods for two additional people who transport the milk, and provided better access to the milk market for 225 farmers. Furthermore, the truck is used for other transportation purposes outside of milk transporting hours which provides additional income. KMF now pays the farmers directly at a rate of Rs 12/litre who do not have to pay the middleman. Meanwhile KMF pays Rs $9.5 / \mathrm{km}$ for the transportation of milk, which covers maintenance and the wages of the drivers.

The important point to note about this model is that Mr. Ramesh continuously identifies unmet needs among the villagers, such as the need for farmers to continue the milk route, and look for viable technical solutions which S3IDF help to acquire and fund, mainly in the form of loans. Since S3IDF has access to capital to invest in a vehicle or bulk purchase phone cards or stoves, it provides CRWCWS with the opportunity to provide more services, and at a better rate, than had it provided services on its own. S IDF is here a facilitator providing finance and a network. For S'IDF's part, a trustworthy local partner significantly reduces information asymmetries and associated risks. CRWCWS takes care of the day-to-day running of projects including money collections, skills training and scouting for new infrastructure opportunities. Furthermore, Mr. Ramesh has, through his many 
projects, a very wide network at grassroots level which is a help to S3IDF when looking for new projects or entrepreneurs to get involved with. Therefore these two periphery organisations are both benefiting from the partnership and each other's networks: whilst CRWCWS can more easily access finance, S3IDF is able to access local entrepreneurs and find out about new funding opportunities. Furthermore, SIIDF avoids the time-consuming day-to-day micro management of individual household projects and loans that the NGO takes care of locally.

\subsubsection{Conclusion}

S3IDF as a social merchant bank builds and implements models of infrastructure services for the poor. It provides mainly debt and partial debt guarantees (to attract debt financing from banks for its projects). The organisation works with two types of partners- either directly with poor entrepreneurs that are trained by S3IDF to manage and own operations that support mainly micro entrepreneurs such as hawkers or farmers; and with locally established NGOs that provide a number of smaller scale services at the household level.

The projects have a direct impact on the poor since they both own or operate the ventures and benefit from the infrastructure services.

S'IDF is positioned closer to Aavishkaar's model in terms of risk capital, whilst its entrepreneurs and its involvement in building up models that are run by local entrepreneurs more closely resemble the work of CTD (chapter 7) or BASIX. Though this initial project implementation is risky by conventional standards, the established projects are successfully relying on debt finance supplied by banks. This is result of a great effort by S3IDF to build a rapport with local banks to attract bank financing for its clients. That state banks in Karnataka have agreed to finance $S^{3} I_{D F}$ 's infrastructure projects across the state is a major achievement in this regard.

SIIDF has some links with BASIX, and some academic institutions, but otherwise partners mainly with local technology suppliers, banks and NGOs.

This chapter looked at two organisations that provides small-scale finance for mainly poor entrepreneurs and farmers. The next chapter will go on to study organisations that act as innovators and incubators. 


\section{CASE \#3: Rural Innovators and Incubators}

At the grassroots level, organisations assisting innovation and entrepreneurship put their main focus on non-financial support, providing knowledge, building capacity and facilitating linkages to finance, markets and suppliers based on the resources that local rural people have.

Rural innovators and incubators include two types of organisations. Firstly, there are organisations, such as CTD, that themselves identify issues in rural areas that can be solved with the help of new and appropriate technology together with new innovative ways of organising production, reaching markets or using natural resources. Such organisations essentially innovate for the poor, but in a participatory manner.

A second type of grassroots organisation provides incubation support for rural entrepreneurs with exciting ideas. Organisations such as Villgro and GIAN believe that innovation occurring in rural India will yield results in the form of technologies and practices that are more applicable to life in village India than are technologies transferred from non-rural sources. These organisations incubate such technologies and entrepreneurial ideas by providing networks, business management support and market linkages, and bring them to other parts of rural India, to some extent a transfer of technologies within rural India.

\subsection{Centre for Technology Development}

Where there is not enough capacity in the local community to undertake productive entrepreneurship and innovation, organisations themselves intervene and spearhead the innovation process. The emphasis is on building capacity through non-financial support, innovating and creating sustainable interventions which a community can run independently. One organisation that is inspired by the Gandhian idea of village self-reliance is the Centre for Technology Development (CTD). 


\subsubsection{CTD ${ }^{154}$ the Organisation}

\section{Background, Mission and Objectives ${ }^{155}$}

CTD is a Delhi based organisation set up in $1982^{156}$ that puts together and implements interventions based on available raw materials and skills among very poor and disadvantaged communities in rural India. The organisation looks at the raw material and existing skills available in a particular area and constructs an intervention based on a strategy of processing and marketing that raw material, for example, hides for leather-making or clay for pottery. In addition CTD creates or adapts technology to improve the processing, and trains local communities in new production methods. These interventions are community-based and, over time, community-driven. Therefore, an important aspect is capacity building to form supportive institutions within the community. CTD puts together one general intervention type for each section and that intervention is fine-tuned into approximately six slightly different versions with the help of local organisations it works with. In this way CTD manages to make a quite general intervention in each sector context specific. It also allows CTD to adapt its interventions to local requirements so that, for example, in Mandi, Himachal Pradesh (HP), a fruit processing unit is using a technology for producing jams and juices, whilst in Kavali, Andhra Pradesh the same intervention type and technology is used to grind spices such as garlic.

CTD first developed its intervention strategy after noticing that the terms of trade from rural to urban areas were deteriorating as they were benefiting the urban areas at the cost of rural ones. This resulted in deskilling of rural areas because whilst the raw material would come from the rural areas, the processing would take place in urban locations. As a result, the artisan networks which rural India had relied heavily upon were falling apart. Influenced by the idea of village self reliance promoted by Gandhi, CTD began to create technology-focussed business models based on the raw material and artisan skills available in a particular area.

\footnotetext{
154 Information sources include: website www.ctd.in, accessed on 2 May, 2007, 10 September, 2009, 21 April, 2010; Interviews with staff at CTD in Delhi on 15-18 May, 2007; Field visit and interviews with STD in Kullu and Mandi, Himachal Pradesh on 22-25 May, 2007; STD Brochure, 2006; STD Report, 2006; CTD Project Proposal Pottery, 2003; CTD Project Proposal for non-edible oils, 2007; CTD and STD Project Proposal for Stoves, 1995; CTD Final Project Report for Leather, 1990; Project brochures (various) of STD, 2006; Portfolio overview, 2008 downloaded from www.ctd.in, on 21 April, 2010; Information on investment areas downloaded from www.ctd.in, on 21 April, 2010; Description of fruit processing downloaded on, 21 April, 2010.

155 Based on the following sources: 2010; Interviews with staff at CTD in Delhi on 15-18 May, 2007; Field visit and interviews with STD in Kullu and Mandi, Himachal Pradesh on 22-25 May, 2007; STD Brochure, 2006; STD Report, 2006.

${ }^{156}$ It was set up as an independent entity backed by the Department for Science and Technology (DST)
} 
As the approach that CTD uses is multidisciplinary, the core team is made up of social scientists, technical experts and engineers. They work together on new solutions in a manner that integrates social aspects (community /group formation, trust building, skills training, awareness), new technologies and knowledge of, and access to, new markets. Thus CTD has access to a number of different knowledge types already within its team. This differs from, for example, Aavishkaar or S3IDF, which rely on external technical experts to a greater extent. CTD believes that its interdisciplinary approach differs from others in that it substantially alters technologies to fit with particular local needs. ${ }^{157}$ The organisation therefore undertakes a lot of in-house research, development, standardization and trials. Furthermore, the focus on institutional and organisational innovation alongside technological innovation ensures that CTD has moved beyond the trap of standard technology transfer programmes of previous decades. ${ }^{158}$

Beyond the grassroots innovation and intervention it undertakes, CTD influences sector policy in two ways. First, CTD acts as an expert for Government ministries. Second, the CTD team acts as a policy lobbyist to influence the kind of strategies that are taken up by government bodies such as the Department for Science and Technology of the Government of India (DST).

Each of the interventions that CTD is involved in is implemented in partnership with a local NGO. These local NGOs are of central importance since the NGOs take over much of the management of the community projects over time. ${ }^{159}$ Other crucial partners are the academic and research institutes that provide sector specific expertise, such as Dr. YS Parmar University of Horticulture and Forestry in Solan, Himachal Pradesh for fruit processing models, and the Central Leather Research Institute in Chennai, Tamil Nadu, for technical expertise on leather models. So CTD has access to a wide range of knowledge types both within its organisation and its network.

\section{Organisation ${ }^{16 o}$}

CTD is a non-profit organisation. The core team of six to seven people, headed by D. Raghunandan, an engineer by training, is multi-disciplinary, also including natural

\footnotetext{
157 Furthermore, CTD emphasises the need for technologies that have a considerable lifespan as the organisation takes a long-term view and aims to make its technologies as flexible as possible to provide room for future changes so that the technologies can be functional for considerable period of time.

${ }_{158}$ As noted in chapter 2, these transferred technologies were often of little use when they reached the end-users. Even when technically excellent, the interventions often did not fit with the local context, such as large tractors in small Indian fields.

${ }^{159}$ Most of the NGO contacts stem from the All India People's Science Network (AIPSN), that CTD is a member of. AIPSN is a network for organisations that work on science and technology based solutions for poverty alleviation.

160 Information sources include: website www.ctd.in, accessed on 2 May, 2007, 10 September, 2009, 21 April, 2010; Interviews with staff at CTD in Delhi on 15-18 May, 2007.
} 
and social scientists. In addition, there are three to four consultants with expertise in different business areas and sectors, that are based elsewhere but who are working virtually full-time for the organisation.

At CTD, the core team, based in Delhi, works with local NGOs that run field stations in rural parts of India. Together CTD and the local NGO implement and run the community models. Once the technology and business models have been implemented successfully locally, the NGO is expected to take charge of the management of the interventions. CTD likens the local organisations to semiindependent franchises of CTD. Only one unit based in Dehradun, Uttarakhand in North India is formally part of CTD.

\section{Activities ${ }^{161}$}

At the time of fieldwork, CTD had implemented intervention types in leather and carcass utilisation, fruit processing and pottery. Furthermore, interventions in nonedible oils were being tested and refined. By 2009, CTD had additionally created an intervention for processing Mahua flowers.

Since these intervention types take several years to build up, CTD simultaneously works on several of them, but at different stages. Whilst finishing one intervention type, the team is already thinking about the next one whilst a third one is being implemented.

In 2007, for example, CTD was disseminating its interventions in fruit processing and leather whilst refining its interventions in non-edible oils, and looking into the next possible area of work. CTD is in other words continuously evolving. This flexibility and ability to evolve and change lies not in a unique type of intervention or investment for each community that it supports, but in its ability to create a generic type of intervention with several versions that, when implemented with knowledgeable local partners, become context specific. ${ }^{162}$

\section{Funded By ${ }^{163}$}

CTD uses multiple sources of funding to support its activities. According to CTD, the funds that are used to research, create, implement, and maintain interventions, include fees from dissemination, problem solving and consulting work that CTD

\footnotetext{
${ }^{161}$ Information sources include: website www.ctd.in, accessed on 2 May, 2007, 10 September, 2009, 21 April, 2010; Interviews with staff at CTD in Delhi on 15-18 May, 2007; Portfolio overview, 2008 downloaded from www.ctd.in, on 21 April, 2010; Information on investment areas downloaded from www.ctd.in, on 21 April, 2010.

162 Other activities that CTD undertakes include consulting on short-term projects within their expert areas. This is mainly done in order to finance the implementation of their business models, beyond the financing provided by the grants that CTD receives.

163 Information sources include: website www.ctd.in, accessed on 21 April, 2010; Interviews with staff at CTD in Delhi on 15-18 May, 2007; Portfolio overview, 2008 downloaded from www.ctd.in, on 21 April, 2010; Information on investment areas downloaded from www.ctd.in, on 21 April, 2010; Description of fruit processing downloaded on, 21 April, 2010.
} 
does in addition to its work on the community-based interventions (50\%), public grants $(30 \%)$, and miscellaneous research and demonstration projects $(20 \%)$. The grant funding for CTD comes mainly from DST's Science and Society Division. ${ }^{164}$ However, what DST programme provides funding for is 'innovation' in the technical sense which means it does not take fully into account the social aspects of the innovation process. For instance, financing is available to establish a new technical tool or machine- an invention, as well as to pilot test and to a certain extent implement it. However, the funds do not cover the work that goes into forming groups or building non-technology specific capacity. Furthermore, once dissemination of an intervention is complete, DST does not provide further funding for improving, upgrading and changing existing technologies and processes to grow or diversify a community-run project. Instead CTD relies on fees earned on consulting services.

Alternatively, if it related to a local intervention that has been successfully implemented and is run by the community itself, CTD assists local communities and NGOs managing the interventions, to apply for bank finance locally. Such local funding, needed to expand local projects, is raised from local banks, with difficulty, NABARD refinance schemes and the government sponsored small-scale funding scheme for artisans called Village Khadi Industries scheme.

It should be noted that all the funds that CTD uses originate from within India. This is a clear policy, which has its political origin in a belief in self-reliance. At a more practical level, CTD does not want to be constrained by international grantgiving agencies that tend to provide funding only against a host of stringent conditions and timeframes.

Thus, unlike the other case study organisations looked at so far in this thesis, CTD relies to a great extent on direct government funding in the form of grants from DST. Its links with other financial actors at the core of the financial system are weak, with the exception of local banks in areas where CTD has been established for some time, such as in HP. CTD believes that grant-based funding is essential at the start-up and implementation phase of its projects as the local community does not have the ability to repay. Here CTD differs from those case study organisations that seek to operate without grants from the outset. It cannot be expected that the private financial firms at the core, such as banks, provide such grants-based funding. Therefore, by providing such grant finance, the government would assist in creating viable enterprises, and these ventures would be more likely to be able to access bank finance once established. This is the case in some of CTD's local projects in Himachal Pradesh which have been able to access local bank finance. Hence, the government would not only provide start-up capital to start a business, but by

\footnotetext{
${ }^{164}$ In addition, CTD acquire funding from specific publicly financed programmes such as the AllIndia Coordinated Programme (ACIP) for leather, for instance.
} 
providing such capital it would attract future private sector capital, thus narrowing the gap to the core financial institutions.

\section{Portfolio ${ }^{165}$}

CTD creates and implements interventions in five distinct sectors: leather, carcass utilisation, fruit processing, pottery and non-edible oils. These sectors were chosen through surveys of available raw materials and skills at the rural field stations which CTD had set up. By restricting itself to certain sectors, CTD has been able to build up its expertise in those areas and to develop several versions of each intervention type.

Whilst CTD's interventions have been implemented across India, initial field stations were set up in five locations in central and north India: Dehradun (Uttaranchal), Mandi (Himachal Pradesh), Ukrhul (Manipur) and Kavali (Andhra Pradesh). CTD's interventions have also been implemented in other states in collaboration with local governments and organisations, but on a consultancy basis. CTD then offers the technology and business model package that makes up the intervention together with an implementation strategy. Whilst CTD oversees the implementation process, the local organisations or government agency are running the intervention. The fruit processing intervention has, for instance, been set up in 43 units across India.

Only the field station at Dehradun remains part of CTD. The others are now run as franchises by local NGOs. These franchises operate quite independently of CTD, which means that the interventions are sometimes implemented differently. For instance, whilst in Mandi, HP, the local NGO, Society of Technology Development (STD), has implemented a fruit value-added strategy that includes processing and marketing, the same intervention type has been implemented in Dehradun, Uttarakand by a different NGO without the marketing aspect.

\footnotetext{
165 Data stems from: website www.ctd.in, accessed on 10 September, 2009, 21 April, 2010; Interviews with staff at CTD in Delhi on 15-18 May, 2007; Field visit and interviews with STD in Kullu and Mandi, Himachal Pradesh on 22-25 May, 2007; CTD Final Project Report for Leather, 1990; Project brochures (various) of STD, 2006; Portfolio overview, 2008 downloaded from www.ctd.in, on 21 April, 2010; Information on investment areas downloaded from www.ctd.in, on 21 April, 2010; Description of fruit processing downloaded on, 21 April, 2010.
} 
Table 7.1 CTD portfolio overview

\begin{tabular}{|c|c|c|c|c|}
\hline Area & Description & Products & $\begin{array}{l}\text { CTD } \\
\text { Innovation }\end{array}$ & Outcome \\
\hline Leather & $\begin{array}{l}\text { Forming producer } \\
\text { groups of flayers, } \\
\text { improving the } \\
\text { processing of } \\
\text { hides including } \\
\text { improved } \\
\text { grading, tanning } \\
\text { and commercial } \\
\text { products. }\end{array}$ & $\begin{array}{l}\text { Vegetable } \\
\text { tanned and wet- } \\
\text { blue tanned } \\
\text { hides sold to } \\
\text { finishing units; } \\
\text { bags and shoes }\end{array}$ & $\begin{array}{l}\text { Scaled-down } \\
\text { vegetable } \\
\text { tanning } \\
\text { machine; wet- } \\
\text { blue tanning at } \\
\text { small-scale } \\
\text { level }\end{array}$ & $\begin{array}{l}\text { Significantly increased } \\
\text { income for flayers } \\
\text { through improved } \\
\text { prices for their hides; } \\
\text { new livelihoods for } \\
\text { flayer families in } \\
\text { tanning unit and } \\
\text { factory. Flayers' } \\
\text { children now attend } \\
\text { school, and social } \\
\text { acceptance increased. }\end{array}$ \\
\hline $\begin{array}{l}\text { Carcass } \\
\text { utilisation* }\end{array}$ & $\begin{array}{l}\text { processed using } \\
\text { pressure cookers } \\
\text { followed by } \\
\text { mincing the meat } \\
\text { and powdering of } \\
\text { the bone. }\end{array}$ & $\begin{array}{l}\text { Tallow/fat for } \\
\text { soap making; } \\
\text { meat meal used } \\
\text { in poultry feed; } \\
\text { bone meal used } \\
\text { as fertilizer in } \\
\text { horticulture and } \\
\text { poultry feed. }\end{array}$ & $\begin{array}{l}\text { Pressure } \\
\text { cooker } \\
\text { Bone crusher }\end{array}$ & $\begin{array}{l}\text { Increased income from } \\
\text { carcass that would } \\
\text { otherwise not be used } \\
\text { for productive } \\
\text { purposes; created new } \\
\text { livelihoods. }\end{array}$ \\
\hline $\begin{array}{l}\text { Fruit } \\
\text { Processing }\end{array}$ & $\begin{array}{l}\text { Forming producer } \\
\text { groups setting up } \\
\text { processing } \\
\text { factories of fruit } \\
\text { and vegetables } \\
\text { that growers sell } \\
\text { their produce to. }\end{array}$ & $\begin{array}{l}\text { Fruit: juices, } \\
\text { concentrates, } \\
\text { squash, pulp, } \\
\text { nectar and jelly. } \\
\text { Onion and } \\
\text { garlic: powder } \\
\text { and paste. } \\
\text { Ginger and } \\
\text { mango: powder. }\end{array}$ & $\begin{array}{l}\text { Fruit } \\
\text { processing } \\
\text { machine for } \\
\text { small amounts } \\
\text { of fruits, which } \\
\text { can be adapted } \\
\text { to different } \\
\text { kinds of fruits. }\end{array}$ & $\begin{array}{l}\text { Increases income for } \\
\text { growers and for the } \\
\text { producer group. The } \\
\text { production unit has } \\
\text { created jobs, mainly for } \\
\text { poor women. }\end{array}$ \\
\hline Pottery & $\begin{array}{l}\text { Units with } \\
\text { machinery that } \\
\text { uses abundant red } \\
\text { clay rather than } \\
\text { scarce and } \\
\text { expensive white } \\
\text { clay. A wider } \\
\text { range of products } \\
\text { can be produced } \\
\text { in the unit, than } \\
\text { manually. }\end{array}$ & $\begin{array}{l}\text { Pots, plates, } \\
\text { vases, } \\
\text { containers. }\end{array}$ & $\begin{array}{l}\text { Mixture of } \\
\text { additives that } \\
\text { makes red clay } \\
\text { suitable for } \\
\text { pottery; small- } \\
\text { scale pottery } \\
\text { machine which } \\
\text { scales up the } \\
\text { pottery output. }\end{array}$ & $\begin{array}{l}\text { Improved income from } \\
\text { cheaper clay and faster } \\
\text { production } \\
\text { mechanisms. With more } \\
\text { diversified designs, } \\
\text { potters are better able to } \\
\text { compete in the market. }\end{array}$ \\
\hline $\begin{array}{l}\text { Non- } \\
\text { edible oils }\end{array}$ & $\begin{array}{l}\text { Collecting plants } \\
\text { in tribal forests } \\
\text { and producing } \\
\text { plant-based oils } \\
\text { used by industry } \\
\text { instead of mineral } \\
\text { oils. }\end{array}$ & $\begin{array}{l}\text { Oil used by } \\
\text { industry in } \\
\text { paints, } \\
\text { varnishes, ink, } \\
\text { adhesives, soaps } \\
\text { and } \\
\text { disinfectants. }\end{array}$ & $\begin{array}{l}\text { A multi-seed } \\
\text { Decorticator } \\
\text { with modular } \\
\text { design } \\
\text { enabling } \\
\text { adjustment for } \\
\text { different seeds. }\end{array}$ & $\begin{array}{l}\text { Provide livelihood and } \\
\text { income for tribal people } \\
\text { who traditionally live } \\
\text { off the forest. } \\
\text { Environmentally } \\
\text { friendly oils for } \\
\text { manufacturing. }\end{array}$ \\
\hline
\end{tabular}

The portfolio comprises clusters of interventions in several sectors around each field station (and local NGO partner). In HP, for instance, CTD has, together with the local NGO, STD, implemented interventions in leather and carcass utilisation in 
the same community. Elsewhere in the same area, CTD and STD have implemented fruit processing as well as pottery interventions. In this way, CTD is able to benefit from economies of scale. These clusters of CTD interventions also benefit from already established links with the local community, local NGOs, local government and local banks. Clustering interventions has a further advantage in that new interventions benefit from the tacit knowledge relevant to the local area that CTD and the local NGO already possess. This is important since CTD relies to a large extent on supportive institutions, or habits and practices being in place to deal with risks.

Financially, the interventions are doing well after the initial implementation. Of the community-run units at the field stations that process fruits or hides, for example, about $75-80 \%$ were profitable within five years. In terms of risk, CTD's interventions have a low failure rate of approximately $10-20 \%$. The main reason for failure is a lack of entrepreneurship among the local NGOs that supervise or manage the interventions locally. To that end, CTD has moved towards working only with organisations that have a proven track record in entrepreneurial endeavours. Thus, just as in other case study organisations, the (often tacit) knowledge of how to run an entrepreneurial venture and innovate, is not widely available among NGOs in rural India. This lack of entrepreneurial spirit and business acumen among local NGOs acts as a constraint to replicate interventions for several of the case study organisations.

For the local communities, the interventions provide additional livelihoods through new jobs created in processing units. For instance, the leather intervention in Mandi, HP that includes a leather tanning unit and a finishing unit altogether employs about 30 staff, all members of flayer families. The fruit processing unit in the same area where the labourers are predominantly female (a strategy to provide women with livelihood opportunities), provides employment for approximately 15 women. In addition, their income has increased through improved harvests, better technologies (such as for flaying), improved inputs and additional value-added through processing the raw material. Another point to note is that any profit that is left after reinvestment in manufacturing and marketing is shared among the growers or flayers that make up the producer groups providing raw materials for the processing units. In this way CTD ensures that growers or flayers have an additional incentive to provide their produce to the processing unit.

Furthermore, it should be noted that CTD's interventions have a clear social impact beyond the obvious increase in income provided by improved technologies and bargaining power as well as an increased number of livelihood opportunities. For instance, the flayers in HP, who suffered from severe caste-related discrimination, have found that increased income, resulting in better housing and schooling for their children, has reduced such discrimination. Family members working in the leather goods producing factory have found their status increasing once they became factory workers rather than daily labourers. That small details, 
such as having a uniform that shows that one works in a factory, can have an important impact on the community is something that CTD works with as part of its interventions. It is this type of context specific tacit knowledge that CTD has built up over a long period that makes it able to understand what works and what does not work locally among communities that are very poor and disadvantaged (through lack of schooling or discrimination, for instance). Therefore, CTD does not only improve livelihood opportunities and income for poor rural communities, but by targeting low caste or tribal communities that are often suffering from discrimination, CTD also empowers people. This in turn breaks down social barriers.

\subsubsection{The Support Model at CTD}

The support that CTD provides is systemic and integrated in the sense that it creates a complete intervention strategy which includes technology implementation, maintenance, monitoring and upgrading. The support includes the following four broad steps: research and feasibility survey; technology innovation and creation of business strategy; group formation, capacity building and implementation; and monitoring and upgrading.

Whilst CTD is initially the main driver of the intervention that is being implemented, its involvement decreases over time as the local community starts operating more independently and the local NGO builds its capacity to manage the intervention. It follows that CTD's role evolves towards a mentoring or supervisory role over time, where it is mainly involved in upgrading of processing units and interventions. However, it should be noted that CTD never leaves projects, and therefore does not look for 'exits' unlike several of the other case study organisations.

Finally, to deal with risk, CTD uses two tools. One is building up relationships and trust over many years with the local community, and the local NGO. The second is building the capacity of local NGOs which eventually take over. Since these NGOs are operating locally, they are likely to be better informed, which reduces the asymmetric information risks.

\section{Deal Source, Decision Making and Due Diligence ${ }^{166}$}

CTD does not scout individual opportunities or entrepreneurs, but looks for poor, disadvantaged communities that have access to raw material, that have some basic

\footnotetext{
166 Information sources include: website www.ctd.in, accessed on 2 May, 2007, 21 April, 2010; Interviews with staff at CTD in Delhi on 15-18 May, 2007; Field visit and interviews with STD in Kullu and Mandi, Himachal Pradesh on 22-25 May, 2007; STD Brochure, 2006; STD Report, 2006; Project brochures (various) of STD, 2006; Information on investment areas downloaded from www.ctd.in, on 21 April, 2010.
} 
skills in processing the raw material, and where there is an NGO that CTD can partner with.

The due diligence approach includes an initial survey and feasibility study of the local area to establish what raw materials are available, what the existing skills are, what the needs of the local communities are, and distribution channels and distance to markets. When developing its original operational intervention in leather and pottery, for instance, CTD first looked at census data which showed that there was a certain pattern to the village and rural economy. This pattern was further elaborated by a mapping exercise in Mandi and Kullu districts of Himachal Pradesh in North India. CTD found that there was generally a town around which there were nodal villages (larger ones) around which there were satellite villages which were much smaller. Each village had its own cluster of artisans but only the nodal villages had certain services and markets, and only the town had specialized material or processing units. This was the case both in pottery and in leather. CTD's interventions are therefore based on a collective and diversified form of production. Rather than small livelihood units, the focus is on labour intensive small-scale units that are decentralised. Each decentralized smaller unit does separate tasks which are assembled and finished at larger central units. This decentralisation of operations is thus based on the network pattern of villages in rural India, as verified by the surveys and feasibility studies.

During the survey, CTD also establishes rapport with the local community and starts building relationships, which are later used as a way to reduce risks inherent in the community interventions. Another important aspect of the due diligence is finding a local NGO with the required entrepreneurial skills (or understanding of entrepreneurship) to partner with.

Given that CTD spends a lot of time exploring the availability of raw materials, existing skills and potential markets in rural areas, it can be argued that the organisation works with both invisible local demand, such as hides or fruit juices that previously were not available in the area, and invisible supply such that with the right infrastructure and capacity, already existing skills can be upgraded and put to more productive use.

\section{Financial Support ${ }^{167}$}

CTD does not provide financial support in the form of loans or grants for the communities it supports. Instead it uses the finance it obtains to research, create and implement interventions, as well as for building capacity. In the early stages of an intervention, CTD uses mainly grant funding from the Department for Science and

\footnotetext{
167 Sources are: website www.ctd.in, accessed on 21 April, 2010; Interviews with staff at CTD in Delhi on 15-18 May, 2007; Field visit and interviews with STD in Kullu and Mandi, Himachal Pradesh on 22-25 May, 2007; STD Brochure, 2006; CTD Final Project Report for Leather, 1990; Portfolio overview, 2008 downloaded from www.ctd.in, on 21 April, 2010; Information on investment areas downloaded from www.ctd.in, on 21 April, 2010.
} 
Technology for surveys and feasibility studies, technology adaptation and implementation. However, once the initial implementation is completed, CTD's projects suffer from a finance gap where DST will not provide further grant finance.

CTD finds that local banks are often unwilling to provide credit because they do not see the investments as safe. Acquiring loans from banks is especially difficult for larger investments or for groups rather than individuals. For instance, it took more than a year for the local partner STD in Himachal Pradesh to have a loan sanctioned for one of its project. This in spite of the fact that the project was profitmaking, and looked to significantly expand operations to respond to increased demand. However, in the areas where CTD and its local partners have been established for many years, individual working capital loans are relatively easy to come by if the local NGO is established and well known, and the intervention for which the loan is sought has been proven to be sustainable. Nevertheless, CTD has found that the outcome of a loan application at a bank very much depends on the individual branch manager and the relationship the local or central organization has built up with that person. For example, in 2006, STD and CTD applied for a large loan to upgrade a fruit processing unit in $\mathrm{HP}$, which had in principle been sanctioned by a local bank. However, the retirement of the bank officer in charge with whom CTD and STD had built up a relationship over a long period of time, meant that a new manager came in. The new manager decided against sanctioning the loan and CTD and STD had to abandon the plans for significant upgrading. Hence, individual actors play a significant role, and by building relationships with these actors over time, CTD managed to reduce the perceived risk of the projects it wishes to finance.

CTD additionally relies on a number of non-bank sources of project finance including NABARD refinance schemes, government sponsored Khadi Village Industries refinance schemes, and one-off horticultural and agricultural schemes by state and federal governments and other public sector bodies, such as CAPART. ${ }^{168}$

Finally, local projects use the profit from businesses for reinvestment where possible.

\section{Non-Financial Support ${ }^{169}$}

Before embarking on the actual implementation of a project, CTD spends a lot of time and effort creating links with the local community. This is to build up trust that will later 'cement' the new technology and business strategy in the community. In order to win the trust of its local clients, CTD, for example, provides certain basic

\footnotetext{
168 CAPART is a science council which was referred to in ch. 4.

169 Information sources include: website www.ctd.in, accessed on 10 September, 2009, 21 April, 2010; Interviews with staff at CTD in Delhi on 15-18 May, 2007; Field visit and interviews with STD in Kullu and Mandi, Himachal Pradesh on 22-25 May, 2007; STD Brochure, 2006; STD Report, 2006; Information on investment areas downloaded from www.ctd.in, on 21 April, 2010; Description of fruit processing downloaded on, 21 April, 2010.
} 
needs which are expected of them. ${ }^{170}$ In Himachal Pradesh, for instance, CTD and its local partner STD assisted in providing toilet facilities, and in Madhya Pradesh some of the early work among the tribal population included training women on how to use money, as well as providing basic medical facilities, schooling and infrastructure. This emphasis on trust and building relationships is likely to reduce information asymmetries over time since each party acquires a lot of knowledge and information about the other party. In fact, CTD is the case study organisation that works on creating lasting relationships and trust the most since it uses these ties as an alternative to collateral or stringent monitoring.

Furthermore, because CTD works with poor communities often ostracised by the rest of society, much effort goes into changing social attitudes such as those persisting towards leather workers in Himachal Pradesh. For example, as noted earlier, the uniforms provided to factory workers in a leather goods manufacturing unit became a symbol of having a secure and relatively well-paid job. Therefore CTD not only improves livelihood opportunities and income for poor rural communities, but by targeting low case and tribal communities that ore often discriminated against, CTD also empowers people. This in turn breaks down social barriers.

As part of an intervention, CTD produces new technologies, or scaled-down versions of existing technologies in its in-house workshop, thus acting as an innovator for the poor. The organisation often redevelops already existing machines to fit with the environment of small-scale poor producer groups as in the case of the fruit processing machines, which can be used periodically, as and when required, without costing as much as the industrial version, or the carcass boilers which are smaller scale versions of already existing pressure cookers. By sizing down the cooker it can be used on a daily basis without requiring too much electricity. It is also better suited to the lower number of carcasses available in a small unit as compared to an industrial sized factory.

To make the most of these technological and organisational innovations, CTD builds capacity related to the management among both the local communities and local NGO partners. CTD's capacity building for instance includes managerial training and marketing. There are both technical and social aspects to this. On the technical side it entails learning to operate the machine or production line or use new kinds of seeds or tools. On the social side however, it concerns building management skills among the local NGOs as well as business acumen and knowhow among the local community's producer groups that run the processing units. It also includes learning to spot market gaps and how to adjust production to take advantage of those gaps. In Himachal Pradesh for example, a lot of effort has gone into teaching farmers, with the help of experts from the local horticultural

\footnotetext{
${ }^{170}$ It is expected of external organisations that come in with social motives since these organisations have much better links to, and influence over, local and state officials.
} 
university, to grow fruit and vegetables instead of wheat, the usual crop. Furthermore, the fruit processing unit is run by a group from the local community that has been trained in all aspects of managing the plant, such as book-keeping, business management and strategy, production and logistics, regulation, quality assurance and marketing. The marketing and sales aspect is something that CTD works a great deal on. It is an integral part of the interventions since the businesses need to become financially sustainable through sales once they have been implemented.

CTD creates innovation capacity in part by shaping the habits and practices associated with the process through retraining and learning. For instance, flayers used to tan leather themselves, resulting in low quality hides that were sold to middlemen on very unfavourable terms. CTD, however, upgraded and centralised the tanning process. It also built capacity among flayers, helping them to grade the hides appropriately and find out the correct market value. The flayers were therefore able to get a better price for their hides. Furthermore, because hides were sold centrally, the flayers had improved bargaining power.

When the implementation of a project works well, CTD eventually takes on a mentoring or consultancy role, ready to assist when problems arise but otherwise leaving the daily running of the projects to the local communities and local NGOs. Its main task then is to look for further possibilities to provide income and livelihoods through value addition and to innovate to put new strategies into practice. For instance, carcass utilisation, now a separate intervention type, evolved out of a search for value added for flayers. Having already started factories to process some of the tanned leather, CTD looked into what could be done with the waste- the carcasses. So it built an intervention based on boiling, mincing and powdering the carcasses. Since CTD is involved long-term in the communities where its interventions have been implemented (over 25 years in the case of leather, for example), it has the ability to evolve the interventions over time.

\section{Monitoring, Feedback and Learning ${ }^{171}$}

The aim of CTD's monitoring is to establish whether its interventions are working efficiently, and whether the interventions are creating enough livelihood opportunities and enough income for the poor. To that end, CTD visits all the field stations twice a year, or more often if a new intervention is being implemented. CTD also monitors the local NGOs that provide the day-to-day support for the communities where projects have been set up. To that end, there are twice-yearly review meetings with all local NGOs, where the core team and franchises discuss how the interventions are functioning in the rural communities. CTD sees the meetings as way to establish that the core principles of the intervention are in place

\footnotetext{
171 Information based on: interviews with staff at CTD in Delhi on 15-18 May, 2007; Field visit and interviews with STD in Kullu and Mandi, Himachal Pradesh on 22-25 May, 2007.
} 
in all sites where its interventions are implemented. CTD also encourages convergence among local organizations across India to decrease moral hazard issues from interventions diverging into too many different kinds of versions.

There are no formal mechanisms in place for reporting beyond the twice-yearly meetings with CTD.

Finally, it should be highlighted that CTD never exits or completes a project but the role it has changes over time from initial research and creator of a intervention to implementer and hands-on manager to later taking on more of a consultancy role whom the local communities or NGOs can turn to for further business or technical development or advice. In this way, CTD monitors the implemented interventions and can, when required, intervene to alter the business strategy or technology over time.

\subsubsection{Cases: Leather and Fruit Processing}

The two cases to be illustrated in this case study are of leather and fruit processing. The leather case additionally involves carcass utilisation, as this intervention evolved from the leather intervention. Both cases are from Himachal Pradesh. CTD has worked with the same local group of people since 1983, and in 1990 the local group formed the Society for Technology Development (STD). ${ }^{172}$ The society has since then been running the field station in HP as a franchise, though CTD is involved with the interventions, especially in looking for new areas of diversification, and frequently visits. STD's head office is based in Bhadyal, near Mandi, HP, whilst it operates field stations in Malori and Nagwain.

\section{\#1: Leather173}

\section{Business Overview}

In rural Himachal Pradesh, as in other parts of India, flayers have as their duty, often by birth, to collect dead carcasses from nearby farmlands. Flayers process the animal hides and sell them on to middlemen or make leather sandals (chappals). The flayers in HP were exploited and very poor, suffering the discrimination of

\footnotetext{
172 STD is, like CTD, a multidisciplinary group of people with a specific interest in action research and replicable models interfacing science, technology and society. STD has implemented a number of projects sponsored by DST and CAPART. Beyond the projects it works with CTD on, STD is also involved in horticultural processing and preservation, blacksmithy and sustainable construction technology.

173 Information sources include: website www.ctd.in, accessed on 2 May, 2007, 21 April, 2010; Interviews with staff at CTD in Delhi on 15-18 May, 2007; Field visit and interviews with STD in Kullu and Mandi, Himachal Pradesh on 22-25 May, 2007; STD Brochure, 2006; CTD Final Project Report for Leather, 1990; Project brochures (various) of STD, 2006; 2010; Information on investment areas downloaded from www.ctd.in, on 21 April, 2010.
} 
being at the bottom of a harsh and rigid rural caste system. ${ }^{174}$ Flayers would sell the hides to middlemen and traders of the tanning industry for about Rs 50 - much below the market rate and barely enough to cover the labour cost. The middlemen then sold the same hides to the industry for Rs 250. Furthermore, traders often acted as moneylenders, lending small amounts to flayers with high interest rates which flayers repaid by selling the hides at very low prices, so that flayers were locked into a perpetual cycle of debt. It followed that $85 \%$ of hides were leaving the area to be processed by bigger factories elsewhere. CTD noted, during an initial survey of the area, that flayers were clearly not making a sustainable business out of the hides and that they were being taken advantage of by the traders. Furthermore, CTD saw a gap in the capacity of flayers to retain better earnings from their existing flaying and sandal-making skills.

\section{CTD's Role}

CTD initially began its intervention in leather by visiting HP for a survey of the needs, skills and resources of flayers in 1983-1984. Having established that an intervention which would help flayers achieve better income by improving the processing of hides, CTD proceeded, with the help of an initial grant by DST, to work on the technical and business side of the intervention in Delhi. Whilst doing so, the team was simultaneously building local capacity, starting at the very basic levels related to self worth and forming groups. Their leather intervention was subsequently made in several phases, with technical support throughout the development of the different phases from the Central Leather Research Institute (CLRI) in Chennai.

In the first phase, CTD focused on sole leather because it involves the simplest tanning method. They networked all the local flayers to pull them together and taught them about grading their hides in order to get a fair price. They also did grading to sort out the different quality of leather ranging from A (superior) to D (poor quality), and these were subsequently sold in separate batches. Furthermore, CTD persuaded the flayers to begin to sell some of the hides to a tanning unit which CTD/STD set up instead, which offered to purchase the hides for a fair price. In the first instance, a vegetable tanning unit was set up, and this was still, at the time of fieldwork, the core of the intervention. The unit is able to cater for up to 200 flayers in 100-150 villages within a $20 \mathrm{~km}$ radius. Soon $85 \%$ of $\mathrm{B}$ and $\mathrm{C}$ grade hides were retained in the area, as these were processed at the local unit. The traders were still kept in business as suppliers to tanneries.

The second phase involved the stabilization of the business, followed by diversification. The local tannery was unable to process the top quality A and B grade hides because the physical processing of this leather is very costly.

\footnotetext{
${ }^{174}$ Including for example lack of schooling, lack of adequate housing, lack of access to water, lack of access to certain parts of the villages (Interview with staff at CTD in Delhi, 15-18 May, 2007).
} 
Investment in this technology was far too expensive so instead CTD sought out another technology. The organisation therefore took the intermediate step of 'wetblue' tanning which is cheaper than the full process. The wet-blue tanned leather cannot be used after this process, but is sold on to industrial finishing units. Rather than selling all of the wet-blue leather however, the organisation took truckloads to a nearby finishing unit themselves. The leather was produced to their requirements and then brought back to the area where it was sold to leather artisans.

In phase three, CTD looked at further value addition. For instance, CTD went forward in processing of the leather to make bags and shoes. A local factory was established to make bags, shoes, belts and jackets, where members of the flayer families were offered work, thus increasing the livelihood opportunities in the local community. STD has additionally opened a showroom in Mandi Town where bags and other leather goods are sold. Furthermore, the artisans have developed a good reputation in the local market.

In the final phase, CTD went backwards in the value-chain, to carcass utilisation. Such processing produces for example, fat which is sold to soap makers and bone which is used in horticulture. The carcass is boiled at a very high temperature to kill bacteria. This produces digested bone and cooked meat which is pulverised and minced, respectively, and dried as powder. This is put in poultry feed or used as farmland fertilizer. The initial step of the carcass utilisation intervention was a survey by CTD of the raw material available, which found that one nodal unit would need three to four carcasses per day which would mean a catchments area of 15 villages. CTD then looked for a suitable technology, but found that the industrial units would cost in the region of Rs 20000 000, which was not viable. CTD found that Khadi or village industries in the 1950's (during the village self reliance movement) had invented large meat processing machines. However, these were huge boilers which were not pressurized. Instead CTD, together with the Animal Byproduct Division of CLIR, invented a pressurized carcase cooker which makes bone soft enough to crush but that was at the same time both cleaner and cheaper and small enough to hold only one carcass at a time. The carcass cooker has a capacity of 150 or $250 \mathrm{~kg}$, which is adequate for the amount of animals that are brought into the unit on a weekly basis. The carcass utilisation unit is based at the same field station as the tanning unit.

The difference between carcass utilization and the tanning unit is that this technology is cheaper and could theoretically be placed in several different places in an area with only the bone crusher having to in a nodal unit whilst the tanning unit needs to be at a nodal unit. Therefore there could be semi-processing at the satellite unit and final processing at the nodal unit.

The organization thus set out to building a community-based business around leather and tanning in several phases. They set up a central tanning unit which employed some flayers and most of the middlemen were cut out whilst price for the hides went up to Rs 100. 


\section{Social impact and commercial sustainability}

In the leather project in Mandi, HP, there were in 2007, 176 people bringing hides. The unit processes leather for shoe soles through vegetable tanning, wet blue tanning, and sell the best quality hides. All in all, $85 \%$ of the hides are now retained in the area in comparison with the $15 \%$ that were previously retained.

There has also been significant social change. For instance:

1) Many tanners having previously emigrated from the area in search of employment started coming back;

2) Tanners working in tanneries are earning considerably above minimum pay. They became one of the better earners in their local society and caste prejudices were no longer as strong.

3) Artisans working in the bag or tanning units no longer saw themselves as artisans of low status but as factory workers which has much higher status. This brought about social improvement and acceptance.

\section{\#2: Fruit Processing 175}

\section{Business Overview}

In 1993 CTD undertook a survey of what fruit and vegetable growers produced and the market access they had. CTD found that processing fruit and vegetable would be a good strategy. One reason was that the fresh produce, such as plum and apricot was often spoiled by the time it reached the market, and a second that the apple variety that grew in this area was not of adequate quality or the right kind ${ }^{176}$ to be sold fresh in the local markets. In 1994, following the survey, CTD set up a fruit processing unit together with STD. DST provided grant-funding of Rs 600000 in 1996. The unit was in particular expected to create livelihoods for women, because there were fewer employment options available for them. By 1998 the unit was profitable, and running independently of the grant, whilst in 1999, the producer group acquired a bank loan with the help of CTD and STD to invest in a car for marketing purposes. The loan had been repaid in full at the time of fieldwork. Furthermore, in 2001, the producer group formed their own society, which now runs strategy and management of the unit. Finally, in 2006, the unit received a Rs 200000 loan through a rural credit scheme, with which the producer group has

\footnotetext{
175 Information sources include: website www.ctd.in, accessed on 2 May, 2007, 10 September, 2009, 21 April, 2010; Interviews with staff at CTD in Delhi on 15-18 May, 2007; Field visit and interviews with STD in Kullu and Mandi, Himachal Pradesh on 22-25 May, 2007; STD Brochure, 2006; STD Report, 2006; Project brochures (various) of STD, 2006; Information on investment areas downloaded from www.ctd.in, on 21 April, 2010; Description of fruit processing downloaded on, 21 April, 2010.

176 The only variety growing successfully was Golden, which is yellow and unpopular as a fresh apple since red apples are preferred. However, it could be used for processing.
} 
bought raw material, packing and chemicals. It is also used to provide bulk storage of fruit for processing so when the season starts in March the produce is ready.

\section{CTD's Role}

CTD began looking into fruit processing once their leather intervention had been proven to work. The organisation looked to use a similar 'nodal' intervention strategy in rural India with different levels of productions and processing. Therefore, CTD began setting up a production unit in Kullu, HP, together with its local partner, STD, in 1994, as part of a pan-Indian CTD project on fruit processing funded by DST.

Just as in leather, CTD developed a technology package together with a operation and marketing strategy. In the fruit processing intervention that includes three levels: household, village and nodal. Since women are particularly disadvantaged in rural India, and also stand for the majority of cooking, CTD aimed to involve mainly women. Therefore, at the first level, women of grower families would collect the fruit, in the case of Kullu that was initially apple, and do initial processing including washing and sorting. At a second level, a village or a group of villages would set up a satellite unit for semi-processing, where drying, pulping and juicing would take place, for example. The semi-processed fruits would then be taken to the nodal unit, which would cater for 15-20 villages.

The nodal unit does all the final processing and packaging, employing up to five women full-time. The nodal unit also undertakes food standard compliance exercises and research and development for further product development. For instance, the apple drink which was developed and is produced in Kullu, is one of its kind in the local market. The unit also experiments with new products like plum or rhododendron juice every year. CTD plays an important role in providing the necessary expertise for product development and mentoring when it comes to commercialising the products.

Marketing and sales are also undertaken at the nodal unit and a lot of innovation and creativity has gone into the distribution of products. To that end, CTD and STD have assisted the unit in Kullu in purchasing a car to transport its products to a network of sales outlets. The sales outlet numbered 300 in 2007 after a strong marketing campaign in the local area, where members of the producer team and STD visited every sales outlet in the local area before signing an agreement with 300 of them. Furthermore, the unit also has its own Farmer's Factory Outlet on the national highway nearby the production unit. CTD and STD also tried other marketing avenues. For instance, they tried establishing agreements with sales outlets in Delhi but had problems as the unit was at times asked to supply a lot of produce at short notice, which it did not have the capacity for. They also tried selling through a wholesaler in Chandigarh, which is a city relatively close by, but when the retailer was unhappy with produce, he refused to pay the wholesaler so that the unit in Kullu did not receive payment. After these incidents, it was decided 
that all marketing efforts should go into selling locally, and taking advantage of the tourist season.

The farmer's production unit meets every month to look at production and marketing. As part of its commitment to innovate, the unit tries something new every quarter, whether in production, marketing or organisation.

The processing unit is popular because it uses up excess and faulty produce that would otherwise have gone to waste. Instead, growers receive the minimum price, and they receive it straight away, something that is important for smallholders that have very limited income. ${ }^{177}$ Secondly, growers can to some extent use the processing units, at least at the satellite units, for their own consumption.

\section{Social impact and commercial sustainability}

The capacity building of the local producer group resulted in the group forming the Society for Fruit Development to manage the processing unit, in 2001. Furthermore, by 1998 the unit was profit-making and until 2003, the profit was steadily increasing. Though the profit was stagnant at approximately Rs 800000 from 20042006, by 2007, the profit was expected to rise to Rs 1200 000. One reason for this, was the increase in the number of sales outlets from 220 to 300 in 2007.

The intervention has also increased the number of livelihood opportunities for women in the area. Furthermore, whilst reducing the waste of the harvest, i.e. spoiled fruit due to transportation problems, or lack of access to markets, it has also increased the income for local growers.

Finally, CTD's intervention has been adopted by a number of organisations across India. For instance, DST, the Ministry of Rural Development and CAPART have taken up the intervention, as have several state level science and technology councils. All in all, over 40 units have been set up across India.

\subsubsection{Conclusion}

In conclusion, CTD innovates for the rural poor by researching, creating, implementing and maintaining interventions based on innovative technology and an integrated business strategy. Rather than individual support, CTD focuses on building interventions that will provide livelihood for a community. Furthermore, it emphasises non-financial support, including capacity building and forming viable institutions, or habits and practices. Finally, it should be noted that CTD has had an important social impact in the communities it works in.

\footnotetext{
177 The Government of India provides payment at a minimum price for certain crops, such as apple. However, a major problem with this Government imposed minimum price is that it generally takes six to nine months for the payment to come through.
} 


\subsection{Villgro}

The empirical part of this thesis has so far looked at four organisations that all operate at the periphery of the financial system, but that target different kinds of innovation and entrepreneurship. Although the organisations are complementary, they are not closely connected. However, Villgro, an incubator, has links to both Aavishkaar and BASIX. Business incubators are common within mainstream innovation finance, often attached to universities, where they commercialise new ideas and small ventures. The incubator improves business management skills, tests and builds a prototype, researches the market and assists in formulating a competitive business plan with which the venture will attempt to attract external financing, such as seed and venture capital, or debt financing. Social entrepreneurship and innovation need incubation too. An early venture may be too premature for micro venture capital, such as that offered by Aavishkaar, but it might have outgrown the support it receives from BASIX or perhaps S3IDF. This is where an incubator, such as Villgro, can step in to fill a void.

Villgro was, at the time of fieldwork, called the Rural Innovation Network (RIN) and was primarily focussed on a grants-based incubator programme called LRAMP, and on documenting rural innovations on a database. However, in 20082009, Villgro not only opted for a new name, but significantly changed direction, strategy and goal, to the same extent that BASIX had done through its OLE process. The change of strategy and name was a result of a review of operations in 2008. A programme called Innovations to Market had closed down in 2007, having failed to make an impact, and the successful L-RAMP incubator programme was up for funding renewal. The organisation decided that providing a number of complementary programmes would improve its ability to support innovation. To mark the change in strategy, it also changed its name as part of a branding exercise.

Given that ignoring these changes will not only misrepresent the organisation, but also provide a much less interesting case, this case study will incorporate the changes that occurred in 2008-2009 and the way Villgro operates since 2008, rather than the status quo in November, 2007, when the initial fieldwork was carried out. The organisation will be referred to as Villgro throughout. 


\subsubsection{Villgro ${ }^{178}$ the Organisation}

\section{Background, Mission and Objectives ${ }^{179}$}

The rural innovation incubator Villgro is based in Chennai, Tamil Nadu, South India. The organisation was set up out of a belief that there was a vast knowledge bank of local innovation in rural areas which was unexploited because of lack of resources. There were organisations involved in rural technology transfer, but this essentially involved transfer of technology from external sources. Villgro instead looked to support innovation that occurs in rural areas, and to transfer these to other rural areas to benefit a larger section of rural society.

The founder of Villgro, Paul Basil, was inspired by the Grassroots Innovations Augmentation Network in Gujarat which is linked to IIM Ahmedabad and its Honeybee Network - a database of rural inventions. With the support of GIAN and technical and financial help of venture capital company Impact Partners, Villgro set out to replicate GIAN in the South of India with the name GIAN Foundation South (GIANFS) in 2001. ${ }^{180}$ However, problems in the working relationships with GIAN meant that GIANFS decided to become an independent entity, and changed its name to Rural Innovations Network (RIN). Up until 2008 the organisation focussed its attention on two areas: incubation activities, as well as building a database of rural inventions. However, in 2007-2008, following the closure of one of its incubation programmes, the organisation re-evaluated itself and in 2009 presented a new strategy, and a new name, Villgro. The organisation evolved from focussing mainly on inventors through its L-RAMP programme, and on setting up an innovation database, to a multifaceted organisation supporting social entrepreneurship and innovation in several ways. These include, apart from entrepreneur and innovation incubation, also business plan competitions for students, a chain of retail outlets to market rural inventions, and an increased emphasis on research on social innovation and entrepreneurship in India. This emphasis on research is part of an attempt to build sectoral capacity and to create a

\footnotetext{
178 Data sources include the RIN Annual Reports 2001/2002-2006/2007; Villgro Annual Report 2008/2009, RIN website www.rinovation.org, accessed 27 October, 2007, 10 February, 2008; Villgro website www.villgro.org, accessed 20 November, 2009, 9 March, 2010, 15 March, 2010; Mahalingam, P., Basil, P., and Nigam, A. (2007), The Entrepreneurs, the Environment and the Ties between them: A case study of the Process of Social Entrepreneurship. Villgro Working Paper.; interviews at Villgro 6-7 November, 2007; Visits to two Villgro Entreprenurs, Mr. Mukundan and Dr. Venkata Krishna, 7 November, 2007; Email discussions with Villgro CEO, P. Basil, 10-25 February, 2010; Villgro Programme Brochure, 2010.

179 The information in this subsection stems from RIN Annual Report 2006/2007; Villgro Annual Report 2008/2009, RIN website www.rinovation.org, accessed 27 October, 2007; VILLGRO website www.villgro.org, accessed 20 November, 2009, 9 March, 2010, 15 March, 2010; interviews with staff at Villgro 6-7 November, 2007; Email discussions with Villgro CEO, P. Basil, 10-25 February, 2010; VILLGRO Programme Brochure, 2010.

${ }^{180}$ It was established as a non-profit company under section 25 of the Indian Companies Act.
} 
network of inventors, entrepreneurs, technical experts, funders, mentors and business people that forms an innovation ecosystem.

Another aspect of building an eco-system is policy. To influence policy, Villgro participates in a number of forums at both the state and federal levels ${ }^{181}$ discussing rural innovation, entrepreneurship and development. One such forum is its annual conference 'Unconvention'182 that draws attention to social entrepreneurship and innovation for the rural poor. In this way Villgro is able to have an impact on the sector including other incubators, as well as at the macro level - on the system in general.

As with many of the other case study organisations, the core team at Villgro is small, so in order to provide the range of services it is offering, Villgro works in partnership with a number of organisations from the public, NGO, private and academic sectors to provide its services, including hands-on support for its portfolio as well as sectoral and policy work. The main partner is IIT-Madras (IIT-M), in Chennai, together with which Villgro has been running L-RAMP since the inception of the programme. ${ }^{183}$

Furthermore, village level entrepreneurs (VLE) and small-scale firms partner with Villgro on its Villgro Store local outlet initiative and on their programme testing the viability of innovations (see the section on activities below). Finally, it should be highlighted that Villgro collaborates with Aavishkaar where the micro venture capitalist is a potential future funding source for its portfolio companies. It has also previously worked with another organisation featured as a case study in this thesis- BASIX, on a programme that is now closed. ${ }^{184}$

\section{Organisational Structure ${ }^{185}$}

Villgro is run by the CEO, and founder, Paul Basil. Under his leadership the day-today running of Villgro is managed by a number of team leaders that run the different programmes. Villgro has recently gone through a rapid expansion phase

\footnotetext{
181 In India the federal level is usually called "All-India"

$182 \mathrm{http}: / /$ www.villgro.org/unconvention/

183 Other partners that act as rural innovation 'nodes' for the incubation programmes are Vellore Institute of Technology (VIT), Vellore; PSG College of Technology, Coimbatore; Tamil Nadu Agricultural University (TNAU), Coimbatore; Gandhigram Rural Institute and Deemed University, Dindigul; and TANSTIA-FNF Services Centre (TFSC), Chennai.

${ }^{184}$ It was a programme testing innovations in rural villages. BASIX provided the ground level support, using its unit offices in Andhra Pradesh.

185 Sources: RIN Annual Report 2006/2007; Villgro Annual Report 2008/2009; VILLGRO website www.villgro.org, accessed 20 November, 2009, 9 March, 2010, 15 March, 2010; interviews at Villgro 6-7 November, 2007; Email discussions with Villgro CEO, P. Basil, 10-25 February, 2010; VILLGRO Programme Brochure, 2010.
} 
and the total staff numbered 42 in 2009- an increase by 22 people from the beginning of the year. ${ }^{186}$

The Board of Directors includes members with expertise in rural development, innovation finance and social entrepreneurship. Among these, two directors are particularly noteworthy: Vineet Rai, CEO of Aavishkaar, which has signed a MoU with Villgro, and Mr Mukundan, entrepreneur and CEO of Servals, which was an early company to be incubated at Villgro, and subsequently one of Aavishkaar's portfolio companies (and featured as one of the Aavishkaar cases in chapter 5). On the investment side, there is an Investment Committee which approves initial financing for incubation. There is also an Incubation Committee that closely reviews the progress of the initiatives being incubated. Villgro thus has three levels of decision-making within its organisation. This structure is quite similar to what Aavishkaar has put in place, and ensures that there is a high level of quality assurance since the different boards have members with different kinds of expertise that is used to ultimately evaluate whether an investment is going ahead or not. The boards also provide Villgro with useful links both to the core financial system, as well as to other periphery organisations. One example, of course, is the CEO of Aavishkaar that sits on the main board.

\section{Activities ${ }^{187}$}

There are currently three innovation incubation-related programmes, one retail outlet, two talent development programmes as well as a newly developed knowledge management programme. The bulk of the work that Villgro does, however, is centred around its incubation programmes.

The longest running, and by far the biggest and best known activity is the Lemelson Recognition and Mentoring Programme (L-RAMP), which has been active since 2004. It incubates innovations that are expected to have a positive impact on the rural poor. L-RAMP is the main focus of this case study. A more recently implemented programme is User Centred Innovation Development (UCID) which seeks to address the gap between the attributes of innovation and the actual user needs that the rural poor have by market testing innovations in rural villages.

A similar programme, the Innovation to Market Programme which aimed to scale up the marketing and distribution effort of inventions through collaborations with organizations such as BAIF, was running up until 2007 but was closed down as it had not been a success. Though it is interesting to note that the programme had

\footnotetext{
${ }^{186}$ In addition, Villgro accepts about two interns a year (generally foreign graduates) as well as a number of fellows through its fellowship programme.

187 RIN Annual Reports 2001/2002-2006/2007; Villgro Annual Report 2008/2009; VILLGRO website www.villgro.org, accessed 20 November, 2009, 15 March, 2010; interviews at Villgro 6-7 November, 2007; Email discussions with Villgro CEO, P. Basil, 10-25 February, 2010; VILLGRO Programme Brochure, 2010.
} 
undertaken pilot testing in Andhra Pradesh in cooperation with BASIX, which is the subject of the first case study of chapter six.

A major lesson that Villgro drew from its early years of operation was that the inventor was not necessarily the best person to commercialise the innovation. Rather, entrepreneurial skills are crucial, something that inventors often do not possess. Therefore, since October, 2008, Villgro runs an Innovator to Entrepreneurs (I2E) programme which seeks to transfer technology from inventors to able entrepreneurs. Products that are ready to be commercialised from either of the incubation programmes, such as kerosene burners and bio fertilizers, are marketed, among other channels, through Villgro's retail outlets, Villgro Stores. The retail outlets look to create access for rural poor to new products through village level entrepreneurs. Villgro Stores has existed since 2007, though at the time of fieldwork, the idea of VLE's had not yet been developed.

Finally, in 2008 Villgro started a Knowledge Management (KM) programme that seeks to produce and disseminate knowledge at the intersection of entrepreneurship, innovation and the rural poor. The focus of this programme is academic and policy research. Another part is the database, or management information programme, that documents rural inventions. This database initiative has been active since 2004. The database of innovation is a project where Villgro aims to create an eco-system for innovation' by building a database of innovation as well as those that for part of the system supporting such innovation. This, it is hoped, will become a network of inventors, entrepreneurs and those that can provide mentoring, expertise and further networks and contacts. ${ }^{188}$

Villgro has, since the time of fieldwork, moved from a small organisation with two separate areas of work (a database of inventions and one active incubation programme) to an organisation that seeks to spur innovation and entrepreneurship on multiple levels. It now has a number of interconnecting incubation programmes, it has set up business plans for both entrepreneurs and students, it has set up schemes for local entrepreneurs working with the retail outlet, and it is seeking to further establish a knowledge management and research centre. Each of these programmes links with other programmes at Villgro.

\section{Funding 189}

Villgro has so far been funded by a number of investments from various national and international organisations. These investments are grant-based and generally provided over three year periods. In 2008, Villgro was supporting L-RAMP through

\footnotetext{
188 Additionally, to ensure that these programmes, and innovation and entrepreneurship in rural areas in general has a pool of talent that can manage innovation and entrepreneurship related activities, Villgro puts effort into building up human capital. The Talent Development Programme (TDP) is aimed at attracting talented staff to Villgro.

189 Information from: RIN Annual Reports 2001/2002-2006/2007; Villgro Annual Report 2008/2009; Villgro Programme Brochure, 2010.
} 
an investment by the Lemelson Foundation of the USA. The programme budget for 2008/2009 was Rs 36,916,000 (USD812,000). ${ }^{190}$ Furthermore, in 2007, the DST's Technopreneur Promotion Programme (TePP) ${ }^{191}$ awarded a grant JS Milker, a Villgro investee.

Villgro is evidently dependent on relatively short-term grants to fund its programmes (an average of three years) from international development organisations. This is likely to have an impact on the ability of Villgro to follow its investments long-term and to work on long-term strategies. In fact, just as mainstream banks and microfinance are constrained by the short-term nature of their loans, Villgro appears, at the time of fieldwork, to have been dependent on international grant-giving organisations.

It is clear that Villgro links mainly to grant-giving national and international organisations, because that is where its finance originates from. However, with the social venture capital sector taking off in India, as noted in chapter 5, it is likely that Villgro's links with this sub-sector of the periphery of the financial system will strengthen. Though, to do so, Villgro must ensure that it incubates ventures that are attractive to, for example, micro venture capital organisations. Until 2009 this had not always been the case since Villgro's main focus is clearly on incubating rural innovation that benefits the poor. It may be argued that if the social factor of an innovation is emphasised or nurtured more than the business factor, such a venture will not make an attractive proposition to a micro venture capital firm that has a clear mandate to make a profit.

\section{Portfolio192}

Villgro incubates ventures in four specific sectors, where it has amassed expertise, and which are of particular relevance to the rural poor. These sectors are: agriculture, dairy, water and energy. As noted earlier, Villgro rolls out its incubation programmes with the main partner, IIT-M as well as four nodal

\footnotetext{
${ }^{190}$ Furthermore, Samruddhi was supported by the Sir Darabji Tata Trust (SDTT) to the tune of Rs $5,023,500$ (USD110,400) in 2008/2009, and Dutch organisation HIVOS supported the I2E programme with Rs 1,940,000 (USD 43,000) in 2008/2009. HIVOS had up to 2007 supported the 'Innovation to Market' Programme together with Tata Consultancy. The Rockefeller Foundation made a new three year investment in 2008/2009 in UCID. The budget for 2008/2009 was Rs 8,920,000 (USD 196,000) which was also expected to cover some costs in the TDP programme and a new InnoCentre.

${ }^{191}$ See chapter 4 for further details on the TePP programme.

192 RIN Annual Reports 2006/2007; Villgro Annual Report 2008/2009, RIN website www.rinovation.org, accessed 10 February, 2008; Villgro website www.villgro.org, accessed 20 November, 2009, 9 March, 2010, 15 March, 2010; Mahalingam, P., Basil, P., and Nigam, A. (2007), The Entrepreneurs, the Environment and the Ties between them: A case study of the Process of Social Entrepreneurship. Villgro Working Paper.; interviews at Villgro 6-7 November, 2007; Visits to two Villgro Entreprenurs, Mr. Mukundan and Dr. Venkata Krishna, 7 November, 2007.
} 
partners, ${ }^{193}$ and the portfolio companies tend to be geographically close to one of these partners. Therefore it primarily operates in South India, and mainly in the states of Tamil Nadu and Andhra Pradesh. This is for the same reason that Aavishkaar and SIIDF keep their investments close by: the expense and time it takes to provide hands-on mentoring and management of the portfolio companies. Furthermore, having been established in Chennai for some time, Villgro has built up a critical network of local service providers it can access, such as technology experts, suppliers of raw material, and sales agents. It is the same for the nodal partners, which are all renowned academic institutions.

Villgro invests between Rs 1,000,000 to Rs 2500000 (USD23,000-55,000), with an average of Rs 1,500,000 (USD 33,000), through its L-RAMP programme, the largest programme by far. Importantly, the organisation has recognised that the success of investing in, and mentoring, a venture or innovation may be severely restricted by the inventor's (in)ability to adapt to the process of innovation, building up a venture and commercialisation. Therefore, Villgro now solicits entrepreneurs that are willing to acquire innovations from the innovator and commercialise the incubation through one of the incubation programmes. In fact, in 2007, at the time of fieldwork, four out of 12 innovations then being incubated through L-RAMP were run by entrepreneurs that had taken over the innovations with the facilitation of Villgro. One example of an entrepreneur that has incubated an innovation of someone else is Mr Mukundan who appeared in chapter 5 on Aavishkaar, and who will feature in a case later in this chapter.

\footnotetext{
193 These are Vellore Institute of Technology (VIT), Vellore; PSG College of Technology, Coimbatore; Tamil Nadu Agricultural University (TNAU), Coimbatore; Gandhigram Rural Institute and Deemed University, Dindigul.
} 
Table 7.2 Villgro portfolio overview: number of investments by programme and year (author's own based on Annual Reports 2006/2006, 2008/2009)

\begin{tabular}{|c|c|c|c|c|c|c|c|}
\hline Year & $\begin{array}{l}\text { L- } \\
\text { RAMP }\end{array}$ & $\begin{array}{l}\text { L-RAMP } \\
\text { Pre- } \\
\text { incubation }\end{array}$ & IMP & UCID & $\begin{array}{l}\text { My Idea } \\
\text { Student } \\
\text { programme }\end{array}$ & Exits & $\begin{array}{l}\text { Commercial } \\
\text { Success }\end{array}$ \\
\hline 2006 & 4 & & & $\mathrm{n} / \mathrm{a}$ & & & \\
\hline 2007 & 8 & 81 & 7 & $\mathrm{n} / \mathrm{a}$ & $\begin{array}{l}13 \text { meetings; } \\
23 \text { projects } \\
\text { supports }\end{array}$ & & \\
\hline 2008 & 11 & & $\mathrm{n} / \mathrm{a}$ & & & & \\
\hline 2009 & 13 & 107 & $\mathrm{n} / \mathrm{a}$ & $\begin{array}{l}3 \\
\text { projects } \\
\text { put in } \\
\text { shops; } \\
22 \\
\text { tested }\end{array}$ & $\begin{array}{l}40 \text { meetings } \\
\text { organised, } \\
728 \text { ideas } \\
\text { applied; } 23 \\
\text { funded }\end{array}$ & $\begin{array}{l}\text { 7: left } \\
\text { because of } \\
\text { market } \\
\text { opportunities } \\
\text { (3); due lack } \\
\text { of progress } \\
\text { (3); innovator } \\
\text { pulling out } \\
\text { (1) }\end{array}$ & $\begin{array}{l}\text { 3: Pin } \\
\text { Pulverize, } \\
\text { Nemaste, } \\
\text { Mastitis Kit }\end{array}$ \\
\hline
\end{tabular}

By 2009, the number of new L-RAMP incubation clients rose to 13 , up by $18 \%$ on the previous year, and a full $63 \%$ on 2007. Villgro has thus been steadily increasing its investment volume since restructuring the organisation. ${ }^{194}$ In addition, L-RAMP runs a pre-incubation. In 2006/2007, 81 projects had participated in preincubation programmes focussing on business strengthening and putting together a business plan, whilst 13 projects had been provided with proposal development support. By 2009, the participants of the pre-incubation programme had risen to 107. So by providing more generic support (in the form of training classes and seminars rather than individual mentoring), Villgro is able to reach a larger number of innovative entrepreneurs than it would if it had focussed merely on its incubation programmes and portfolio companies.

As regards the other Villgro programmes, the Innovation to Market Programme which aimed to scale up marketing and distribution of innovations through collaborations with organizations such as BAIF, incubated fewer innovations than L-RAMP- with a total of seven in 2007 when it closed after three years. Furthermore, the UCID programme, which followed on from IMP in 2008, had in the spring of 2009 carried out tests on 22 projects in total, and put three projects in retail outlets through Villgro Stores. These were Nemaste- a fertilizer, Pseudocoan- a bio fungicide, and Viswa 55- a cattle feed pellet. By early 2009, Nemaste had made total sales worth Rs 181,505 (USD 4,000) whilst Viswa 55 had made a total of Rs 224,970 (USD 5,000). The change from IMP to UCID seems to have moved Villgro towards a more efficient model of commercialisation of innovation.

${ }^{194}$ Furthermore, funding for the L-RAMP programme had been secured for the period 2009-2011, which is likely to have contributed to the increased volume. 
It should be noted that one of the important sales and marketing channels is the Villgro Stores which have been running since 2007. In 2009, there were four shops which had reached 1127 customers in 87 villages, with total sales worth Rs134,511 (USD 3000). ${ }^{195}$ Having its own sales outlet is a unique feature of the Villgro programme, as Samruddhi acts as a sales outlet and as an information source as regards marketing.

The flexibility that Villgro has achieved after its restructuring (of complementary services) has provided the organisation with an improved ability to support PEBI. Through its pre-incubation support, for instance, Villgro increases its base of potential investments, whilst also supporting pro-poor entrepreneur-based innovation more widely in rural areas. This contrasts with the core which does not seek out its clients, or provide any kind of preparatory capacity training for potential customers. Another example is to undertake market research of L-RAMP investees through the UCID programme. The Villgro Stores, which is a major marketing tool for innovations links both with L-RAMP by selling products by LRAMP entrepreneurs, and with UCIP since it tests potential products.

The kind of complementarities in services that Villgro has put together is rather unique among the case study organisations. BASIX does offer the possibility to graduate towards larger loans, but does not have this smooth transition from preincubation to incubation and on to market commercialisation and networking. The dynamism provided by the complementary set of services also sets Villgro apart from the core financial system. So whilst Villgro can provide a different programme for different stages of an innovation's evolution, banks do not.

Turning to evidence of success of Villgro's portfolio, in 2007, out of 12 innovations, three had filed for provisional patent applications in India. Furthermore, by 2009, Villgro estimated that the impact since it had started included the creation of 400 jobs. ${ }^{196}$ The L-RAMP awards programme alone had by 2009 identified 2000 innovators and provided over 30 awards in total. A further 2500 grassroots innovators had been identified for pre-incubation support and out of them, 185 had received training.

\subsubsection{The Support Model at Villgro}

The aim of Villgro's incubation services is to make its portfolio innovations ready to be sold on the market or further financed by other, external sources of finance, such as micro venture capital. The support that the incubation model provides therefore includes putting together a prototype and evaluating its technical capability, as well as its sales and marketing potential. By doing so, Villgro achieves a good understanding of whether a product is ready to be brought to market and whether

\footnotetext{
195195 By March 2010, the CEO Paul Basil, noted that there were 10 Villgro Stores, 4000 customers and total sales worth Rs 6,700,000 (or USD 130 000).

${ }^{196}$ Data from Villgro 2009 Summary Brochure
} 
there is a market niche in which it can viably establish itself. It also provides Villgro with more information with which it can evaluate whether to invest further financial or non-financial assistance and effort, and whether it is feasible to try to link the venture to core financial organisations.

Villgro works towards exits for its incubation ventures, generally including either the sale of the whole company to a larger established firm, or further financing from external sources. In addition, Villgro has taken the initiative to exit itself from companies that have not cooperated well or where the innovation turned out not to be a viable one. ${ }^{197}$ To avoid such risks, Villgro has moved from a focus on innovators to an emphasis on entrepreneurs, as noted earlier. Other risk-mitigating strategies include setting up accounting systems of its portfolio companies to provide transparency, and to implement quarterly reports and reviews to codify knowledge about how the venture, its operations and management. Such codification and increased transparency appeals to the core financial institutions which work at arm's length to a greater extent and therefore rely on easily obtainable and transparent information.

\section{Deal Source, Decision Making and Due Diligence 198}

Whilst Villgro used to rely almost exclusively on business plan competitions to source potential investments, by 2007, the organisation had moved to focusing on deal flow coming through its own network. Business plan competitions instead developed into two separate sub-programmes.

In L-RAMP, the programme with the bulk of the projects, Villgro begins the investment process by assessing the feasibility and potential of a possible investment. Given the lack of codified knowledge in such early stage investments, Villgro relies to a large extent on tacit knowledge gained through visits to, and interviews with the innovator and/or entrepreneur. Villgro approaches manufacturers in similar or related areas to try to understand whether a gap in the market exists. ${ }^{199}$

Earlier Villgro did not assess the business qualities or entrepreneurial capabilities of a venture but after failed attempts to make inventors more business minded, this had become an important criterion. In some cases Villgro even insists

\footnotetext{
${ }^{197}$ In this case the companies have not always had to repay the interest-free loan that the incubated firms generally have to repay once the incubation has been completed and the firm is making a profit.

198 Villgro Annual Report 2008/2009, RIN website www.rinovation.org, accessed 27 October, 2007, 10 February, 2008; Villgro website www.villgro.org, accessed 20 November, 2009, 9 March, 2010, 15 March, 2010; interviews at Villgro 6-7 November, 2007.

199 These are often large-scale manufacturers since they are likely to operate more efficiently and have better access to new market knowledge than small-scale manufacturers that operate in isolation.
} 
on bringing an entrepreneur on board as part of the package, when investing. ${ }^{200}$ After the changes that took place in 2008, matching an innovation with an entrepreneur is in fact part of its core mission.

To approve investments, Villgro uses a two-tier decision making system. First, the internal selection committee shortlists candidates which are taken through a due diligence process. Second, the Investment Committee approves investments up to Rs 2500000 (USD55,000).

Once either of these committees approves an investment, an incubator plan is drawn up, which includes a number of milestones to be reached. These milestones are tailored to each new investment. Villgro then releases funding according to the set of agreed milestones when these have been met. Villgro thus tailors its support to each new investment.

\section{Financial Support ${ }^{201}$}

Villgro essentially provides two types of financial support. The initial, preincubation support takes the form of grants for establishing a business plan. Once that is done and the investment has passed the investment committee, Villgro provides, through its L-RAMP programme, interest-free loans of up to Rs 2500000 (USD 55,000), although the average is between Rs 1,000,000-2,500,000. By 2010 Villgro was still providing interest-free loans, but a new financial product was under development.

The main focus of Villgro is not its financial support, but the incubation process of commercialising the enterprise. This contrasts with BASIX and Aavishkaar for instance, which both focus on providing a package of appropriate finance together with non-financial support. Villgro also takes a very different approach compared to the core financial institutions in supporting pro-poor entrepreneur-based innovation, since the banks provide finance only, Villgro provides some finance, but focuses mainly on the support-package around the financial services.

Furthermore, Villgro assists investees in finding additional external funding such as debt financing (bank loans), or other co-financiers including government programmes and micro venture capital.

In its choice of grant financing, it is not innovative, and grant financing has been criticised in earlier chapters for not being sustainable. However, just as with CTD, it is questionable whether certain early-stage activities can be paid for by

\footnotetext{
200 This had, by 2008, resulted in four cases with either an entrepreneur and an inventor working and managing a venture together, or the technology being transferred from the inventor to an entrepreneur.

201 RIN Annual Reports 2006/2007; Villgro Annual Report 2008/2009, RIN website www.rinovation.org, accessed 10 February, 2008; Villgro website www.villgro.org, accessed 20 November, 2009, 9 March, 2010; Mahalingam, P., Basil, P., and Nigam, A. (2007), The Entrepreneurs, the Environment and the Ties between them: A case study of the Process of Social Entrepreneurship. Villgro Working Paper.; interviews at Villgro 6-7 November, 2007.
} 
profit-seeking financial institutions. In Villgro's case that would include the work it does with the pipeline, such as pre-incubation support, and evaluation, or due diligence, of potential investments.

\section{Non Financial Support ${ }^{202}$}

Alongside the financial support, Villgro provides non-financial support in a number of related areas. First, a business plan is written and/ or refined as part of the incubation process, in order to put together a viable business strategy for the incubated venture, as well as to attract external interest from potential investors. ${ }^{203}$

Second, it assists in the production of prototypes. Though these are done externally, Villgro is involved in the quality assurance, cost and efficiency reviews and technical improvements. For the technical aspects, Villgro uses engineers within its existing network, including experts based at its main partner, IIT-M.

Third, Villgro provides marketing support such as market research in rural areas with the help of volunteers and students. This is done to make the innovation process more suitable to market needs (e.g. the rural poor). The marketing process also includes field demonstrations and participation in conferences and trade fairs, direct sales and putting together a marketing strategy, including establishing links with dealers and sales agents. Here Villgro actively connects with markets, which it is likely to provide ventures with access and a better chance to sell their products and become financially sustainable. Furthermore, having an established sales record is likely to make these ventures appear more attractive and less risky to core financial institutions as well as other periphery organisations such as micro venture capital.

Finally, Villgro provides support in administrative, managerial and intellectual property matters. For instance, it sets up transparent financial structures within the new ventures including accounting and book keeping systems and management information systems. Villgro also ensures that documentation including licenses and taxes are done properly. This includes filing patent applications so that entrepreneurs can protect their innovations. By improving the transparency of the incubated company, Villgro both improves the ability to monitor the company, and make it more attractive to external investors since the problem of asymmetric information decreases. Capacity is strengthened by building up a small management team behind the entrepreneur, sometimes of only person, that can act as a manager for the venture.

202 RIN Annual Reports 2006/2007; Villgro Annual Report 2008/2009, RIN website www.rinovation.org, accessed 10 February, 2008; Villgro website www.villgro.org, accessed 20 November, 2009, 9 March, 2010; Mahalingam, P., Basil, P., and Nigam, A. (2007), The Entrepreneurs, the Environment and the Ties between them: A case study of the Process of Social Entrepreneurship. Villgro Working Paper.; interviews at Villgro 6-7 November, 2007; Visits to two Villgro entrepreneurs, Mr. Mukundan and Dr. Venkata Krishna, 7 November, 2007.

${ }^{203}$ There is a pre-incubation programme at Villgro is devoted to putting together a business plan. 
A type of non-financial support that is popular among venture capital and incubator organisations at the core is mentoring by external experts. However, Villgro tried providing mentoring soon after it was set up, as part of its nonfinancial services, but was not successful. This, it believes, is because the inventors are reluctant to let people in on their invention- especially people unknown to them. Furthermore, inventors do not feel the need for a mentor because they often believe they have the required expertise, technically as well as business wise, to be successful. In addition, the investees were unwilling to pay for the mentoring from the interest free loan they receive from Villgro. At the same time, Villgro found it difficult to attract good mentors. Therefore, Villgro instead provides support similar to mentoring in-house

\section{Monitoring, Feedback and Learning ${ }^{204}$}

Villgro monitors its investments in order to make sure that the support it provides is sufficient, and to learn lessons from its incubation services. These lessons are used both internally to improve the services on offer, and externally to disseminate knowledge on how to incubate rural innovation, and more generally to highlight that there is innovation in rural areas.

Villgro does not appear to emphasise regular monitoring, evaluation and dissemination as strongly and regularly as the other case study organisations. However, the investees submit quarterly and yearly reports. Furthermore, Villgro pays regular visits to the ventures to monitor the investment and what they may need additional support with, usually once a month.

In 2008, Villgro put an increased emphasis on disseminating the feedback and learning about the rural innovation and incubation process. The organisation does so by having interns and fellows working with the incubation services that are expected to bring that experience with them elsewhere, through a new conference (Unconvention), and through an increased emphasis on research, including a plan to set up a research centre on social entrepreneurship and innovation.

\subsubsection{Cases: Servals and Mastitis Kit}

The first case, Servals, has already been studied in some detail in the case study on Aavishkaar in chapter 5. However, it merits further mention as it was introduced to Aavishkaar by Villgro. This case study will therefore detail what had happen to the business prior to Aavishkaar investing, and the work that Villgro had undertaken.

\footnotetext{
${ }^{204}$ Data sources include: Villgro Annual Report 2008/2009, RIN website www.rinovation.org, accessed 27 October, 2007; Villgro website www.villgro.org, accessed 9 March, 2010, 15 March, 2010; Mahalingam, P., Basil, P., and Nigam, A. (2007), The Entrepreneurs, the Environment and the Ties between them: A case study of the Process of Social Entrepreneurship. Villgro Working Paper.; interviews at Villgro 6-7 November, 2007; Visits to two Villgro Entreprenurs, Mr. Mukundan and Dr. Venkata Krishna, 7 November, 2007.
} 
The second case is the Udder Care Kit for Prevention of Mastitis- essentially a testing kit for mastitis, also based in South India.

\section{\#1: Servals: the Venus Burner2o5}

\section{Business Overview}

Servals is, as already noted in chapter 5, a social enterprise that manufactures products that provide clean and affordable energy to the poor, including energy efficient batteries, stoves and burners. Its flagship product, the Venus Burner, was invented by Mr. Thiyagarajan, an engineer from Tamil Nadu, South India. Mr. Thiyagarajan looked to construct an energy efficient burner that reduced the amount of kerosene needed, whilst still priced at an affordable rate. Mr. Thiyagarajan had amassed a large amount of debt during the initial innovation process and felt that he needed assistance with bringing the new burner to market whilst not incurring further expenses. He therefore approached Mr. Mukundan of Servals for assistance with manufacturing and selling the burner. Mr. Mukundan is well known in the grassroots innovation and small-scale industries sector because he is a member of a number of forums like the Energy and Fuel Users Association of India, and Patriotic and People Oriented Science and Technology (PPST). It was through the latter forum that Mr Mukundan came into contact with Paul Basil, the CEO of Villgro.

\section{Villgro's Role}

Since Servals was in need of funding in order to test and manufacture the burner, the first thing that Villgro did was to introduce Servals to Aavishkaar Micro Venture Capital. A deal was agreed whereby Servals retained a 51\% stake whilst Aavishkaar took a $49 \%$ stake in the company.

It was the connection between the inventor, the entrepreneur and Villgro that together made the decision that the entrepreneur should take on the responsibility for taking the technology to market. It was through linkages that Villgro had that Servals was able to meet with Aavishkaar who provided venture capital. Though Servals and its owner Mr Mukundan did not have difficulties in acquiring debt financing considering his reputation as an established entrepreneur and business man, the link with Villgro made a substantial equity investment from Aavishkaar possible. Next, Servals was introduced by Villgro to an African burner competition

\footnotetext{
205 Data sources: RIN Annual Reports 2006/2007; Villgro Annual Report 2008/2009, RIN website www.rinovation.org, accessed 10 February, 2008; Villgro website www.villgro.org, accessed 20 November, 2009, 9 March, 2010, 15 March, 2010; Mahalingam, P., Basil, P., and Nigam, A. (2007), The Entrepreneurs, the Environment and the Ties between them: A case study of the Process of Social Entrepreneurship. Villgro Working Paper.; interviews at Villgro 6-7 November, 2007; Visits to Mr. Mukundan, 7 November, 2007; Mr Mukundan's website and blog: http://servalsgroup.blogspot.com.
} 
which it won and in this way made contacts with the World Bank and British Petroleum (BP) that hosted it. Though little tangible came of these contacts it added credibility to the technology and the team working on it. However, the product and Mr Mukundan's increased visibility and wider network resulted in Servals and Villgro being invited to participate in forums, and eventually asked to provide the burners as part of a Tsunami Relief Package for South India. This was in part due to contacts Mr. Mukundan had with some of the organizers. This points to the importance of personal contacts and the establishment of mutual trust which can take a long time to build up and is of central importance in India. The validity of the product was further strengthened by Mr Mukundan's links with a Bureau of Standards in India. With the extra income from the sales resulting from its inclusion in the Tsunami relief effort, the burner went through tests and given high scores in terms of energy efficiency.

The early contacts with a number of wholesales, though problematic, proved that the burner was too expensive and difficult to sell. For instance, feedback from wholesalers suggested that the price was too high and nature of the burner, its light weight was discouraging some (conservative) buyers from purchasing the burner. This information was used to redevelop the burner to cut pricing and establish connections with fewer but well established and trusted wholesalers of such equipment. This proved a successful strategy as the fewer but more reputable wholesalers have increased sales to the extent that the product is now profitable.

Another important change implemented with the help of Villgro was setting up a manufacturing unit in rural India. The burner is manufactured with the help of an NGO called Trust for Village which supervises landless village women (currently numbering 40). ${ }^{206}$ This particular village was chosen because the village leaders were keen to look for opportunities to improve economic development in the village. With the assistance of the local NGO, Servals agreed with the village leaders to provide the employment opportunities for landless rural poor. The villagers are more committed to their chief than they would be to an external leader or organization. Therefore, it was important to work with the village leaders to ensure that villagers would turn up regularly for work so that production was not interrupted. Thus Servals and Villgro found an innovative alternative to collateral in involving the village leaders in the production agreement. The village leaders are in a better position to influence the habits and practices of the landless poor in the villages than are external actors. For their part, the village leaders benefit from a more prosperous village when the poorest are provided with livelihood opportunities.

In the early days of the manufacturing partnership, Servals paid for all the goods produced regardless of the quality but as better habits and practices were

\footnotetext{
206 The motivation for the NGO to manage the production is the payment it receives which allows it to become sustainable and not completely rely on grants and donations.
} 
established, which improved quality of the goods, the unit started to operate as a regular manufacturing unit. In 2007, at the time of fieldwork, Servals was only paying for goods of adequate quality. Servals feels that it is important to make the villagers understand that the market does not accept faulty products even if it comes from a social venture.

An interesting point to note as regards cooperation with local organisations and entities, is that Servals finds it difficult to interact with rural SHGs because they often do not understand that in business the SHGs must deliver something in return for the livelihood opportunities provided to them. This is due to the assumption many have that anybody coming with money into the rural areas are doing so with freely flowing and subsidized Government funds. This results in a lack of work ethics, or loyalty to the company or willingness to produce quality output. Hence, as noted in other case study organisations, building supportive and business minded habits and practices is very important to make business models for the poor work in the long run, and achieve financial sustainability.

\section{Social impact and commercial sustainability}

The Venus Burner cuts kerosene use by $27 \%$ which is likely to substantially improve the health of especially women of the households that use the burners. It also reduces household expenses as kerosene is expensive. The burner was part of the Tsunami relief package, during which it was provided as part of the Tsunami relief effort to 130000 households. In 2006, 10000 burners were sold through the Chennai-based sales agents Singhvi Brothers.

\section{\#2: Mastitis Testing and Treatment Kit:207}

\section{Business Overview}

The Udder Care Kit for Prevention of Mastitis is a kit used to detect and prevent mastitis in cattle before clinical symptoms show. The kit consists of a prognosis kit (Arvin Milk Test Kit) and a prevention kit (Arvin Udder Care Kit) used to treat the affected cattle. The kit is the innovation of Dr. Venkatakrishnan, a retired veterinarian and Professor at the Veterinary College, Chennai, from Tamil Nadu, South India. The innovation was a response to the problems of bovine mastitis which is a bacterial disease severely affecting cows' milk production if not detected and treated early, and often leading to animals dying. Dairy farmers regularly lose income because they do not have the means to detect the mastitis, or treat it. Most current tests and treatments are too complicated and costly for farmers to carry out

\footnotetext{
${ }^{207}$ Data sources include the RIN Annual Reports 2006/2007; Villgro Annual Report 2008/2009, RIN website www.rinovation.org, accessed 27 October, 2007,; Villgro website www.villgro.org, accessed, 15 March, 2010; interviews at Villgro 6-7 November, 2007; Visit to Dr. Venkata Krishna, 7 November, 2007.
} 
themselves, but this mastitis kit is simple and cheap enough for farmers to do so. The test kit also detects mastitis about a week earlier than conventional tests. Dr Venkatakrishnan had developed a number of veterinary innovations over the years, and came to Villgro when he had developed the Udder Care Kit in order to seek help with the commercialisation of the kit.

\section{Villgro's Role}

Villgro has been supporting the Mastitis Kit through its L-RAMP programme. Dr. Venkatakrishnan was offered a loan of Rs 5700000 for a one-year study of the feasibility and to commercialise the kit if it proved to be feasible. Villgro's incubation services have included technology validation, business development, pilot marketing and technology transfer. At the time of fieldwork, in 2007, the kit was field-tested. Villgro additionally assisted Dr Venkatakrishnan in filing a patent application in India. Furthermore, Villgro has also been instrumental in identifying partners that could help commercialise and market the product. For instance, at the time of fieldwork, in 2007, he was working with Bharttiya AgroIndustries Federation (BAIF), an NGO which did the preliminary field testing. At that time, a market research study was underway, studying how dairy farmers reacted to the testing kit, in particular looking at farmer acceptance and farmer cooperation.

\section{Social impact and commercial sustainability}

The mastitis kit is able to detect mastitis early on, ahead of clinical symptoms, which means it can be more efficiently and cheaply treated. That saves farmers the cost of more expensive testing, veterinary services and medication on the one hand, and reduces the lack of income from a sick animal on the other, by being detected before it has a significant impact on milk production.

In 2007, the treatment kit cost USD5 whilst the antibiotics that are usually prescribed with conventional treatments cost around USD40- a substantial saving for the dairy farmers.

To summarise, Villgro is an incubator which supports rural entrepreneurs and innovators. At the time of fieldwork, Villgro comprised two incubation programmes and a database on rural innovation. However, by 2009, the organisation had developed into a multifaceted organisation with complementary services along the innovation value chain, including business plan competitions, incubation support, market testing and a retail outlet for commercialised innovations. Villgro has shifted its emphasis from supporting inventors to supporting entrepreneurs in the commercialisation process and to this end has a programme which specifically focuses on matching innovations with entrepreneurs. Villgro mainly support the rural poor indirectly by providing innovative products and services through local entrepreneurs. 


\subsubsection{Conclusion}

Villgro is an incubator which supports rural entrepreneurs and innovators which has developed into a multifaceted organisation with complementary services along the innovation value chain, including business plan competitions, incubation support, market testing and a retail outlet for commercialised innovations. Importantly, Villgro has shifted its emphasis from supporting inventors to supporting entrepreneurs in the commercialisation process and to this end has a programme which specifically focuses on matching innovations with entrepreneurs. Villgro fits in nicely to the eco-system of innovation support as it works with ventures that are not yet ready to for investments from micro venture capital firms such as Aavishkaar, but has outgrown small-scale finance that BASIX may provide.

This chapter has looked at two periphery organisations that support innovation at the grassroots level. They do so mainly through grant-based financing. CTD focuses on a rural community and innovates to put in place a business model that will provide value added to existing raw materials. Villgro, meanwhile, incubates existing innovation and supports individual innovators and entrepreneurs to create a business plan, build a prototype, test the idea and research the market.

The chapter also concludes the three case study chapters which highlighted different kinds of pro-poor innovation in rural areas, and described in detail how such innovation can be supported. It is evident that innovation is heterogeneous and that the financial and non-financial support cannot use a one-size-fits-all approach. The next chapter will further discuss the similarities and differences of the case study organisations. Chapter eight compares and contrasts the case study organisations, based on the discussion of the INUS conditions of chapter three. 


\section{Discussion of Case Studies in light of the Conceptual Framework}

This thesis has explored the financing of pro-poor entrepreneur-based innovation both theoretically (chapters 2-3) and empirically with an overview of the financial system (chapter 4) and with case studies of periphery organisations (chapters 5-7). The current chapter will tie these parts together by discussing the case studies in light of the conceptual framework of chapter 3. Section 8.1 discusses innovation and knowledge flows of the rural financial system based on the core-periphery structure, as set out in the conceptual framework in section 3.2. That is followed by an analysis of the six INUS conditions for financing of pro-poor entrepreneur-based innovation, set out in section 3.4 of the conceptual framework, using evidence from the case studies. Section 8.3 summarises the findings of this chapter.

\subsection{A Financial System with a Core-Periphery Structure}

In chapter 3 , section 2 , the financial system was depicted as having a core-periphery structure with the banks at the core and the alternative financing sector at the periphery. In the core-periphery structure it was expected that knowledge flowing within the system would result in stronger knowledge accumulation at the core than the periphery. Furthermore, the periphery was not only acquiring less knowledge because of the knowledge flows of the system, but was also dependent on the core for inputs, innovation and knowledge. However, when the system has stabilised and matured, knowledge accumulation may slow down, resulting in stagnation of both innovation and knowledge flows at the core (Arora, 2009).

Chapter 4 provided evidence from India of a financial system with a core (the rural banks) and a periphery (the case study organisations). The evidence supported the idea that the core has matured and become rather rigid with limited knowledge flows and little innovation as regards providing financial services. Instead the periphery organisations appear to be innovating and making use of different kinds of accumulated knowledge. However, these organisations are at the margin, and 
few in numbers, thus still dependent on the core to varying degrees. There are therefore three important aspects worth considering: innovation in financial services; top-down versus bottom-up information flows and decision-making; and the links that exist between the core and the periphery.

\section{Innovation in Range of Services}

The core of the rural financial system in India is relatively rigid and there is evidence of path dependence and institutional lock-in (as noted in section 4.3). For instance, rural banks are unlikely to take on borrowers that do not fit the classical borrower profile. That classical borrower profile is rather standardised. Hence, banks offer a narrow range of services that tend to be financial-only in nature. The case studies of periphery organisations depicted in chapters 5-7, however, highlight that innovation and entrepreneurship in rural areas are heterogeneous and that these require different kinds of support, financial as well as non-financial. For example, Aavishkaar which invests in established entrepreneurs that have existing management teams and business plans, is almost at the polar opposite of CTD which innovates, creates and implements complete business and technology models. Whilst Aaviskaar invests for a set and comparatively short period of time with a clear view to exit from the investment, CTD provides capacity building over a long period of time and never exits an investment, instead evolving its role from active to passive. Thus, the overarching goal of periphery organisations is to support entrepreneur-based innovation. However, they differ from one another in who they target and how they support their clients. In other words, their specific targets and goals differ and consequently they innovate in the range of services provided so that these services are tailored to the particular kind of entrepreneurbased innovation that each organisation supports.

\section{Top-down vs. Bottom-up Information Flows and Decision Making}

It was argued in chapter 4 that the hierarchical nature of the system, and the way it affects knowledge flows, has resulted in banks having matured into a stable system with little dynamism. Within the hierarchical structure of banks, information and decisions flow from the top (the central office of the bank, or the apex institutions of the Indian banking system, such as NABARD) to the bottom (local rural bank branches). Furthermore, stringent regulations, inflexible loan application forms that may be processed away from the local bank branch, and the risk of having to personally answer for bad loans that are granted at local branches combine to offer very few incentives for taking new initiatives at the local, decentralised level. Instead priority is given to risk-free loans and larger loans for well-off clients. The case study organisations on the other hand, actively seek out information and new knowledge at grassroots level on which they base their decisions in a bottom-up, 
and often decentralised, manner. For instance, BASIX has a vast management information system that holds information on all its clients. This locally collected information is valued and is the basis for making major decisions at the highest level within the organisation. It was, for instance, information about the lack of effectiveness of the loans granted to poor farmers that made the Directors of BASIX take the decision to undertake a complete review of all its activities. Furthermore, although BASIX has a head office which makes major decisions, it is also a decentralised organisation where each unit office has considerable freedom as regards who their services target and the local initiatives it undertakes. Another example is CTD which operates a central unit in Delhi whilst the majority (all but two) field stations are operated independently as franchises by local NGOs. This provides substantial freedom for local units to adjust their innovation and entrepreneurship support according to local requirements.

\section{Core-Periphery Links}

There are still strong links between the core and the periphery. In particular, many periphery organisations still appear dependent on the core for finance. Three ways in which the periphery organisations are depending on, or working with, the core for finance are evident. First, CTD, for example, receives grant funding from the Department for Science and Technology to create and implement its interventions. Second, in the case of Aavishkaar and BASIX, the periphery organisations have raised finance from the core (equity only in the case of Aavishkaar and equity and debt for BASIX). Third, S3IDF works with local banks to encourage them to provide debt finance directly to the entrepreneurs running the projects that the organisation supports. Not only does this working relationship benefit S'IDF's entrepreneurs, but it also provides the banks at the core with new potential clients that have low risks because of S'IDF's backing in the form of credit risk guarantee.

This section has noted that whilst the core is showing signs of having matured and become rather rigid, an eco-system of different innovation support has sprung up at the periphery- including financial services, rather than exclusively relying on finance. It is recognised that there are different kinds of needs within rural areas. For example, those involved in grassroots innovation support work differently to those supporting innovation through micro venture capital. Nevertheless, despite operating differently from the core financial institutions, the periphery organisations still retain strong links with the core, and are often dependent on the core for finance.

The next section will discuss why it is possible for these periphery organisations to provide finance where the core institutions, the banks have failed. 


\subsection{INUS Conditions Affecting the Provision of Finance}

With the core-periphery structure as an underlying theme, the final section of chapter 3 outlined six insufficient but necessary (INUS) conditions which could explain the existence of appropriate PEBI finance at the periphery. This section will discuss each of the INUS conditions in light of the case studies and chapter 4 on the financing system.

\section{Flexible and Dynamic Approach to Finance}

An organisation that is flexible in the services it provides is likely to be in a better position to adapt to the heterogeneous needs of rural pro-poor entrepreneur-based innovation. Furthermore, an organisation that provides such flexible support is likely to have a dynamic operating model, which in turn puts it in a better position to adapt more quickly to new situations and challenges.

\section{Flexible}

Whilst banks have been found to adhere to a narrow range of services, ${ }^{208}$ the case study organisations are far more flexible in supporting PEBI. They are essentially flexible in two ways: either by providing tailor-made support to each client, or by offering several models, or types of support, to choose from. BASIX, for instance, has set loan appraisal procedures, but a number of different lending models to fit different types of rural clients. Whilst the larger loans applicable to micro growth entrepreneurs are provided on an individual basis, for established entrepreneurs such as Mr. Nagaswany that can provide a collateral, loans that form part of the MACS and market linkage models (e.g. with PepsiCo) are much smaller and provided through group lending. Furthermore, clients can choose whether to add on non-financial services and insurance.

SIIDF and Aavishkaar, on the other hand, provide support to much fewer customers than BASIX, but evaluate potential investees and tailor support, both financial and non-financial, on a case by case basis. The organisations are also flexible in the way they provide the support. S3IDF, for instance, found that the technological solutions provided for the hawker lighting were not satisfactory, and therefore went beyond investee investments to sponsor the technology supplier to improve the lighting solutions offered to the entrepreneur. S3IDF has since made investing in suppliers one of its side activities. CTD operates in between the case by case models of Aavishkaar and the set models of BASIX, with several versions of each sector model that are tweaked to fit the local context.

\footnotetext{
${ }^{208}$ One reason is the risk of being investigated for bad loans if lending to unorthodox clients whilst another has its roots in the nature of the loan approval process that makes approving lending for non-standard projects difficult and complicated.
} 


\section{Dynamic}

Underlying the flexibility in service provision is a dynamic operating model in all of the organisations studied. Given that the challenges that pro-poor innovative entrepreneurs face are evolutionary in nature, any model and organisation supporting such activities needs to have the ability to change and adapt too. This can be seen on three levels: at the client level; at the level of the support model; and at the level of the organisation.

As regards the first level, the client level, it was shown in the case of BASIX that the farmers in the Koutla-B MACS started as a Joint Liability Group which evolved to a MACS. Their first loan was a small group-based loan of Rs 10 000, which, as the MACS evolved, evolved into a Rs 300000 loan to the MACS itself for upgrading of facilities and machinery. Even the Micro Growth Entrepreneur Mr Nagaswany, started with a small individual loan of Rs 10,000 for a buffalo, which grew steadily to Rs 50,000 and then Rs 200,000 as he went from a client of a individual buffalo loan to a larger scale investment in a small enterprise, the quarry. CTD is dynamic in a different way as regards its clients. The organisation is heading the innovation process in rural areas and evolves with the changing nature of each project and model. The organisation takes on different roles throughout the life-cycle of a project and importantly looks to root the project locally and then removes itself actively, instead letting local NGOs and the community itself lead, leaving CTD with a consultancy role.

At the second level, BASIX is a good example in the way it evaluates and improves its support models continuously through its in-house innovation department, the IGS services. IGS also pioneers various forms of complementary non-financial support for farmers- the Ag-BDS services, as well as insurance and the management information system. One poignant example is the Livelihood Triad Fund which was introduced to provide new ideas into existing services. It was a three-year fund set up with the specific remit to encourage innovation in its financial and non-financial services provision.

CTD meanwhile works in tandem on several different models at various stages of development. A particular strength of CTD is therefore its ability to change its support services with the changing nature of its projects.

Finally, the third level concerns the dynamic organisation itself. Both BASIX and Villgro for example, have completely overhauled their organisations (BASIX in 2001 through the OLE process and Villgro in 2008), to become more flexible and more efficient in providing their services. Aavsihkaar meanwhile started on a small scale so that the organisation could learn from early investments since there were no precedents of micro venture capital when it set up. It has since grown through raising further, and larger, rounds of finance, which has enabled the organisation to increase both the number of investments, and the amount it invests. It has also come 
to focus more specifically on certain sectors such as healthcare, renewable energy and handicraft.

In conclusion, there are two types of flexibility of service provision evident among the case study organisations. One type is flexible by offering several different support models for different types of investments and clients, such as BASIX and CTD. Other organisations like Aavishkaar and S3IDF tailor each intervention or investment package according to the evaluation of the individual project. It may be that size is a factor here since those with larger volumes of clients are providing choices of support models rather than bespoke services.

Furthermore, the case study organisations are dynamic in that they evolve over time on several levels. At the client level BASIX allows clients to graduate between packages whilst Villgro uses different incubation programmes to support its clients in different tasks such as market research or sales. CTD is instead dynamic at the support model level as it looks for forward and backwards linkages for its business model interventions, as in the case of carcass utilisation that was a result of backward linkages from leather tanning. Finally, both Villgro and BASIX are examples of organisations that have completely overhauled their organisations.

\section{A Wide Network of Actors with Varied Knowledge}

By having access to a wide network of actors with different knowledge types, the periphery organisations can access expertise to better evaluate and manage the risk of potential endeavours or clients. In addition, a wide network provides new knowledge that can be used to improve existing models of finance. Furthermore, working in partnership with different kinds of actors makes it possible to offer a much wider range of services than if all services were to be provided in-house. Among these networks it is noteworthy that specific individuals rather than groups play particularly important roles.

The periphery organisations appear to rely on a wide range of knowledge types through their large networks of different actors. They use these networks in six different ways: to acquire expertise to assess potential applicants, to acquire expertise to improve existing or new service or operating models, to co-finance or provide an 'exit' for its clients, to finance their operations, to work in partnership in order to provide a broader range of services, and finally to influence the sector, policy or core financial institutions. The case study organisations have links with a number of different kinds of actors from the public sector, private sector, academia, core financial institutions, international development agencies, NGOs, periphery finance organisations, and entrepreneurs. Each of these eight types of actors will be considered in turn, highlighting what role, if any, they play for the case study organisations. 


\section{Public Sector (Government)}

The public sector is important on a general level for providing an enabling environment through supportive policies. To this end, none of the case study organisations reported that government regulation was a major barrier. However, organisations such as BASIX and CTD still work with Government committees and apex finance institutions, such as NABARD and SIDBI, to improve the policies and regulations governing the financing of PEBI.

Furthermore, public funds are important sources of finance for CTD, which relies to a large extent on financing of rural innovation and technology from the Department for Science and Technology.

Periphery organisations such as BASIX and S3IDF also engage in joint service provision by working in partnership with state dairy boards. For example, BASIX provides veterinary services together with the state dairy board in Andhra Pradesh, whilst the state dairy board in Karnataka part finances a milk route supported by S'IDF and its local NGO partner CRWCWS.

\section{Academia}

The academic sector is involved in the periphery organisations as sector experts and/or partners. For instance, Villgro runs its incubator programme L-RAMP together with IIT-Madras, which also provides important expertise when refining the technologies and prototypes of the products that are being incubated. In addition, several other academic institutions act as nodal partners for Villgro's incubator programmes, including its business plan competitions for students and rural innovators. In this way Villgro is able to use the technical expertise, networks and physical assets of its academic partners. Villgro, in fact, moved to the business park of IIT-M in 2009. However, it should be noted that this is not a onedimensional partnership, as IIT-M benefits from Villgro's expertise in rural innovation and access to the grassroots. To that end, Villgro offers a masters course in rural innovation and entrepreneurship at IIT-M. Furthermore, through the student business plan competitions initiated by Villgro, students are encouraged to innovate and think entrepreneurially, which benefits the academic institute too.

CTD also relies heavily on academic institutes for technical expertise and has worked with the Central Leather Research Institute in Chennai over a number of years when creating, adapting and refining its models in leather and carcass utilisation.

\section{Core Financial Institutions}

There are, as noted in the first part of this chapter, still links between the core and the periphery organisations in the financial system. Notably, the periphery organisations still to a large extent depend on the core for finance. This is important since it suggests that periphery organisations are not operating in isolation and that 
with established and well functioning links to the core, scaling up of the activities at the periphery is likely to be easier to achieve. The first type of link is the straightforward investment by core institutions in periphery organisations. Aavishkaar, for instance, has attracted a number of equity investors from the core, as has BASIX. Both organisations did so by proving their business model over time and in this way persuading investors of the beneficial risk-reward profile. BASIX has additionally acquired a number of loans from large-scale core lenders.

A second type of interaction occurs when the periphery organisations seek additional debt financing for its investees. Aavishkaar, BASIX and CTD have all found that accessing debt finance early on was difficult as the banks considered their clients too risky. However, over time it has become much easier to acquire debt finance from banks with which these organisations have established good personal relationships.

A final type of link, and probably the most innovative, is that which S3IDF is establishing with banks in South India. S IDF acts as a facilitator and as such has persuaded local banks to finance its small-scale infrastructure projects. It did so by providing a credit risk guarantee instrument, equivalent to $25 \%$ of the loan. Having started with local bank branches, S3IDF has been able to persuade banks such as Syndicate Bank to make it a policy to debt finance small-scale infrastructure projects in the SIIDF model across Karnataka State. This kind of partnership is an important step towards narrowing the financing gap that exists between the core and the periphery as regards financing PEBI.

\section{Private Sector}

The private sector is vital in a market-based sustainable support model of PEBI. A number of different kinds of private sector actors are used at the periphery, from providing inputs to manufacturing, and selling products. S3IDF, for example, works with technology provider Selco to provide improved technology for its hawker lighting projects. When S3IDF could not find an appropriate technology it in fact sponsored Selco to improve the existing technologies. This kind of investment in suppliers has become an important element of the S3IDF model.

BASIX, as a large organisation has struck up a number of partnerships with private sector firms to provide services. For instance, it works with insurance firms such as AVIVA and Royal Sundaram to provide insurance to its clients (since it is not allowed to provide insurance itself). It also works with PepsiCo in its market linkage model where it facilitates links between small-holder farmers in Jharkhand and the large-scale manufacturer.

\section{Third Sector (NGOs)}

In all case study organisations apart from Aavishkaar, NGOs are vital partners in the provision of services. Both S3IDF and CTD rely on local NGO partners to carry 
out the day-to-day management of projects. CTD is the most obvious example, with local NGOs such as STD operating the local field stations as franchises. This provides the local NGO with considerable freedom.

At Villgro, one of its entrepreneurs, Mr Mukundan, uses a local NGO to oversee manufacturing at a rural unit that employs landless rural poor. This partnership is mutually beneficial as Mr Mukundan has a reliable NGO to take care of the management of the manufacturing unit and its staff, whilst the NGO benefits from a reliable and steady source of income which is not linked to charity or aid cycles.

It should be noted that it was highlighted in several case study organisations that working with NGOs is difficult. This is chiefly for two reasons: firstly they are often not business minded, preferring instead to focus on 'doing good', and secondly, very few of them are entrepreneurial and understand how to support entrepreneurship and innovation. To address this, CTD has run workshops to train NGOs in entrepreneurship and innovation management, but the organisation still encounters difficulty in finding NGOs that act and think creatively. This, in other words, appears to be a barrier to scaling up the activities of the periphery organisations.

\section{International Development Finance}

The organisations that prominently feature partnerships with international development finance organisations are BASIX, Villgro and S'IDF. However, whilst Villgro and S3IDF rely on development finance for programme funding, BASIX uses it for additional services beyond financing PEBI. It, for example, received a major grant from the Swiss Development Fund to run a three-year innovation fund called the Livelihood Triad Fund discussed in section 8.2.1.

\section{Entrepreneurs}

Whilst innovative rural entrepreneurs are the main clients of the case study organisations, they are also crucial partners of many of the organisations. In the case of Aavishkaar, they provide useful connections to new investment opportunities. At Villgro, entrepreneurs like Mr Mukundan of Servals take over and commercialise innovations that could not be taken forward efficiently by the inventor. Furthermore, Mr Mukundan is particularly important in that he provides mentoring for new entrepreneurs and innovators with nascent ideas at Villgro but also more generally in the sector related to sustainable technologies and goods for the poor. In recognition of the important role that Mr Mukundan plays he also sits on the Board of Villgro. 


\section{Periphery Finance Organisations}

Several of the case study organisations work closely with other financing organisations at the periphery supporting rural PEBI. For example, Villgro has signed a memorandum of understanding with Aavishkaar agreeing to provide information on any promising firms being incubated at Villgro. Aavishkaar has also started a fund together with BASIX.

At the sectoral level, BASIX has built a vast network of organisations involved in finance in rural areas through co-founding the Sa-Dhan microfinance umbrella organisation. It also builds capacity in the sector through its Livelihood School for practitioners, and consultancy services for microfinance organisations.

To sum up, a large number of different actors are part of the networks of the periphery organisations. They often provide services with the help of external actors, as in the case of S3IDF which acts as a facilitator linking banks with technology suppliers and local entrepreneurs. BASIX is another example using private core-sector insurance companies to provide insurance for its clients. Another interesting partnership is that formed between academia, the NGOs and the organisation, as in CTD and Villgro. Here the academics provide expertise in building business and technology models, or providing feedback on potential investments, whilst NGOs provide expertise on the local area. NGOs also often manage projects locally as their context specific knowledge decreases the risk of asymmetric information problems arising.

Furthermore, the organisations do actually work with core financial institutions to a great extent. In the case of S3IDF, the business model is built on the idea of facilitating finance from banks by providing a credit risk guarantee, whilst at Aavishkaar and Villgro, the aim of 'exiting' investments includes involving core financial institutions as investors. Even those organisations that do not focus on finance, such as CTD, admit that banks are vital for providing additional financing for its community interventions.

These examples also highlight how the periphery organisations are deliberately creating links between otherwise unconnected members of their networks. It is noteworthy that in the organisations particular individuals, generally the founder(s) are very important for the network. This appears to be particularly the case at S3IDF where the founder holds the large international network, and Villgro where the founder has access to the organisation's national network.

\section{Relationships, Risk Profile and Collateral}

By forming and entertaining close relationships with its clients, an organisation can improve the understanding of the level of risk attached to its investments, and thereby ameliorate the risk profile of its clients as well as its own investment portfolio. Such relationships can in addition reduce the reliance on and necessity for collateral. Separately, by acting as a 'go-between', organisations can use their 
relationships to transfer trust to its clients and therefore do away with some of the risk that normally requires collateral in arm's length financial transactions. However, relationships can equally act as formidable barriers to access to finance for those that have not formed them.

There are thus three sets of relationship-related aspects to discuss: relationships reduce asymmetric information; relationships reduce the need for collateral; and relationships deepen and widen networks by transferring trust (go-betweens).

\section{Relationships and Asymmetric Information}

The case study organisations use relationships to reduce asymmetric information in different ways. At BASIX, for instance, the Livelihood Service Assistants (LSAs) based at the decentralised unit offices, hold a central role in building relationships between the organisation and its clients. Weekly and monthly visits by the LSAs means that they get to know their clients well. Furthermore, these LSA-based relationships build trust which further reduces moral hazard issues. This in turn provides BASIX with an opportunity to spot potential problems, and clients with a chance to voice their concerns.

At S3IDF, on the other hand, the head office directly interacts with its clients. The relationship is built up over the course of the implementation of the project and S3IDF has found that the success of a local NGO, such as CRWCWS or entrepreneurs, such as Mr. Murugesh, in running a business or project to some extent depends on the ties that have been formed.

CTD differs from the other case study organisations in that it relies solely on relationships for reducing asymmetric information and moral hazard problems. The organisation therefore prioritises establishing solid relationships based on trust right from the outset of a project. CTD starts building these relationships at the stage where its team goes to survey the local skills and raw materials available, and local market demand. CTD has highlighted that the process of building relationships and establishing mutual trust is a lengthy one and that the organisation that is attempting to build that trust may have to go beyond its immediate remit in order to establish such trust. CTD, for instance, provided villages in HP with sanitation services before starting its intervention in leather or fruit, whilst in Madhya Pradesh it provided infrastructure in the form of assistance to build a road to a tribal village as well as support to set up education and healthcare facilities.

\section{Relationships and Collateral}

The clearest example of using relationships to replace collateral is CTD. At CTD relationships formed with clients and NGOs are used in place of collateral. This relationship of mutual trust that is in part built up before the actual implementation of a business model begins is a defining characteristic of CTD, as noted in the 
section on asymmetric information. The other case study organisations all use different forms of collateral, or alternatives to collateral. Whilst BASIX uses group lending models (SHGs and JLGs) as an alternative for collateral for small loans, in the case of larger individual loans to growth micro enterprises, the organisation requires classical collateral. Another way for BASIX to substitute collateral, or part of collateral requirements, is to systematically increase the credit amount provided as a relationship with a client is established and business model proved. Meanwhile, S3IDF, Villgro and Aavishkaar which work with small firms, and are closer to conventional business start-up finance such as seed funding, early-stage venture capital and business incubators, all require 'sweat equity', e.g. a small amount of co-investment from the entrepreneur. They therefore depend less on relationships as collateral than BASIX and CTD.

\section{Relationships and Go-between's}

At BASIX, the unit officers based at the field offices, act as 'go-betweens' effectively connecting ventures and entrepreneurs in its portfolio with new markets, suppliers and external sources of finance (such as government schemes or bank finance). PepsiCo would not have established potato cultivation and manufacturing deals with small-holder farmers in Jharkhand if BASIX had not acted as the facilitator. BASIX persuaded the manufacturer to get involved by offering to provide institutional development support as well as financial and non-financial support to the farmers. It was likely the reputation of BASIX and the trust between PepsiCo and BASIX which made Pepsico take this pioneering step.

Another obvious example is S3IDF. It uses credit risk guarantees and trust established between itself and the local banks which it transfers to its infrastructure entrepreneurs. In this way the entrepreneurs are able to access bank finance. Finally, it is worth mentioning that Aavishkaar uses its trust and acts as a go-between, when it uses the relationships with financial institutions at the core that it has built up for exiting existing investees.

To sum up, close relationships help reduce the need for collateral, as shown in the case of CTD which does not use collateral at all, and BASIX which does not use collateral for small group-based loans. Villgro and Aavishkaar instead use traditional collateral as their models are closer to traditional business start-up finance at the core.

Asymmetric information can also be reduced through relationships and building up trust, as noted in the case of CTD. Another interesting example is provided by BASIX which uses its LSAs to reduce information asymmetries through weekly or monthly visits.

Finally, in terms of acting as 'go-betweens' to transfer trust, BASIX for example used its clout to establish contracts between a group of farmers in Jharkhand and the PepsiCo company, so that farmers could supply potatoes in the lean season. 
Aavishkaar instead mainly uses its ability to transfer trust to find potential exit possibilities for its clients.

\section{Knowledge, Feedback Loops and Learning}

By emphasising tacit knowledge rather than simply codified knowledge organisations are likely to access 'newer' and more context-specific knowledge. By doing so, they are in a better situation to understand local and/or new developments and problems, for which their financial models can then be adjusted. Additionally, efficient communication and feedback loops that transfer knowledge within the organisations as well as between the organisation and its clients and other stakeholders are required. However, for the feedback loops and new knowledge to have real value long-term, the organisations need to emphasise learning.

\section{Kinds of Knowledge}

Whilst banks are relying on codified knowledge ${ }^{209}$ almost exclusively, the organisations at the periphery rely more heavily on tacit knowledge. However, the extent to which the organisations rely on tacit and codified knowledge differs. Aavsihkaar, for instance, relies to a greater extent on codified knowledge as it expects applicants to have existing business plans. Villgro too prefers applicants with a business plan, although not to the same level as Aavishkaar. At the opposite end of the spectrum is CTD, which completely relies on tacit knowledge and undertakes its own surveys to gather such knowledge. BASIX too relies mainly on tacit knowledge, through its LSAs further discussed below.

Also worth highlighting is the fact that the organisations often codify important knowledge about their investments or about rural innovation in general. The tacit knowledge gathered by the LSAs at BASIX for instance is entered on an information management system which keeps information about all its investments. Once the knowledge has been put on the database, or codified, it transfers rapidly to the head office and other unit offices, and is thus much easier to share and disseminate. Villgro meanwhile set up a database on which to store information about rural innovation, and more recently, in 2009, started a knowledge management programme to support its incubator programmes in codifying and storing knowledge about rural innovation and its investments. Another important aspect of Villgro's support activities is to help entrepreneurs and innovators at the incubation or pre-incubation stage to formulate a business plan, in other words codifying knowledge about the innovation and the venture. Aavishkaar too works with its portfolio companies in refining their business plans, since such codified

\footnotetext{
209 Banks rely on codified knowledge through their emphasis on standardised loan application procedures and on arm's length transaction through requirements such as collateral. They need it in order to be able to provide the kind of documentation demanded in the financial sector.
} 
knowledge makes them more attractive to investors among the core financial institutions.

\section{Feedback Loops and Communication}

To transfer knowledge across or beyond the organisation, efficient feedback loops, with two-way communication, are necessary. Whilst the organisations provide information to their portfolio companies, they all also emphasise information flowing from the clients to the head office on the usefulness and quality of the services provided. BASIX has, for instance, invested substantially in a management information system to codify and transfer locally specific knowledge throughout the organisation and uses it to evaluate the services and the impact these are having on a monthly, quarterly and annual basis. Furthermore, regular reviews that include local field staff as well as head office and external stakeholders, ensure that feedback flows within the organisation. This emphasis on two-way communication and feedback from grassroots level is emphasised in its OLE operational review of BASIX from 2005.

Meanwhile, at Aavishkaar the main feedback loops occur through the quarterly and yearly reviews with investee companies as well as through the weekly telephone conversations with, or visits to, the portfolio companies. Finally, CTD, which runs a decentralised system, relies on yearly meetings with all the NGOs that run franchises, together with regular visits by the CTD team in Delhi to the field stations.

\section{Learning}

The case study organisations emphasise learning in different ways, both in terms of organisational learning and operational or service model learning.

Aavishkaar, for instance, highlighted that it made very few investments to start with in order to learn from these early investments, before scaling up operations, learning by doing, in other words. Meanwhile, BASIX has its own division focussed on learning in the Indian Grameen Services, its R\&D department. IGS trials models and new ideas before disseminating them, more widely, across the organisation. IGS also undertakes evaluations of existing services and activities. BASIX also emphasises learning through, for example, its quarterly reviews where external visitors visit unit offices to learn about and review the models that BASIX uses. Crucially, BASIX thus manages to both encourage dissemination of its models and at the same time learn from the feedback it is receiving from its visitors. Furthermore, the Livelihood School is specialised in disseminating learnings from the work that BASIX undertakes more widely by running courses on rural livelihood finance.

Two organisations that have as a central remit to disseminate learnings, or lessons, are S3IDF and Villgro. Whilst Villgro has set up an institute to collect, codify 
and disseminate knowledge about rural innovation and entrepreneurship, S3IDF aims to disseminate lessons from its small-scale infrastructure projects among international organisations such as the World Bank.

In conclusion, it appears that those organisations which have a stronger local presence such as BASIX, through its LSAs, S3IDF and CTD through their work with local NGOs are more reliant on tacit knowledge and have put feedback loops in place that are able to catch this. In terms of how knowledge is acquired, there are essentially two types of models at work here. Whilst BASIX, CTD and S3IDF rely on local entrepreneurs and/or NGOs to provide them with local, time and context specific knowledge which is often tacit in nature, Villgro and Aavishkaar are more centrally run, relying instead on the head office making direct contact with their clients.

\section{Lead Users and Innovators}

Related to the feedback loops, knowledge accumulation and learning of the previous section, is an organisation's ability to innovate. The banks at the core of the financial system can not be seen as innovators, especially at the level of local lending. There are new products, services and organisations being tried out at the apex level by organisations like NABARD and SIDBI, but the schemes do not appear to have much effect on the availability of credit for rural entrepreneur-based innovation.

The organisations at the periphery, however, act as lead users of finance as they acquire finance from sources at the core of the financial system and provide these sources of finance in innovative ways to entrepreneurs involved in rural propoor entrepreneur-based innovation. They are in several cases also innovating on the ground, improving the organisational processes or technologies used by the client, so as to improve the efficiency of the financial support, whilst reducing the risk. In doing so, the organisations are able to circumvent the lack of supply of credit to pro-poor entrepreneur-based innovation. An innovator as a lead user is additionally in a better position to evaluate the usefulness of a certain model.

That the periphery organisations are more involved in innovative activities than the banks is clear. The organisations are participating in the financial innovation process where they experiment with new ways of providing financial and non-financial support to their clients. Beyond that, the organisations are drivers or facilitators of the innovation processes taking place in rural areas.

\section{Financial Services Innovation}

Aavishkaar is innovating financially to provide venture capital at a micro level and to attract further funding for its portfolio companies, such as the co-financing of Vaatsalya by new venture capitalist Seedfund. Meanwhile, S3IDF is innovative in 
the way it uses credit risk guarantees to entice local banks to support small-scale infrastructure projects, something that the banks did not previously do.

BASIX has focussed on innovating in the delivery of non-financial services that support the finance it provides. On the ground, BASIX looks to create new market linkages between the rural poor or rural entrepreneurs and larger firms, such as PepsiCo, or new markets for example. This is done at the field offices as well as through the established R\&D department, the IGS in Hyderabad. Whilst the field office staff are directly involved in improving the technologies available to farmers and entrepreneurs through its own search and experimentation (for example testing new seed varieties at the offices), the IGS services pilot larger programmes or models including Ag/BDS, linkages to dairy and new forms of group or individual lending and insurance.

SIIDF instead facilitates innovation, rather than actively innovating themselves. It does so by providing the idea for improved infrastructure services and bringing together local entrepreneurs, technology suppliers, banks and NGOs. For example, for the hawker lights, the organisation brought together a local entrepreneur that made his own improvements to the technology, with the technology supplier. By financially supporting the suppliers, S3IDF improved the technology available to the entrepreneur. S3IDF also facilitated for the local bank to provide a loan for Mr. Murugesh to expand his business.

Finally, CTD is actively spearheading rural innovation at grassroots level by creating innovation and growth focussed business models. Furthermore, once these models have been implemented and ownership has been taken over by local communities and/or NGO's, CTD continue to look for new ways to improve the business models or diversify the activities of local communities. CTD in other words continues to innovate.

To sum up, the three organisations that exhibit clear signs of being innovators in financial services provision are Aavishkaar, S3IDF and BASIX. Aavishkaar, which provides equity, and S3IDF which provides credit risk guarantees are innovators in finance. Both organisations are using financial instruments that were previously not used for PEBI support. BASIX is instead focussed on innovative non-financial solutions, and complementary services, such as insurance. In addition, S3IDF is innovative in seeing its main role as a facilitator of locally available finance, technology and entrepreneurial capacity to run infrastructure interventions sustainably.

\section{A Systemic, Integrated Approach to Finance}

Operating in a systemic manner requires organisations to be dynamic and evolutionary in nature in order to respond to new changes and challenges. Local banks do not tend to evolve significantly over time, suffering instead from being locked into certain ways of operating. Aavishkaar and S3IDF both highlighted that it was a long and cumbersome process to acquire additional financing for its portfolio 
companies from banks when they had just started. Furthermore, both BASIX and Asvishkaar found getting financed by core financial institutions problematic when they first set up as they were too different from already existing financial organisations. ${ }^{210}$

The case study organisations at the periphery, on the other hand, operate more dynamically than the banks, evolve and adjust their operation as well as funding models as they learn from new knowledge gained through established feedback loops, and face new challenges or opportunities. For instance, Aavishkaar started out small with only two investments in the first year in order to learn from these and stabilising the model before scaling up operations. Furthermore, both BASIX and Villgro have undergone complete overhauls of their operating models. BASIX undertook the year-long OLE review, using both external experts and staff to evaluate its practices and strategy. The end result was a move away from microfinance to a more complex and multi-faceted organisation that provides both financial and non-financial support in a number of ways within the wider remit of livelihood promotion services. Villgro, which is much smaller, instead undertook internal reviews that resulted in a shift from two similar incubator programmes to a number of new programmes which provide complementary support in the invention-entrepreneur-commercialisation chain. Rather than narrowly focusing on incubation in the sense of building and testing a prototype, research the market and trying to sell the product, Villgro has put together support programmes that encourage innovation (business plan competition), business plan writing (preincubations support), incubation, appropriateness of innovation, and a retail outlet for innovation. In addition it is also focussing efforts on research and diffusion of new knowledge about rural innovation and innovation incubation through a research centre. However, there are not only big, incremental changes, but also the many small adaptations of the organisations' operating models to better support their clients. For instance, CTD's work with fruit growers in HP was evolutionary in nature and included many small changes over time. First CTD formed producer groups among the growers and set up a manufacturing unit. These are incremental changes. However, the producer group constantly experiments with different kinds of fruit juices, both in the raw material used, such as rhododendron, or in refining the actual juice recipe.

Interconnected with the notion of operating in a systemic manner, is the idea of an integrated approach to finance which recognises that non-financial support not only provides for the most efficient use of the financial support, but also reduces client risk. In doing so, it reduces the portfolio risk of the financing organisation too. Moreover, at the sectoral level, an integrated approach means that these organisations are involved financing innovation beyond grassroots activities. They

\footnotetext{
210 Nevertheless the situation has improved in recent years as witnessed by the increased funding from the core for the case study organisations at the periphery.
} 
have an impact on the financial system in a number of ways, including lobbying for policy, supporting and strengthening the sector, and diffusing best practices nationally and internationally. This integrated approach thus operates on two levels. On the level of the organisation, it includes a mixture of financial and nonfinancial support, whilst at a sectoral level it includes policy lobbying, best practices dissemination and strengthening the sector.

\section{Integrated Financial and Non-financial Support}

Banks typically offer only credit, with little additional support in how to manage or make the most out of that funding. There is generally not a menu of financial options at the core of the financial system. The periphery organisations meanwhile tend to provide a variety of non-financial support services in addition to their financial solutions. BASIX, for example, takes an integrated view to its support services as witnessed by its non-financial support strategy, Ag/BDS, which has developed into comprehensive support services for farm and non-farm activities including advice on crop, fertilizer, market linkages and business development. Ag/BDS works both at the head office level where major trials are coordinated, and at the local unit office level. Locally it, for instance, looks for technologies used elsewhere which would be suitable locally. An example is the implementation of the procedure of turning sugarcane residuals into fertilizer which is widely used in Maharasthra but not yet in Andhra Pradesh. BASIX introduced this in Andhra Pradesh in order to reduce the cost of fertilizer for farmers. Ag/BDS has also been active in linking producers such as in dairy with chilling stations and factories along the value chain.

S3IDF instead departs from the infrastructure services needed and works around that to arrange for finance; finding suppliers, even investing in them to acquire the correct technology inputs; and training local entrepreneurs and NGOs so that there is local capacity to manage the infrastructure initiatives. S3IDF has thus placed itself as a facilitator within a system of infrastructure provision where it brings disparate parts of the system together to offer such infrastructure services.

Aavishkaar instead provides support to improve the efficiency of its financial investment, and to make the investee more attractive to core financial institutions.

Another integrated model is CTD's which comprises business and technology components, and integrates social, technical and organisational aspects. It is able to root the projects in the local community by spending a lot of time and effort on relationship building and forming enabling institutions (or habits and practices).

\section{Integrated Sectoral Support}

At the setoral level BASIX plays several roles. It has gathered finance providers as one of the initiators behind Sa-Dhan, the MFI umbrella organisation. In addition it provides training for other NGOs and MFIs through its Livelihood School. Finally, 
it works with the government and advocates for better policies and regulations towards the MFI sector as well as together with academia to research the impact of its programmes and the potential for new models.

SIIDF, meanwhile, focuses on opening banks up to investing in small-scale infrastructure projects across the sector. Beyond its grassroots work, it also tries to influence policy at international institutions.

Finally, Aavishkaar and Villgro both organise major yearly conferences that bring the sector together. Aavishkaar organises Sankalp with its sister company Intellecap whilst Villgro runs the Unconvention conference. Both conferences are aimed at PEBI, but whilst Sankalp targets ventures closer to the core financial system, Villgro is closer to the rural grassroots. It should also be noted that Villgro links with other organisations within the sector.

In conclusion, Aavishkaar provides integrated financial and non-financial support, where the non-financial support is expected to make the the portfolio companies more efficient as well as more attractive to prospective funders. Villgro and S3IDF on the other hand act more as facilitators, providing some start-up finance but otherwise focussing on finding external buyers or financiers (Villgro) or acquire bank loans (S ${ }^{3} \mathrm{IDF}$ ). CTD is more focussed on the non-financial side, providing little financial support beyond the finance going into the implementation of an intervention. Finally, organisations such as BASIX and CTD are active at the sectoral level, influencing government policy towards the sector and building the capacity of the sector. S3IDF is also active at a sector level, but unlike the other organisations it focuses directly on providers of finance, the banks.

\subsection{Conclusion}

This chapter has shown that a range of different models are used to support different kinds of pro-poor entrepreneur-based innovation in rural areas. The case study organisations fulfil the INUS conditions in different ways and not all case study organisations fulfil all of the conditions, as the summarising table below highlights.

The first point to note is that the organisations provide flexibility essentially in two ways: either by offering several different support models for different types of investments and clients (BASIX and CTD), or by tailoring each intervention or investment according to the individual project (Aavishkaar and Villgro). The due diligence may be done in a more generic way according to one of the models (as is done at BASIX) or on a case by case basis as in Aavishkaar or S3IDF. Furthermore, the case study organisations are dynamic in that they evolve over time on several levels. At the client level BASIX allows clients to graduate between packages whilst Villgro use different incubation programmes for different types of incubation support for its portfolio companies. 


\section{Table 8.1 Overview of case study organisations and the INUS conditions}

\begin{tabular}{|c|c|c|c|c|c|c|}
\hline & $\begin{array}{l}\text { Flexible/ } \\
\text { Dynamic }\end{array}$ & $\begin{array}{l}\text { Networks and } \\
\text { Actors }\end{array}$ & Relationships & \begin{tabular}{|l|} 
Knowledge, \\
Learning and \\
Feedback
\end{tabular} & Innovators & Systemic \\
\hline BASIX & $\begin{array}{l}\text { Flexibility } \\
\text { provided by } \\
\text { numerous } \\
\text { models. } \\
\text { Choice of } \\
\text { non-financial } \\
\text { services. } \\
\text { IGS ensures } \\
\text { that } \\
\text { operations } \\
\text { are dynamic } \\
\text { and } \\
\text { evolving. }\end{array}$ & $\begin{array}{l}\text { Partners with } \\
\text { institutions to } \\
\text { supply services } \\
\text { to clients; with } \\
\text { NGOs to } \\
\text { improve sector } \\
\text { capacity and } \\
\text { government for } \\
\text { policy. Lead } \\
\text { person is the } \\
\text { founder who is } \\
\text { active } \\
\text { academically, in } \\
\text { policy and } \\
\text { practice. }\end{array}$ & $\begin{array}{l}\text { LSAs act as the } \\
\text { ears and eyes } \\
\text { on the ground } \\
\text { reporting in } \\
\text { two ways } \\
\text { between clients } \\
\text { and } \\
\text { organisation. } \\
\text { Field office } \\
\text { staff act as 'go- } \\
\text { betweens' to } \\
\text { connect } \\
\text { suppliers and } \\
\text { banks to clients }\end{array}$ & \begin{tabular}{|l} 
Great \\
emphasis on \\
tacit \\
knowledge \\
through \\
LSAs and \\
extensive \\
information \\
management \\
system. \\
Feedback \\
and learning \\
from these \\
are \\
prioritised. \\
Continuous \\
search for \\
better \\
solutions.
\end{tabular} & $\begin{array}{l}\text { Acts as an } \\
\text { innovator on } \\
\text { several levels } \\
\text { including } \\
\text { financially, } \\
\text { organisationa } \\
\text { lly and in } \\
\text { terms of } \\
\text { collateral and } \\
\text { non-financial } \\
\text { support } \\
\text { integration. } \\
\text { Has an } \\
\text { innovation } \\
\text { department } \\
\text { (IGS). }\end{array}$ & $\begin{array}{l}\text { Active at the } \\
\text { sectoral level } \\
\text { influencing policy } \\
\text { and building } \\
\text { capacity. } \\
\text { Integrated } \\
\text { financial and non- } \\
\text { financial support, } \\
\text { often tailoring } \\
\text { NFS after specific } \\
\text { needs as a pay for } \\
\text { service. However, } \\
\text { clients can opt for } \\
\text { finance only }\end{array}$ \\
\hline CTD & $\begin{array}{l}\text { Several } \\
\text { versions of } \\
\text { each model } \\
\text { and local } \\
\text { franchise- } \\
\text { NGO can } \\
\text { adjust } \\
\text { model. } \\
\text { Always } \\
\text { involved to } \\
\text { search for } \\
\text { new } \\
\text { solutions, } \\
\text { products, } \\
\text { markets and } \\
\text { technologies }\end{array}$ & $\begin{array}{l}\text { A small core } \\
\text { team creates } \\
\text { business model } \\
\text { by relying on a } \\
\text { vast network } \\
\text { spanning } \\
\text { academia, } \\
\text { NGOs } \\
\text { technology } \\
\text { experts and } \\
\text { government. } \\
\text { Lead person is } \\
\text { the founder } \\
\text { who is involved } \\
\text { in creating all } \\
\text { models as well } \\
\text { as policy and } \\
\text { has a large } \\
\text { network. }\end{array}$ & $\begin{array}{l}\text { Relies on } \\
\text { relationship } \\
\text { between local } \\
\text { NGO, local } \\
\text { community and } \\
\text { themselves to } \\
\text { set up and run } \\
\text { projects. Based } \\
\text { on mutual trust } \\
\text { slowly built up. } \\
\text { Reduces its role } \\
\text { over time as } \\
\text { local NGO and } \\
\text { community } \\
\text { take } \\
\text { ownership. } \\
\text { Lack of NGOs } \\
\text { with } \\
\text { entrepreneurial } \\
\text { skills an issue. }\end{array}$ & $\begin{array}{l}\text { Build models } \\
\text { on tacit local } \\
\text { knowledge } \\
\text { and codify } \\
\text { these models. } \\
\text { Franchised } \\
\text { NGOs have } \\
\text { two meetings } \\
\text { a year with } \\
\text { CTD but } \\
\text { communicati } \\
\text { on and } \\
\text { feedback are } \\
\text { not } \\
\text { regulated. } \\
\text { Avoid } \\
\text { institutional } \\
\text { lock-in and } \\
\text { rigidity by } \\
\text { decentralisin } \\
\text { g. }\end{array}$ & $\begin{array}{l}\text { Not } \\
\text { innovating in } \\
\text { finance. } \\
\text { Instead } \\
\text { innovates in } \\
\text { technology, } \\
\text { production } \\
\text { and } \\
\text { marketing. }\end{array}$ & $\begin{array}{l}\text { At the sectoral } \\
\text { level CTD is } \\
\text { involved with } \\
\text { government } \\
\text { policy through } \\
\text { Committees, } \\
\text { sector capacity } \\
\text { through } \\
\text { technology } \\
\text { network. The } \\
\text { support is non- } \\
\text { financial, beyond } \\
\text { financing the } \\
\text { implementation } \\
\text { of projects. }\end{array}$ \\
\hline
\end{tabular}




\begin{tabular}{|c|c|c|c|c|c|c|}
\hline SIDF & \begin{tabular}{|l} 
Evaluates on \\
a case by \\
case basis, \\
using \\
infrastructur \\
e needs of \\
rural poor as \\
point of \\
departure. \\
Creates \\
infrastructur \\
e package \\
through \\
linking local \\
entrepreneur \\
s, NGOs, \\
banks and \\
technology \\
suppliers.
\end{tabular} & $\begin{array}{l}\text { Main role as } \\
\text { facilitator } \\
\text { matching } \\
\text { infrastructure } \\
\text { need and } \\
\text { community } \\
\text { with } \\
\text { technology, } \\
\text { inputs and } \\
\text { finance through } \\
\text { varied network. } \\
\text { Lead person is } \\
\text { the founder } \\
\text { who appears to } \\
\text { decide on all } \\
\text { important } \\
\text { matters, and } \\
\text { who has the } \\
\text { central network. }\end{array}$ & $\begin{array}{l}\text { Relies on } \\
\text { relationship } \\
\text { with local } \\
\text { entrepreneur or } \\
\text { NGO to } \\
\text { manage } \\
\text { projects once } \\
\text { implemented. } \\
\text { Use } \\
\text { relationships } \\
\text { with suppliers } \\
\text { and banks to } \\
\text { provide finance } \\
\text { and input for } \\
\text { projects with } \\
\text { fairer deals. } \\
\text { Lack of NGOs } \\
\text { with } \\
\text { entrepreneurial } \\
\text { skills an issue. }\end{array}$ & \begin{tabular}{|l|} 
Relies on \\
codified \\
infrastructur \\
e models of \\
technology \\
and \\
implementati \\
on which is \\
tweaked with \\
the help of \\
local tacit \\
knowledge. \\
Rely on local \\
entrepreneur \\
s and NGOs \\
for tacit \\
knowledge.
\end{tabular} & $\begin{array}{l}\text { Innovating in } \\
\text { finance by } \\
\text { using tools } \\
\text { like credit } \\
\text { guarantees to } \\
\text { reduce } \\
\text { perceived } \\
\text { risk of } \\
\text { projects by } \\
\text { banks, and } \\
\text { by acting as a } \\
\text { facilitator } \\
\text { linking } \\
\text { technology } \\
\text { suppliers, } \\
\text { banks and } \\
\text { local } \\
\text { entrepreneur } \\
\text { s. }\end{array}$ & $\begin{array}{l}\text { Works with } \\
\text { Banks to make } \\
\text { debt finance } \\
\text { available. } \\
\text { Provides finance } \\
\text { and non-financial } \\
\text { support including } \\
\text { a network and } \\
\text { capacity training. }\end{array}$ \\
\hline $\begin{array}{l}\text { Aavishka } \\
\text { ar }\end{array}$ & $\begin{array}{l}\text { Due } \\
\text { diligence on } \\
\text { case by case } \\
\text { basis with } \\
\text { set financial } \\
\text { criteria but } \\
\text { flexible } \\
\text { social ones. } \\
\text { Provide } \\
\text { support } \\
\text { services } \\
\text { depending } \\
\text { on } \\
\text { milestones } \\
\text { agreed and } \\
\text { how venture } \\
\text { progresses. }\end{array}$ & $\begin{array}{l}\text { Uses in } \\
\text { particular the } \\
\text { personal } \\
\text { networks of the } \\
\text { founder and the } \\
\text { Board of } \\
\text { Directors in two } \\
\text { ways: to find } \\
\text { new investment } \\
\text { opportunities } \\
\text { and potential } \\
\text { further } \\
\text { funding/exit } \\
\text { opportunities } \\
\text { for investees. }\end{array}$ & $\begin{array}{l}\text { Does not rely } \\
\text { on forming } \\
\text { relationships to } \\
\text { offset collateral. } \\
\text { Though uses it } \\
\text { to manage risk. } \\
\text { Also uses } \\
\text { networks to } \\
\text { search for } \\
\text { potential exits } \\
\text { for its } \\
\text { investments. }\end{array}$ & \begin{tabular}{|l|} 
Relies \\
increasingly \\
on codified \\
knowledge to \\
evaluate \\
potential \\
investments. \\
Tacit \\
knowledge \\
acquired \\
through \\
regular \\
feedback \\
including \\
regular calls \\
and quarterly \\
reporting.
\end{tabular} & $\begin{array}{l}\text { Pioneering in } \\
\text { the use of } \\
\text { venture } \\
\text { capital style } \\
\text { finance, } \\
\text { support and } \\
\text { risk } \\
\text { management } \\
\text { at the rural } \\
\text { PEBI level } \\
\text { and looking } \\
\text { to do so } \\
\text { profitably } \\
\text { and } \\
\text { sustainably. }\end{array}$ & $\begin{array}{l}\text { Does not work } \\
\text { extensively at the } \\
\text { sector level } \\
\text { beyond } \\
\text { organising a } \\
\text { yearly conference. } \\
\text { Provides } \\
\text { integrated finance } \\
\text { and non-financial } \\
\text { support. Works } \\
\text { on investee's } \\
\text { business } \\
\text { management } \\
\text { skills and } \\
\text { increases financial } \\
\text { transparency. }\end{array}$ \\
\hline Villgro & $\begin{array}{l}\text { In business } \\
\text { plan } \\
\text { competitions } \\
\text { there are set } \\
\text { criteria, } \\
\text { otherwise } \\
\text { provide case } \\
\text { by case } \\
\text { incubation } \\
\text { through } \\
\text { different } \\
\text { programmes. }\end{array}$ & \begin{tabular}{|l|} 
Acts as a \\
facilitator, using \\
its network to \\
connect its \\
clients to \\
market \\
opportunities, \\
other finance \\
and experts. \\
Work with \\
academia to \\
find and \\
support projects \\
and with \\
Aavishkaar for \\
further finance.
\end{tabular} & $\begin{array}{l}\text { Run centrally } \\
\text { and does not } \\
\text { rely on } \\
\text { building a close } \\
\text { relationships } \\
\text { with clients. }\end{array}$ & \begin{tabular}{|l|} 
Regular \\
reporting \\
and contacts \\
investees \\
weekly but \\
no \\
established \\
feedback \\
loops. In 2009 \\
it set up a \\
centre to \\
analyse and \\
disseminate \\
learnings \\
about rural \\
innovation.
\end{tabular} & $\begin{array}{l}\text { Is not the first } \\
\text { incubator in } \\
\text { the . } \\
\text { However, } \\
\text { Villgro is } \\
\text { innovative in } \\
\text { its new } \\
\text { integrated } \\
\text { approach to } \\
\text { different } \\
\text { kinds of } \\
\text { complementa } \\
\text { ry incubator } \\
\text { programmes } \\
\text { and activities. }\end{array}$ & $\begin{array}{l}\text { Provides the } \\
\text { finances for } \\
\text { building a } \\
\text { prototype. Also } \\
\text { pays for market } \\
\text { testing. Otherwise } \\
\text { most of the } \\
\text { support is non- } \\
\text { financial in } \\
\text { nature. The } \\
\text { different } \\
\text { incubator } \\
\text { programmes are } \\
\text { complementary. }\end{array}$ \\
\hline
\end{tabular}

CTD is instead dynamic at the support model level as it looks for forward and backwards linkages for its business model interventions. Finally, both Villgro and 
BASIX are examples of organisations that have completely overhauled their organisations.

Second, in terms of networking Aavishkaar uses its board of directors as well as its founder as the sources of different knowledge types in its networks, primarily to find potential investments and future finance, whilst BASIX and CTD are relying on a much wider network to also provide services in addition to what they provide themselves. Furthermore, some organisations are interlinked with each other (Villgro and Aavishkaar; Aavishkaar and BASIX) or similar ones (e.g. BASIX and its Sa-Dhan network). S3IDF is a facilitator that relies on linking a number of actors to provide finance, technology and local management for its infrastructure projects. Furthermore, the organisations work with, or rely on, core financial institution for finance. This is especially true in the case of Aavishkaar and S3IDF. There are thus quite strong links with the core of the financial system, but in different ways. In all organisations individuals play pivotal roles in terms of vision, strategy, operations and network. ${ }^{211}$

Third, as regards relationships, there are two types of models at work. Whilst BASIX, CTD and SIIDF rely on local entrepreneurs and/or NGOs to provide them with area, time and context specific knowledge which is often tacit in nature, Villgro and Aavishkaar are more centrally run, relying instead o the head office making direct contact with their clients. Furthermore, close relationships not only help in reducing the reliance on collateral, but can also provide additional external services beyond what the organizations themselves can offer. However, it was noted by several case study organisations that the lack of entrepreneurial skills among local NGOs often acts as an important barrier.

Fourth, those organisations which have a clearer local presence such as BASIX, through its LSAs, S3IDF and CTD through their work with or franchising to local NGOs are more reliant on tacit knowledge and have put feedback loops in place for this purpose. These organisations are also emphasising very clearly the need to learn, adapt and change. This is visible in the way their models operate. Furthermore, both BASIX and Villgro gather, analyse and distribute information and knowledge about rural innovation and how it can be supported. To that end BASIX has an internal R\&D department, whilst Villgro set up a knowledge or research centre in 2009.

Fifth, whilst BASIX innovates mainly non-financially, Aavishkaar is innovating financially. S3IDF is innovative in its approach to using financial tools such as credit guarantee schemes on a small-scale basis and investing in suppliers to acquire the required technology or input. CTD and Villgro do not appear to innovate financially. However, CTD sets up and implements complete business interventions including innovate new technology, processing methods and market access. S3IDF

211 This point is considered further in chapter 9 , in the discussion on scaling up. 
scales down infrastructure projects combined with a reliance on local entrepreneurs and NGOs to run these are pioneering.

Sixth, organisations such as BASIX, CTD and Villgro are actively building capacity at the sector level by starting or participating in sector-wide networks, influencing government policy by attending high-level government committees, and hosting conferences. S3IDF on the other hand works closely with banks to persuade them to provide finance to PEBI. Aaviskkaar does not appear to be involved in sector-level capacity building beyond organising a major yearly conference.

In terms of integrated financial and non-financial support, Aavishkaar provides mainly finance, coupled with business management support and capacity training to make the investees more attractive to investors from the core of the financial system. CTD on the other hand does not provide financial support beyond supporting the implementation of its interventions. Instead its focus is firmly on non-financial support. BASIX provides packages including financial and nonfinancial support though as the non-financial support is a pay-for service, clients can opt out of it. Finally, Villgro and S3IDF provide finance to incubate an idea, and to implement infrastructure services, respectively. Both organisations look to facilitate finance from other sources, beyond the initial financing provided to build a prototype and test the market (Villgro) or put in place an infrastructure project and train a local entrepreneur and/or NGO (S 3 IDF).

This marks the end of the discussion chapter. Next the thesis will consider scaling up and policy implications. 


\section{What now? Prospects and Policy}

Chapters two and three of this thesis evaluated existing theory, showing that there is a gap in the understanding of pro-poor entrepreneur-based innovation and how it should be finance. The thesis has also looked at recent empirical data - chapter four analysed the current rural financial system in India, noting that there is little financial support from the core, whilst chapters five to seven detailed several existing organisations at the periphery that are pioneering support for entrepreneur-based pro-poor innovation. These organisations have shown that there are interesting models currently in operation in India.

This chapter will instead look to the future and discuss the possibilities for scaling up the financing models that the periphery organisations are using. If these types of pro-poor entrepreneur-based innovation financing are going to have a substantial impact, change needs to occur within the financial system. However, such change will not happen through periphery organisations alone. Instead, they should be better linked with the core of the financial system. In order for that to happen, improved and more supportive policy needs to be in place. This is where a move towards emphasising pro-poor innovation and its importance needs to occur at government level, something that will be detailed further in the last part of this chapter. However, policy is unlikely to be put in place unless there is a real possibility to replicate or scale up these initiatives in order to have the desired impact. Therefore an important question is whether these organisations are inherently local in nature, or whether they can indeed be scaled up or replicated on a state or national level.

This chapter will begin by introducing scaling up and replication before discussing the efforts made to date by the case study organisations to scale up. That will be followed by an analysis of factors affecting scaling up and evidence from the case studies of scaling up and replication across the sector. Then some remarks on policy implications and solutions will be made. 


\subsection{Scaling Up and Replication}

\subsubsection{Introduction and Theory}

To scale up is to expand, adapt or sustain programmes or projects in order to reach a greater number of people (Binswanger and Aiyar, 2003; Desai, 2007; Hartmann and Linn, 2008; WB, 2003). ${ }^{212}$ Scaling up is generally considered to be quantitativereaching a larger number of entrepreneurs undertaking innovative activities (Hartmann and Linn, 2008; Hartmann and Linn, 2007). ${ }^{213}$ In addition, it could be functional, as is the case at BASIX where the organisation has gone from providing microfinance and microcredit to credit and support for micro growth entrepreneurs. Furthermore, to achieve impact on a state or federal level, institutional and political scaling up may be required to provide the necessary environment and enabling policies.

Development interventions were until recently focussed on universalist methods of scaling up (WB, 2003), as noted in the large subsidised credit programmes in India and still visible in NABARD's microcredit bank-linkage programmes. However, such a model is unlikely to provide the right framework for interventions that are as context specific, and require as much flexibility and capacity to adapt to change as those detailed in the case studies. Nevertheless, there are some advantages to the universalist model, such as keeping costs down, and having a relatively clearly codified model to disseminate. CTD, for example, has a partially universalist dissemination model in providing a basic intervention type which has been fine-tuned into several versions that have enough flexibility to be context specific whilst still being rolled out across India. However, a more context specific and flexible model should be the focus.

\footnotetext{
212 The debate on scaling up has been ongoing since 1970s (Hartmann and Linn, 2008). Early studies on scaling up development programmes included Korten (1980) and Myers (1984) whilst the International Institute of Rural Reconstruction (IIRR) (2000) put together a framework of key aspects (in Hartmann and Linn, 2008). Most literature however, is sector specific with Desai (2007) focussing on poverty alleviation programmes and Binswanger and Aiyar (2003) building a conceptual framework for community driven development programmes. Finally, the World Bank (2003) and Hartmann and Linn $(2007 ; 2008)$ provide analytical overviews of the scaling up literature and process.

${ }^{213}$ Quantitative scaling up increases the number of people reached whilst staying within the same functional area; functional scaling up expands the scope of services on offer; political scaling up entails influencing the political process itself, reaching political stakeholders at different levels; organisational, or institutional, scaling up involves an increased number of institutions, or the creation of new institutional forms (Hartmann and Linn, 2007; 2008).
} 


\subsubsection{Scaling Up- Existing Evidence from the Case Studies}

The case study organisations have scaled up in different ways. The exception, at the time of fieldwork, was Villgro which had failed to scale up quantitatively or functionally. However, as previously noted, Villgro has undergone substantial changes since 2007, and has scaled up functionally as well as quantitatively in 20082009. In terms of functionality it started several new programmes such as the Innovation into Use programme, and the Knowledge Management programme. It has also been reaching a lot more innovators and entrepreneurs through the increased number of programmes and increased capacity due to much higher staff numbers.

BASIX, on the other hand, has over a long period of time, been steadily scaling up by increasing the number of borrowers, its geographical reach, the kinds of clients it reaches, the functions it has as well as the financial and non-financial services it offers. However, the number of micro growth entrepreneurs was still small at the time of fieldwork in 2007, and the other exciting initiative, the market linkage programme, had only just begun. Nevertheless, the Livelihood Triad Fund which BASIX ran 2006-2009, was expected to increase the scale and outreach of these programmes.

At Aavishkaar, scaling up has resulted in raising larger funds, as well as making more frequent and larger investments. Having started on a small scale to learn from its early investments, the organisation has scaled up quantitatively by increasing investment numbers and amounts substantially by 2009 . The organisation has also scaled up functionally by starting two new funds since 2007.214 Additionally, Aavishkaar has, for one of its new funds, recently teamed up with microfinance institutions to start a microfinance fund (though it is not clear why the management chose to diversify towards microfinance). Organisationally it scaled up by opening an office in Hyderabad.

Meanwhile, in 2007, S3IDF had made 53 transactions, most of which had been made since 2005. Furthermore, in the pipeline were more than 100 projects, which were scheduled to be evaluated and implemented in 2008. However, the organisation was suffering severe financial constraints which was likely to affect its ability to scale up quantitatively. In 2007, S3IDF also scaled up organisationally by establishing an office in Hyderabad.

Finally, CTD started with interventions in leather and pottery in one location, gradually scaling up organisationally and institutionally by involving locla NGOs as franchises across India. Once those models had reached a point where they could be diffused and replicated, CTD scaled up functionally to fruit processing models.

\footnotetext{
${ }^{214}$ One of its new funds is an investment fund into microfinance, started together with BASIX, which seems to be at odds with its core business, micro venture capital, since microfinance has not been supportive innovative entrepreneurs, as highlighted in chapter 2 .
} 
The organisation has since scaled up quantitatively (reaching new clients), functionally (evolving existing models and starting work on new models) and organisationally by involving additional NGOs.

This section has shown that the case study organisations have scaled up but in different ways. Whilst BASIX and CTD have scaled up operations substantially over the years, the other organisations such as Aavishkaar have not scaled up as much quantitatively, (although Aavishkaar has scaled up functionally). Even at BASIX, which has scaled up rapidly, the programmes that are directly relevant to pro-poor entrepreneur-based innovation remain small compared to its other areas of operation. Finally, Villgro had at the time of fieldwork failed to scale up its operations, and an outcome of that was the overhaul of its operations that it underwent in 2008.

In order to scale up further, a there are factors which will have to be taken into account since these may act as incentives or barriers. The next section will consider these factors.

\subsubsection{Factors Affecting the Ability to Scale Up}

There are a number of factors that affect the ability of an organisation, initiative or sector to scale up, as noted by Hartmann and Linn (2008). ${ }^{215}$ For instance, if the alternative financing sector is to scale up to a level where it has considerable impact, it needs an enabling environment including availability of finance, regulation conducive to investment in PEBI, political backing at the national and community level, organisational capacity, supportive institutions, actors and the possibility to form partnerships within the system. Each of these factors will be considered in turn.

\section{Finance}

Whilst increasing size can lead to economies of scale, in the case of context specific development interventions, the unit cost can in fact increase because of the increased infrastructure related costs as well as the need for additional capacity to manage programmes. Therefore the boutique nature of the type of financial and non-financial support model advocated by periphery organisations may make them unsuitable for large-scale implementation. Furthermore, related to financial sustainability are cost recovery and affordability of the financing models. For instance, BASIX provides its financial services in a financially sustainable manner, whilst at CTD, the financing of the implementation of its interventions are not financially sustainable as yet. Instead the organisation uses a patchwork of financial sources including grants from government, income from the business models it has set up and income from consultancy services which it undertakes on the side to

\footnotetext{
${ }^{215}$ Communication and feedback on Hartmann and Linn's (2008) list of 'factors' were omitted here because these have already been discussed extensively in chapter 8 .
} 
generate funds for its projects. That CTD relies to a large extent on grants when it comes to implementing its projects can be seen as necessary start-up finance for the poorest communities that need to build innovative capacity and basic infrastructure before the private sector can or will get involved. If the Government supports CTD's investments through grants, it is indirectly providing new customer to core financial institutions, such as banks, since the communities that run the projects apply for bank finance for future expansion and working capital, once the project has been established.

As another example, it could be argued that S3IDF and Aavishkaar both aim to be financially sustainable but as investors of larger amounts of finance, with a longterm view to profits and repayment, neither organisation can so far boast sufficient return on investment for reinvestments in portfolio companies (SIDF) or to pay shareholders (Aavsihkaar). Aavishkaar, unlike the other case studies, is aiming mainly for few but large-scale pay-offs from the exit of companies rather than frequent by small returns in the form of interest on loans and royalty from sales. The organisation has not yet had a successful exit from its portfolio (which is unsurprising given how young the company is) but when it does, it could bring substantial financial rewards that could be used to pay shareholders and to reinvest in the portfolio. Villgro on the other hand, was not sustainable at the time of fieldwork in 2007. It was relying on grants from international development organisations (such as the Lemelson Foundation) to fund its incubator programmes and did not have any sustainable income streams, with the exception of its Samruddhi retail outlet which had just begun operations. However, by 2009 the organisation had changed its operating strategy and added several services that brought income, such as market testing in rural areas. Furthermore, the Samruddhi outlets and the local entrepreneurs acting as sales agents were bringing in income. The incubator programme now had a large loan component which was expected to be repaid once a venture had been incubated successfully and become profitable. Therefore, by 2009, Villgro was looking more likely to operate sustainably, even if it still relies on grant funding to some extent.

The lack of adequate funding is a considerable constraint for all organisations. CTD highlights that further rounds of funding beyond the initial funds for implementation fare difficult to obtain. The same issue exists at the sector level where organisations are constrained by the available funding for scaling up their operations. For instance, going beyond an original government or donor grant to larger scale operations requires a much larger loan or grant and currently there are few sources of such scaling up finance available in India. S3IDF has noted that its operations are hindered by the lack of such finance (after it started strongly with a very large international grant from the Shell Foundation). BASIX and Aavishkaar meanwhile have been able to attract private and third sector national and international funding. 


\section{Regulations}

The case study organisations have noted that regulations in India in general do not pose a particular problem, but there are some concerns. As highlighted by Aavishkaar, BASIX and S3IDF, acquiring 'non-bank financial institution' (NBFI) status, which is what the non-charity focussed financial organisations should be considered to be, is a cumbersome process. The result is that some organisations operate under charitable status when it would have been more appropriate to operate as a NBFI. Furthermore, BASIX attempted to start local banks called KBS Local Area Banks (KBSLAB) that would lend micro amounts whilst also providing saving services. However, as noted in chapter 6, this was very difficult to do because of the regulations involved, the bureaucracy and the large amount of initial funding required as a deposit. Therefore, BASIX was only able to start operations in three rural districts in Andhra Pradesh before discontinuing this line of business (these local area banks are nevertheless still operating successfully).

Finally, it should be noted that the vast banking sector is highly regulated. However these regulations are not currently providing incentives for investing in rural small-scale entrepreneurial and innovative activities, as noted in chapter 4 . Even specific regulations such as priority sector lending are circumvented as much as possible by, for instance, investing required funding in government projects or funds, and by the broadened definition of what constitutes a priority sector firm (as was noted in chapter 4).

\section{Politics}

Organisations and models being scaled up, especially beyond the local level need two types of political backing. Firstly policy makers and politicians, local as well as national, need to agree with the main aims of the programmes in order for the programmes to have adequate backing and access to finance and other support. Though, as noted by Basu (2006), larger scale programmes may start to look (too) attractive to politicians and can fall prey to political manoeuvring. In India this has been visible within the microcredit bank linkage programmes as well as in the earlier debt forgiveness programmes, where politicians and local strongmen used these programmes to further political ambitions and/or weaken opposition. BASIX has noted that local politicians can have very strong vested interests in not allowing programmes to expand in rural areas. ${ }^{216}$

Another important kind of political backing is that given by the local community. If the end users, the local community, does not feel ownership of the intervention or has not been deeply involved in its implementation and running, the

\footnotetext{
${ }^{216}$ Because when external organisations come in and provide finance, build capacity and educate local people about their rights, the strongmen lose their ability to use publicly provided finance as a power tool(to, for instance, sway voters or retain a monopoly on manufacturing or wholesale activities (source: interviews at unit offices, 25-27 April, 2007).
} 
intervention is unlikely to last once the hands-on backing by the organisation has ceased. CTD is particularly focussed on spending time establishing trust within the local communities before the implementation of a project. As an example, in both its leather and fruit processing interventions in Himachal Pradesh, CTD spent more than a year establishing relations beforehand and noted that it took a further several years before the community trusted its staff.

\section{Culture and Institutions}

That institutions, or habits and practices, are important has already been extensively discussed in chapters 3 and 8 . The right institutions are vital, not only for establishing and sustaining projects, but also for scaling them up. The case studies confirm that a lot of non-financial work goes into changing such habits and practices- whether at firm or community level. As highlighted by CTD, if the local community is not heavily involved in the implementation, or has not formed habits and practices that 'root' the intervention in the local community, it is unlikely to survive past the initial implementation and running phase sponsored by the external NGO or financing organisation, let alone be scaled up. Therefore CTD works extensively with the local community to shape new habits and practise, for instance, forming groups among the flayers, and collectives among fruit growers. S3IDF deals with institutional problems by training local entrepreneurs to manage and sometimes own the infrastructure projects. Furthermore it uses locally available finance and technology suppliers so that implemented projects can be sustainable by relying on local resources.

BASIX, meanwhile, has dedicated one of its departments, Institutional Development Services, (IDS), towards institution building, and focuses much of IDS' work with poor women on forming groups and starting regular savings habits before providing a loan. Building such borrowing, saving and repayment habits ensures that the women will be reliable customers and that they can both save in order to make productive investments (rather than frequent small-scale purchases), and that the amount they borrow, or BASIX lends, can be scaled up over time.

\section{Organisational Capacity}

A substantial issue facing the case study organisations is the lack of entrepreneurial skills and the behaviour and attitudes conducive to innovation activities. Local organisations are too often working in old-fashioned and rigid ways, suffering from path dependence and institutional lock-in that has resulted in an inability to provide the kind of dynamic and flexible operations that the new alternative finance organisations require from partners. Furthermore, local organisations are often not able, or in some cases, not willing, to run operations in a for-profit manner, choosing instead to prioritise non-monetary principles and charity based missions. As noted in chapter 7, CTD has highlighted the lack of entrepreneurially minded 
local NGOs as a particularly important constraint to enlarging its operations. In relation to S3IDF's hawker lighting, as detailed in chapter 6, the use of local entrepreneurs can have a two-sided effect. According to a senior manager interviewed,

"the hawker business is reliant on entrepreneurs. This is the danger when scaling up the business- if the entrepreneur is good it works very well, but if this is not the case S IDF can stand to lose a lot". ${ }^{217}$

Finally, to build capacity beyond its own organisation, BASIX has chosen to train MFIs and NGOs in-house at its Livelihood School in order to improve the capacity of the sector as a whole.

\section{Actors: Individual or Team effort}

Highlighted in innovation systems theory and clearly noticeable in all the case study organisations is the key role of actors, and, in particular, specific individuals with a vision and long-term commitment that drive change forward, scale up and engage with other actors within the system. For instance, at BASIX, the expansion, functionally, geographically and quantitatively, has to a large extent been driven by its founding team. The operations of Aavishkaar rely greatly on the vision and network of its co-founder whilst S3IDF sees all its strategy written by the founder. However, such emphasis on individuals can of course seriously constrain scaling up efforts, since an organisation that relies to a great extent on one person's vision, effort and network may reach a critical size after which it does not have the capacity to expand further. One way to avoid this issue is putting in place proper organizational structures, something that some of the case study organisations have done. BASIX, for instance, is run by a large management team with clearly divided areas of responsibility, so a manager running the lending business does not also oversee the non-financial services. However, at S3IDF there appears to be a much greater reliance on the founder based in the US, for networking and fundraising. Whilst its interventions appear to be operating relatively independently, the organization itself seems dependent on the effort of a small number of people. Nevertheless, S3IDF has scaled up by opening an office in Hyderabad, with its own investment team. This will show whether an organization so dependent on its founder can expand beyond its initial size.

Aavishkaar on the other hand has a number of experts on its Boards and highly networked and experienced staff. For the organisation, the worry may not be so much how to expand beyond relying on the efforts of the founder, which has already happened with the addition of two more funds, but how to retain such highly qualified staff who could earn considerably more within the 'standard' private venture capital sector.

${ }^{217}$ Interview with Senior Management, 16 November, 2007 at S3IDF, Bangalore. 
The case study organisation that, at the time of fieldwork, appeared to raise concerns over whether it is inherently local, with little ability to scale up because of its reliance on its founder, was Villgro. In 2007, Villgro appeared not to have a clearly formulated sustainable strategy for the coming years. It also appeared to depend very much on its founder.

\section{Partnerships}

Partnerships and networks have already been discussed in chapter 8. However, it should be highlighted that several case study organisations use partnerships to extend their services far beyond what they could provide in-house. CTD for instance, has a small core team of less than 10 people in Delhi, but oversees the implementation of projects all over India, thanks to franchise partnerships with local organisations. BASIX, meanwhile, has scaled up functionally by partnering with insurance providers, such as Aviva, to provide insurance to the rural poorsomething that BASIX as a NBFI is not allowed to do itself.

Finally, the lack of viable local organisations with which to form partnerships is a serious constraint to scaling up, as noted by both CTD and S3IDF in chapters 7 and 6 , respectively, and discussed in more detail in the section on capacity building of this chapter.

Given these factors, that may act as incentives or constraints to scale up, the organisations and interventions highlighted in the case study chapters, supportive policies need to be put in place. The next section will go on to consider a number of plausible policy initiatives.

\subsection{Policy Implications}

A major question is how to scale up without losing the flexibility and dynamism that the periphery organisations are characterised by. Given the limited success, or out-right failure, of former technology transfer programmes, large-scale rural development programmes and banking sector initiatives such as priority sector lending, it would be better to restrict direct government and apex institution interventions. Therefore, the focus should be on providing an enabling environment for these successful existing periphery organisations to grow, and be replicated, rather than establishing a new high-level and large-scale strategy or programme. Here the state sector and apex institutions have a crucial role to play in enabling the scaling up and replication of the organisations that are today supporting pro-poor entrepreneur-based innovation.

\section{Using what is Already There}

In India, the two cornerstones of the rural financial system are the formal banking system and the government programmes. Any scaled up effort to provide better finance and support for pro-poor entrepreneur-based innovation needs to 
incorporate both. Rather than suggesting a completely new set of institutions or organisations, policy for scaling up should focus on the complementarities as well as linkages between the existing financial institutions and programmes at the core, and the new innovative organisations at the periphery. So linkages such as those which S IDF is forming with local banks in Karnataka, are likely to have a real potential because whilst the periphery organisations can reduce the risk of an investment by being able to undertake due diligence, knowing the local environment, and understanding how to best support innovation, the banks, which are not (as) financially constrained, should be able to provide financial backing more easily. In fact, the bank-linkage programmes that are common within microfinance show that there are indeed banks that are looking outside of their established client groups (Basu and Srivastava, 2005). The Government too is focussing efforts on innovation as well as the rural poor, but so far the (separate) programmes have not met with success, as noted in the final part of chapter 4 . However, by increasing its investment in, say, CTD, the Government programmes may become more efficient in supporting entrepreneur-based innovation in rural areas by working with periphery organisations to a greater extent.

Furthermore, the microfinance sector could play an important role by, for example, provide larger loans than the micro-scale SHG and JLG loans it mainly provides at the moment; incorporate more non-financial support; and shift its focus from necessity entrepreneurs, who often operate at subsistence level, to entrepreneurs engaging in innovative activities and providing sustainable livelihoods. Just as with government-originated finance, there is evidence that some microfinance organisations are moving towards the core of the financial system. One recent example is the successful IPO of large microfinance organisation SKS of Hyderabad, South India.

A three pronged strategy could be put in place to create incentives and the right environment for pro-poor entrepreneur-based innovation to flourish. These include policies to: create an enabling environment by prioritising innovation and establishing a PEBI agency; provide an apex innovation fund; and build capacity in the PEBI sector. Each of these areas will be considered in turn.

\section{Creating an Enabling Environment}

Firstly, there needs to be a recognition on the part of the government (at both state and federal level) that pro-poor innovation is important, and that it is as important as other already prioritised urban technological or business innovation. To date, pro-poor as well as rural innovation have come under the development banner. However, the entrepreneurship and innovation aspects need to be emphasised more, rather than grouping PEBI with purely developmental efforts that are often not sustainable in nature. This would in other words mean a strategy that focuses on innovation and entrepreneurship policies, where development is an outcome 
through increased livelihood opportunities and improved goods and services, rather than development policies, where innovation is one of many aspects.

To provide the right enabling environment, the government could set up an innovation agency with the specific aim to advance pro-poor innovation and entrepreneurship, and to address the factors affecting it, as discussed in the previous section on scaling up. The agency would have an overall strategy implementation and coordinating role so that efforts from disparate parts of the public, private and third sectors complement each other rather than duplicate or overlap. Examples of agencies that have this kind of role include for instance the successful Sitra in Finland or Vinnova in Sweden. ${ }^{218}$ As regards the public sector, the PEBI agency would ensure that initiatives from different departments and councils are complementary. Currently there are several programmes rolled out or cosponsored by the Indian state, with the intention to support entrepreneurship and innovation, as noted in chapter 4, including the Department for Science and Technology, Department for Women and Children, the government sponsored agency CAPART; and Indian financial apex institutions such as SIDBI and NABARD. However, they operate separately, often overlapping rather than providing complementary support and funds.

The agency could also support the organisation of the private and third sectors, by for instance establishing a PEBI finance association and/or an umbrella organisation such as Sa-Dhan. Currently, there are banks, such as ICICI Bank (which is a relatively newly established and forward thinking bank), that actively search for ways to better support entrepreneurial ventures. If the agency partners with such pioneering core financial institutions, the strategy of the banking sector as a whole can potentially start to change to be more supportive of PEBI, as more traditional banks see that the innovative banks are supporting PEBI without increasing their portfolio risks notably. Another role the PEBI agency could play would be in research, or by supporting research, on pro-poor innovation and entrepreneurship. Such research would look at both the emerging field of pro-poor innovation and entrepreneurship in India, as well as the specific tools that can support it. There are already initiatives such as Villgro's newly established research institute on rural innovation and entrepreneurship at IIT-M that the PEBI agency could partner with, for example.

The right policies should be complemented by regulations that make it easy for periphery organisations to set up, including becoming a NBFI, and providing their financial services. ${ }^{219}$ Furthermore, policies should act as incentives for banks to lend

\footnotetext{
218 Though these agencies operate in small European countries, they are quite unique in their success and their systemic ways of operating and therefore serve as interesting examples.

${ }^{219}$ It was noted in several of the case studies including Aavishkaar, BASIX and S3IDF, that establishing themselves as a NBFI is complicated because of the bureaucracy involved. Furthermore, BASIX had to give up its savings services when it became impossible to set up a Local Area Bank.
} 
to organisations supporting PEBI as well as to innovative entrepreneurs themselves. At the moment banking policies are more of a hindrance and local officers lending to 'risky' clients are reprimanded. The problem of collateral could perhaps be solved by working in close cooperation with the periphery organisations in evaluating the risk and providing collateral guarantees.

\section{A PEBI Fund}

Secondly, a large government sponsored fund, or group of funds run by experts rather than government officials, could provide the whole sector with extra security and finance. As was noted above, at the moment, DST has several technology funds, whilst other departments including Department for Women and Children have funds supporting entrepreneurship. In addition, both SIDBI and NABARD run funds for innovation or entrepreneurship. Furthermore, each state has its own funds targeting innovation and entrepreneurship, although these are mainly focussed on high-tech, urban innovation. However, there are exceptions such as GIAN which was set up in Gujarat with the help of the state, and the VELUGU programme set up by the Andhra Pradesh government. If some of all this funding was put towards a central PEBI fund, this coordinated fund would be likely to have a higher impact because of economies of scale as well as a coherent strategy (as opposed to several separate small-scale funding strategies and initiatives).

The PEBI fund could for example invest in periphery organisations, taking equity stakes and providing reasonable loans for scaling up, or diversifying operations, and provide a credit guarantee scheme to solve the problem of collateral and low valuations of assets. The PEBI fund could perhaps also provide schemes for start-up capital and on-lending finance to the different types of innovation and entrepreneurship that is occurring. These funds need to establish links with those organisations that are supporting innovation, as highlighted in this thesis.

\section{Building Sector Capacity}

Thirdly, the capacity of the sector, in particular local NGOs and MFIs and possibly even banks would need to improve. To do so the Government could set up a number of centres or programmes that train organisations in entrepreneurial skills and in dynamic and flexible working practices as well as understanding the nature of PEBI and the needs that innovative entrepreneurs have. Furthermore, such a programme could improve the capacity of bank staff in the ability to judge risk and credit needs of periphery organisations and PEBI firms. Organisations would also benefit from training in business management and for-profit methodologies. Finally, as part of building up capacity in the sector, a network, similar to Sa-Dhan created by BASIX among others for microfinance organisations or a micro-venture and incubation capital organisation could be formed where ideas can be exchanged, 
networks built and partnerships formed. It could in addition act as a forum for policy initiatives and expertise.

\subsection{Conclusion}

This chapter has discussed issues surrounding scaling up were discussed and a number of factors can hinder the scaling up process including a lack of finance, unsuitable regulations, a lack of organisations with the right capacity to form partnerships with, the importance of actors and especially individuals in driving the process forward and scaling up, and finally creating enabling institutions and be open to communication, feedback and learning.

A three-pronged strategy was suggested that combines enabling regulations and an overarching agency, with a government sponsored fund that can provide financial support for periphery organisations and credit guarantee schemes for organisations as well as individual entrepreneurs, and a programme to build capacity in the sector, especially among local NGOs, MFIs and banks. 


\section{Concluding Remarks}

This thesis set out to understand how rural innovation is supported. Specifically it has looked at how rural pro-poor entrepreneur-based innovation supported by the financial sector. It found that within the financial system the core, that is the formal financial institutions including banks, does not support PEBI. Instead, an alternative financial sector has emerged at the periphery of the system that is able to support PEBI. Crucially, it takes a more systemic and integrated approach, providing nonfinancial support alongside finance.

\subsection{Summary and Main Findings}

The thesis consists of three parts: a theoretical part, an empirical, and finally a discussion and policy part which brings the theoretical and empirical sections together. Chapters two and three form the theoretical chapters whilst chapter four looks at the financial system supporting rural PEBI in India and chapters five, six and seven analyse in detail five case studies of organisations at the periphery of India's financial system that are able to circumvent the problems encountered by the banks. Finally, chapter eight binds the two parts together, discussing the case studies in light of the conceptual framework, whilst chapter nine considers scaling up and puts forward some policy solutions. Below is a summary of each chapter and the main contribution of each part of the thesis.

Following an introductory chapter that highlighted the need for studying the finance gap relevant to pro-poor entrepreneur-based innovation, chapter two reviewed the literature relevant to rural development, innovation, entrepreneurship as well as on how finance should be used in relation to these concepts. It was noted that explicitly putting innovation at the centre and seeing development and innovation as a systems phenomena is a relatively recent development, but one that this thesis draws on extensively. Though innovation focused theories pertinent to rural development have tended to focus on agriculture and small-holder farmers.

Chapter two, therefore, incorporated ideas from the sustainable rural livelihoods school. However, whilst innovation theories centre around the farmer and the livelihood approach on the household, this thesis posits that rural 
entrepreneurs and small firms are vital to innovation and development. Therefore, entrepreneurship theories have been includes as well. The entrepreneurship literature makes a distinction between necessity and opportunity entrepreneurs, noting that opportunity entrepreneurs are more likely to be active in the innovation process. Therefore this thesis looked at innovative entrepreneurs that are providing goods, services and livelihoods opportunities for the rural poor. Just as with innovation theory, financial theories have moved towards a systems perspective where a number of factors impact on the financial system as a whole and the provision of finance. The literature on access to financial markets has noted that small firms, entrepreneurs and poor households have significant problems in accessing finance and various measures have been used to map the extent to which financial access is a problem. However, there is no explicit analysis of what obstructs the access to finance, especially for pro-poor entrepreneur-based innovation in rural areas. Chapter two thus established that there is a gap in the literature on PEBI, as well as on how to finance PEBI.

Chapter three went on to discuss several arguments explaining this lack of available finance. First, credit may be rationed due to information problems. Second, there is uncertainty related to innovation focussed investments. Third, to combat such risk the financial intermediaries may rely on collateral, and relationship-based finance that can lead to financial exclusion. Fourth, the demand for finance may not be clearly visible since accessing finance may be too cumbersome and/or expensive for rural entrepreneurs. Fifth, the financial system itself may affect the flow of credit in a number of ways due to regulatory issues and government policy, legal barriers and contract enforcement, information flow and the physical infrastructure supporting the system. Considering the financial system as made up of a core and a periphery, the chapter went on to suggest that the way tacit and codified knowledge flows within the system and the knowledge types that can be accessed through networks matter. So do the trust and relationship that exists, and the ability of organisations to accumulate new knowledge. This analysis was taken a step further in the third section where the knowledge flows at the core were contrasted with those at the periphery of the financial system. At the core, path dependence and institutional lock-in together with a closed network of similar knowledge types and a dependence on arm's length transactions and collateral, rather than relationships resulted in rigidity and a closed system. The periphery organisations however, were able to avoid these issues for a number of reasons which form the basis for the INUS conditions in the final section of this chapter. The INUS conditions posit that finance is available when organisations within the system (or part of the system as is the case of the periphery) have the following characteristics: dynamic and flexible approach to finance; a wide network of actors with varied knowledge; relationship focused (because it reduces the risk profile as well as the need for collateral); an emphasis on tacit knowledge, feedback loops and 
learning; ability to innovate close to or with the end user thus acting as a lead user innovator; and finally by adopting a systemic and integrated approach to finance.

The contribution of this first part of the thesis is threefold. Firstly, the thesis proposes to focus on pro-poor entrepreneur-based innovation in rural areas. Innovation studies generally focus on manufacturing industries whilst those studies aimed at the poor have mostly targeted agriculture. In this thesis it is recognised that a majority of rural poor are landless poor and improved practices in agriculture will not necessarily lead to improved livelihoods or income of the majority of the rural poor. Instead, the thesis takes a broader view looking at the rural sector as a whole where entrepreneur-based activities form a substantial part of pro-poor income and employment possibilities, either in connection with agriculture or the non-farm sector. The thesis draws on different schools of thought to put together a literature reviewing concepts relevant to pro-poor entrepreneur-based innovation in rural areas. A second novelty is the review of financing of such pro-poor entrepreneur-based innovation. Within the innovation systems literature there has been little focus on finance, whilst other literature has not combined finance with an explicit focus on pro-poor innovation. The result is a conceptual framework which details a novel way of conceptualising why there appears to be a lack of finance supporting rural PEBI as well as giving some reasons why there are organisations that are able to circumvent these problems and a number of conditions under which finance is available.

The second part of the thesis began with chapter four on the set-up of the financial system in India and the ability of the institutions at the core to finance rural PEBI. The chapter found that the Indian banking system does not efficiently support rural pro-poor innovation. Though there is finance in the system and even credit specifically allotted to the rural poor and entrepreneurs, banks are unwilling to lend. Instead, there is a decrease of credit in rural areas and a decrease in credit towards small and micro enterprises. In fact, the chapter suggests that there is a flow of credit from rural to urban areas. Several initiatives have been set up by the government to deal with the financing gap but so far they have had little impact. Instead an alternative financing sector has been emerging recently. There are three broad categories of organisations in this sector: micro venture capital firms, smallscale finance providers, and grassroots innovators and incubators. The discussion of the alternative financing sector suggests that there is a move away from microfinance and SHGs as the solution to rural pro-poor finance among these organisations. Instead the focus is on how to support rural ventures, entrepreneurs and innovation. An eco-system of different innovation support has sprung upincluding finance, rather than exclusively relying on finance. There is a recognition that there are different kinds of needs within rural areas. For example, those involved in grassroots innovation support work differently to those supporting innovation through micro scale venture capital. 
To further explore this alternative financial sector at the periphery of the financial system, the next three chapters detailed five case studies of the alternative financial sector in depth. The first group, micro venture capital, was represented by Aavishkaar which invests in firms that provide products and services for the rural poor. The second group, small-scale financiers beyond microfinance, included S3IDF, a social merchant bank which invests in small-scale rural infrastructure projects, and BASIX, a livelihood finance provider that formerly worked as a microfinance institution but has now moved on to provide a wider range of services including larger loans for rural micro growth entrepreneurs. The third group, financial innovators and incubators, included Centre for Technology Development which is an NGO active in the rural innovation process through building complete and sustainable business models, and Villgro which incubates inventions and small firms coming out of rural India.

Chapter five introduced Aavishkaar, a micro venture capital organisation. Aavishkaar is innovative in its use of the venture capital model, by using equity instead of debt for its portfolio investments. It provides comparatively large investments in relatively established ventures and entrepreneurs, compared to other case studies in this thesis. The model is mainly supporting the poor indirectly by financing ventures that provide improved products and services to the poor- from healthcare to internet access and better stoves. In addition, these ventures create livelihood opportunities. Aavishkaar is the most 'commercial' of the case studies as it is positioned the closest to commercial financing options including banks at the core but also regular seed or venture capital. As such, its portfolio companies do not have problems in obtaining external (debt) financing from banks once Aavishkaar has invested, as this signals that the venture is commercially sound.

Chapter six continued the empirical focus by studying small-scale financiers BASIX and S3IDF. BASIX is a livelihood financial services provider that finances and supports a wide range of rural clients, primarily using debt. The financing is complemented by pay-for non-financial services such as agriculture and dairy expertise and new technology training as well as business development. BASIX is a complex organisation which runs a number of different models, the three most interesting for this thesis being the Micro Growth Entrepreneurs, the MACS (farmer cooperatives), and the establishment of market linkages between farmers and big firms such as potato farmers with PepsiCo. BASIX is unique in the way it caters to such a wide range of rural clients. Whilst the MGEs generally need financial support and some business development services and improved linkages to new markets, MACS and the market linkage projects need a greater amount of services.

SIIDF as a social merchant bank builds and implements models of infrastructure services for the poor. It provides mainly debt and credit risk guarantees (to attract debt financing from banks for its projects). The organisation works with two types of partners- either directly with poor entrepreneurs that are trained by S3IDF to manage and own operations that support mainly micro 
entrepreneurs such as hawkers or farmers; and with locally established NGOs that provide a number of smaller scale services, generally at the household level.

Chapter seven went on to look at innovators and incubators, with CTD an example of an innovator and Villgro an incubator. CTD innovates for the rural poor by researching, creating, implementing and maintaining technology-based business models. Rather than individual support, CTD focuses on building up businesses that will provide livelihoods for a community. Furthermore, it emphasises nonfinancial support, including capacity building and forming viable institutions, or habits and practices. The organisation works in partnership with local NGOs that oversee the community-run interventions relatively independently. CTD has had an important social impact on the communities it works in.

Villgro is an incubator which supports rural entrepreneurs and innovators. At the time of fieldwork, Villgro comprised two incubation programmes and a database on rural innovation. However, by 2009, the organisation had developed into a multifaceted organisation with complementary services along the innovation value chain, including business plan competitions, incubation support, market testing and a retail outlet for commercialised innovations. Villgro has shifted its emphasis from supporting inventors to supporting entrepreneurs in the commercialisation process, and to this end has a programme which specifically focuses on matching innovations with entrepreneurs. Villgro mainly support the rural poor indirectly by providing innovative products and services through local entrepreneurs.

Chapter seven concluded the empirical part of this thesis. Its main contribution lies in the in-depth study of five organisations that operate at the periphery of the financial system that are supporting PEBI. These organisations recognise that there are different kinds of pro-poor entrepreneur-based innovation in rural areas and that different types of PEBI need different types of financial and non-financial support. Therefore, each of the organisations are targeting different kinds of innovative entrepreneurs, from S3IDF's local entrepreneurs that are trained by the organisation, to Aaviskaar's already established entrepreneurs that are setting up or expanding larger ventures, and CTD's poor communities.

The third part of the thesis discussed the case studies in light of the conceptual framework of chapter three. It also looked into scaling up and policy implications.

Chapter eight began by discussing knowledge flows at the periphery of the financial system. In sum, the case studies were innovating in the range of services, though in different ways. Furthermore, as regards information flows, the periphery organisations more actively seek out information, often using a bottom-up approach rather than a top-down approach favoured by banks. Finally, within the system there are still significant and important links between the core and the periphery. It is especially the periphery that relies on the core for input including finance. Chapter eight also brought the theoretical and empirical parts together by analysing the INUS conditions set up in the conceptual framework of chapter three in light of 
the empirical chapters. The analysis concluded that the case study organisations proved a number of conditions were fulfilled but in different ways, as summarised below.

Dynamic and flexible approach to finance: the case study organisations are dynamic in that they evolve over time on several levels. At the client level BASIX allows clients to graduate between packages whilst Villgro use different incubation programmes. CTD is instead dynamic at the support model level as it looks for forward and backwards linkages for its business model interventions. Both Villgro and BASIX are examples of organisations that have completely overhauled their organisations. Furthermore, this feeds flexibility since responding to feedback from different customers is likely to require different kinds of support. They provide this flexibility essentially in two ways: either by offering several different support models for different types of investments and clients, or by tailoring each intervention or investment according to the evaluation of the individual project. Generally, the support includes non-financial assistance, though in the case of BASIX it is possible for customers to choose not to use this service.

A wide network of actors with varied knowledge: the case study organisations appear to rely on a wide range of knowledge types through their large networks of different actors including the public sector, private sector, academia, core financial institutions, international development agencies, NGOs, periphery finance organisations, and entrepreneurs. These networks are used in six different ways: to acquire expertise to assess potential applicants (Villgro; Aavishkaar), to acquire expertise to improve existing or new service or operating models (CTD), to cofinance (SIDF) or provide an 'exit' for its clients (Aavishkaar), to finance its operations, to provide a broader range of services (S3IDF; BASIX), and finally to influence the sector, policy or core financial institutions (BASIX). Links with core financial institutions are especially important when it comes to financing.

Relationships: close relationships not only help in reducing the reliance on collateral, as highlighted by the use of alternative methods such as group lending at BASIX, and (perceived) asymmetric information, but also in providing more external services or financing beyond what the organisations alone can offer. S3IDF is able to provide finance for its portfolio companies through the relationships it has struck up with local banks that have resulted in state-wide agreements on infrastructure-related loans. However, relationships can also act as a barrier to finance, as highlighted by Aavsihkaar and CTD who found it difficult to acquire finance for their portfolio companies before the organisations themselves had built up good working relationships.

Emphasis on tacit knowledge, feedback loops and learning: those organisations which have a clearer local presence such as BASIX, through its LSAs, S3IDF and CTD through their work with local NGOs are more reliant on tacit knowledge and have put feedback loops in place that are able to catch these. In terms of how knowledge is acquired, there are essentially two types of models at work here. 
Whilst BASIX, CTD and S3IDF rely on local entrepreneurs and/or NGOs to provide them with local, time and context specific knowledge which is often tacit in nature, Villgro and Aavishkaar are more centrally run, relying instead on the head office making direct contact with their clients.

Ability to innovate as a lead user: Whilst BASIX innovates on several levelsorganisationally as well as financially, Aavishkaar is innovating financially in its use of equity. S3IDF is innovating in its approach to using different kinds of financial tools such as credit risk guarantee schemes on a small-scale. Furthermore, S3IDF is innovative in its role as a facilitator, relying on external finance, technology suppliers and local entrepreneurs. CTD is not innovating in finance, but is instead innovation at the grassroots level, providing new technology, value-added processes and market access. Villgro however, does not appear to act as a lead user innovator.

Adopting a systemic and integrated approach to finance: The case study organisations are systemic in that they evolve over time and use integrated financial and non-financial support packages. In this way they are able to meet new demands or challenges. Furthermore, all the organisations are integrated in terms of providing non-financial support as well as financial support. Furthermore, several of them, including BASIX and CTD, are active at the sectoral level, influencing government policy towards the sector.

In chapter nine, issues surrounding scaling up were discussed. A number of factors can hinder the scaling up process including a lack of finance, unsuitable regulations, a lack of organisations with the right capacity to form partnerships with, the reliance on certain actors and especially individuals in driving the process forward and scaling up, and finally a lack of enabling institutions open to communication, feedback and learning. In terms of policy, a three-pronged strategy was suggested that combines 1) enabling regulations with 2) a government sponsored fund that can provide financial support for periphery organisations and credit guarantee schemes for organisations and individual entrepreneurs, as well as 3) a programme to build capacity in the sector, especially among local NGOs, MFIs and banks. It should be noted that any policy initiatives should build on the already existing infrastructures in place, including the vast bank network, and should be seen as complementary, rather than disruptive.

The contribution of the third part was thus to provide insights into how certain organisations at the periphery of the financial system are able to support PEBI when the core is not. It was noted, however, that the core still plays an important role by providing finance to many of these organisations that in turn support PEBI. By discussing the possibilities for scaling up it also provided a basis on which to form policy recommendations. 


\subsection{Possible Future Research}

The findings of this thesis have a number of implications for future research. Firstly, the concept of financing pro-poor innovation deserves more attention in order to improve the understanding of how finance can be best used for rural development. With more and more studies (including the fashionable impact evaluations) finding that microfinance and especially microcredit is having little actual impact, it is time to look for new ways to provide the rural poor with employment and income opportunities as well as better, and affordable, products and services. By focusing on entrepreneur-based innovation, the study moves away from agriculture-centred activities as well as the microcredit style micro entrepreneur, to focus on entrepreneurs and small enterprises that are actually more likely to grow and thus offer employment and income opportunities for a larger section of the rural poor.

Studies using surveys to more widely confirm the results of this thesis could be one avenue of future research. Another is to go beyond the geographical boundaries of India to look at financial models supporting rural PEBI in other locations. A further area of interest would be that focussing on how to scale up financial services that are as flexible and dynamic as those detailed in this thesis are. A major problem with scaling up, as noted in chapter nine, is the potential for institutional lock-in resulting in rigidity. How can organisations that are providing tailor their support model scale up without losing those features that make them successful at the periphery?

Finally, it should be noted that whilst in India the vast majority of poor live in rural areas, this is not necessarily the case in other countries. Further studies on propoor entrepreneur-based innovation could therefore focus on urban and peri-urban areas and entrepreneur-based innovation activities there.

\subsection{Conclusion}

To sum up, this thesis proposed a new way of conceptualising the financing of propoor innovation in rural areas by focusing on pro-poor entrepreneur-based innovation and considering the knowledge flows in the financial system between the core and the periphery. Theoretically the core suffers from institutional lock-in resulting in rigidity whilst the periphery organisations are better able to obtain and act on new knowledge. Empirically, the thesis found that the Indian banking system does not efficiently support rural pro-poor entrepreneur-based innovation. Instead an alternative financing sector has been emerging recently. There are three broad categories of organisations in this sector: micro venture capital firms, small-scale financiers beyond microfinance, and grassroots innovators and incubators. Together they complement each other and form an ecosystem of finance for different types of rural PEBI. What these organisations have in common is an integrated approach to support which includes both financial and non-financial assistance; an emphasis on partnerships and networks to provide better services and acquire expertise; 
continuous involvement in the investees that goes beyond a simple credit disbursement contract; and finally a dual bottom line approach recognising the need for a sustainable business as well as the importance of social objectives. 


\section{Bibliography}

Adams, DW, Graham, DH and Pischke, JD. von (eds.) (1984) Undermining Rural Development with Cheap Credit, Boulder, Colorado: Westview Press

Ahmad, S (1966) On the theory of induced invention. Economic Journal 76: 344-357

Akerlof, GA (1970) The Market for 'Lemons': Quality Uncertainty and the Market Mechanism. Quarterly Journal of Economics 84: 488-500

Aleem, I (1993) Imperfect information, screening, and the costs of informal lending: a study of a rural credit market in Pakistan. In Hoff, K, Braverman, A and Stiglitz, JE (eds) The economics of rural organization: Theory, Practice, and Policy. (pp xiii, 590). New York: Oxford University Press

Allen, F and Gale, D (2000) Comparing Financial Systems. Cambridge, MA: MIT Press

Arora, S (2009) Knowledge Flows and Social Capital: A network perspective on rural innovation. PhD Thesis. Maastricht: University of Maastricht and UNU-MERIT

Arrow, KJ (1962) Economic Welfare and the Allocation of Resources for Invention. In Nelson, R (ed) The Rate and Direction of Inventive Activity. Princeton, N. J: Princeton University Press

Arrow, KJ (1963) Uncertainty and the Welfare Economics of Medical Care. The American Economic Review 53: 941-973

Arrow, KJ (1974) The Limits of Organization. New York: Norton

Banerjee, A, Cole, S and Duflo, E (2005) Bank Finance in India. In Tseng, W and Cowen, D (eds) India's and China's Recent Experience with Reform and Growth. (pp 138-). London: Palgrave Macmillan for the IMF

Banerjee, A, Duflo, E, Glennerster, R and Kinnan, C (2009) The miracle of microfinance? Evidence from a randomized evaluation. Research into Action Working Papers. Cambridge, MA: Abbdul Latif Jameel Poverty Action Lab, MIT

Banerjee, AV, Duflo, E and Centre for Economic Policy Research (Great Britain) (2006) The economic lives of the poor. London: Centre for Economic Policy Research

Bartzokas, A and Mani, S (2004) Financial systems, corporate investment in innovation, and venture capital. Cheltenham: Edward Elgar Pub.

Basu, P (2005) India's financial sector : recent reforms, future challenges. Delhi: Macmillan

Basu, P (2006) Improving Access to Finance for India's Rural Poor. Washington D.C.: The World Bank

Basu, P, Srivastava, P and World Bank. South Asia Regional Office. Finance and Private Sector Development Unit. (2005) Scaling-up microfinance for India's rural poor. Washington, D.C.: World Bank South Asia Region Finance and Private Sector Development Unit

Baumol, WJ (1990) Entrepreneurship: Productive, Unproductive, and Destructive. The Journal of Political Economy 98: 893-921

Beck, $\mathrm{T}$ and de la Torre, A (2007) The basic analytics of access to financial services. Policy Research Working Paper Series. Washington: The World Bank

Beck, T, Demirguc-Kunt, A and Peria, MSM (2006a) Banking Services for Everyone? Barriers to Bank Access and Use around the World. World Bank Policy Research Working Paper. World Bank

Beck, T and Demirguc-Kunt, A (2008) Access to Finance: An Unfinished Agenda. The World Bank Economic Review 22: 383-396

Beck, T, Demirguc-Kunt, A and Maksimovic, V (2004) Bank Competition, Financing and Access to Credit. Journal of Money, Credit and Banking 36: 627-648

Beck, T, Demirguc-Kunt, A and Levine, R (2006b) Bank supervision and corruption in lending. Journal of Monetary Economics 53: 2131-2163

Beck, T, Demirguc-Kunt, A and Maksimovic, V (2006c) The influence of financial and legal institutions on firm size. Journal of Banking \& Finance 30: 2995-3015

Beck, T, Levine, R and Loayza, N (2000) Finance and the sources of growth. Journal of Financial Economics 58: 261-300 
Bell, M, Fransman, M and King, K (1984) 'Learning' and the Accumulation of Industrial Technological Capacity in Developing Countries. Technological Capability in the Third World. (pp 187-209). New York: St. Martin's Press

Bell M.R., Pavitt K. (1992), Technological Accumulation and Industrial Growth: Contrasts between developed and developing countries, Industrial and Corporate Change, 2 (2):157-210.

Benjamin, MP, Yaron, J and Piprek, GL (1997) Rural Finance: issues, design and best practices. Washington, D.C.: World Bank

Berdegue, JA (2005) Pro-poor innovation systems: Background paper. Rome: International Fund for Agriculture and Development: http://www.ifad.org/events/gc/29/panel/e/julio.pdf

Berger, AN and Udell, GF (2006) A more complete conceptual framework for SME finance. Journal of Banking \& Finance 30: 2945-2966

Bester, H (1985) Screening vs. Rationing in Credit Markets with Imperfect Information. American Economic Review 75: 850-855

Bhatt, VV (1995) Financial systems, innovations and development. New Delhi ; London: Sage

Biggs, S and Smith, G (1998) Beyond Methodologies: Coalition-Building for Participatory Technology Development. World Development 26: 239-248

Biggs, SD (1990) A Multiple Source of Innovation Model of Agricultural Research and Technology Promotion. World Development 18: 1481-1499

Biggs, SD and Clay, EJ (1981) Sources of Innovation in Agricultural Technology. World Development 9: 321-336

Biggs, T and Shah, MK (2006) African SMES, networks, and manufacturing performance. Journal of Banking \& Finance 30: 3043-3066

Biggs, TS (1991) Heterogeneous Firms and Efficient Financial Intermediation in Taiwan. In Roemer, M and Jones, C (eds) Developing Countries: Parallel, Fragmented and Black. (pp 167-197). San Francisco: International Center for Economic Growth

Binswanger, H and Aiyar, S (2003) Scaling Up Community Driven Development, Theoretical Underpinnings and Program Design Implications World Bank Policy Research Working Paper. Washington D.C.: World Bank

Binswanger, HP (1978) The microeconomics of induced technical change. In Binswanger, HP and Ruttan, VW (ed) Induced Innovation: Technology, Institutions, and Development. Baltimore: Johns Hopkins University Press

Binswanger, HP and Ruttan, VW (1978) Induced Innovation: Technology, Institutions, and Development. Baltimore: Johns Hopkins University Press

Birdar, RR and Jayasheela (2000) Rural finance : A village study. Kurukshetra 48: 19-25

Blair, HW (1984) Agricultural Credit, Political Economy, and Patronage. In W.Adams, D, Graham, DH and Pischke, JDV (eds) Undermining Rural Development with Cheap Credit. Boulder, Colo: Westview Press

Borgatti, SP and Everett, MG (2000) Models of core/periphery structures. Social Networks 21: 375-395

Bose, S (2004) Regional rural banks: the past and the present debate.

Bougheas, S (2004) Internal vs External Financing of R\&D. Small Business Economics 22: 11-17

Bourne, C and Graham, DH (1984) Problems with Specialized Agricultural Lenders. In W.Adams, D, Graham, DH and Pischke, JDV (eds) Undermining Rural Development with Cheap Credit. Boulder, Colo: Westview Press

Burgess, R and Pande, R (2003) Do Rural Banks Matter? Evidence from the Indian Social Banking Experiment. Discussion Paper No. DEDPS/40, London School of Economics and Political Science, August.

Burgess, R, Pande, R and Wong, G (2004) Banking for the poor: Evidence from India. LSE Working Paper. London: London School of Economics

Carlin, W and Mayer, C (2003) Finance, investment, and growth. Journal of Financial Economics 69: 191-226

Carlsson, B and et al. (2002) Innovation Systems: Analytical and Methodological Issues. Research Policy 31: 233-245 
Carney, D (1998) Sustainable Rural livelihoods: what contribution can we make? London: Department for International Development

Chambers, R (1983) Rural Development: Putting the Last First. Harlow: Longman

Chambers, R and Conway, G (1992) Sustainable rural livelihoods: practical concepts for the 21st century. Brighton: Institute of Development Studies

Chambers, R, Pacey, A and Thrupp, LA (1989) Farmer first: farmer innovation and agricultural research. London: Intermediate Technology Publications

Christen, RP (1997) Banking Services for the Poor: Managing for Success. ACCION International

Christen, RP, Jayadeva, V and Rosenberg, R (2004) Financial Institutions with a Double Bottom Line: Implications for the Future of Microfinance. Occasional Paper Washinton DC: CGAP

Christensen, JL and Lundvall, B-A (1992) The Role of Finance in National Systems of Innovation. National systems of innovation: Towards a theory of innovation and interactive learning. (pp 146168). London: Pinter; distributed in the U.S. and Canada by St. Martin's Press, New York

Claessens, S (2005) Access to financial services: a review of the issues and public policy objectives. Policy Research Working Paper Series Washington: The World Bank

Claessens, S, Demirguc-Kunt, A and Moshirian, F (2009) Global financial crisis, risk analysis and risk measurement. Journal of Banking \& Finance 33

Clark, N (2002) Innovation Systems, Institutional Change and the New Knowledge Market: Implications for Third World Agricultural Development. Economics of Innovation and New Technology 11: 353-368

Clark, N, Hall, A, Sulaiman, R and Naik, G (2003) Research as Capacity Building: The Case of an NGO Facilitated Post-harvest Innovation System for the Himalayan Hills. World Development 31: 1845-1863

Cooke, P. 2001 Regional innovation systems, clusters, and the knowledge economy. Industrial and Corporate Change, 10 (4): 945-974.

Coriat, B and Weinstein, O (2002) Organizations, firms and institutions in the generation of innovation. Research Policy 31: 273-290

Cowan, R, David, PA and Foray, D (2000) The Explicit Economics of Knowledge Codification and Tacitness. Industrial and Corporate Change 9: 221-251

Cowan, R and Foray, D (1997) The Economics of Codification and the Diffusion of Knowledge. Industrial and Corporate Change 6: 595-622

Cowan, R and Gunby, P (1996) Sprayed to death: path dependence, lock-in and pest control strategies. The Economic Journal 106: 521-542

Cull, R, Demirguc-Kunt, A and Morduch, J (2006) Financial performance and outreach : a global analysis of leading microbanks. Policy Research Working Paper Series. Washington: The World Bank

Datta, P (2004) The great Indian divide. Frontline, 21

David, PA (1994) Why are Institutions the 'Carriers of History'?: Path dependence and the evolution of conventions, organizations and institutions. Structural Change and Economic Dynamics 5: 205-220

Davis, J (2004) Using the Rural Economic and Enterprise Development (REED) framework for analysis and joint action: implications for spatial development, International Conference on Local Development. Washington: Natural Resource Institute

Davis, JR and Bezemer, D (2004) The Development of the Rural Non-Farm Economy in Developing Countries and Transition Economies: Key Emerging and Conceptual Issues. Chatham, UK: Natural Resources Institute

Demirguc-Kunt, A, Beck, T and Honohan, P (2008) Finance for All?: Policies and Pitfalls in Expanding Access. World Bank Policy Research Report. Washington: World Bank

Demirguc-Kunt, A and Maksimovic, V (2002) Funding growth in bank-based and market-based financial systems: evidence from firm-level data. Journal of Financial Economics 65: 337-363

Deraniyagala, S, Fine, B, Lapavitsas, C and Pincus, J (2003) From Washington to Post-Washington: Does It Matter for Industrial Policy? Development policy in the twenty-first century: 
Beyond the post-Washington consensus. (pp 80-98). Studies in Development Economics, vol. 17. London and New York:Routledge

Desai, R (2007) The Political Economy of Poverty Reduction: Scaling Up Antipoverty Programs in the Developing World. Washington DC: Wolfensohn Center for Development Working Paper

Djankov, S, McLiesh, C and Shleifer, A (2007) Private credit in 129 countries. Journal of Financial Economics 84: 299-329

Dosi, G, Freeman, C, Nelson, RR, Silverberg, G and Soete, L (1988) Technical Change and Economic Theory. London: Pinter

Douthwaite, MB (2002) Enabling innovation: a practical guide to understanding and fostering technological change. London: Zed Books

Dutz, MA and Dahlman, C (2007) Unleashing India's innovation: toward sustainable and inclusive growth. Washington: World Bank

Edquist, C (1997) Systems of innovation : technologies, institutions and organizations. London: Pinter

Ellis, F and Biggs, S (2001) Evolving Themes in Rural Development 1950s-2000s. Development Policy Review 19: 437-448

Engel, P and Salomon, ML (1997) Facilitating innovation for development: A RAAKS resource box. Amsterdam: KIT Publishers

Fan, S, Chang-Kang, C and Mukherjee, A (2005) Rural and Urban Dynamics and Poverty: Evidence from China and India. FCND Discussion Paper. IFPRI

FAO (2001) Farming Systems and Poverty: Improving Farmers' livelihoods in a changing World. Rome: Food and Agriculture organization of the United Nations

Frame, WS and White, LJ (2004) Empirical Studies of Financial Innovation: Lots of Talk, Little Action? Journal of Economic Literature 42: 116-144

Freeman, C (1987) Technology policy and economic performance : lessons from Japan. London ; New York: Pinter Publishers

Fu, X, Soete, L and Sonne, L (2010) Science, Technology and Development: Emerging concepts and visions. In Fu, X and Soete, L (eds) The Rise of Technological Power in the South. Oxford: Oxford University Press

Gonzalez-Vega, C (1984) Cheap Agricultural Credit: Redistribution in Reverse. In W.Adams, D, Graham, DH and Pischke, JDV (eds) Undermining Rural Development with Cheap Credit. Boulder, Colo: Westview Press

Gonzalez-Vega, C (1994) Stages in the Evolution of Thought on Rural Finance: A Vision from the Ohio State University. Economics and Sociology Occasional Paper. Columbus: Ohio State University, Department of Agricultural Economics and Rural Sociology

Goodland, A, Onumah, G, Amadi, J and Natural Resources Institute (Great Britain) (1999) Rural finance. Greenwich: Natural Resources Institute University of Greenwich

Gupta, A (1997) The Honey Bee Network: Linking Knowledge-rich Grassroots Innovations. 40: 3640

Hall, A, Clark, N, Sulaiman, R, Sivamohan, MVK and Yoganand, B (2003) From Measuring Impact to learning Institutional lessons: an innovation systems perspective on improving the management of international agricultural research. Agricultural Systems 78: 213-241

Hall, A and et al. (2001) Why Research Partnerships Really Matter: Innovation Theory, Institutional Arrangements and Implications for Developing New Technology for the Poor. World Development 29: 783-797

Hall, A, Sivamohan, MVK, Clark, NG, Taylor, S and Bockett, G (1998) Institutional developments in Indian agricultural research systems: Emerging patterns of public and private sector activities. Science, Technology and Development 16: 51-76

Hall, A, Yoganand, B, Sulaiman, RV, Raina, RS, Prasad, CS, Naik, GC and Clark, NG (2004) Innovations in Innovation: Reflections on Partnership, Institutions and Learning. New Delhi and Andhra Pradesh: CPHP/ICRISAT/NCAP

Hall, BH (2002) The Financing of Research and Development. Oxford Review of Economic Policy 18: $35-51$ 
Hartmann, A and Linn, JF (2007) Scaling Up: a path to effective development. 2020 Focus brief on the world's poor and hungry people. Washington DC: International Food Policy Research Institute (IFPRI)

Hartmann, A and Linn, JF (2008) Scaling Up: A framework and lessons for development effectiveness from literature and practice. The Brookings global economy and development working paper series. Washington DC: Wolfensohn Center for Development at Brookings

Haug, R (1999) From Integrated Rural Development to Sustainable Livelihoods: What Is the Role of Food and Agriculture? Forum for Development Studies: 181-201

Hayami, Y and Ruttan, VW (1970) Factor Prices and Technical Change in Agricultural Development: The United States and Japan, 1880-1960. The Journal of Political Economy 78: 1115-1141

Hayami, Y and Ruttan, VW (1971) Agricultural Development: An International Perspective. Baltimore: The Johns Hopkins Press

Helms, B (2006) Access for all : building inclusive financial systems. Washington, DC: World Bank

Henrekson, M (2007) Entrepreneurship and Institutions. Stockholm, Sweden: Research Institute of Industrial Economics (IFN), Stocholm School of Economics

Herbert, RF and Link, AN (1989) In Search of the Meaning of Entrepreneurship. Small Business Economics: $39-49$

Hippel, E. von (1988) The sources of innovation. New York ; Oxford: Oxford University Press

Hippel, E. von and Riggs, W (1996) A lead user study of electronic home banking services : lessons from the learning curve. Sloan Working Paper. Massachusetts: Sloan School of Management, Massachusetts Institute of Technology

Hirschman, AO (1958) The Strategy of Economic Development. New Haven: Yale University Press

Hoff, K, Braverman, A, Stiglitz, JE and World Bank. (1993) The Economics of Rural Organization: theory, practice, and policy. New York: Published for the World Bank by Oxford University Press

Honohan, P (2008) Cross-country Variation in Household Access to Financial Services. Journal of Banking \& Finance 32: 2493-2500

Hunt, D (1989) Economic Theories of Development: an analysis of competing paradigms. New York; London: Harvester Wheatsheaf

Johnston, BF and Mellor, JW (1961) The Role of Agriculture in Economic Development. American Economic Review 51: 566-593

Juma, C and Yee-Cheong, L (2005) Innovation: Applying Knowledge in Development. London: Task Force on Science, Technology and Innovation, UN Millennium Project

Karlan, D, Valdivia, M and Frisancho, V (2008) Business Training for Microfinance Clients: How it Matters and for Whom? Cahiers de recherche PMMA. PEP-PMMA

Katz, JMe (1987) Technology generation in Latin American manufacturing industries. New York: St. Martin's Press

Kiggundu, R (2006) Innovation Systems and Development : the journey of a Beleaguered Nile Perch Fishery in Uganda. UNU-MERIT. Maastricht: University of Maastricht

King, RG and Levine, R (1994) Capital fundamentalism, economic development, and economic growth. Policy Research Working Paper Series. Washington DC: The World Bank

Kirzner, IM (1994) The Entreprenuer in Economic Theory. In Dahmen, E, Hanna, L and Kirzner, IM (eds) The Dynamics of Entrepreneurship: : Crafoord Lectures No. 5. Malmo: Lund University Press

Klapper, L, Laeven, L and Rajan, R (2006) Entry Regulation as a Barrier to Entrepreneurship. Journal of Financial Economics 82: 591-629

Kline, S and Rosenberg, N (1986) An Overview of Innovation. In Landau, R and Rosenberg, N (eds) The positive sum strategy. (pp 275-305). Washington, D.C: National Academy Press

Kneiding, C, Al-Hussayni, E and Mas, I (2009) Multi-country Data Sources for Access to Finance: A technical note. Consultative Group to Assist the Poor, World Bank 
Kumar, A, Beck, T, Campos, C and Chattopadhyay, S (2005) Assessing Financial Access in Brazil World Bank Working Papers. Washington: the World Bank

Lall, S (1987) Learning to Industrialize: the acquisition of technological capability by India. Basingstoke: Macmillan

Lall, S, Kim, L and Nelson, RR (2000) Technological Change and Industrialization in the Asian Newly Industrializing Economies: Achievements and Challenges. Technology, learning, and innovation: Experiences of newly industrializing economies. (pp 13-68). Cambridge; New York and Melbourne: Cambridge University Press

Lanjouw, JO and Lanjouw, P (2000) The Rural Non-farm Sector: Issues and Evidence from Developing Countries. Agricultural Economics 26: 1-23

Lazonick, W (2005) The Innovative Firm. In Fagerberg, J, Mowery, DC and Nelson, RR (eds) The Oxford handbook of innovation. (pp 29-55). Oxford and New York: Oxford University Press

Lazonick, W (2008) Entrepreneurial Ventures and the Developmental State: Lessons from the Advanced Economies. UNU-WIDER Discussion Paper. Helsinki: UNU-WIDER

Leland, HE and Pyle, DH (1977) Informational Asymmetries, Financial Structure, and Financial Intermediation. The Journal of Finance 32: 371-387

Levine, R (2004) Finance and Growth: Theory and Evidence. NBER Working Paper. NBER

Lewis, WA (1955) The Theory of Economic Growth. London: George Allen \& Unwin

Lingelbach, DC, De La Vina, L and Asel, P (2005) What's Distinctive about Growth-Oriented Entrepreneurship in Developing Countries? Centre for Global Entrepreneurship Working Paper San Antonio, Texas: UTSA College of Business

Lipton, M (1977) Why poor people stay poor; a study of urban bias in world development. London: Temple Smith

Lipton, M and Eastwood, RK (2000) Rural-urban dimensions of inequality change. UNU-WIDER Working Paper. Helsinki: United Nations University-World Institute for Development Economics Research

Lipton, M and Longhurst, R (1989) New seeds for poor people. London: Unwin Hyman

Lundvall, B-A (1992) National Systems of Innovation: Towards a Theory of Innovation and Interactive Learning. Pinter Publrs,

Mackie, JL (1974) The Cement of the Universe: a study of causation. Oxford: Clarendon Press

Malerba, F (2004) Sectoral systems of innovation: concepts, issues and analyses of six major sectors in Europe. Cambridge: Cambridge University Press

Mani, S (2009) Growth of Knowledge-intensive Entrepreneurship in India 1991-2007. WIDER Research Paper, 49. Helsinki: UNU-WIDER

Marshall, A (1961) Principles of Economics. London: Macmillan

Mellor, JW (1966) The Economics of Agricultural Development. Ithaca: Cornell University Press

Mellor, JW (1976) The New Economics of Growth: a strategy for India and the developing world. Ithaca: Cornell University Press

Metcalfe, JS (1988) The Diffusion of Innovations: an interpretive study. In G. Dosi, C, Freeman, Nelson, R, Silverberg, G and Soete, L (eds) Technical Change and Economic Theory. London: Pinter

Meyer, RL and Alicbusan, AP (1984) Farm-Household Heterogeneity and RuralFinancial Markets: Insights from Thailand. In W.Adams, D, Graham, DH and Pischke, JDV (eds) Undermining Rural Development with Cheap Credit. Boulder, Colo: Westview Press

Misra, BS (2008) Regional rural banks in India: past, present and future. Delhi: Atlantic Publishers

Mokyr, J (2002) The Gifts of Athena : historical origins of the knowledge economy. Princeton, N.J. ; Oxford: Princeton University Press

Morduch, J (1998) Does Microfinance Really Help the Poor? New Evidence from Flagship Programs in Bangladesh. Unpublished mimeo.

Morduch, J (1999) The Microfinance Promise. Journal of Economic Literature 37: 1569-1614 
Morduch, J and Armendariz, B (2004) Microfinance: Where Do We Stand? In Goodhart, C (ed) Financial Development and Economic Growth: Explaining the Links. Basingstoke, Hampshire, UK: Palgrave Macmillan

Morduch, J, Cull, R and Demirguc-Kunt, A (2009) Microfinance Meets the Market. Journal of Economic Perspectives 23: 167-192

Mosse, D, Farrington, J and Rew, A (1998) Development as Process: concepts and methods for working with complexity. London: Routledge

Myers, S and Majluf, N (1984) Corporate financing and investment decisions when firms have information that investors do not have. Journal of Financial Economics 13: 187- 221

Mytelka, LK (1999) Competition, innovation and competitiveness in developing countries. Paris: Development Centre Organisation for Economic Co-operation and Development

Nair, TS (2006) Financial Intermediation for Rural Development: Exploring the Role and Contribution of Commercial Banks. Readings on Financial Inclusion, In Indian Institute of Banking and Finance New Delhi: Taxmann Publications

Naudé, W (2008) Entrepreneurship in Economic Development. WIDER Research Paper. Helsinki: UNU-WIDER

Nelson, RR (1993) National innovation systems: a comparative analysis. New York ; Oxford: Oxford University Press

Nelson, RR and Winter, SG (1982) An evolutionary theory of economic change. Cambridge, Mass ; London: Belknap Press of Harvard University Press

Norman, D (1989) Communication and Information Systems in Farming Systems Work: an Overview. In Arkansas, Uo (ed) Farming Research Symposium 1987: How Systems Work. (pp 287303). Fayetteville, USA: University of Arkansas and Winrock International Institute for Agricultural Development

Norman, D and Collinson, M (1986) Farming Systems Research in Theory and Practice. In Remenyi, J (ed) Agricultural Systems Research for Developing Countries, ACIAR, No. 11. (pp 16-30). Canberra, Australia: Australian Council for International Agricultural Research

NSSO (2005) Household Assets Holding, Indebtedness, Current Borrowings and Repayments of Social Groups in India. NSS 59th Round (January- December, 2003). New Delhi: National Sample Survey Organisation, Ministry of Statistics and Programme Impact, Government of India

Nurkse, R (1953) Problems of capital formation in underdeveloped countries. Oxford: Blackwell

O'Sullivan, M (2004) Finance and innovation. In Fagerberg, J, Mowery, DC and Nelson, RR (eds) Oxford handbook of innovation. Oxford: Oxford University Press

OECD (1997) National Innovation Systems. Paris: OECD

Oyelaran Oyeyinka, B and Barclay, LA (2004) Human Capital and Systems of Innovation in African Development. African Development Review/Revue Africaine de Developpement 16: 115-137

Patrick, HT (1966) Financial Development and Economic Growth in Underdeveloped Countries. Economic Development and Cultural Change 14: 174

Peachey, S and Roe, A (2006) Access to finance, measuring the contribution of savings banks. Working Paper. World Savings Bank Institute

Penny, DH (1968) Farm Credit Policy in the Early Stages of Agricultural Development. Australian Journal of Agricultural Economics 12: 32-45

Petersen, MA and Rajan, RG (1994) The Benefits of Lending Relationships: Evidence from Small Business Data. Journal of Finance 49: 3-37

Pischke, JD. von (1991) Finance at the Frontier: Debt Capacity and the Role of Credit in the Private Economy. Washington D.C.: The World Bank

Pischke, JD. von, Adams, DW and Donald, G (1983) Rural Financial Markets in Developing Countries : their use and abuse. Baltimore; London: Published for the Economic Development Institute of the World Bank by the Johns Hopkins University Press 
Pitt, MM and Khandker, SR (1998) The Impact of Group-Based Credit Programs on Poor Households in Bangladesh: Does the Gender of Participants Matter? Journal of Political Economy 106: 958-996

Prahalad, CK (2006) The Fortune at the Bottom of the Pyramid: eradicating poverty through profits. New Jersey: Whartoon School Publishing

Rajan, RG and Zingales, L (1998) The Governance of the New Enterprise. CRSP Working Papers. Center for Research in Security Prices, Graduate School of Business, University of Chicago

Ramesha, K (2003) Co-operative Banking and Financial Sector Reforms in India- agenda for future research. International conference on mapping co-operative studies in the new millennium. Victoria: British Columbia Institute for Co-operative Studies, University of Victoria

Richards, P (1985) Indigenous Agricultural Revolution. London: Hutchinson and Co.

Robinson, MS (1994) Financial Intermediation at the Local Level: Lessons from Indonesia. HIID Development Discussion Paper. Cambridge, Mass.: Harvard Institute for International Development

Robinson, MS (2001) The microfinance revolution. Washington, D.C., New York: World Bank ; Open Society Institute

Rosenstein-Rodan, PN (1964) Capital formation and economic development. London: Allen \& Unwin

Rostow, WW (1960) The stages of economic growth : a non-communist manifesto. Cambridge: Cambridge University Press

Roumasset, J and Thapa, G (1983) Explaining Tractorization in Nepal: An Alternative to the 'Consequences Approach'. Journal of Development Economics 12: 377-395

Röling, N (1986) Extension science: increasingly preoccupied with knowledge systems. Sociologia Ruralis 25

Röling, N (1988) Extension science. Cambridge, UK: Cambridge University Press

Röling, N and Engel, PGH (1992) The development of the concept of Agricultural Knowledge Information Systems (AKIS): Implications for extension. In Rivera, WM and Gustafson, DJ (eds) Agricultural extension: Worldwide institutional evolution and forces for change. Amsterdam, the Netherlands: Elsevier Science Publishers

Sagasti, FR (2004) Knowledge and Innovation for Development: the Sisyphus challenge of the 21st century. Cheltenham: E. Elgar

Satish, P (2004) Rediscovering Rural Finance by Retooling the Existing Institutions. In Ford, C and Waters, E (eds) Paving the Way Forward for Rural Finance. Madison, WI: USAID and BASIX-CRSP, University of Wisconsin

Schramm, CJ (2004) Building Entrepreneurial Economies. Foreign Affairs 83: 104-115

Schultz, TW (1964) Transforming traditional agriculture. New Haven ; London: Yale University Press

Schumacher, EF (1973) Small is Beautiful: a study of economics as if people mattered. London: Blond and Briggs

Schumpeter, JA (1934) The Theory of Economic Development. Cambridge: Harvard University Press (New York: Oxford University Press, 1961)

Schumpeter, JA (1944) Capitalism, Socialism, and Democracy. London: Allen \& Unwin

Schumpeter, JA and Opie, R (1961) The Theory of Economic Development: an Inquiry into Profits, Capital, Credit, Interest, and the Business Cycle. New York: Oxford University Press

Shah, M, Rao, R and Shankar, PSV (2007) Rural Credit in 20th Century India: Overview of History and Perspectives. Economic and Political Weekly 42: 1351-1364

Schumacher Society, (2008) http://www.smallisbeautiful.org/.

Spielman, DJ (2005) Innovation Systems Perspectives on Developing-Country Agriculture: A Critical Review. ISNAR Discussion Paper. International Food Policy Research Institute

Start, D (2001) The Rise and Fall of the Rural Non-Farm Economy: Poverty Impacts and Policy Options. In Maxwell, S and Ashley, C (eds) Theme Issue: Rethinking Rural Development. Development Policy Review. 
Stiglitz, JE and Weiss, A (1981) Credit Rationing in Markets with Imperfect Information. American Economic Review 71: 393-410

Sundaram, K and Tendulkar, S (2003) Poverty among Social and Economic Groups in India in the 1990's. Economic and Political Weekly 38: 1385-1394

Szirmai, A (2005) The Dynamics of Socio-Economic Development: An introduction. Cambridge: Cambridge University Press

Szirmai, A, Naude, W, Goedhuys, M, (2011) Entrepreneurship, Innovation and Development: An overview. Oxford: Oxford University Press

Tejerina, L, Bouillon, CP and Demaestri, E (2006) Access to Financial Services and Poverty Reduction in Latin America and the Caribbean. Inter-American Development Bank

UNDP (2001) Human Development Report 2001. Making New Technologies Work for Human Development. New York: United Nations Development Programme

UNDP (2004) Unleashing Entrepreneurship: Making Business Work for the Poor. New York: United Nations Development Programme

Uzzi, B (1996) The Sources and Consequences of Embeddedness for the Economic Performance of Organizations: The Network Effect. American Sociological Review 61: 674-698

Uzzi, B (1997) Social Structure and Competition in Interfirm Networks: The Paradox of Embeddedness. Administrative Science Quarterly 42: 35-67

World Bank (1986) World Development Report. New York: The World Bank

World Bank (1999) World Development Report 1998-1999: Knowledge for Development. New York: The World Bank

World Bank (2003) Scaling Up the Impact of Good Practices in Rural Development. Working Paper to support the Rural Development Strategy. Washington: Agriculture and Rural Development Department of The International Bank for Reconstruction and Development, World Bank

World Bank (2006) World Bank Enterprise Survey India. The World Bank Enterprise Analysis Unit, World Bank

Wennekers, S and Thurik, R (1999) Linking Entrepreneurship and Economic Growth. Small Business Economics 13: 27-55

Vogel, RC (1984) Savings Mobilization:The Forgotten Half of Rural Finance. In W.Adams, D, Graham, DH and Pischke, JDV (eds) Undermining Rural Development with Cheap Credit. Boulder, Colo: Westview Press

Yunus, M (1999) Banker to the Poor: Micro-Lending and the Battle Against World Poverty. New York:: BBS Public Affairs

Zavatta, R (2008) Financing Technology Entrepreneurs and SME's in Developing Countries: Challenges and Opportunities. Washington: InfoDev, World Bank 


\section{Sammenvatting}

Pro-poor entrepreneur-based innovation (PEBI) is essentieel voor de ontwikkeling van, en de armoedebestrijding op, het platteland. Het schept werkgelegenheid, verhoogt de inkomsten en zorgt voor betere goederen en diensten. Een vitale factor die van invloed is op PEBI is financiering. Echter, PEBI lijdt aan een gebrek aan financiering, met name van de banken die de kern vormen van het financiële stelsel. In plaats van te weinig steun van de kern, komt er hulp uit alternatieve bronnen aan de rand van het financiële stelsel. Deze aanzienlijke kloof in de financiering voor plattelandsontwikkeling PEBI is de focus van dit proefschrift. Eerst wordt een aantal financiële belemmeringen beschouwd, waaruit een conceptueel kader is opgebouwd. Het kader bestaat uit het financiële stelsel opgebouwd uit een kern (de banken) en een periferie, waar de manier waarop kennis stromen binnen het systeem, de aard van de kennis die kan worden benadert en verzameld, en het soort relaties dat bestaat. De periferie organisaties zijn beter in staat om nieuwe kennis op te doen en te verkrijgen, en te handelen (en te voorzien in financiën) om een aantal redenen. Deze omvatten: een dynamische en flexibele aanpak tot financiering; een breed netwerk van actoren, een nadruk op de stilzwijgende kennis en leren; vermogen om te innoveren in de buurt van de gebruikers, en een geïntegreerde aanpak van de financiering. Het proefschrift onderzoekt de PEBI financiering in India. Het platteland van India lijdt aan een gebrek aan financiële diensten, ondanks de overheidsprogramma's ter ondersteuning van 'sociaal bankieren'. Tegelijkertijd zijn kredieten op kleine schaal aan ondernemers en kleine bedrijven vermindert, wat suggereert dat bankkrediet niet heeft voldaan aan PEBI ondersteuning. Er is echter onlangs een alternatieve financiële sector ontstaan om PEBI te ondersteunen. Er zijn drie brede categorieën: 1) micro durf kapitaalfondsen die ondersteuning bieden voor ondernemingen een betere dienstverlening, producten of werkgelegenheid bieden voor de arme plattelandsbevolking, 2) kleinschalige financiële organisaties die verder zijn gegaan dan microfinanciering om landelijke boeren en ondernemers te ondersteunen; 3) organisaties die innovatie ondersteunen, hetzij door lokaal te innoveren, of als incubators voor de landelijke ondernemers en uitvinders. Het proefschrift bestaat uit vijf casestudies uit deze sector: Aavishkaar, Basix, S3IDF, Centre for Technology Development, en Villgro. De organisaties zijn complementair en vormen een ecosysteem van verschillende soorten van financiële steun. Ze nemen een geïntegreerde aanpak tot ondersteuning, met inbegrip van zowel financiële als niet-financiële ondersteuning. $\mathrm{Zij}$ benadrukken partnerschappen en netwerken voor een betere dienstverlening, verwerven deskundigheid om de sector zelf te beïnvloeden. Ze zijn flexibel en kunnen aanpassen aan nieuwe uitdagingen. Ten slotte, de organisaties sluiten aan met de banken in de kern, wat belangrijk is voor opschaling. 


\section{About Lina}

Lina's research interests are at the intersection of inclusive innovation and entrepreneurship, livelihoods and poverty alleviation and development. In her previous, non-academic, life, she worked in the investment team of early stage VC and innovation think-tank NESTA, London, UK. She has also managed stints at GE Capital, a start-up called Boardex, the UK Department for Education, and a London model agency (accounts department!). Lina has obtained an MSc in Business Economics from City University, London, and a BA (Hons) in European Studies.

For further information and a blog attempt: www.linasonne.com 